\title{
OCD matters in psychosis
}

Citation for published version (APA):

Van Dael, F. W. J. J. (2014). OCD matters in psychosis. [Doctoral Thesis, Maastricht University]. Maastricht University. https://doi.org/10.26481/dis.20141204fv

Document status and date:

Published: 01/01/2014

DOI:

$10.26481 /$ dis.20141204fv

Document Version:

Publisher's PDF, also known as Version of record

\section{Please check the document version of this publication:}

- A submitted manuscript is the version of the article upon submission and before peer-review. There can be important differences between the submitted version and the official published version of record.

People interested in the research are advised to contact the author for the final version of the publication, or visit the DOI to the publisher's website.

- The final author version and the galley proof are versions of the publication after peer review.

- The final published version features the final layout of the paper including the volume, issue and page numbers.

Link to publication

\footnotetext{
General rights rights.

- You may freely distribute the URL identifying the publication in the public portal. please follow below link for the End User Agreement:

www.umlib.nl/taverne-license

Take down policy

If you believe that this document breaches copyright please contact us at:

repository@maastrichtuniversity.nl

providing details and we will investigate your claim.
}

Copyright and moral rights for the publications made accessible in the public portal are retained by the authors and/or other copyright owners and it is a condition of accessing publications that users recognise and abide by the legal requirements associated with these

- Users may download and print one copy of any publication from the public portal for the purpose of private study or research.

- You may not further distribute the material or use it for any profit-making activity or commercial gain

If the publication is distributed under the terms of Article $25 \mathrm{fa}$ of the Dutch Copyright Act, indicated by the "Taverne" license above, 


\section{OCD matters in psychosis}


ISBN 978-90-5335-980-8

Lay-out | Frank Van Dael

Print | Ridderprint BV, www.ridderprint.nl

Cover|Denies Damiaens

\section{(C) 2014}

All rights reserved. No parts of this publication may be reproduced or transmitted in any form or by any means, electronic or mechanical, including photocopy, recording or otherwise, without prior written permission of the author. 


\section{OCD matters in psychosis}

PROEFSCHRIFT

Ter verkrijging van de graad van de doctor aan de Universiteit Maastricht, op gezag van de Rector Magnificus, Prof. dr. L.L.G. Soete

volgens het besluit van het College van Decanen, in het openbaar te verdedigen op donderdag 4 december 2014 om 14.00 uur

door

Frank Willem Johan Joeri Van Dael. 


\section{Promotores}

Prof. dr. J. van Os

Prof. dr. I. Myin-Germeys

\section{Beoordelingscommissie:}

Prof. dr. P. Delespaul (voorzitter)

Prof. dr. M. van der Gaag (Vrije Universiteit Amsterdam)

Prof. dr. Lieuwe de Haan (Academisch Medisch Centrum Amsterdam)

Prof. dr. P. van Harten

Dr. K. Schreurs

The research in this thesis was conducted at the department of Psychiatry and Psychology of the School of Mental Health and Neuroscience, Maastricht University.

Publication of this thesis was financially supported by Eumedica, Janssen-Cilag and Lundbeck 

Paranimfen:

Gregg Van De Putte

Patrick Domen 


\title{
Contents
}

Chapter 1 Introduction

Chapter 2 Can obsessions drive you mad? Longitudinal evidence that obsessive-compulsive symptoms worsen the outcome of early psychotic experiences

Chapter 3 Evidence for a shared etiological mechanism of psychotic symptoms and obsessive-compulsive symptoms in patients with psychotic disorders and their siblings

Chapter 4 Evidence that hallucinations as well as obsessions originate from intrusive thoughts and that transition to psychosis is mediated by delusional appraisal.

Chapter 5 Data gathering: biased in psychosis?

Chapter 6 General Discussion

Chapter 7 Valorization

\author{
Summary \\ Samenvatting \\ Dankwoord \\ Curriculum Vitae \\ Publications
}





\title{
Chapter
}

\author{
Introduction
}



For more than a century, many individuals have been diagnosed with schizophrenia, obsessive-compulsive disorder (OCD) or both. In both disorders, many psychological domains can be affected. The impact of both disorders on the life of the affected person and his or her environment varies, but can be profound. Consequently, when both disorders cooccur, the impact may be even more pervasive. Unfortunately, rates of comorbidity are much higher than chance rate, as has been reported repeatedly for decades (Achim et al., 2011; Bland, Newman, \& Orn, 1987; Jahrreis, 1926; Karno, Golding, Sorenson, \& Burnam, 1988). Furthermore, comorbidity has been associated with a marked poor prognosis (Berman, Kalinowski, Berman, Lengua, \& Green, 1995; Fenton \& McGlashan, 1986; Lysaker, Lancaster, Nees, \& Davis, 2004; Nechmad et al., 2003). Still, the origins and the nature of this comorbidity remain poorly understood. The mechanism of the covariation of OCD and schizophrenia as well as the impact on each other over time is not thoroughly investigated. Though overlap has been shown in the neurocircuitry and neurobiology involved in the etiology of OCD and schizophrenia (Bottas, Cooke, \& Richter, 2005; Gross-Isseroff, Hermesh, Zohar, \& Weizman, 2003; Whitney, Fastenau, Evans, \& Lysaker, 2004), as well as in the psychological models of formation and maintenance of obsessive-compulsive symptoms and symptoms of psychosis (Morrison \& Baker, 2000; Morrison, Haddock, \& Tarrier, 1995), direct evidence for shared etiologic mechanisms for both disorders has not been examined, to the best of our knowledge. In this thesis, we aimed to further elucidate the nature of the association between $O C D$ and schizophrenia. One of the first problems lies in the definition of the comorbid "disorders".

\section{The phenomenology of schizophrenia}

Schizophrenia is considered the most severe of all psychotic disorders with a prevalence of approximately $1 \%$ (Jablensky et al., 1992). The core symptoms of schizophrenia include positive and negative psychotic symptoms. According to the Diagnostic and Statistic Manual of Mental Disorders (DSM IV), the currently prevailing diagnostic system, schizophrenia is diagnosed if (i) at least two of the following symptoms are present: delusions, hallucinations, disorganized speech, catatonic behavior, or negative symptoms (flat affect, avolition, social withdrawal, poverty of thought and speech) for at least one month; (ii) the symptoms interfere with social and occupational functioning, and are not due to the acute effects of substance abuse or a medical condition (Association, 1994). Other common symptoms in schizophrenia that are not mentioned in the current DSM criteria are alterations in neurocognition (impairment in attention, memory and executive functions) and social cognition (e.g. theory of mind, source monitoring, jumping to conclusions) (Frith \& Corcoran, 1996). Age of onset typically is in early adolescence and men are affected more often than women (Aleman, Kahn, \& Selten, 2003).

\section{Heterogeneity}

The DSM IV definition of schizophrenia intrinsically holds symptom heterogeneity. There is no real "prototype" for the diagnostic category nor pathognomonic symptoms. Instead, the disorder shows symptom heterogeneity: two individuals fulfilling the diagnostic criteria for the same diagnosis may show a quite different clinical picture with a different symptom profile, even regardless of the variability in course (Kirkbride et al., 2006; Lochner \& Stein, 2006a; McCormick \& Flaum, 2005; McGrath, 2005; Tandon, Nasrallah, \& Keshavan, 2009). It is of note that the term schizophrenia was used in plural at its very introduction by Bleuler, 
now more than a century ago (Bleuler, 1911). Ever since, many attempts have been made to define subtypes of schizophrenia, with only modest success in increasing homogeneity within one subtype (Carpenter, Arango, Buchanan, \& Kirkpatrick, 1999; Crow, 1980; McGorry et al., 1992; Murray, O'Callaghan, Castle, \& Lewis, 1992; Robins \& Guze, 1970; Sham, Castle, Wessely, Farmer, \& Murray, 1996).

On the contrary, in the past decades, epidemiological data and findings on genetic and environmental etiological mechanisms show a better fit with a dimensional approach, in which psychopathology can be quantified on several symptom dimensions such as a positive, negative, cognitive/disorganized and affective (depressive and manic) symptom dimension (McGorry, Bell, Dudgeon, \& Jackson, 1998; Van Os, Gilvarry, et al., 1999; van Os \& Kapur, 2009). Indeed, although the heritability of schizophrenia is high, the role of individual genetic or environmental risk factors turned out to be small and not very specific for the categorical diagnostic classes (Tsutsumi et al., 2011). Moreover, schizophrenia was found to share genetic vulnerability with bipolar disorder (thus affective symptom dimension) (Jabben, Arts, Krabbendam, \& van Os, 2009; Tijssen et al., 2010) and autism (van Os \& Kapur, 2009).

\section{Continuity}

The notion of a dichotomous diagnostic threshold may have (had) its merits in clinical practice. As clinical decisions often are dichotomous, it is much more convenient to assume that symptoms or diagnoses can just be present or absent. However, there is robust evidence that subclinical psychotic experiences are very common in the general population (Bijl, Ravelli, \& van Zessen, 1998; Kendler, Gallagher, Abelson, \& Kessler, 1996). Thus the natural distribution of the psychosis phenotype doesn't fit well in this categorical classification, and may be described more appropriately as a continuous distribution, ranging from subclinical symptoms and experiences in the general population to clinically relevant symptoms in psychotic disorder (Johns \& van Os, 2001; Linscott \& van Os, 2010; van Os, Hanssen, Bijl, \& Ravelli, 2000; van Os \& Kapur, 2009). Although most of the self-reported subclinical psychotic experiences do not convert into clinical symptoms (Kendler et al., 1996; van Os, Hanssen, Bijl, \& Vollebergh, 2001), there is substantial evidence for familial and etiological continuity between this transitory subclinical phenomena and clinically relevant psychotic disorders (Johns \& van Os, 2001; Kendler, McGuire, Gruenberg, \& Walsh, 1995; van Os, Linscott, Myin-Germeys, Delespaul, \& Krabbendam, 2009; Van Os, Verdoux, et al., 1999). Familial continuity is seen when relatives of schizophrenia patients show subclinical psychotic experiences that are qualitatively similar to the psychotic symptoms in patients, and quantitatively more expressed than in the relatives of matched controls (Kendler \& Walsh, 1995). Etiological continuity is suggested by the finding that subclinical psychotic experiences and clinical psychotic symptoms show a similar association with several risk factors (Johns \& van Os, 2001).

Therefore, it may be helpful to examine these psychotic symptoms in non-clinical population at increased risk of developing the disorder, such as first-degree relatives of patients with a psychotic disorder or subjects with psychometrically defined high risk (chapter 5 and 3). An additional advantage of this approach is that some potential confounding factors inherent to clinical illness or its treatment are avoided. 


\section{Phenomenology of obsessive-compulsive disorder}

$O C D$ is characterized by recurrent, persistent and intrusive thoughts or images that cause anxiety and distress (obsessions), and repetitive behaviors or mental acts aimed at reducing this anxiety or distress (compulsions). Typically, obsessions and compulsions are recognized as a product of one's own mind ("insight"). In order to fulfill diagnostic criteria for OCD according to the DSM IV, obsessions and compulsions should be time-consuming, cause marked distress and interfere with social and occupational functioning (Association, 1994). Once considered extremely rare, epidemiological data of the last decades suggest lifetime prevalence of about 3\% (Stein, 2002). Age of onset of OCD has a bimodal distribution, with a juvenile onset and an onset in adulthood (Stein, 2002).

\section{Heterogeneity}

Similar to what is described for schizophrenia above, the distribution and course of heterogeneous symptoms doesn't correspond well with the notion of a homogeneous categorical class. Resembling efforts to define homogenous subtypes have been made for OCD, with equally modest success (Calamari, 2005; Lochner \& Stein, 2006b; D. McKay et al., 2004). Here too, evidence from research on epidemiology and genetics show a better fit with a dimensional view (García-Soriano, Belloch, Morillo, \& Clark, 2011; James F. Leckman et al., 2010; Mataix-Cols, Rosario-Campos, \& Leckman, 2005; Morillo, Belloch, \& GarcíaSoriano, 2007). Indeed, the heritability of OCD as a categorical class may be well-established (Jonnal, Gardner, Prescott, \& Kendler, 2000; Gerald Nestadt, Grados, \& Samuels, 2010; van Grootheest, Boomsma, Hettema, \& Kendler, 2008), but the influence of individual risk factors is small (Van Grootheest, Cath, Beekman, \& Boomsma, 2007). Over the past few years, shared epidemiological features and genetic vulnerability has emerged with so-called obsessive-compulsive spectrum disorders such as body dysmorphic disorder, hypochondriasis and impulse control disorders (Hollander, Kim, Braun, Simeon, \& Zohar, 2009; Lochner \& Stein, 2006b, 2010; Phillips et al., 2010; Stein \& Lochner, 2006) and other disorders such as autism (Jacob, Landeros-Weisenberger, \& Leckman, 2009).

\section{Continuity}

There is solid evidence that subclinical obsessive-compulsive symptoms are very common in the general population (Angst, 2004; de Bruijn, Beun, de Graaf, Ten Have, \& Denys, 2010; Fullana et al., 2009; Valleni-Basile et al., 1994). Epidemiological data have shown that obsessive-compulsive symptoms occur during normal development and are mainly transient (Evans et al., 1997; Valleni-Basile et al., 1996), yet there is substantial evidence for familial and etiological continuity between transitory subclinical phenomena and clinically relevant OCD dimensions (Blom, Hagestein-de Bruijn, de Graaf, ten Have, \& Denys, 2011; de Bruijn et al., 2010; Grabe et al., 2006; Hasler et al., 2007; G. Nestadt et al., 2000; Pauls, Alsobrook, Goodman, Rasmussen, \& Leckman, 1995; Taberner et al., 2009). As a consequence, research on the phenotype should include the obsessive-compulsive symptoms below the diagnostic threshold, in the general population and notably in unaffected relatives of OCD patients (chapter 3).

\section{Comorbidity}

Co-occurrence between OCD and schizophrenia has been reported for more than a century (Westphal, 1878) with considerable variation in rates (Byerly, Goodman, Acholonu, Bugno, \& 
Rush, 2005). Reported rates of schizophrenia in OCD patients ranges from $4.0 \%$ to $12.2 \%$ (Eisen \& Rasmussen, 1993; Karno et al., 1988; Kolada, Bland, \& Newman, 1994), and the reported prevalence of OCD in subjects with schizophrenia from $1.1 \%$ to $59.2 \%$ (Bland et al., 1987; Jahrreis, 1926). Many factors may contribute to the variance in reported results. In clinical studies, diagnoses were based in most but not all studies on diagnostic hierarchy as defined in DSM, thus excluding, for example, obsessions that in content were related to any other Axis 1 disorder. Two studies, assessing lifetime occurrence of OCD and schizophrenia in a general population sample without hierarchical exclusions, yielded considerably higher comorbidity rates $(59.2 \%$ OCD in schizophrenia, compared to $1.1 \%-46.6 \%$ in reports applying hierarchical exclusions and $12.2 \%$ schizophrenia in OCD compared to $4.0 \%$, respectively) (Berman et al., 1998; Bland et al., 1987; Eisen \& Rasmussen, 1993; Karno et al., 1988). Other factors influencing heterogeneity of study findings include sample selection, type of assessment of prevalence and symptoms, applied to two heterogeneous disorders that have been shown to display a broad range of symptoms (Berman et al., 1998; Bland et al., 1987; Eisen \& Rasmussen, 1993; Karno et al., 1988; Reay, Mitford, McCabe, Paxton, \& Turkington, 2010). But essentially, the concept of comorbidity by definition implies the cooccurrence of unitary nosological entities. Hence, it inherits the limitations of the applicability of that concept, notably its lack of validity, its fuzziness due to symptom heterogeneity and its insufficient account for a distribution across the diagnostic threshold.

Another problem in the notion of "categorical" comorbidity in patients with need for care is the so-called Berkson's bias or referral bias: subjects with more than one disorder are more likely to be part of a clinical sample (Maric et al., 2004; Regeer et al., 2009). Therefore, if we aim to understand the true nature of the comorbidity between different "symptom dimensions", we should investigate the association in a general, non-clinical population.

The comorbidity concept gives rise to additional conundrums: though nosological descriptions may appear conceptually distinct, (covert) overlapping diagnostic criteria may complicate research. For example, obsessions and delusions have historically gradually been distinguished from each other over the last century, and now represent core symptoms of different nosological entities. Delusions typically are defined as false beliefs that are held with high conviction, not amenable to reason, and ego-syntonic by their holder, who is lacking insight and does not unfold any resistance. Obsessions are defined as recurrent and persistent thoughts, impulses or images, that are experienced as intrusive and inappropriate (i.e. ego-dystonic), and typically accompanied by insight: they are recognized as a product of one's own mind and elicit resistance (Association, 1994). However, delusions and obsessions share some features in their conceptualisation: both concern persistent thoughts or ideas that become overvalued and go together with elevated preoccupation, distress, anxiety and, frequently, impact on behaviour (Freeman, Garety, Kuipers, Fowler, \& Bebbington, 2002; Jenike, 2004).

Considering these issues, it is argued that research on comorbidity, its epidemiology, etiological mechanisms, maintaining factors, course and outcome may benefit from a deconstruction of the clinical diagnostic entities with their subclinical extensions. Proposed symptom dimensions for schizophrenia are positive, negative, affective, and cognitive/disorganized symptoms, and developmental cognitive alterations. For obsessivecompulsive disorder, symptoms can be clustered as obsessions and compulsions, though 
generally, proposed dimensions are checking/aggressive/sexual/religious, symmetry/hoarding and contamination/cleaning (J. F. Leckman, Bloch, \& King, 2009; Stewart et al., 2008).

Moreover, symptom dimensions in both schizophrenia and OCD, can be further "dissected". Typically, dimensions concern features, which vary, but do not co-vary across different patients. For example, the positive symptom dimension of psychosis encompasses hallucinations and delusions, and within the symptom dimension delusions, several dimensions can be identified, such as conviction, preoccupation, interference and resistance (Garety \& Hemsley, 1987; Kendler, Glazer, \& Morgenstern, 1983). Dimensions may not be unique to one symptom or clinical phenomenon. In this case, the mentioned dimensions can also be identified in obsessions and compulsions (Jakes \& Hemsley, 1996; Stern \& Cobb, 1978). Given the heterogeneity of the categorical diagnostic classes and the distribution of the symptom dimensions of both disorders, it may well be possible that there is a quantitative variation in symptom dimensions within the comorbidity. Furthermore, the expression of (subclinical) symptoms and their mutual impact may evolve over time. Therefore, it may be useful to investigate the broad distribution of symptom dimensions longitudinally, as in chapter 2 and chapter 4.

\section{Comorbidity: due to overlapping etiology?}

Decomposition into dimensions may not only be useful to comprehend the phenomenology and examine comorbidity, but also may be helpful in the investigation of etiological pathways. A dimensional approach shifts the focus from clinical syndromes to quantifiable observable features of the phenotype, such as cognitive or behavioral characteristics. Such characteristics may be eligible as an endophenotype. An endophenotype is a quantifiable intermediate factor, more proximal in the gene-to-behavior pathway than the clinical symptoms of the phenotype, giving a better hold to go on in research on genetic and biological mechanism for psychopathology (Gottesman \& Gould, 2003; Gould \& Gottesman, 2006).

From a psychological as well as from a neurobiological perspective, the etiological pathways to psychosis and obsessive-compulsive disorder seem to show overlap and similarities. In both conditions, an internal or external precipitant may give rise to an unwanted intrusive thought or image. Though often a variant of an essentially normal experience, specific vulnerability factors and environmental conditions may facilitate an appraisal of the experience as unacceptable, resulting in the development to persistent distressing symptoms interfering with behavior and functioning.

\section{Cognitive mechanisms of psychosis}

Specific cognitive biases or dysfunctions have been associated with symptom dimensions of psychosis. It has been shown that neurocognitive dysfunctions are associated with negative symptom dimensions (Addington, Saeedi, \& Addington, 2005; Ventura, Hellemann, Thames, Koellner, \& Nuechterlein, 2009; Villalta-Gil et al., 2006), and other cognitive dysfunctions, typically deficits or biases of "social cognition" with positive psychotic symptoms dimensions. For example, an association has been shown between positive symptoms (delusions and hallucinations) and deficits in source monitoring (Hommes et al., 2012; Mlakar, Jensterle, \& Frith, 1994; Schnell et al., 2008; Versmissen et al., 2007; Wang, Metzak, 
\& Woodward, 2011), alterations in recognition of facial expression (Pinkham, Hopfinger, Pelphrey, Piven, \& Penn, 2007; Silver et al., 2006; van Rijn et al., 2011), theory of mind (Janssen, Krabbendam, Jolles, \& van Os, 2003; Randall, Corcoran, Day, \& Bentall, 2003), attributional style (R. P. Bentall, Corcoran, Howard, Blackwood, \& Kinderman, 2001; R. P. Bentall, Kinderman, \& Kaney, 1994; Blackwood et al., 2003; Blackwood et al., 2000; Craig, Hatton, Craig, \& Bentall, 2004) and decision making (Colbert \& Peters, 2002; Corcoran et al., 2006; Freeman et al., 2006; Lincoln, Ziegler, Mehl, \& Rief, 2010; Linney, Peters, \& Ayton, 1998; R. McKay, Langdon, \& Coltheart, 2006; S. Moritz \& Woodward, 2005). These findings contributed to the development of multifactorial psychological account of the formation and maintenance of delusions and hallucinations (Hemsley, 1993; Maher, 1974). A challenge for these models is to incorporate automatic cognitive processes as well as maladaptive conscious appraisals, and consider the role of emotion and social factors. The mechanism proposed by Garety, Freeman et al. assumes that a triggering event in a predisposed person gives rise to a disruption of cognitive processes. The new internal or external (sensory) input does not match with stored memories or pre-existing beliefs and therefore cannot adequately be interpreted and may lead to further unintended intrusions from memory. Additionally, cognitive dysfunctions such as source monitoring deficits lead to the person's own intentions to act (or speek) not being recognized and therefore experienced as alien. A delusional interpretation can further be reinforced by biases in cognitive processes such as externalizing attributional biases, deficits in understanding social situations and the intentions of others. As a delusional ideation often is held with high conviction and typically is "not amenable to reason", it has been suggested that a jumping to conclusion reasoning bias may predispose for the development and maintenance of delusions. In chapter 5 , it is investigated whether an information gathering cognitive style characterized by jumping to conclusions is associated with the liability for (specific dimensions of) psychosis.

These biased appraisal processes generally are made worse by negative emotional states (e.g. anxiety, depression, anger) (Richard P. Bentall, 1994; Freeman et al., 2002; Garety \& Freeman, 1999; Garety, Kuipers, Fowler, Freeman, \& Bebbington, 2001; Morrison et al., 1995). These processes are likely to occur against a conducive social-cognitive background: (early) adverse events as well as daily hassles, exposure to stressors (urbanitcity, ethnic minority) and toxic agents (cannabis) may enhance stress-reactivity and facilitate negative schemes about the self and the world, and hence promote external attributions and low selfesteem.

\section{Cognitive models of OCD}

Obsessions may develop from intrusive thoughts or images that are perceived as unwanted or unacceptable (Rachman, 1998). A particular deficit in source monitoring (thought-action fusion) may facilitate intrusion into the conscious mind. Individuals prone to OC disorder typically tend to make unsuccessful attempts to suppress intrusive thoughts, paradoxically making them reoccur more repetitively and vividly (Tolin, Hamlin, \& Foa, 2002) . A metacognitive style, characterized by (over)responsibility for the possible consequences of someone's own thoughts and actions, and the belief that anticipated harm has to be neutralized, may increase distress, consequently reinforcing this process and resulting in symptoms (Barrera \& Norton, 2011; Rachman \& Hodgson, 1980; Salkovskis \& Harrison, 1984). 
Individuals prone to develop OCD -similar to those prone to develop hallucinatory symptoms- seem to share some features in their cognitive style, for example a high subjective need to control thoughts together with negative beliefs about their controllability, low cognitive confidence, a high self-consciousness and a tendency to make negative interpretations that involve the idea that the person's choice can result in harm (Steffen Moritz, Peters, Larøi, \& Lincoln, 2010; Varese \& Bentall, 2011).

Based on the similarities in the cognitive models of the positive symptoms of psychosis and those of OCD, the epidemiological evidence for a partial common pathway in the development of psychotic and obsessive-compulsive symptoms was investigated in the EDSP study in chapter 4.

More specific, it was hypothesized that the co-occurrence of obsessive and psychotic symptoms may originate from a partial common pathway from intrusive thoughts to obsessions or hallucinatory symptoms respectively, with delusional appraisals facilitating the pathway to further psychosis. A confirmation of this hypothesis could contribute to a better understanding of the higher then chance comorbidity between schizophrenia and OCD.

\section{Outline and aim of this thesis}

The main aim of this thesis is to investigate the relation between psychosis and obsessivecompulsive disorder. Whereas comorbidity inherently implies categorical diagnoses, symptom dimensions, individual symptoms, and psychological markers were used to investigate similarity, overlap and mutual impact.

1. In chapter 2 , the co-occurrence and mutual impact of (sub)clinical psychotic and OC symptoms along the continuum was investigated with a longitudinal design in a general population sample of more than 7000 subjects. It was the first study to examine whether the co-occurrence of subclinical psychotic and OC symptoms increased the risk for impairment and help-seeking over time, i.e. poor prognosis.

2. Given (i) the evidence for familial and etiological continuity between transitory subclinical phenomena and clinically relevant symptom dimensions in OCD and in schizophrenia, (ii) the high rates of comorbidity (including co-occurrence of subclinical $\mathrm{OC}$ and psychotic experiences), (iii) the evidence for shared neuropsychological neurobiological correlates (Bottas et al., 2005; Whitney et al., 2004), and similarities in psychological models explaining $\mathrm{OC}$ and psychotic symptoms, the question rises whether the $\mathrm{OC}$ and psychosis phenotype share etiological mechanisms. In chapter 3 , in a large sample with patients, their unaffected relatives and controls in the general population, two approaches are used to test the hypothesis that familial psychosis liability (indexed by patient-unaffected sibling-control) predisposes for OC symptoms. First, the association between OCS and psychosis liability is examined. It was predicted that in case OCS and psychotic symptoms share a familial or genetic etiology, unaffected siblings of patients with psychosis will have an elevated risk for the development of OCS compared to controls. Second, cross-sib cross-trait analyses were conducted to investigate whether psychosis levels in one sibling are associated with OC symptoms levels in the other sibling. It was predicted that, In case of a shared genetic or familial etiology, OCS in a patient will show an association with psychosis dimensions in the unaffected sibling and vice versa. 
It is discussed to what extent the findings are compatible with the existence of a partially shared etiological pathway.

3. In chapter 5 , the role of a particular reasoning bias, referred to as a "jumping to conclusions", or more precisely, a "data gathering bias" in the formation and maintenance of delusions was investigated. In an earlier study, a data gathering bias was shown to be negatively correlated with obsessive-compulsive disorder (Fear \& Healy, 1997). In the present study, involving several measurements in 3 groups (patients, first degree relatives and controls) it was investigated whether this reasoning bias was associated with particular symptoms dimensions of psychosis, and whether the JTC was associated with psychosis liability, defined as genetic (first degree relatives of patients with psychosis) or psychometric risk (group with above average vs. under average delusional experiences). The aim was to determine whether the reasoning bias had the characteristics of a stable trait rather than a temporal state. If such a feature has the characteristics of a trait, it may be eligible as a candidate endophenotype. An endophenotype is a quantifiable intermediate factor, more proximal in the gene-to-behavior pathway than the clinical symptoms of the phenotype, giving a better hold to go on in research on genetic and biological mechanism for psychopathology (Gottesman \& Gould, 2003; Gould \& Gottesman, 2006).

4. In chapter 4, in a large general population sample, followed over several years, it was examined whether the co-occurrence of obsessive and psychotic symptoms may originate from a partial common pathway from intrusive thoughts to obsessions or hallucinatory symptoms respectively, with delusional appraisals facilitating the pathway to further psychosis.

Starting from psychological models on the pathogenesis of $O C D$, it was investigated whether the paradigm that intrusive thoughts lead to obsessive-compulsive symptoms was confirmed. The next question was whether data supported a similar pathway to psychotic symptoms with need for care. The implications of the possibility of a partial common pathway are discussed. 


\section{References}

Achim, A. M., Maziade, M., Raymond, É., Olivier, D., Mérette, C., \& Roy, M.-A. (2011). How Prevalent Are Anxiety Disorders in Schizophrenia? A Meta-Analysis and Critical Review on a Significant Association. Schizophrenia Bulletin, 37(4), 811-821. doi: 10.1093/schbul/sbp148

Addington, J., Saeedi, H., \& Addington, D. (2005). The course of cognitive functioning in first episode psychosis: changes over time and impact on outcome. Schizophrenia research, 78(1), 35-43. doi: 10.1016/j.schres.2005.05.008

Aleman, A., Kahn, R. S., \& Selten, J. P. (2003). Sex differences in the risk of schizophrenia: evidence from meta-analysis. Archives of General Psychiatry, 60(6), 565-571. doi: 10.1001/archpsyc.60.6.565

Angst, J. A. J. R. V. D. s. W. (2004). Obsessive-compulsive severity spectrum in the community: prevalence, comorbidity, and course. European Archives of Psychiatry \& Clinical Neuroscience, 254(3), 156-164.

Association, A. P. (1994). Diagnostic and statistic manual of mental disorders (4th edn. ed.). Washington,DC: American Psychiatric Press.

Barrera, T. L., \& Norton, P. J. (2011). The Appraisal of Intrusive Thoughts in Relation to ObsessionalCompulsive Symptoms. Cogn Behav Ther, 1.

Bentall, R. P. (1994). Cognitive biases and abnormal beliefs: Towards a model of persecutory delusions. In A. S. E. David \& J. C. E. Cutting (Eds.), The neuropsychology of schizophrenia (Vol. xvi, 406 pp., pp. pp.337 360). Hillsdale, NJ, England: Lawrence Erlbaum Associates, Inc.

Bentall, R. P., Corcoran, R., Howard, R., Blackwood, N., \& Kinderman, P. (2001). Persecutory delusions: a review and theoretical integration. Clin Psychol Rev, 21(8), 1143-1192.

Bentall, R. P., Kinderman, P., \& Kaney, S. (1994). The self, attributional processes and abnormal beliefs: towards a model of persecutory delusions. Behav Res Ther, 32(3), 331-341.

Berman, I., Kalinowski, A., Berman, S. M., Lengua, J., \& Green, A. I. (1995). Obsessive and compulsive symptoms in chronic schizophrenia. Compr Psychiatry, 36(1), 6-10.

Berman, I., Merson, A., Viegner, B., Losonczy, M. F., Pappas, D., \& Green, A. I. (1998). Obsessions and compulsions as a distinct cluster of symptoms in schizophrenia: a neuropsychological study. $J$ Nerv Ment Dis, 186(3), 150-156.

Bijl, R. V., Ravelli, A., \& van Zessen, G. (1998). Prevalence of psychiatric disorder in the general population: results of The Netherlands Mental Health Survey and Incidence Study (NEMESIS). Soc Psychiatry Psychiatr Epidemiol, 33(12), 587-595.

Blackwood, N. J., Bentall, R. P., ffytche, D. H., Simmons, A., Murray, R. M., \& Howard, R. J. (2003) Self-responsibility and the self-serving bias: an $\mathrm{fMRI}$ investigation of causal attributions. Neuroimage, 20(2), 1076-1085.

Blackwood, N. J., Howard, R. J., ffytche, D. H., Simmons, A., Bentall, R. P., \& Murray, R. M. (2000). Imaging attentional and attributional bias: an $\mathrm{fMRI}$ approach to the paranoid delusion. Psychol Med, 30(4), 873-883.

Bland, R. C., Newman, S. C., \& Orn, H. (1987). Schizophrenia: lifetime co-morbidity in a community sample. Acta Psychiatr Scand, 75(4), 383-391.

Bleuler, E. (1911). The Fundamental Symptoms of Dementia Praecox or the Group of Schizophrenias (Translated by Zinkin J., Trans.). New York: International Universties Press.

Blom, R. M., Hagestein-de Bruijn, C., de Graaf, R., ten Have, M., \& Denys, D. A. (2011). Obsessions in normality and psychopathology. Depression and Anxiety, 28(10), 870-875.

Bottas, A., Cooke, R. G., \& Richter, M. A. (2005). Comorbidity and pathophysiology of obsessivecompulsive disorder in schizophrenia: is there evidence for a schizo-obsessive subtype of schizophrenia? J Psychiatry Neurosci, 30(3), 187-193.

Byerly, M., Goodman, W., Acholonu, W., Bugno, R., \& Rush, A. J. (2005). Obsessive compulsive symptoms in schizophrenia: frequency and clinical features. Schizophr Res, 76(2-3), 309-316. 
Calamari, J. E. (2005). Understanding the heterogeneity of OCD. The American journal of psychiatry, 162(11), 2193-2194; author reply 2194. doi: 10.1176/appi.ajp.162.11.2193

Carpenter, W. T., Jr., Arango, C., Buchanan, R. W., \& Kirkpatrick, B. (1999). Deficit psychopathology and a paradigm shift in schizophrenia research. Biological Psychiatry, 46(3), 352-360.

Colbert, S. M., \& Peters, E. R. (2002). Need for closure and jumping-to-conclusions in delusion-prone individuals. J Nerv Ment Dis, 190(1), 27-31.

Corcoran, R., Cummins, S., Rowse, G., Moore, R., Blackwood, N., Howard, R., . . Bentall, R. P. (2006). Reasoning under uncertainty: heuristic judgments in patients with persecutory delusions or depression. Psychol Med, 36(8), 1109-1118.

Craig, J. S., Hatton, C., Craig, F. B., \& Bentall, R. P. (2004). Persecutory beliefs, attributions and theory of mind: comparison of patients with paranoid delusions, Asperger's syndrome and healthy controls. Schizophr Res, 69(1), 29-33.

Crow, T. J. (1980). Molecular pathology of schizophrenia: more than one disease process? British medical journal, 280(6207), 66-68.

de Bruijn, C., Beun, S., de Graaf, R., Ten Have, M., \& Denys, D. (2010). Subthreshold symptoms and obsessive-compulsive disorder: evaluating the diagnostic threshold. Psychol Med, 40(6), 989997.

Eisen, J. L., \& Rasmussen, S. A. (1993). Obsessive compulsive disorder with psychotic features. J Clin Psychiatry, 54(10), 373-379.

Evans, D. W., Leckman, J. F., Carter, A., Reznick, J. S., Henshaw, D., King, R. A., \& Pauls, D. (1997). Ritual, habit, and perfectionism: the prevalence and development of compulsive-like behavior in normal young children. Child development, 68(1), 58-68.

Fear, C. F., \& Healy, D. (1997). Probabilistic reasoning in obsessive-compulsive and delusional disorders. Psychol Med, 27(1), 199-208.

Fenton, W. S., \& McGlashan, T. H. (1986). The prognostic significance of obsessive-compulsive symptoms in schizophrenia. Am J Psychiatry, 143(4), 437-441.

Freeman, D., Garety, P., Kuipers, E., Colbert, S., Jolley, S., Fowler, D., . . Bebbington, P. (2006). Delusions and decision-making style: use of the Need for Closure Scale. Behav Res Ther, 44(8), 1147-1158.

Freeman, D., Garety, P. A., Kuipers, E., Fowler, D., \& Bebbington, P. E. (2002). A cognitive model of persecutory delusions. Br J Clin Psychol, 41(Pt 4), 331-347.

Frith, C. D., \& Corcoran, R. (1996). Exploring 'theory of mind' in people with schizophrenia. Psychol Med, 26(3), 521-530.

Fullana, M. A., Mataix-Cols, D., Caspi, A., Harrington, H., Grisham, J. R., Moffitt, T. E., \& Poulton, R. (2009). Obsessions and compulsions in the community: prevalence, interference, helpseeking, developmental stability, and co-occurring psychiatric conditions. Am J Psychiatry, 166(3), 329-336. doi: appi.ajp.2008.08071006 [pii]10.1176/appi.ajp.2008.08071006

García-Soriano, G., Belloch, A., Morillo, C., \& Clark, D. A. (2011). Symptom dimensions in obsessivecompulsive disorder: From normal cognitive intrusions to clinical obsessions. J Anxiety Disord, 25(4), 474-482. doi: http://dx.doi.org/10.1016/j.janxdis.2010.11.012

Garety, P. A., \& Freeman, D. (1999). Cognitive approaches to delusions: a critical review of theories and evidence. Br J Clin Psychol, 38 ( Pt 2), 113-154.

Garety, P. A., \& Hemsley, D. R. (1987). Characteristics of delusional experience. European archives of psychiatry and neurological sciences, 236(5), 294-298.

Garety, P. A., Kuipers, E., Fowler, D., Freeman, D., \& Bebbington, P. E. (2001). A cognitive model of the positive symptoms of psychosis. Psychol Med, 31(2), 189-195.

Gottesman, II, \& Gould, T. D. (2003). The endophenotype concept in psychiatry: etymology and strategic intentions. The American journal of psychiatry, 160(4), 636-645.

Gould, T. D., \& Gottesman, II. (2006). Psychiatric endophenotypes and the development of valid animal models. Genes, brain, and behavior, 5(2), 113-119. doi: 10.1111/j.1601183X.2005.00186.X 
Grabe, H. J., Ruhrmann, S., Ettelt, S., Buhtz, F., Hochrein, A., Schulze-Rauschenbach, S., . . Wagner, M. (2006). Familiality of obsessive-compulsive disorder in nonclinical and clinical subjects. Am J Psychiatry, 163(11), 1986-1992.

Gross-Isseroff, R., Hermesh, H., Zohar, J., \& Weizman, A. (2003). Neuroimaging communality between schizophrenia and obsessive compulsive disorder: a putative basis for schizo-obsessive disorder? World J Biol Psychiatry, 4(3), 129-134.

Hasler, G., Pinto, A., Greenberg, B. D., Samuels, J., Fyer, A. J., Pauls, D., ... Murphy, D. L. (2007). Familiality of factor analysis-derived YBOCS dimensions in OCD-affected sibling pairs from the OCD Collaborative Genetics Study. Biological Psychiatry, 61(5), 617-625. doi: 10.1016/j.biopsych.2006.05.040

Hemsley, D. R. (1993). A simple (or simplistic?) cognitive model for schizophrenia. Behav Res Ther, 31(7), 633-645. doi: 0005-7967(93)90116-C [pii]

Hollander, E., Kim, S., Braun, A., Simeon, D., \& Zohar, J. (2009). Cross-cutting issues and future directions for the OCD spectrum. Psychiatry Research, 170(1), 3-6.

Hommes, J., Krabbendam, L., Versmissen, D., Kircher, T., van Os, J., \& van Winkel, R. (2012). Selfmonitoring as a familial vulnerability marker for psychosis: an analysis of patients, unaffected siblings and healthy controls. Psychol Med, 42(02), 235-245. doi: doi:10.1017/S0033291711001152

Jabben, N., Arts, B., Krabbendam, L., \& van Os, J. (2009). Investigating the association between neurocognition and psychosis in bipolar disorder: further evidence for the overlap with schizophrenia. Bipolar disorders, 11(2), 166-177. doi: 10.1111/j.1399-5618.2009.00663.x

Jablensky, A., Sartorius, N., Ernberg, G., Anker, M., Korten, A., Cooper, J. E., . . Bertelsen, A. (1992). Schizophrenia: manifestations, incidence and course in different cultures. A World Health Organization ten-country study. Psychological medicine. Monograph supplement, 20, 1-97.

Jacob, S., Landeros-Weisenberger, A., \& Leckman, J. F. (2009). Autism spectrum and obsessivecompulsive disorders: OC behaviors, phenotypes and genetics. Autism Research, 2(6), 293311. doi: 10.1002/aur.108

Jahrreis, W. (1926). Uber Zwangvorstellungen im Verlauf der Schizophrenie. Arch. Psychiatr. Nervenkr., 77, 740-788.

Jakes, I. C., \& Hemsley, D. R. (1996). The Characteristics of Obsessive-Compulsive Experience. Clinical Psychology \& Psychotherapy, 3(2), 93-102. doi: 10.1002/(sici)1099-0879(199606)3:2<93::aidcpp86>3.0.co;2-q

Janssen, I., Krabbendam, L., Jolles, J., \& van Os, J. (2003). Alterations in theory of mind in patients with schizophrenia and non-psychotic relatives. Acta Psychiatr Scand, 108(2), 110-117.

Jenike, M. A. (2004). Clinical practice. Obsessive-compulsive disorder. N Engl J Med, 350(3), 259-265.

Johns, L. C., \& van Os, J. (2001). The continuity of psychotic experiences in the general population. Clin Psychol Rev, 21(8), 1125-1141.

Jonnal, A. H., Gardner, C. O., Prescott, C. A., \& Kendler, K. S. (2000). Obsessive and compulsive symptoms in a general population sample of female twins. Am J Med Genet, 96(6), 791-796.

Karno, M., Golding, J. M., Sorenson, S. B., \& Burnam, M. A. (1988). The epidemiology of obsessivecompulsive disorder in five US communities. Arch Gen Psychiatry, 45(12), 1094-1099.

Kendler, K. S., Gallagher, T. J., Abelson, J. M., \& Kessler, R. C. (1996). Lifetime prevalence, demographic risk factors, and diagnostic validity of nonaffective psychosis as assessed in a US community sample. The National Comorbidity Survey. Arch Gen Psychiatry, 53(11), 10221031.

Kendler, K. S., Glazer, W. M., \& Morgenstern, H. (1983). Dimensions of delusional experience. The American journal of psychiatry, 140(4), 466-469.

Kendler, K. S., McGuire, M., Gruenberg, A. M., \& Walsh, D. (1995). Schizotypal symptoms and signs in the Roscommon Family Study. Their factor structure and familial relationship with psychotic and affective disorders. Arch Gen Psychiatry, 52(4), 296-303.

Kendler, K. S., \& Walsh, D. (1995). Schizotypal personality disorder in parents and the risk for schizophrenia in siblings. Schizophr Bull, 21(1), 47-52. 
Kirkbride, J. B., Fearon, P., Morgan, C., Dazzan, P., Morgan, K., Tarrant, J., . . Jones, P. B. (2006). Heterogeneity in incidence rates of schizophrenia and other psychotic syndromes: findings from the 3-center AeSOP study. Arch Gen Psychiatry, 63(3), 250-258. doi: 10.1001/archpsyc.63.3.250

Kolada, J. L., Bland, R. C., \& Newman, S. C. (1994). Epidemiology of psychiatric disorders in Edmonton. Obsessive-compulsive disorder. Acta Psychiatr Scand Suppl, 376, 24-35.

Leckman, J. F., Bloch, M. H., \& King, R. A. (2009). Symptom dimensions and subtypes of obsessivecompulsive disorder: a developmental perspective. Dialogues in Clinical Neuroscience, 11(1), 21-33. doi: D - NLM: PMC3181902 EDAT- 2009/05/13 09:00 MHDA- 2009/07/08 09:00 CRDT2009/05/13 09:00 PST - ppublish

Leckman, J. F., Denys, D., Simpson, H. B., Mataix-Cols, D., Hollander, E., Saxena, S., . . Stein, D. J. (2010). Obsessive-compulsive disorder: a review of the diagnostic criteria and possible subtypes and dimensional specifiers for DSM-V. Depression and Anxiety, 27(6), 507-527. doi: 10.1002/da.20669

Lincoln, T. M., Ziegler, M., Mehl, S., \& Rief, W. (2010). The jumping to conclusions bias in delusions: Specificity and changeability. Journal of Abnormal Psychology, 119(1), 40-49.

Linney, Y. M., Peters, E. R., \& Ayton, P. (1998). Reasoning biases in delusion-prone individuals. Br J Clin Psychol, 37 ( Pt 3), 285-302.

Linscott, R. J., \& van Os, J. (2010). Systematic reviews of categorical versus continuum models in psychosis: evidence for discontinuous subpopulations underlying a psychometric continuum. Implications for DSM-V, DSM-VI, and DSM-VII. Annu Rev Clin Psychol, 6, 391-419. doi: 10.1146/annurev.clinpsy.032408.153506

Lochner, C., \& Stein, D. J. (2006a). Does work on obsessive-compulsive spectrum disorders contribute to understanding the heterogeneity of obsessive-compulsive disorder? Progress in neuropsychopharmacology \& biological psychiatry, 30(3), 353-361. doi: 10.1016/j.pnpbp.2005.11.004

Lochner, C., \& Stein, D. J. (2006b). Does work on obsessive-compulsive spectrum disorders contribute to understanding the heterogeneity of obsessive-compulsive disorder? Prog Neuropsychopharmacol Biol Psychiatry, 30(3), 353-361. doi: S0278-5846(05)00348-9 [pii]10.1016/j.pnpbp.2005.11.004

Lochner, C., \& Stein, D. J. (2010). Obsessive-compulsive spectrum disorders in obsessive-compulsive disorder and other anxiety disorders. Psychopathology, 43(6), 389-396. doi: 000321070 [pii]10.1159/000321070

Lysaker, P. H., Lancaster, R. S., Nees, M. A., \& Davis, L. W. (2004). Patterns of obsessive-compulsive symptoms and social function in schizophrenia. Psychiatry Res, 125(2), 139-146.

Maher, B. A. (1974). Delusional thinking and perceptual disorder. J Individ Psychol, 30(1), 98-113.

Maric, N., Myin-Germeys, I., Delespaul, P., de Graaf, R., Vollebergh, W., \& Van Os, J. (2004). Is our concept of schizophrenia influenced by Berkson's bias? Soc Psychiatry Psychiatr Epidemiol, 39(8), 600-605. doi: 10.1007/s00127-004-0803-z

Mataix-Cols, D., Rosario-Campos, M. C., \& Leckman, J. F. (2005). A multidimensional model of obsessive-compulsive disorder. Am J Psychiatry, 162(2), 228-238. doi: 162/2/228 [pii]10.1176/appi.ajp.162.2.228

McCormick, L. M., \& Flaum, M. (2005). Diagnosing schizophrenia circa 2005: how and why? Current psychiatry reports, 7(4), 311-315.

McGorry, P. D., Bell, R. C., Dudgeon, P. L., \& Jackson, H. J. (1998). The dimensional structure of first episode psychosis: an exploratory factor analysis. Psychological Medicine, 28(4), 935-947.

McGorry, P. D., Singh, B. S., Connell, S., McKenzie, D., Van Riel, R. J., \& Copolov, D. L. (1992). Diagnostic concordance in functional psychosis revisited: a study of inter-relationships between alternative concepts of psychotic disorder. Psychological Medicine, 22(2), 367-378.

McGrath, R. E. (2005). Conceptual Complexity and Construct Validity. J Pers Assess, 85(2), 112-124. doi: $10.1207 /$ s15327752jpa8502_02 
McKay, D., Abramowitz, J. S., Calamari, J. E., Kyrios, M., Radomsky, A., Sookman, D., . . W Wilhelm, S. (2004). A critical evaluation of obsessive-compulsive disorder subtypes: Symptoms versus mechanisms. Clinical Psychology Review, 24(3), 283-313. doi: 10.1016/j.cpr.2004.04.003

McKay, R., Langdon, R., \& Coltheart, M. (2006). Need for closure, jumping to conclusions, and decisiveness in delusion-prone individuals. J Nerv Ment Dis, 194(6), 422-426.

Mlakar, J., Jensterle, J., \& Frith, C. D. (1994). Central monitoring deficiency and schizophrenic symptoms. Psychol Med, 24(3), 557-564.

Morillo, C., Belloch, A., \& García-Soriano, G. (2007). Clinical obsessions in obsessive-compulsive patients and obsession-relevant intrusive thoughts in non-clinical, depressed and anxious subjects: Where are the differences? Behaviour Research and Therapy, 45(6), 1319-1333. doi: http://dx.doi.org/10.1016/j.brat.2006.11.005

Moritz, S., Peters, M. J. V., Larøi, F., \& Lincoln, T. M. (2010). Metacognitive beliefs in obsessivecompulsive patients: A comparison with healthy and schizophrenia participants. Cognitive Neuropsychiatry, 15(6), 531-548.

Moritz, S., \& Woodward, T. S. (2005). Jumping to conclusions in delusional and non-delusional schizophrenic patients. Br J Clin Psychol, 44(Pt 2), 193-207.

Morrison, A. P., \& Baker, C. A. (2000). Intrusive thoughts and auditory hallucinations: a comparative study of intrusions in psychosis. Behaviour Research and Therapy, 38(11), 1097-1106.

Morrison, A. P., Haddock, G., \& Tarrier, N. (1995). Intrusive Thoughts and Auditory Hallucinations: A Cognitive Approach. Behavioural and Cognitive Psychotherapy, 23(03), 265-280. doi: doi:10.1017/S1352465800015873

Murray, R. M., O'Callaghan, E., Castle, D. J., \& Lewis, S. W. (1992). A neurodevelopmental approach to the classification of schizophrenia. Schizophrenia Bulletin, 18(2), 319-332.

Nechmad, A., Ratzoni, G., Poyurovsky, M., Meged, S., Avidan, G., Fuchs, C., . . Weizman, R. (2003). Obsessive-compulsive disorder in adolescent schizophrenia patients. Am J Psychiatry, 160(5), 1002-1004.

Nestadt, G., Grados, M., \& Samuels, J. F. (2010). Genetics of Obsessive-Compulsive Disorder. Psychiatric Clinics of North America, 33(1), 141-158. doi: http://dx.doi.org/10.1016/j.psc.2009.11.001

Nestadt, G., Samuels, J., Riddle, M., Bienvenu, O. J., 3rd, Liang, K. Y., LaBuda, M., . . . Hoehn-Saric, R. (2000). A family study of obsessive-compulsive disorder. Arch Gen Psychiatry, 57(4), 358-363.

Pauls, D. L., Alsobrook, J. P., 2nd, Goodman, W., Rasmussen, S., \& Leckman, J. F. (1995). A family study of obsessive-compulsive disorder. Am J Psychiatry, 152(1), 76-84.

Phillips, K. A., Stein, D. J., Rauch, S. L., Hollander, E., Fallon, B. A., Barsky, A., . . Leckman, J. (2010). Should an obsessive-compulsive spectrum grouping of disorders be included in DSM-V? Depression and Anxiety, 27(6), 528-555. doi: 10.1002/da.20705

Pinkham, A. E., Hopfinger, J. B., Pelphrey, K. A., Piven, J., \& Penn, D. L. (2007). Neural bases for impaired social cognition in schizophrenia and autism spectrum disorders. Schizophr Res.

Rachman, S. (1998). A cognitive theory of obsessions: elaborations. Behav Res Ther, 36(4), 385-401.

Rachman, S., \& Hodgson, R. (1980). Obsessions and compulsions. New Jersey: Prentice/Hall International: Hemel Hempstead.

Randall, F., Corcoran, R., Day, J. C., \& Bentall, R. P. (2003). Attention, theory of mind, and causal attributions in people with persecutory delusions: A preliminary investigation. Cognitive Neuropsychiatry, 8(4), 287-294.

Reay, R., Mitford, E., McCabe, K., Paxton, R., \& Turkington, D. (2010). Incidence and diagnostic diversity in first-episode psychosis. Acta Psychiatr Scand, 121(4), 315-319.

Regeer, E. J., Krabbendam, L., De Graaf, R., Have, M. T., Nolen, W. A., \& Van Os, J. (2009). Berkson's bias and the mood dimensions of bipolar disorder. Int J Methods Psychiatr Res, 18(4), 279286. doi: $10.1002 / \mathrm{mpr} .290$

Robins, E., \& Guze, S. B. (1970). Establishment of diagnostic validity in psychiatric illness: its application to schizophrenia. The American journal of psychiatry, 126(7), 983-987. 
Salkovskis, P. M., \& Harrison, J. (1984). Abnormal and normal obsessions--a replication. Behav Res Ther, 22(5), 549-552.

Schnell, K., Heekeren, K., Daumann, J. r., Schnell, T., Schnitker, R., MÃףller-Hartmann, W., \& Gouzoulis-Mayfrank, E. (2008). Correlation of passivity symptoms and dysfunctional visuomotor action monitoring in psychosis. Brain, 131(10), 2783-2797. doi: 10.1093/brain/awn184

Sham, P. C., Castle, D. J., Wessely, S., Farmer, A. E., \& Murray, R. M. (1996). Further exploration of a latent class typology of schizophrenia. Schizophrenia Research, 20(1-2), 105-115.

Silver, H., Goodman, C., Bilker, W., Gur, R. C., Isakov, V., Knoll, G., \& Feldman, P. (2006). Impaired error monitoring contributes to face recognition deficit in schizophrenia patients. Schizophr Res, 85(1-3), 151-161. doi: 10.1016/j.schres.2006.02.027

Stein, D. J. (2002). Obsessive-compulsive disorder. Lancet, 360(9330), 397-405.

Stein, D. J., \& Lochner, C. (2006). Obsessive-compulsive spectrum disorders: a multidimensional approach. Psychiatr Clin North Am, 29(2), 343-351.

Stern, R., \& Cobb, J. (1978). Phenomenology of obsessive-compulsive neurosis. British Journal of Psychiatry.

Stewart, S. E., Rosario, M. C., Baer, L., Carter, A. S., Brown, T. A., Scharf, J. M., . . Pauls, D. L. (2008). Four-Factor Structure of Obsessive-Compulsive Disorder Symptoms in Children, Adolescents, and Adults. Journal of the American Academy of Child \&amp; Adolescent Psychiatry, 47(7), 763-772. doi: 10.1097/CHI.0b013e318172ef1e

Taberner, J., Fullana, M. A., Caseras, X., Pertusa, A., Bados, A., van den Bree, M., . . Mataix-Cols, D. (2009). Are obsessive-compulsive symptom dimensions familial in nonclinical individuals? Depress Anxiety, 26(10), 902-908. doi: 10.1002/da.20606

Tandon, R., Nasrallah, H. A., \& Keshavan, M. S. (2009). Schizophrenia, "just the facts" 4. Clinical features and conceptualization. Schizophrenia Research, 110(1-3), 1-23. doi: 10.1016/j.schres.2009.03.005

Tijssen, M. J., van Os, J., Wittchen, H. U., Lieb, R., Beesdo, K., Mengelers, R., . . Wichers, M. (2010). Evidence that bipolar disorder is the poor outcome fraction of a common developmental phenotype: an 8-year cohort study in young people. Psychological Medicine, 40(2), 289-299. doi: $10.1017 /$ S0033291709006138

Tolin, D. F., Hamlin, C., \& Foa, E. B. (2002). Directed forgetting in obsessive-compulsive disorder: replication and extension. Behav Res Ther, 40(7), 793-803.

Tsutsumi, A., Glatt, S., Kanazawa, T., Kawashige, S., Uenishi, H., Hokyo, A., . . Yoneda, H. (2011). The genetic validation of heterogeneity in schizophrenia. Behavioral and Brain Functions, 7(1), 43.

Valleni-Basile, L. A., Garrison, C. Z., Jackson, K. L., Waller, J. L., McKeown, R. E., Addy, C. L., \& Cuffe, S. P. (1994). Frequency of obsessive-compulsive disorder in a community sample of young adolescents. J Am Acad Child Adolesc Psychiatry, 33(6), 782-791.

Valleni-Basile, L. A., Garrison, C. Z., Waller, J. L., Addy, C. L., McKeown, R. E., Jackson, K. L., \& Cuffe, S. P. (1996). Incidence of obsessive-compulsive disorder in a community sample of young adolescents. J Am Acad Child Adolesc Psychiatry, 35(7), 898-906.

van Grootheest, D. S., Boomsma, D. I., Hettema, J. M., \& Kendler, K. S. (2008). Heritability of obsessive-compulsive symptom dimensions. American journal of medical genetics. Part $B$, Neuropsychiatric genetics : the official publication of the International Society of Psychiatric Genetics, 147B(4), 473-478. doi: 10.1002/ajmg.b.30622

Van Grootheest, D. S., Cath, D. C., Beekman, A. T., \& Boomsma, D. I. (2007). Genetic and environmental influences on obsessive-compulsive symptoms in adults: a population-based twin-family study. Psychol Med, 37(11), 1635-1644.

Van Os, J., Gilvarry, C., Bale, R., Van Horn, E., Tattan, T., White, I., \& Murray, R. (1999). A comparison of the utility of dimensional and categorical representations of psychosis. UK700 Group. Psychol Med, 29(3), 595-606. 
van Os, J., Hanssen, M., Bijl, R. V., \& Ravelli, A. (2000). Strauss (1969) revisited: a psychosis continuum in the general population? Schizophr Res, 45(1-2), 11-20.

van Os, J., Hanssen, M., Bijl, R. V., \& Vollebergh, W. (2001). Prevalence of psychotic disorder and community level of psychotic symptoms: an urban-rural comparison. Arch Gen Psychiatry, $58(7), 663-668$.

van Os, J., \& Kapur, S. (2009). Schizophrenia. Lancet, 374(9690), 635-645. doi: 10.1016/S01406736(09)60995-8

van Os, J., Linscott, R. J., Myin-Germeys, I., Delespaul, P., \& Krabbendam, L. (2009). A systematic review and meta-analysis of the psychosis continuum: evidence for a psychosis pronenesspersistence-impairment model of psychotic disorder. Psychological Medicine, 39(2), 179-195. doi: 10.1017/S0033291708003814

Van Os, J., Verdoux, H., Maurice-Tison, S., Gay, B., Liraud, F., Salamon, R., \& Bourgeois, M. (1999). Self-reported psychosis-like symptoms and the continuum of psychosis. Soc Psychiatry Psychiatr Epidemiol, 34(9), 459-463.

van Rijn, S., Aleman, A., de Sonneville, L., Sprong, M., Ziermans, T., Schothorst, P., ... Swaab, H. (2011). Misattribution of facial expressions of emotion in adolescents at increased risk of psychosis: the role of inhibitory control. Psychological Medicine, 41(03), 499-508. doi: doi:10.1017/S0033291710000929

Varese, F., \& Bentall, R. P. (2011). The metacognitive beliefs account of hallucinatory experiences: A literature review and meta-analysis. Clinical Psychology Review, 31(5), 850-864.

Ventura, J., Hellemann, G. S., Thames, A. D., Koellner, V., \& Nuechterlein, K. H. (2009). Symptoms as mediators of the relationship between neurocognition and functional outcome in schizophrenia: a meta-analysis. Schizophrenia research, 113(2-3), 189-199. doi: 10.1016/j.schres.2009.03.035

Versmissen, D., Janssen, I., Johns, L., McGuire, P., Drukker, M., a Campo, J., . . . Krabbendam, L. (2007). Verbal self-monitoring in psychosis: a non-replication. Psychol Med, 37(4), 569-576. doi: S0033291706009780 [pii]10.1017/S0033291706009780

Villalta-Gil, V., Vilaplana, M., Ochoa, S., Haro, J. M., Dolz, M., Usall, J., \& Cervilla, J. (2006). Neurocognitive performance and negative symptoms: Are they equal in explaining disability in schizophrenia outpatients? Schizophrenia research, 87(1-3), 246-253. doi: http://dx.doi.org/10.1016/i.schres.2006.06.013

Wang, L., Metzak, P. D., \& Woodward, T. S. (2011). Aberrant connectivity during self- other source monitoring in schizophrenia. Schizophrenia Research, 125(2-3), 136-142.

Westphal, K. (1878). Ueber Zwangvorstellungen. Arch. Psychiatr. Nervenkr., 8, 734-750.

Whitney, K. A., Fastenau, P. S., Evans, J. D., \& Lysaker, P. H. (2004). Comparative neuropsychological function in obsessive-compulsive disorder and schizophrenia with and without obsessivecompulsive symptoms. Schizophr Res, 69(1), 75-83. 
If a man is offered a fact which goes against his instincts, he will scrutinize it closely, and unless the evidence is overwhelming, he will refuse to believe it. If, on the other hand, he is offered something which affords a reason for acting in accordance to his instincts, he will accept it even on the slightest evidence. The origin of myths is explained in this way.

Bertrand Russell (1872 - 1970) 


\title{
Chapter
}

\section{Can Obsessions Drive You Mad?}

\section{Longitudinal Evidence that Obsessive-Compulsive Symptoms} Worsen the Outcome of Early Psychotic Experiences

\author{
Frank Van Dael ${ }^{1}$, Jim van Os ${ }^{1.2}$, Ron de Graaf ${ }^{3}$, Margreet ten Have ${ }^{3}$, \\ Lydia Krabbendam4, Inez Myin-Germeys ${ }^{1}$

\footnotetext{
${ }^{1}$ Department of Psychiatry and Psychology, South Limburg Mental Health Research and Teaching Network, EURON, Maastricht University, Maastricht, the Netherlands

${ }^{2}$ King's College London, King's Health Partners, Department of Psychosis Studies, Institute of Psychiatry, Denmark Hill, London, UK

${ }^{3}$ Netherlands Institute of Mental Health and Addiction (Trimbos Institute), Utrecht, The Netherlands

${ }^{4}$ Centre Brain and Learning, Dept. Psychology and Education, VU University Amsterdam
} 



\section{Objectives}

Although there is substantial comorbidity between psychotic disorder and OCD, little is known about how these clinical phenotypes, and their subclinical extended phenotypes, covary and impact on each other over time. This study examined cross-sectional and longitudinal associations between both (extended) phenotypes in the general population.

Method. Data were obtained from the three waves of the NEMESIS-study. A representative population sample of 7076 participants were assessed using the Composite International Diagnostic Interview (CIDI) at baseline (TO), 1 year later at T1 and again 2 years later at T2.

Results. At T0, a lifetime diagnosis of psychotic disorder was present in $1.5 \%$ of the entire sample, in $11.5 \%$ of the people with any OC symptom and in $23.0 \%$ of individuals diagnosed with OCD. OC symptoms at TO predicted incident psychotic symptoms at T2. Similarly, TO psychotic symptoms predicted T2 OC symptoms. The likelihood of persistence of psychotic symptoms or transition to psychotic disorder was higher if early psychosis was accompanied by co-occurring OC symptoms, but not the other way around.

\section{Conclusion.}

OCD and the psychosis phenotype cluster together and predict each other at (sub)clinical level. The co-occurrence of subclinical $O C$ and psychosis may facilitate the formation of a more "toxic" form of persistent psychosis.

\section{Significant outcomes}

- The OCD and psychosis phenotype cluster together and predict each other at clinical and subclinical level.

- When psychotic symptoms are accompanied by obsessive-compulsive symptoms, the risk for transition to psychotic disorder with need for care is increased.

- This knowledge may be helpful for clinicians in decision-making for early interventions and follow-up.

\section{Limitations}

- Despite the large sample, numbers are quite low in some of the longitudinal and more complex interaction models.

- OC symptoms may be underreported with the used questionnaire (CIDI).

- Information is lacking on the role of specific psychotic symptom dimensions (positive, negative disorganisational symptoms) on comorbdity with OC symptoms.

- The three year longitudinal follow-up is relatively short. 


\section{Introduction}

Although the co-occurrence of OCD and schizophrenia has been reported consistently for more than a century (Westphal, 1878), reports are less consistent with regard to the extent of this? comorbidity (Byerly, Goodman, Acholonu, Bugno, \& Rush, 2005). Reported rates of schizophrenia in OCD patients vary from $4.0 \%$ to $12.2 \%$ (Eisen \& Rasmussen, 1993; Karno, Golding, Sorenson, \& Burnam, 1988; Kolada, Bland, \& Newman, 1994), and the reported prevalence of OCD in subjects with schizophrenia ranges from $1.1 \%$ to $59.2 \%$ (Bland, Newman, \& Orn, 1987; Jahrreis, 1926). Many factors may contribute to heterogeneity in reported results. In clinical studies, diagnoses were based mostly on diagnostic hierarchy as defined in DSM, thus excluding, for example, obsessions that in content were related to any other Axis 1 disorder. Two studies, assessing lifetime occurrence of OCD and schizophrenia in a general population sample without hierarchical exclusions, yielded considerably higher comorbidity rates $(59.2 \%$ OCD in schizophrenia, compared to $1.1 \%$ - $46.6 \%$ in reports applying hierarchical exclusions and $12.2 \%$ schizophrenia in OCD compared to $4.0 \%$, respectively ) (Berman et al., 1998; Bland et al., 1987; Eisen \& Rasmussen, 1993; Karno et al., 1988). Other factors influencing heterogeneity of study findings include sample selection, diagnostic criteria, type of prevalence assessment (retrospective, cross-sectional, longitudinal) and type of symptom assessment (therapist report, short or more extensive assessment tools), applied to two heterogeneous disorders that have been shown to display a broad range of symptoms (Berman et al., 1998; Bland et al., 1987; Eisen \& Rasmussen, 1993; Karno et al., 1988; Reay, Mitford, McCabe, Paxton, \& Turkington, 2010). In addition, both psychotic disorder and OCD have sub-threshold extended phenotypes that can be measured in general population samples (de Bruijn, Beun, de Graaf, Ten Have, \& Denys, 2010; Scott et al., 2008); comorbidities may vary depending on whether analysis is carried out at the level of clinical or extended phenotype.

Therefore, in order to fully understand the level of co-variation between psychosis and OCD, the broad distribution of symptomatic expression at both clinical and subclinical level should be included. To our knowledge, no previous studies have included the issue of comorbidity across the spectrum of expression.

It has been suggested that OCD and psychosis may not only cluster cross-sectionally, but also influence each other longitudinally, in terms of onset and prognosis. Studies investigating this issue have reported contradictory results (Byerly et al., 2005; Lysaker, Lancaster, Nees, \& Davis, 2004; Poyurovsky, Weizman, \& Weizman, 2004), OCD impacting positively, negatively or not at all on aspects of course and outcome of schizophrenia (Berman et al., 1998; Byerly et al., 2005; Eisen, Beer, Pato, Venditto, \& Rasmussen, 1997; Fabisch, Fabisch, Langs, Huber, \& Zapotoczky, 2001; Lysaker et al., 2004; Nechmad et al., 2003; Ongur \& Goff, 2005; Poyurovsky et al., 2001). In addition, it is unclear whether OCD is impacting on psychosis or whether there is a reciprocal relationship with psychosis moderating risk for OCD. The current study is a cross-sectional and prospective longitudinal investigation in the general population focusing on clinical and subclinical $\mathrm{OC}$ and psychotic symptoms. 


\section{Aim of the study}

The aim of this study was to examine (i) the cross-sectional association between OCD and psychosis, at clinical and subclinical levels of phenotypic expression, (ii) whether baseline OCD predicts follow-up incidence of psychosis and, vice versa, whether baseline psychosis predicts follow-up OCD, and (iii) whether the co-occurrence of $O C$ and psychotic symptoms predicts persistence of psychosis or OC symptoms respectively.

\section{Methods}

\section{Sample}

The study is part of the Netherlands Mental Health Survey and Incidence Study (NEMESIS), a longitudinal study of the prevalence, incidence, course and consequences of psychiatric disorders in the Dutch general population. Subjects were contacted at three points over a period of 3 years: at baseline ( $T O$ - lifetime assessments), 1 year thereafter ( $T 1$ - assessing the period between T0 and T1) and again 2 years after T1 ( $T 2$ - assessing the period between T1 and T2) (Bijl, van Zessen, Ravelli, de Rijk, \& Langendoen, 1998). A multistage, stratified, random sampling procedure was used to first select 90 municipalities, then a sample of private households, and finally a Dutch-speaking individual aged 18-64 years within each household. Individuals living in institutions, including individuals residing in psychiatric hospitals, were not included in the sampling frame. All subjects were sent an introductory letter from the Minister of Health, inviting them to participate. A total of 7076 subjects were enlisted at T0. The response rate was $69.7 \%$. Nearly $44 \%$ of non-responders agreed to fill in a postal questionnaire, including a General Health Questionnaire (Goldberg \& Williams, 1988), and were found to have the same mean GHQ score (responders: 1.19; non-responders: 1.16). At T1, 5618 subjects participated for the second time (response: $79.4 \%$ ); at T2, 4848 subjects participated (response of T1 participants: $86.3 \%$ ). The sample was found to be representative of the Dutch population in terms of sex, marital status and level of urbanisation (Bijl et al., 1998), with the exception of a slight underrepresentation of individuals in the age group 18-24 years.

Presence of psychiatric disorder at T0, demographic variables held constant, only slightly increased the probability of loss to follow up between T0 and T1, as well as between T1 and T2 (de Graaf, Bijl, Smit, Ravelli, \& Vollebergh, 2000).

\section{Instruments}

\section{CIDI}

Subjects were interviewed at home with the Composite International Diagnostic Interview (CIDI; http://www3.who.int/cidi/), version 1.1 (Robins et al., 1988) which measures DSM III-R diagnoses. The CIDI is a fully structured interview that yields DSM-IIIR and ICD-10 diagnoses. It is designed for use by trained interviewers who are not clinicians and has satisfactory inter-rater reliability (Cottler et al., 1991) and test-retest reliability (Wittchen, 1994). Ninety interviewers experienced in systematic data collection administered the interview, having 
received a 3-day training course in recruiting and interviewing, followed by a 4-day course at the World Health Organization-CIDI training centre in Amsterdam, The Netherlands.

Camberwell assessment of Need (CAN)

Need for care was assessed using the Camberwell Assessment of Need (CAN)(Phelan et al., 1995). The CAN includes 22 items (e.g. daytime activities, psychological distress, household skills). All CAN items can be scored 0 (no problem), 1 (there was a problem, but the problem is met), 2 (unmet need).

\section{CIDI psychosis rating}

Ratings from the 17 items of the CIDI core psychosis sections, assessed at T0, T1 and T2 on delusions (13 items) and hallucinations (4 items) were used (items G1-G13, G15, G16, G20, G21). These concern classic psychotic symptoms involving, for example, thought interference and passivity phenomena (i.e. first-rank delusions), persecution and auditory hallucinations. All these items can be rated in six ways: ' 1 '- no symptom; ' 2 '- symptom present but not clinically relevant (not bothered by it and not seeking help for it); ' 3 'symptom result of ingestion of drugs; ' 4 '- symptom result of somatic disease; ' 5 ' - clinical psychotic symptom (presence of distress and help-seeking); ' 6 '-symptom may not really be a symptom because there appears to be some plausible explanation for it. At all three time points, clinical re-interview or clinical consultation procedures were in place in order to reduce false-positive ratings (van Os, Hanssen, Bijl, \& Ravelli, 2000).

For the purpose of the analyses, subclinical psychotic experiences were broadly defined as any CIDI rating of 2,3,4 or 6 on any of the 17 psychosis items. The justification for these broad ratings was derived from a previous study, where it was shown that the different ratings on the CIDI psychosis items were strongly associated with each other (van Os, Hanssen, Bijl, \& Vollebergh, 2001). In addition, the different ratings independently showed a similar pattern of associations with known risk factors for psychosis (van Os et al., 2001).

\section{Psychosis ratings at TO and T1}

Three increasing levels of psychosis were defined: (i) any T0 subclinical psychotic experience (any CIDI rating of 2,3,4 or 6 on any of the 17 psychosis items; hereafter referred to as TO psychotic experience), (ii) any T0 clinical psychotic symptom (a CIDI rating of 5 on any of the $17 \mathrm{CIDI}$ core psychosis items; hereafter referred to as TO psychotic symptom) and (iii) TO diagnosis of psychotic disorder (any DSM-III-R affective or non-affective psychotic disorder; hereafter referred to as TO psychotic disorder). Similar levels were defined for the T1 assessment.

\section{Psychosis outcomes at T2}

In order to assess T2 psychotic experiences in terms of clinical relevance, psychosis at T2 was specified at two levels, one involving the presence of positive psychotic symptoms assessed with the BPRS, and one using additional clinical judgment of need for care (Johns \& van Os, 2001). 


\section{(i) T2 outcome of BPRS psychotic symptoms}

At T2, two items of the Brief Psychiatric Rating Scale (BPRS) (Overall \& Gorham, 1988), 'unusual thought content' and 'hallucinations' were assessed by a clinician in a telephone reinterview with anybody with a rating of 2, 5 or 6 on any of the CIDI psychosis items at T2. The clinical re-interview rate was $74.4 \%$ (163 of 220 individuals). The BPRS ratings were discussed in a consensus meeting attended by two psychologists and two psychiatrists after each telephone re-interview. All four clinicians had received training in the BPRS and used this instrument routinely in clinical practice. They were blind to the information from the $\mathrm{CIDI}$ at T0 and T1, as well as to the hypotheses of this study. The range of scores for each BPRS symptom was from 1 (absent) to 7 (very severe) (Lukoff \& Ventura, 1986). The BPRS was used to define a psychosis outcome, defined as any rating $>1$ on either of the two BPRS items (hereafter: T2 BPRS psychotic symptoms).

(ii) T2 outcome of Needs based diagnosis of psychotic disorder As the most widely used system of classification of psychiatric disorders, the DSM IV (Association, 1994), allocates 'patient status' on the basis of disability and distress rather than clinical need, a procedure was applied that yielded a needs-based diagnosis to identify incident cases of psychosis at T2. This definition of the psychosis outcome allowed us to not only use classical criteria for allocation of patient status on the basis of severity and functional impairment (as, for example, in DSM), but additionally to use a clinical judgement of need for care, as recommended for case identification in the general population (Spitzer, 1998). Need for care in relation to psychotic symptoms and psychological distress was assessed in the consensus meeting by four clinicians, after information was gathered in the areas of need as defined by the Camberwell Assessment of Need (CAN) (Slade, Phelan, Thornicroft, \& Parkman, 1996).

Information on need for care, thus collected was combined with the BPRS to define a more stringent T2 clinical outcome (hereafter: $T 2$ needs-based diagnosis of psychotic disorder), defined as the combination of (i) BPRS pathology-level psychotic symptom (any rating $>3$ on either of the two BPRS positive psychosis items) and (ii) clinician consensus on probable/definite need for care.

\section{CIDI rating of obsessive-compulsive symptoms and disorder}

OC symptoms were examined using 5 from the 19 items of the CIDI OCD-sections. For two obsession items ( $\mathrm{K} 1, \mathrm{~K} 1 \mathrm{a})$, two ratings were provided: ' 1 ', no symptom and ' 5 ', true psychiatric symptom. The three compulsion items (K9, K10, K11) were rated similarly, and in addition a third rating was added of ' 2 ', indicating that the symptom was present but not clinically relevant (not bothered by it and not seeking help for it). OC symptoms were defined both at T0 and T2 at two levels: (i) any obsession or compulsion, defined as a rating of 2 or 5 on any of the obsession/compulsion items mentioned above 
(hereafter: OC symptom), and (ii) presence of OCD, defined as a CIDI-generated DSM-III-R diagnosis of OCD.

\section{Analysis}

All analyses were carried out using the software package STATA, version 11 (StataCorporation, 1984-2009).

\section{1) Cross-sectional association between $O C D$ and psychosis}

Associations between TO OCD (clinical disorder and subclinical OC symptoms) and the three TO psychosis variables (psychotic experience, psychotic symptom and psychotic disorder) were assessed using logistic regression analyses. Associations were adjusted for the a priori demographical confounders of age, sex, level of education, marital status (living alone or not), urbanicity and use of alcohol and drugs.

Associations have been reported between psychosis and affective symptom dimensions (Bora, Yucel, Fornito, Berk, \& Pantelis, 2008; Kaymaz \& van Os, 2009; Krabbendam et al., 2004), between OCD and mood disorders (Denys, Tenney, van Megen, de Geus, \& Westenberg, 2004; Mancebo et al., 2008; Spinella, 2005), and between psychosis and anxiety disorders (Braga, Petrides, \& Figueira, 2004; Ruscio, Stein, Chiu, \& Kessler, 2010). Therefore, in order to assess whether any association between psychosis and OCD was independent from the overlap between psychosis and anxiety and mood disorders in general, all associations were additionally adjusted, in a second step, for lifetime presence of other anxiety disorders (panic disorder, agoraphobia, social phobia, simple phobia, generalized anxiety disorder) and mood disorders (major depression, bipolar disorder, dysthymia).

\section{2) Longitudinal associations between $T O O C D$ and $T 2$ psychosis}

For those without a T0 or T1 diagnosis of psychotic disorder, the risk of T2 BPRS psychotic symptoms and of incident $T 2$ needs-based diagnosis of psychotic disorder was calculated as a function of the presence of a TO OCD. In order to ensure that the associations were not due to any missed diagnosis of psychotic disorder at baseline, associations were additionally adjusted for the variable TO psychotic experience.

Associations were adjusted for the same demographical confounders as well as presence of mood and non-OCD anxiety disorders; the latter adjustment is also necessary for reason of reports that psychotic disorder may be expressed initially as non-psychotic diagnoses (Lewis, David, Malmberg, \& Allebeck, 2000; Svirskis et al., 2005; Weiser et al., 2001).

In order to assess whether the association between TO OCD and T2 psychosis outcomes reflects a predictive function rather than passive comorbidity, the fit of the reverse model was tested, that is, whether T0 psychosis variables increased the risk for T2 OCD. 
3) Association between co-occurrence of subclinical OC and psychotic symptoms and later clinical psychosis

In order to test the hypothesis that individuals with clustering of the OCD extended phenotype and the psychosis extended phenotype would display greater risk of developing T2 needs-based diagnosis of psychotic disorder compared to individuals with either extended phenotype in isolation, an interaction was fitted between T1 OC symptoms and T1 psychotic symptoms as independent variables in the model with T2 BPRS psychotic symptoms and T2 needs-based diagnosis of psychotic disorder as the dependent variable. For the latter analyses, T1 rather than T0 measures were used as the independent variables, given that TO measures reflect lifetime exposure so that symptoms of $\mathrm{OC}$ and psychosis, rated as present at T0, may well have occurred at entirely different periods in time, i.e. they may not reflect true co-occurrence. As the T1 measure reflected the brief interval of 1 year, actual cooccurrence is much more likely if both $\mathrm{OC}$ and psychosis symptoms were rated as present at T1.

The inverse interaction model was also tested: whether the co-occurrence of OCD and psychosis extended phenotypes at T1 was associated with increased risk of developing a diagnosis of OCD or OC symptoms at $\mathrm{T} 2$.

In line with recent advances in the conceptualization of interaction, we calculated the statistical additive interaction rather than the multiplicative interaction, as the former is more likely to yield information on the degree of synergism between causes, that is the extent to which both causes depend on each other or co-participate in disease causation (Darroch, 1997). In order to calculate the statistical interaction under an additive model, the BINREG procedure in the STATA statistical programme (StataCorporation, 1984-2009), which fits generalized linear models for the binomial family estimating risk differences, was used. Interactions were assessed by Wald test.

\section{Risk Set1}

For the TO cross-sectional analyses, the risk set consisted of all individuals who participated in the TO CIDI interview ( $n=7076)$. 

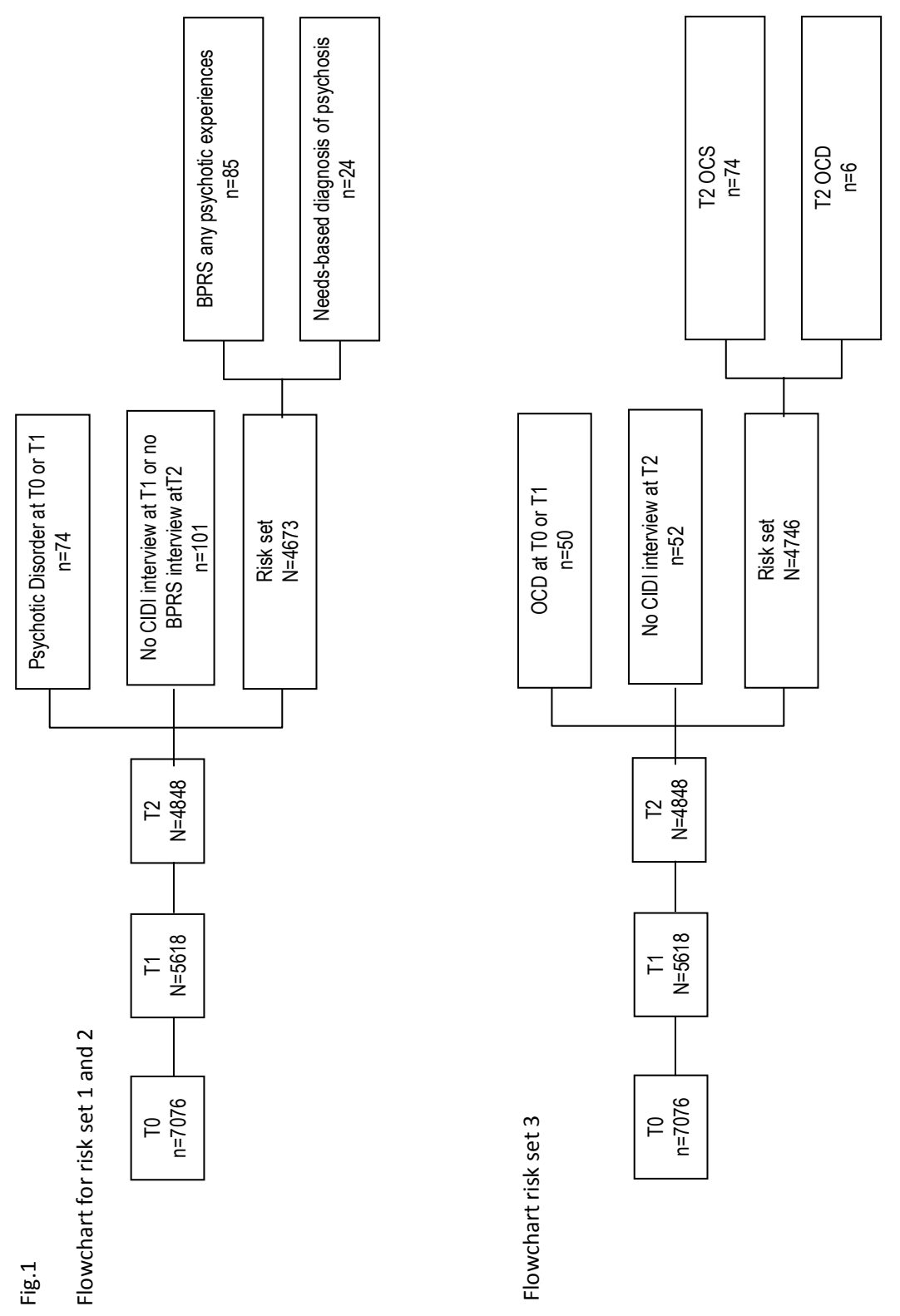


\section{Risk set 2}

For the longitudinal analyses, the sample was restricted to individuals who (i) had participated in the TO CIDI interview with the exception of the individuals with a lifetime diagnosis of psychotic disorder ( $n=107)$, (ii) had post-TO CIDI interviews at T1 ( $n=5536)$, with the exception of the individuals with an incident diagnosis of psychotic disorder at that time ( $n=11$ ) and (iii) had not missed T2 CIDI interview and re-interview by clinicians about the presence of psychotic symptoms if they had been eligible for this clinical re-interview. Applying these combined criteria yielded a risk set for the longitudinal analyses of 4673 individuals. (Fig.1)

\section{Risk set 3}

For the analysis of the inverse model (association between T0 psychosis and T2 OCD), the sample was restricted to all individuals who (i) had participated in the TO CIDI interview with the exception of the individuals with a lifetime diagnosis of OCD ( $n=61)$, (ii) had post-TO CIDI interviews at $\mathrm{T} 1(\mathrm{n}=5567)$, with the exception of the individuals with an incident diagnosis of OCD at that time $(n=13)$ and (iii) had not missed T2 CIDI interview. Applying these combined criteria, the risk set for this analysis consisted of 4746 individuals.

\section{Results}

\section{1) Descriptives}

Data on demographics and OCD and psychosis variables at T0, T1 and T2 are shown in table 1 for risk sets 1, 2 and 3. The distribution of demographic variables was comparable across risk sets.

\section{2) Cross-sectional association between $O C D$ \& psychosis}

TO OCD was present in $0.5 \%$ (28/5838) of the people without any psychotic experience), in $1.2 \%(11 / 930)$ of the people with a TO psychotic experience (without disorder nor symptom), in $3.9 \%(8 / 203)$ of the people with a TO psychotic symptom (without the disorder) and in $13.1 \%(14 / 107)$ of those with a TO psychotic disorder.

Associations between TO OC symptoms and the psychosis phenotype became progressively stronger when increasingly more stringent definitions were used along the psychosis and OCD extended phenotypes respectively (table 2 ).

The associations changed only marginally after adjustment for the confounders age, sex, level of education, marital status, urbanicity and use of alcohol and drugs both at the level of symptom (OR: 3.7, p<0.0005, 95\% Cl: 2.5-5.6) as at the level of disorder (OR: 15.9, p<0.000, $95 \% \mathrm{Cl}: 8.1-31.3)$. When additionally adjusted for other anxiety disorders and mood disorders, the association between presence of $O C D$ and psychosis was reduced but remained significant both at the level of disorder (OR: 2.7, $\mathrm{p}<0.017,95 \% \mathrm{Cl}: 1.2-6.0$ ), at the level of symptoms (OR: 2.4, p<0.0005, 95\% Cl: 1.5-3.7) and even at the lowest measured levels of expression of the phenotype (OR:2.7, $\mathrm{p}<0.0005,95 \% \mathrm{Cl}: 2.1-3.6)$. 
Table 1: Demographics, OCD and psychosis variables at T0, T1 and T2 for risk sets 1, 2 and 3.

\begin{tabular}{|c|c|c|c|}
\hline & Risk set 1 & Risk set 2 & Risk set 3 \\
\hline $\mathbf{N}(\%)$ & $7076(100 \%)$ & $4673(100 \%)$ & $4746(100 \%)$ \\
\hline TO Psychotic experience & $1237(17.5 \%)$ & $676(14.5 \%)$ & $742(15.6 \%)$ \\
\hline TO Psychotic symptom & $295(4.2 \%)$ & $102(2.2 \%)$ & $152(3.2 \%)$ \\
\hline TO Psychotic disorder * & 107 (1.5\%) & 0 & 52 (1.1\%) \\
\hline TO OC symptom & 409 (5.8\%) & 237 (5.1\%) & $229(4.8 \%)$ \\
\hline T0 Obsession & $372(5.3 \%)$ & $219(4.7 \%)$ & $213(1.5 \%)$ \\
\hline TO Compulsion & $83(1.2 \%)$ & $39(0.83 \%)$ & $34(0.7 \%)$ \\
\hline T0 OCDisorder & $61(0.86 \%)$ & $29(0.62 \%)$ & $0(0 \%)$ \\
\hline T1 Psychotic symptom & $72(1.3 \%)$ & $28(0.6 \%)$ & \\
\hline T1 OC symptom & $117(2.1 \%)$ & $81(1.7 \%)$ & \\
\hline T2 BPRS psychotic symptom & $104(2.2 \%)$ & 85 (1.8\%) & $97(2.1 \%)$ \\
\hline T2 needs-based diagnosis of & 33 (0.69\%) & $24(0.5 \%)$ & $30(0.6 \%)$ \\
\hline Mean age (SD) & $41.2(12.2)$ & $41.2(11.9)$ & 41.3 (11.9) \\
\hline Gender (\% male) & 46.6 & 46.8 & 46.6 \\
\hline Level of education Lowest & $28.0 \%$ & $24.3 \%$ & $24.6 \%$ \\
\hline Low & $36.3 \%$ & $36.6 \%$ & $36.5 \%$ \\
\hline High & $7.4 \%$ & $7.6 \%$ & $7.6 \%$ \\
\hline Highest & $27.0 \%$ & $30.4 \%$ & $30.0 \%$ \\
\hline
\end{tabular}

* affective and non-affective

Table 2: Unadjusted cross-sectional associations between TO OC symptoms/OCD and TO psychotic symptom/ TO psychotic disorder (disorder excluded from symptoms excluded from experiences)

\begin{tabular}{|c|c|c|c|c|}
\hline T0 Psychosis & & $\begin{array}{l}\text { T0 ps.experience } \\
13.8 \%(930 / 6765)\end{array}$ & $\begin{array}{l}\text { T0 ps. symptom } \\
2.9 \%(203 / 6968)\end{array}$ & $\begin{array}{l}\text { TO ps. disorder } \\
1.5 \%(107 / 7075)\end{array}$ \\
\hline \multirow{2}{*}{$\begin{array}{l}\text { T0 OC symptom } \\
4.9 \% \quad(348 / 7016)\end{array}$} & $\%(n / N)$ & $11.6 \%(107 / 919)$ & $16.4 \%(32 / 195)$ & $35.5 \%(33 / 93)$ \\
\hline & OR $(95 \% \mathrm{Cl})$ & $\begin{array}{l}4.2(3.3-5.4) \\
p<0.0005\end{array}$ & $\begin{array}{l}4.5(3.0-6.6) \\
p<0.0005\end{array}$ & $\begin{array}{l}11.5(7.4-17.9) \\
p<0.0005\end{array}$ \\
\hline \multirow[t]{2}{*}{$\begin{array}{l}\text { T0 ОCD } \\
0.9 \%(61 / 7076)\end{array}$} & $\%(n / N)$ & $1.2 \%(11 / 930)$ & $3.9 \%(8 / 203)$ & $13.1 \%(14 / 107)$ \\
\hline & OR $(95 \% \mathrm{Cl})$ & $\begin{array}{l}2.5(1.2-5.0) \\
P<0.011\end{array}$ & $\begin{array}{l}7.1(3.3-15.3) \\
P<0.0005\end{array}$ & $\begin{array}{l}22.2(11.8-41.7) \\
P<0.0005\end{array}$ \\
\hline
\end{tabular}

* \% of total sample

Total sample: $n=7076$; OR=odds ratio ( $95 \%$ confidence interval) 


\section{3) Association between TO OCD and subsequent psychosis}

The TO OCD phenotype, at symptom level as well as at disorder level, was significantly associated with an increased risk of (i) T2 BPRS psychotic symptoms, and (ii) a T2 needsbased diagnosis of psychotic disorder (table 3 ). These associations remained significant when adjusted for any TO psychotic symptom or experience.

When adjusted not only for any TO psychotic symptom, but additionally for non-OCD anxiety disorders and mood disorders at T0 and for the confounders age, sex, level of education, marital status, use of alcohol and drugs and urbanicity, associations for TO OC symptoms remained significant, whereas for TOOCD, they remained significant in the model with the $T 2$ needs based psychosis outcome, but were just short of conventional alpha in the model of the T2 BPRS psychotic symptoms (table 3).

Table 3: Association (OR (95\% CI)) between TO OC symptoms/ OCD and T2 psychosis outcomes (= T2 BPRS psychotic symptoms and T2 needs-based diagnosis of psychotic disorder respectively).

\begin{tabular}{lll}
\hline \multicolumn{1}{c}{ T2 Psychosis } & T2 BPRS psychotic symptom & \multicolumn{2}{c}{ T2 needs-based diagnosis of } \\
T0 OC & $\mathbf{1 . 8 \% ~ ( 8 5 / 4 6 7 3 )}$ & psych. disorder $\quad$ 0.5\% (24/4673) \\
\hline TO OC symptom, not adjusted & $4.2(2.4-7.5)$ & $6.4(2.5-16.2)$ \\
5.1\% (237/4673) & $\mathrm{P}<0.0005$ & $\mathrm{P}<0.0005$ \\
TO OC symptom, adjusted for TO & $3.0(1.6-5.6)$ & $3.5(1.3-9.7)$ \\
psychotic symptoms & $\mathrm{P}<0.001$ & $\mathrm{P}<0.015$ \\
Adjusted for TO psychotic & $3.0(1.5-5.9)$ & $3.8(1.2-12.2)$ \\
symptoms and other confounders* & $\mathrm{P}<0.001$ & $\mathrm{P}<0.021$ \\
\hline TO OCD, not adjusted & $6.4(1.9-21.6)$ & $15.6(3.5-69.5)$ \\
0.6\% (29/4673) & $\mathrm{P}<0.003$ & $\mathrm{P}<0.0005$ \\
TO OCD Adjusted for TO psychotic & $4.3(1.1-16.7)$ & $8.6(1.5-48.8)$ \\
symptoms & $\mathrm{P}<0.037$ & $\mathrm{P}<0.015$ \\
Adjusted for T0 psychotic & $3.8(0.9-16.1)$ & $9.4(1.1-79.6)$ \\
symptoms, and other confounders & $\mathrm{P}<0.074$ & $\mathrm{P}<0.040$ \\
\hline
\end{tabular}

* age, sex, level of education, marital status (living alone or not), urbanicity, use of alcohol and drugs, other anxiety disorders, mood disorders

In risk set 3, TO psychotic disorder was significantly associated with T2 OC symptoms, also after adjustment for TO OC symptoms, other anxiety and mood disorders and the other confounders mentioned above. None of the subjects with TO psychotic disorder developed full T2 OCD. Having TO psychotic symptoms without a TO psychotic disorder was significantly associated with both $T 2 O C D$ and $T 2 O C$ symptoms, also after adjustment for $T O O C$ symptoms. (Table 4) 
Table 4: Association (OR (95\% CI)) between TO psychotic symptoms/disorder and T2 OC symptoms/OCD.

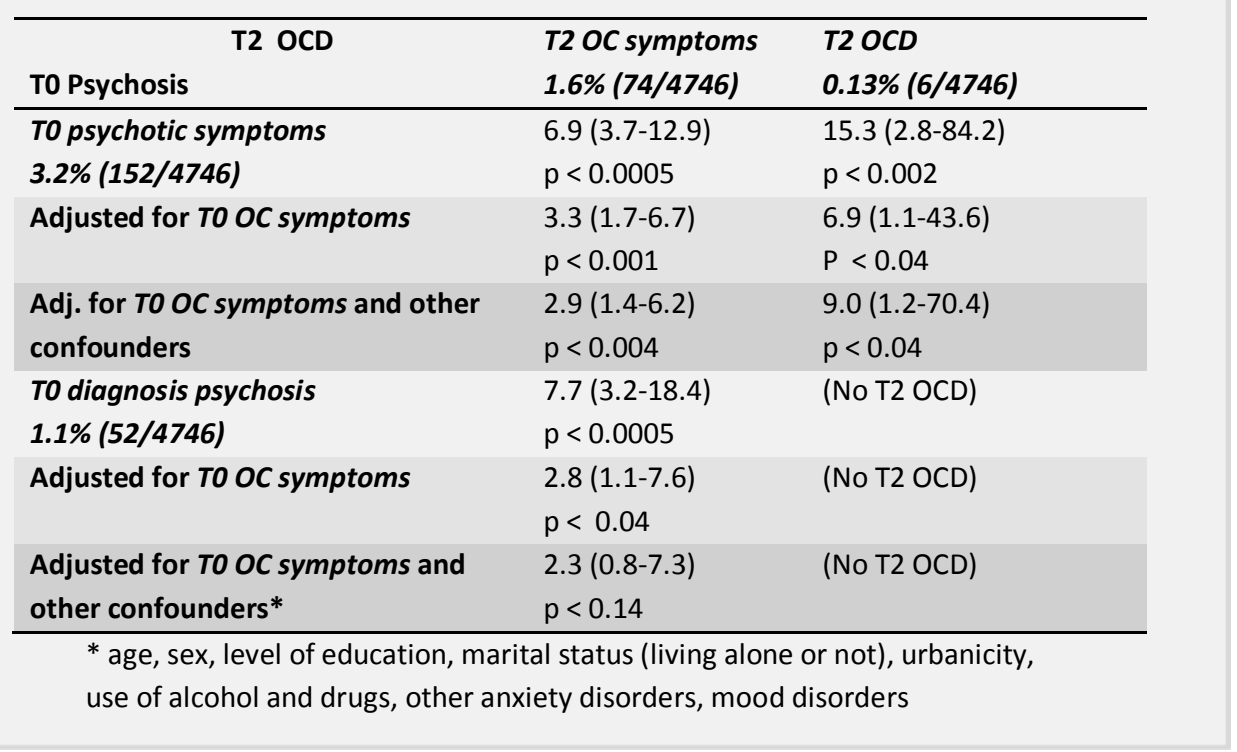

\section{4) Early OCD-psychosis co-occurrence and later clinical outcome}

The presence of $T 1$ psychotic symptoms significantly increased the risk of $T 2$ needs-based diagnosis of psychotic disorder, as reported previously (Hanssen, Bak, Bijl, Vollebergh, \& van Os, 2005). For those with co-occurring T1 OC symptoms, this risk increasing effect was higher compared to those without co-occurring $T 1$ OC symptoms. The difference in risk increase on the additive scale between the groups with and without $T 1$ OC symptoms was (i) $47.2 \%$ for T2 BPRS psychotic symptoms outcome, and (ii) $40.4 \%$ for a $T 2$ needs-based diagnosis of psychotic disorder outcome (Table 5). These interactions remained significant when adjusted for the presence of TO psychotic symptoms (Risk difference: (i) $42.4 \% ; \chi^{2}=5.51 ; \mathrm{P}=0.018$ and (ii) Risk difference: $\left.38.9 \% ; \chi^{2}=4.3 ; P=0.038\right)$ ). In the inverse model, there was no significant interaction between present $T 1$ OC symptoms and $T 1$ psychotic symptoms in predicting $T 2$ OCD or T2 OC symptoms (Table 5; Fig. 2A and 2B).

Figure2A: The OCD extended phenotype (disorder and symptoms without disorder) at T0 predicted incident psychosis (disorder and symptoms) at T2. Similarly, T0 psychotic symptoms predicted $\mathrm{T} 2 \mathrm{OC}$ symptoms.

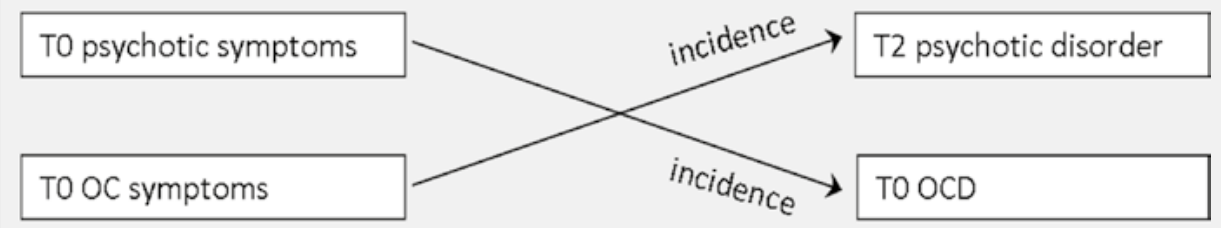


Figure2B: Given the early presence of psychotic symptoms, the likelihood of persistence of psychosis symptoms or transition to psychotic disorder was higher if early psychosis was accompanied by co-occurrence of OC symptoms (dotted grey arrows).

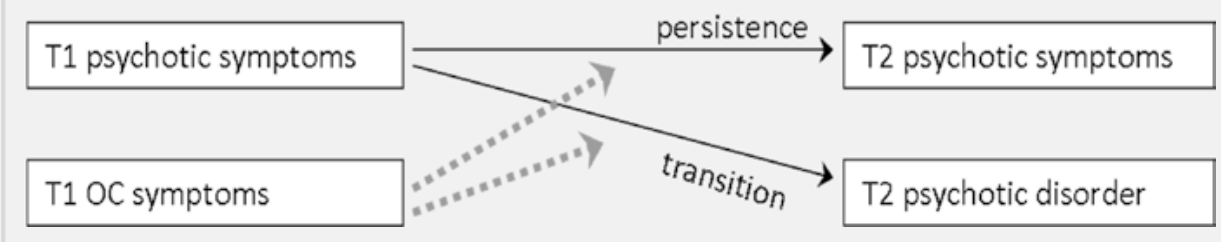

Table 5: Interactions between T1 psychotic symptoms and T1 OC symptoms in predicting psychosis and OCD respectively. Additive scale (risk differences)

\begin{tabular}{|c|c|c|c|}
\hline $\begin{array}{l}\text { Risk for T2 BPRS psychotic } \\
\text { symptoms }(n=85)\end{array}$ & $\begin{array}{l}\text { No } T 1 \text { psychotic } \\
\text { symptom }\end{array}$ & $\begin{array}{l}\text { T1 psychotic } \\
\text { symptom }\end{array}$ & $\begin{array}{l}\text { Increase in risk by T1 psychotic } \\
\text { symptom }\end{array}$ \\
\hline No T1 OCS & $1.6 \%$ & $10.0 \%$ & $8.4 \%$ \\
\hline T1 OCS & $6.8 \%$ & $62.5 \%$ & $55.6 \%$ \\
\hline Difference in risk increase & & & $47.2 \%(10.8-83.7)$ \\
\hline Additive interaction & & & $\chi^{2}=6.44, d f=1, P=0.011$ \\
\hline $\begin{array}{l}\text { Risk for T2 needs-based diagnosis } \\
\text { of psychotic disorder }(n=24)\end{array}$ & $\begin{array}{l}\text { No T1 psychotic } \\
\text { symptom }\end{array}$ & $\begin{array}{l}\text { T1 psychotic } \\
\text { symptom }\end{array}$ & $\begin{array}{l}\text { Increase in risk by T1 psychotic } \\
\text { symptom }\end{array}$ \\
\hline No $T 1$ OCS & $0.4 \%$ & $10.0 \%$ & $9.6 \%$ \\
\hline T1 OCS & $0 \%$ & $50 \%$ & $50 \%$ \\
\hline Difference in risk increase & & & $40.4 \%(3.3-77.5)$ \\
\hline Additive interaction & & & $\chi^{2}=4.56, d f=1, P=0.033$ \\
\hline Risk for $T 2$ OCS & No T1 OCS & T1 OCS & Increase in risk by T1 OCS \\
\hline No T1 psychotic symptom & $1.1 \%$ & $20.6 \%$ & $19.5 \%$ \\
\hline T1 psychotic symptom & $10.5 \%$ & $50 \%$ & $39.5 \%$ \\
\hline Difference in risk increase & & & $20.0 \%$ \\
\hline Additive interaction & & & $\chi^{2}=1.11, \mathrm{df}=1, \mathrm{P}=0.29$ \\
\hline Risk for $T 2 O C D$ & No $T 1$ OCS & T1 OCS & Increase in risk by T1 OCS \\
\hline No T1 psychotic symptom & $0.1 \%$ & $0 \%$ & $-0.1 \%$ \\
\hline T1 psychotic symptom & $0 \%$ & $12.5 \%$ & $12.5 \%$ \\
\hline Difference in risk increase & & & $12.6 \%$ \\
\hline Additive interaction & & & $\chi^{2}=1.16, d f=1, P=0.28$ \\
\hline
\end{tabular}

\section{Discussion}

The results of this population-based study showed a cross-sectional association between subclinical and clinical OCD and subclinical and clinical psychosis, independent of other anxiety and mood disorders and demographic confounders. In the longitudinal analyses, it was shown that the TO OCD (extended) phenotype was associated with the development of future subclinical and clinical psychosis, and conversely, that the TO (extended) psychosis phenotype was associated with future OCD. These findings could still be attributed to the 
high rates of comorbidity, without a specific impact of OC symptoms on the course of psychotic symptoms. However, in the interaction models, the risk-increasing effect of "comorbid" OC and psychotic symptoms on a future psychosis (clinical) outcome was considerably stronger then the risk-increasing effect of co-morbid $\mathrm{OC}$ and psychotic symptoms on a future OCD outcome. This suggests a specific impact of OC symptoms on psychotic symptoms in increasing the risk for transition to psychosis.

\section{Comorbidity}

The analyses revealed a much greater than chance comorbidity. The prevalence of OCD in psychosis was $13.1 \%$, somewhat at the lower end of the reported range from $1 \%$ up to $59 \%$ in previous studies (Bland et al., 1987; Jahrreis, 1926). The rather low estimation in this study is in line with comorbidity findings based on short screening questionnaires like the Diagnostic Interview Schedule (DIS) or its successor the CIDI (8\%-14\%) compared to studies using more extensive questionnaires like PANSS and YBOCS (23\% - 47\%)(Berman et al., 1998). It is possible that the CIDI may lead to underreporting of OC symptoms as it includes only 2 questions regarding obsessions and 3 regarding compulsions. The lifetime prevalence of OCD of $0.86 \%$ in this study indeed was lower than the 2 to $3 \%$ reported in most other studies (Ruscio et al., 2010; Weissman et al., 1994). Thus, the estimates in the current study can be considered conservative.

Comorbidity may arise from a number of sources. The comorbidity between OCD and psychosis may be due to shared etiological influences. Environmental risk factors like preand perinatal stressful events, childhood trauma and negative life events, being part of an ethnic minority and use of cannabis and other drugs tend to be associated with both OCD and psychosis (Cromer, Schmidt, \& Murphy, 2007; Crum \& Anthony, 1993; Hultman, Sparen, Takei, Murray, \& Cnattingius, 1999; Read, van Os, Morrison, \& Ross, 2005; Vasconcelos et al., 2007). An increased vulnerability in late adolescence and a tendency for males to get affected earlier than females are also common correlates of both OCD and psychosis (Bland et al., 1987; Zohar et al., 1992). Both disorders are associated with a number of alterations in neuropsychological performance (impaired attention and error monitoring, impaired inhibition, and impaired visuospatial skills) (Berman et al., 1998)) as well as neuroanatomical and neurobiological changes (volume changes in basal ganglia and prefrontal cortex; alterations in dopaminergic neurotransmission) (Gross-Isseroff, Hermesh, Zohar, \& Weizman, 2003; Stein, 2000).

Overlapping diagnostic criteria may also contribute to the apparent comorbidity. Obsessions and delusions, core symptoms of OCD and psychosis respectively, share some features in their conceptualisation: both concern persistent thoughts or ideas that become overvalued and go together with elevated preoccupation, distress, anxiety and, frequently, impact on behaviour (Association, 1994; Freeman, Garety, Kuipers, Fowler, \& Bebbington, 2002; Jenike, 2004). However, there remains a distinct conceptual difference between these symptoms. Delusions typically are defined as false beliefs that are held with high conviction, not 
amenable to reason, and ego-syntonic by their holder, who is lacking insight and does not unfold any resistance. Obsessions are defined as recurrent and persistent thoughts, impulses or images, that are experienced as intrusive and inappropriate (i.e. ego-dystonic), and typically accompanied by insight: they are recognized as a product of one's own mind and elicit resistance (Association, 1994).

Another possible source of comorbidity is confounding or population stratification, which occurs when two disorders have non-overlapping sets of risk factors, but these risk factors both tend to be more common in certain strata of the population (Klein \& Riso, 1993). The association between (subclinical) OC and psychosis, however, was shown to be independent of confounding by other anxiety and mood disorders as well as a number of non-shared risk factors and demographic variables.

Finally, Berkson's bias may affect the results, when subjects with more than one disorder are more likely to be part of a clinical sample (Maric et al., 2004; Regeer et al., 2009). However, our findings were derived from a non-clinical, general population sample, suggesting that the overlap cannot be explained by the effect of any referral bias. Summarizing, there is some evidence for shared etiological factors contributing to the observed comorbidity, though the role of overlapping diagnostic criteria cannot be ruled out.

\section{OC symptoms predict clinical psychosis}

A second important finding in the longitudinal part of the study is that TO (subclinical) OCD predisposes for incident psychosis and for transition of psychotic experiences to clinical psychosis with need for care. This finding strengthens previous reports of a risk-increasing effect of OCD on the development of psychosis (Niendam, Berzak, Cannon, \& Bearden, 2009; Tien \& Eaton, 1992), although this was not replicated in some studies (Goodwin, Guze, \& Robins, 1969; Poyurovsky \& Koran, 2005). Although we also found a reverse association of psychotic symptoms predisposing for incident OCD, only OC symptoms appeared to have a specific interaction with psychotic symptoms in augmenting the risk for later psychotic disorder with need for care; the reverse was not found. Thus, OC symptoms may have a deleterious influence on the course and outcome of psychosis.

The precise nature of this "toxic" effect remains unclear. In studies on psychological models of $O C D$, persons prone to $O C D$ show a cognitive style characterized by unsuccessful thought suppression and the tendency to make negative interpretations that involve the idea that the person's choice can result in harm, which needs to be neutralized. Consequent to this cognitive style, occasional intrusive thoughts tend to re-occur, cause distress and become a symptom (Salkovskis, 1999). In severe cases of OCD, insight can become tenuous as obsessions progress to overvalued ideas. At some point, an obsessional concern may be regarded as justified and beyond reasonable question, thereby corresponding to the definition of a delusion. It is attractive to speculate that the development of a delusional appraisal or belief of an intrusive thought, particularly in presence of this obsession-prone cognitive style, may also predispose for psychosis, which is in line with current psychological models of psychosis (Maher, 1988). 


\section{Limitations}

Despite the large sample, numbers were quite low in some of the longitudinal analyses. For example, only three subjects with TO OCD developed a T2 needs-based diagnosis of psychotic disorder, and in the interaction models of T1 comorbid psychotic and OC symptoms, controlled for TO psychotic symptoms, there were no subjects with OC symptoms, but without psychotic symptoms, developing psychosis with need for care. This study does not provide information on the difference in nature of symptoms between schizophrenia with OC symptoms and schizophrenia without OC symptoms. For this purpose, the CIDI doesn't cover sufficiently the negative and cognitive symptoms and qualitative differences between different kinds of obsessions and compulsions. As mentioned earlier, the CIDI may lack sensitivity compared to more extensive questionnaires, particularly for $\mathrm{OC}$ symptoms. Finally, the duration of the follow-up period of three years is relatively short.

To our knowledge, this is the first study on the association between clinical and subclinical $O C D$ and psychosis in a general population sample using a longitudinal design. Increased comorbidity rates between $O C D$ and psychosis were found, suggesting an etiological relationship with a partially shared or similar aetiological pathway.

The finding that OC symptoms predict psychotic disorder with need for care is important for identifying subjects at risk for psychosis. For clinicians, it can be helpful in follow-up and treatment planning to account for the apparent deleterious effect of $\mathrm{OC}$ symptoms on psychosis. However, although there is some evidence for an etiological relationship, the mechanism of the mutual impact of $\mathrm{OC}$ and psychotic symptoms is still poorly understood and requires further research. 


\section{References}

American Psychiatric Association, A.P.A. (1994). Diagnostic and statistic manual of mental disorders (4th edn. ed.). Washington,DC: American Psychiatric Press.

Berman, I., Merson, A., Viegner, B., Losonczy, M. F., Pappas, D., \& Green, A. I. (1998). Obsessions and compulsions as a distinct cluster of symptoms in schizophrenia: a neuropsychological study. $J$ Nerv Ment Dis, 186(3), 150-156.

Bijl, R. V., van Zessen, G., Ravelli, A., de Rijk, C., \& Langendoen, Y. (1998). The Netherlands Mental Health Survey and Incidence Study (NEMESIS): objectives and design. Soc Psychiatry Psychiatr Epidemiol, 33(12), 581-586.

Bland, R. C., Newman, S. C., \& Orn, H. (1987). Schizophrenia: lifetime co-morbidity in a community sample. Acta Psychiatr Scand, 75(4), 383-391.

Bora, E., Yucel, M., Fornito, A., Berk, M., \& Pantelis, C. (2008). Major psychoses with mixed psychotic and mood symptoms: are mixed psychoses associated with different neurobiological markers? Acta Psychiatr Scand, 118(3), 172-187. doi: ACP1230 [pii]10.1111/j.1600-0447.2008.01230.x

Braga, R. J., Petrides, G., \& Figueira, I. (2004). Anxiety disorders in schizophrenia. Compr Psychiatry, 45(6), 460-468.

Byerly, M., Goodman, W., Acholonu, W., Bugno, R., \& Rush, A. J. (2005). Obsessive compulsive symptoms in schizophrenia: frequency and clinical features. Schizophr Res, 76(2-3), 309-316.

Cottler, L. B., Robins, L. N., Grant, B. F., Blaine, J., Towle, L. H., Wittchen, H. U., \& Sartorius, N. (1991). The $\mathrm{CIDI}$-core substance abuse and dependence questions: cross-cultural and nosological issues. The WHO/ADAMHA Field Trial. Br J Psychiatry, 159, 653-658.

Cromer, K. R., Schmidt, N. B., \& Murphy, D. L. (2007). An investigation of traumatic life events and obsessivecompulsive disorder. Behav Res Ther, 45(7), 1683-1691.

Crum, R. M., \& Anthony, J. C. (1993). Cocaine use and other suspected risk factors for obsessive-compulsive disorder: a prospective study with data from the Epidemiologic Catchment Area surveys. Drug Alcohol Depend, 31(3), 281-295.

Darroch, J. (1997). Biologic synergism and parallelism. Am J Epidemiol, 145(7), 661-668.

de Bruijn, C., Beun, S., de Graaf, R., Ten Have, M., \& Denys, D. (2010). Subthreshold symptoms and obsessivecompulsive disorder: evaluating the diagnostic threshold. Psychol Med, 40(6), 989-997.

de Graaf, R., Bijl, R. V., Smit, F., Ravelli, A., \& Vollebergh, W. A. (2000). Psychiatric and sociodemographic predictors of attrition in a longitudinal study: The Netherlands Mental Health Survey and Incidence Study (NEMESIS). Am J Epidemiol, 152(11), 1039-1047.

Denys, D., Tenney, N., van Megen, H. J., de Geus, F., \& Westenberg, H. G. (2004). Axis I and II comorbidity in a large sample of patients with obsessive-compulsive disorder. J Affect Disord, 80(2-3), 155-162.

Eisen, J. L., Beer, D. A., Pato, M. T., Venditto, T. A., \& Rasmussen, S. A. (1997). Obsessive-compulsive disorder in patients with schizophrenia or schizoaffective disorder. Am J Psychiatry, 154(2), 271-273.

Eisen, J. L., \& Rasmussen, S. A. (1993). Obsessive compulsive disorder with psychotic features. J Clin Psychiatry, 54(10), 373-379.

Fabisch, K., Fabisch, H., Langs, G., Huber, H. P., \& Zapotoczky, H. G. (2001). Incidence of obsessive-compulsive phenomena in the course of acute schizophrenia and schizoaffective disorder. Eur Psychiatry, 16(6), 336-341.

Freeman, D., Garety, P. A., Kuipers, E., Fowler, D., \& Bebbington, P. E. (2002). A cognitive model of persecutory delusions. Br J Clin Psychol, 41(Pt 4), 331-347.

Goldberg, D., \& Williams, P. (1988). User's guide to the GHQ. Windsor: NFER-Nelson.

Goodwin, D. W., Guze, S. B., \& Robins, E. (1969). Follow-up studies in obsessional neurosis. Arch Gen Psychiatry, 20(2), 182-187.

Gross-Isseroff, R., Hermesh, H., Zohar, J., \& Weizman, A. (2003). Neuroimaging communality between schizophrenia and obsessive compulsive disorder: a putative basis for schizo-obsessive disorder? World J Biol Psychiatry, 4(3), 129-134.

Hanssen, M., Bak, M., Bijl, R., Vollebergh, W., \& van Os, J. (2005). The incidence and outcome of subclinical psychotic experiences in the general population. Br J Clin Psychol, 44(Pt 2), 181-191. 
Hultman, C. M., Sparen, P., Takei, N., Murray, R. M., \& Cnattingius, S. (1999). Prenatal and perinatal risk factors for schizophrenia, affective psychosis, and reactive psychosis of early onset: case-control study. Bmj, 318(7181), 421-426.

Jahrreis, W. (1926). Uber Zwangvorstellungen im Verlauf der Schizophrenie. Arch. Psychiatr. Nervenkr., 77, 740-788.

Jenike, M. A. (2004). Clinical practice. Obsessive-compulsive disorder. N Engl J Med, 350(3), 259-265.

Johns, L. C., \& van Os, J. (2001). The continuity of psychotic experiences in the general population. Clin Psychol Rev, 21(8), 1125-1141.

Karno, M., Golding, J. M., Sorenson, S. B., \& Burnam, M. A. (1988). The epidemiology of obsessive-compulsive disorder in five US communities. Arch Gen Psychiatry, 45(12), 1094-1099.

Kaymaz, N., \& van Os, J. (2009). Murray et al. (2004) revisited: is bipolar disorder identical to schizophrenia without developmental impairment? Acta Psychiatr Scand, 120(4), 249-252.

Klein, D. N., \& Riso, L. P. (1993). Psychiatric disorders: problems of boundaries and comorbidity. In C. G. Costello (Ed.), Basic Issues in Psychopathology (pp. 19-66). New York: Guilford Press.

Kolada, J. L., Bland, R. C., \& Newman, S. C. (1994). Epidemiology of psychiatric disorders in Edmonton. Obsessive-compulsive disorder. Acta Psychiatr Scand Suppl, 376, 24-35.

Krabbendam, L., Myin-Germeys, I., De Graaf, R., Vollebergh, W., Nolen, W. A., ledema, J., \& Van Os, J. (2004). Dimensions of depression, mania and psychosis in the general population. Psychol Med, 34(7), 11771186.

Lewis, G., David, A. S., Malmberg, A., \& Allebeck, P. (2000). Non-psychotic psychiatric disorder and subsequent risk of schizophrenia. Cohort study. Br J Psychiatry, 177, 416-420.

Lukoff, D., \& Ventura, J. (1986). Manual for the Expanded Brief Psychiatric Rating Scale. Schizophr Bull, 12, 594-602.

Lysaker, P. H., Lancaster, R. S., Nees, M. A., \& Davis, L. W. (2004). Patterns of obsessive-compulsive symptoms and social function in schizophrenia. Psychiatry Res, 125(2), 139-146.

Maher, B. A. (1988). Anomalous experience and delusional thinking: The logic of explanations. In B. A. Maher \& T. F. Oltmanns (Eds.), Delusional beliefs. (pp. 15-33). Oxford England: John Wiley \& Sons.

Mancebo, M. C., Garcia, A. M., Pinto, A., Freeman, J. B., Przeworski, A., Stout, R., . . Rasmussen, S. A. (2008). Juvenile-onset OCD: clinical features in children, adolescents and adults. Acta Psychiatr Scand, 118(2), 149-159. doi: ACP1224 [pii]10.1111/j.1600-0447.2008.01224.x

Maric, N., Myin-Germeys, I., Delespaul, P., de Graaf, R., Vollebergh, W., \& Van Os, J. (2004). Is our concept of schizophrenia influenced by Berkson's bias? Soc Psychiatry Psychiatr Epidemiol, 39(8), 600-605. doi: 10.1007/s00127-004-0803-z

Nechmad, A., Ratzoni, G., Poyurovsky, M., Meged, S., Avidan, G., Fuchs, C., . . Weizman, R. (2003). Obsessive-compulsive disorder in adolescent schizophrenia patients. Am J Psychiatry, 160(5), 10021004.

Niendam, T. A., Berzak, J., Cannon, T. D., \& Bearden, C. E. (2009). Obsessive compulsive symptoms in the psychosis prodrome: Correlates of clinical and functional outcome. Schizophr Res, 108(1-3), 170-175.

Ongur, D., \& Goff, D. C. (2005). Obsessive-compulsive symptoms in schizophrenia: associated clinical features, cognitive function and medication status. Schizophr Res, 75(2-3), 349-362.

Overall, J., \& Gorham, D. (1988). The Brief Psychiatric Rating Scale (BPRS): recent developments in ascertainment and scaling. Psychopharmacol Bull, 24, 97-99.

Phelan, M., Slade, M., Thornicroft, G., Dunn, G., Holloway, F., Wykes, T., . . Hayward, P. (1995). The Camberwell Assessment of Need: the validity and reliability of an instrument to assess the needs of people with severe mental illness. Br J Psychiatry, 167(5), 589-595.

Poyurovsky, M., Hramenkov, S., Isakov, V., Rauchverger, B., Modai, I., Schneidman, M., ... Weizman, A. (2001). Obsessive-compulsive disorder in hospitalized patients with chronic schizophrenia. Psychiatry Res, 102(1), 49-57.

Poyurovsky, M., \& Koran, L. M. (2005). Obsessive-compulsive disorder (OCD) with schizotypy vs. schizophrenia with OCD: diagnostic dilemmas and therapeutic implications. J Psychiatr Res, 39(4), 399-408. 
Poyurovsky, M., Weizman, A., \& Weizman, R. (2004). Obsessive-compulsive disorder in schizophrenia : clinical characteristics and treatment. CNS Drugs, 18(14), 989-1010.

Read, J., van Os, J., Morrison, A. P., \& Ross, C. A. (2005). Childhood trauma, psychosis and schizophrenia: a literature review with theoretical and clinical implications. Acta Psychiatr Scand, 112(5), 330-350.

Reay, R., Mitford, E., McCabe, K., Paxton, R., \& Turkington, D. (2010). Incidence and diagnostic diversity in first-episode psychosis. Acta Psychiatr Scand, 121(4), 315-319. doi: ACP1505 [pii]10.1111/j.16000447.2009.01505.x

Regeer, E. J., Krabbendam, L., De Graaf, R., Have, M. T., Nolen, W. A., \& Van Os, J. (2009). Berkson's bias and the mood dimensions of bipolar disorder. Int J Methods Psychiatr Res, 18(4), 279-286. doi: 10.1002/mpr.290

Robins, L. N., Wing, J., Wittchen, H. U., Helzer, J. E., Babor, T. F., Burke, J., . . . et al. (1988). The Composite International Diagnostic Interview. An epidemiologic Instrument suitable for use in conjunction with different diagnostic systems and in different cultures. Arch Gen Psychiatry, 45(12), 1069-1077.

Ruscio, A. M., Stein, D. J., Chiu, W. T., \& Kessler, R. C. (2010). The epidemiology of obsessive-compulsive disorder in the National Comorbidity Survey Replication. Mol Psychiatry, 15(1), 53-63.

Salkovskis, P. M. (1999). Understanding and treating obsessive-compulsive disorder. Behav Res Ther, 37 Suppl 1, S29-52.

Scott, J., Welham, J., Martin, G., Bor, W., Najman, J., O'Callaghan, M., . . McGrath, J. (2008). Demographic correlates of psychotic-like experiences in young Australian adults. Acta Psychiatr Scand, 118(3), 230237.

Slade, M., Phelan, M., Thornicroft, G., \& Parkman, S. (1996). The Camberwell Assessment of Need (CAN): comparison of assessments by staff and patients of the needs of the severely mentally ill. Soc Psychiatry Psychiatr Epidemiol, 31(3-4), 109-113.

Spinella, M. (2005). Mood in relation to subclinical obsessive-compulsive symptoms. Int J Neurosci, 115(4), 433-443.

Spitzer, R. L. (1998). Diagnosis and need for treatment are not the same. Arch Gen Psychiatry, 55(2), 120.

StataCorporation. (1984-2009). STATA Statistical Software: Release 11.0. Texas: College Station.

Stein, D. J. (2000). Neurobiology of the obsessive-compulsive spectrum disorders. Biol Psychiatry, 47(4), 296304. doi: S0006-3223(99)00271-1 [pii]

Svirskis, T., Korkeila, J., Heinimaa, M., Huttunen, J., Ilonen, T., Ristkari, T., . . Salokangas, R. K. (2005). Axis-I disorders and vulnerability to psychosis. Schizophr Res, 75(2-3), 439-446.

Tien, A. Y., \& Eaton, W. W. (1992). Psychopathologic precursors and sociodemographic risk factors for the schizophrenia syndrome. Arch Gen Psychiatry, 49(1), 37-46.

van Os, J., Hanssen, M., Bijl, R. V., \& Ravelli, A. (2000). Strauss (1969) revisited: a psychosis continuum in the general population? Schizophr Res, 45(1-2), 11-20.

van Os, J., Hanssen, M., Bijl, R. V., \& Vollebergh, W. (2001). Prevalence of psychotic disorder and community level of psychotic symptoms: an urban-rural comparison. Arch Gen Psychiatry, 58(7), 663-668.

Vasconcelos, M. S., Sampaio, A. S., Hounie, A. G., Akkerman, F., Curi, M., Lopes, A. C., \& Miguel, E. C. (2007). Prenatal, perinatal, and postnatal risk factors in obsessive-compulsive disorder. Biol Psychiatry, 61(3), 301-307.

Weiser, M., Reichenberg, A., Rabinowitz, J., Kaplan, Z., Mark, M., Bodner, E., . . Davidson, M. (2001). Association between nonpsychotic psychiatric diagnoses in adolescent males and subsequent onset of schizophrenia. Arch Gen Psychiatry, 58(10), 959-964.

Weissman, M. M., Bland, R. C., Canino, G. J., Greenwald, S., Hwu, H. G., Lee, C. K., . . . et al. (1994). The cross national epidemiology of obsessive compulsive disorder. The Cross National Collaborative Group. J Clin Psychiatry, 55 Suppl, 5-10.

Westphal, K. (1878). Ueber Zwangvorstellungen. Arch. Psychiatr. Nervenkr., 8, 734-750.

Wittchen, H. U. (1994). Reliability and validity studies of the WHO--Composite International Diagnostic Interview (CIDI): a critical review. J Psychiatr Res, 28(1), 57-84.

Zohar, A. H., Ratzoni, G., Pauls, D. L., Apter, A., Bleich, A., Kron, S., . . Cohen, D. J. (1992). An epidemiological study of obsessive-compulsive disorder and related disorders in Israeli adolescents. J Am Acad Child Adolesc Psychiatry, 31(6), 1057-1061. 
Every act of perception, is to some degree an act of creation, and every act of memory is to some degree an act of imagination.

Oliver Sacks, Musicophilia 


\title{
Chapter
}

\section{Evidence for a shared etiological mechanism of psychotic symptoms and obsessive-compulsive symptoms in patients with psychotic disorders and their siblings}

\author{
Frank Van Dael ${ }^{2 *}$, Marije Swets ${ }^{1 *}$, Sabine Roza ${ }^{3}$, Robert A Schoevers ${ }^{5}$ \\ Genetic Risk and Outcome of Psychosis (GROUP) investigators ${ }^{6}$
}

* joined first authors

\begin{abstract}
${ }^{1}$ Arkin Mental Health and Addiction Treatment Centre, Amsterdam, the Netherlands ${ }^{2}$ Department of Neuropsychiatry and Psychology, South Limburg Mental Health Research and Teaching Network, EURON, Maastricht University, Maastricht, the Netherlands ${ }^{3}$ Department of psychiatry, Erasmus University Medical Center, Erasmus University, Rotterdam, the Netherlands

${ }^{4}$ Department of psychiatry, Academic Medical Centre, University of Amsterdam, Amsterdam, the Netherlands ${ }^{5}$ Department of psychiatry, University Medical Centre Groningen, University of Groningen, Groningen, the Netherlands ${ }^{6}$ Genetic Risk and Outcome of Psychosis (GROUP) Investigators: Richard Bruggeman ${ }^{(a)}$, Wiepke Cahn ${ }^{(b)}$, Lieuwe de Haan $^{(c)}$, René S. Kahn ${ }^{(b)}$, Carin J. Meijer ${ }^{(c)}$, Inez Myin-Germeys ${ }^{(d)}$, Jim van Os ${ }^{(d, e)}$, Durk Wiersma ${ }^{(a)}$
\end{abstract}

(a) University Medical Center Groningen, Department of Psychiatry, University of Groningen, The Netherlands

(b) University Medical Center Utrecht, Department of Psychiatry, Rudolf Magnus Institute of Neuroscience,

The Netherlands

(c) Academic Medical Centre University of Amsterdam, Department of Psychiatry, Amsterdam The Netherlands (d) Maastricht University Medical Centre, South Limburg Mental Health Research and Teaching Network, EURON, Maastricht, The Netherlands

(e) King's College London, King's Health Partners, Department of Psychosis Studies, Institute of Psychiatry, London, United Kingdom 



\begin{abstract}
The prevalence of obsessive-compulsive disorder in subjects with psychotic disorder is much higher than in the general population. The higher than chance co-occurrence has also been demonstrated at the level of subclinical expression of both phenotypes. Each of both extended phenotypes has been shown to cluster in families. However, little is known about the origins of their elevated co-occurrence. In the present study, evidence for a shared etiological mechanism was investigated in 3 samples with decreasing levels of familial psychosis liability: 987 patients, 973 of their unaffected siblings and 566 healthy controls. The association between the obsessive-compulsive and the psychosis phenotype was investigated in two ways. First, the association was assessed between (subclinical) obsessivecompulsive symptoms and psychosis liability. Second, in a cross-sib cross-trait analysis, it was examined whether (subclinical) obsessive-compulsive symptoms in the patient were associated with (subclinical) psychotic symptoms in the related unaffected sibling. Evidence was found for both associations, which is compatible with a partially shared etiological pathway underlying the obsessive-compulsive and psychosis extended phenotypes. This is the first study that used a cross-sib cross-trait design in patients and unaffected siblings, thus circumventing confounding by disease-related factors present in clinical samples.
\end{abstract}




\section{Introduction}

Obsessive compulsive disorder (OCD) and obsessive compulsive symptoms (OCS) in schizophrenia are a cause of significant suffering (Lysaker \& Whitney, 2009) and often remain undiagnosed (Mukhopadhaya et al., 2009), even though successful treatment for this comorbid condition has been reported (Reznik \& Sirota, 2000). The one-year prevalence rate of comorbid OCD in schizophrenia is over ten times higher than the one-year prevalence for OCD of $1.0 \%$ found in the community (Kessler, Berglund, et al., 2005) (Kessler, Chiu, Demler, Merikangas, \& Walters, 2005). A recent meta-analysis yielded mean average one-year prevalence rates of $13.6 \%$ for comorbid OCD, 20.5\% for OCS defined as a YBOCS score $>9$ and $30.3 \%$ for any comorbid OCS (YBOCS $>0$ ) (Swets et al., 2013). Patients with schizophrenia often have co-morbid conditions (Buckley, Miller, Lehrer, \& Castle, 2009), but the difference in prevalence of OCS in schizophrenia patients compared to the base rate prevalence in the general population is higher than the difference in prevalence of other anxiety disorders and depression (Achim et al., 2011; Bijl, Ravelli, \& van Zessen, 1998). The origin of this high cooccurrence is largely unknown, but some recent findings give reason to examine the evidence for a partially shared pathogenetic mechanism in the development of these two disorders. Mainly due to genetic influences, siblings of patients with schizophrenia have a 5to 10 -fold higher risk to develop schizophrenia (Sullivan, Kendler, \& Neale, 2003). Research has shown that schizotypy and (subclinical) psychotic symptoms cluster in families, and are likely to be part of an extended psychosis phenotype (Fanous, Gardner, Walsh, \& Kendler, 2001; Polanczyk et al., 2010; M. G. Vollema, Sitskoorn, Appels, \& Kahn, 2002). However, little is known about how this liability to psychosis relates to liability to OCS. Other causal mechanisms are also proposed, some of which may be disease-related factors, such as the exposure to antipsychotic medication (de Haan, Beuk, Hoogenboom, Dingemans, \& Linszen, 2002; de Haan, Linszen, \& Gorsira, 1999; Jonkers \& De Haan, 2002).

One method to disentangle the contribution of these mechanisms is to investigate the occurrence of OCS in the unaffected siblings of patients with psychosis, thus ruling out the role of disease-related factors. To our knowledge, only one family study investigated relatives of patients with schizophrenia with and without OCD (Poyurovsky et al., 2005). Relatives of patients with combined schizophrenia and OCD showed significantly increased rates of schizophrenia with co-morbid OCD or obsessive-compulsive personality disorder in comparison to relatives of patients with non-OCD schizophrenia. However, it was not clear whether the risk of OCS was higher in relatives of patients with non-OCD schizophrenia. Furthermore, a substantial portion of the subjects was not interviewed directly, analyses did not control for the fact that data were paired, data of siblings and parents were pooled together and no direct associations between siblings and patients were analysed.

The current study is using the GROUP sample, a large and representative cohort of patients, their non-psychotic siblings (hereafter referred to as "siblings") and healthy controls not related to first or second degree family members with psychotic disorders, to investigate evidence for a shared genetic or familial etiology between psychosis and OCD. 
First, the association between (subclinical) OCS and psychosis liability was examined by using status (patient, sibling or control) as a measure for psychosis liability. It was predicted that in case OCS and psychotic symptoms share a familial or genetic etiology, unaffected siblings would have an elevated risk for the development of OCS compared to controls. If this association remains when controlling for the expression of (subclinical) psychotic symptoms, the indication for a shared genetic or familial etiology would even be stronger.

As OCD itself clusters in families, subclinical OCS in siblings of patients with OCD may reflect a familial OCD liability. In order to exclude the expression of OCD liability that might be coincidentally co-occurring with, but be independent of, psychosis liability, the association between OCS and psychosis liability was examined excluding the siblings of patients with OCD (defined as YBOCS score >=16) (Frost, Steketee, Krause, \& Trepanier, 1995; Lysaker, Whitney, \& Davis, 2009).

Second, using a cross-sib within-trait analysis, it was examined whether OCS cluster within families of patients diagnosed with a psychotic disorder. Finally, cross-sib cross-trait analyses were conducted to investigate whether OCS in one sibling were associated with psychosis levels in the other sibling. The fact that OCS in patients are associated with psychosis dimensions in unaffected siblings would support the hypothesis of a shared genetic or familial etiology.

\section{Methods}

\section{Subjects}

Data were collected from the Genetic Risk and Outcome in Psychosis study (GROUP) (G.R.O.U.P., 2011). In representative geographical areas in the Netherlands and Belgium, patients were identified through clinicians working in regional psychotic disorder services, whose caseload was screened for inclusion criteria. Subsequently, a group of patients presenting consecutively at these services either as out-patients or in-patients and their siblings were recruited for the study. Controls were selected through a system of random mailings to addresses in the catchment areas of the cases. Inclusion criteria for patients were: (i) age range 16 to 50 years, (ii) diagnosis of non-affective psychotic disorder and (iii) good command of Dutch language. Controls had no first degree relative with a psychotic disorder as established by the Family Interview for Genetic Studies with the control as informant (Maxwell, 1992). Diagnosis was based on the Diagnostic and Statistical Manual of Mental Disorder-IV (DSM-IV) criteria (Association, 1994), assessed with the Comprehensive Assessment of Symptoms and History (CASH) interview (Andreasen, Flaum, \& Arndt, 1992) or Schedules for Clinical Assessment for Neuropsychiatry (SCAN 2.1) (Wing et al., 1990). In case a sibling made a transition to a psychotic illness, he or she was allocated to the patient cohort. The study was approved by the standing ethics committee, and all the subjects gave written informed consent in accordance with the committee's guidelines. The current study focused on the patients, siblings and controls in this sample. 


\section{Measurement of compulsive and obsessive symptoms}

An important challenge facing clinicians and researchers is differentiating an obsession from delusion. We used a "conservative approach": OCS was defined according to the Structured Clinical Interview for DSM-III-R patient-edition (SCID-P) as persistent, repetitive, intrusive, and distressful thoughts (obsessions) not related to the subject's psychotic symptoms or repetitive goal directed rituals (compulsions) clinically distinguishable from mannerisms or posturing observed in schizophrenia. Consequently, patients whose obsessions or compulsions were related to psychotic content of thoughts, or patients without insight in their obsessions or compulsions, were not diagnosed with co-morbid OCS in this study. To measure obsessions and compulsions the Yale-Brown Obsession and Compulsion Scale ( $Y$ BOCS) was used. The Y-BOCS is a 13-item semi-structured interview designed to measure the severity of OCS over the previous week (Goodman, Price, Rasmussen, Mazure, Delgado, et al., 1989; Goodman, Price, Rasmussen, Mazure, Fleischmann, et al., 1989). When an OCS is present, its severity is measured with five items. These items address time spent on, interference and distress from, resistance against and perceived control over obsessions or compulsions, rated on a 5 point scale (0-4). The Dutch translation of the Y-BOCS (Arrindell, de Vlaming, Eisenhardt, van Berkum, \& Kwee, 2002) was used in this study. A broad definition of OCS (hereafter called OCS), meaning any symptom present, was defined as a YBOCS score of 0 versus $>0$. In addition, clinical OCS were defined as a Y-BOCS cut-off of $>9$ (value 1) or <=9 (value 0) (hereafter clinical OCS) (Boyette, Swets, Meijer, Wouters, \& Authors, 2011; de Haan et al., 2006).

\section{Psychosis measures}

Psychotic experiences were measured using an interview measure -the Structured Interview for Schizotypy-Revised (SIS-R) (Kendler, Lieberman, \& Walsh, 1989; Meinte G. Vollema \& Ormel, 2000). The SIS-R is an elaborate semi-structured interview measuring subclinical psychotic experiences in non-psychotic subjects, conducted in siblings and controls. Based on results of previous research on the SIS-R, a positive symptom and negative symptom dimension score was calculated, representing the means of the positive schizotypy item scores and of the negative schizotypy scores respectively. Because the distribution of the SIS-R scores was skewed, it was divided by its deciles, in order to create decile groups.

\section{Analyses}

All statistical analyses were performed using SPSS 17.0 or STATA version 12. Given that some families contributed more than 1 sibling, hierarchical clustering of data at the level of family was modelled using the multilevel random regression XTMELOGIT or XTMIXED routine in STATA version 12 statistical software (StataCorporation, 1985-2011). Pearson Chi-Square tests, T-test and logistic regression were used when appropriate, in order to determine demographics, illness characteristics and prevalences. Estimates were adjusted for a priori determined confounders (sex, age, ethnicity, marital status (single or not), education level and IQ). 


\section{Association between OCS and status}

The first approach was to investigate the association between OCS and genetic psychosis liability, operationalized as a three-level categorical variable "status" ( 0 = controls, $1=$ unaffected siblings, 2 = patients with a psychotic disorder). The association between OCS and status was estimated using multilevel logistic regression analysis (xtmelogit) expressed in odds ratios.

In the next step, the comparisons were restricted to siblings and the controls, given absence of confounding by disease-related factors. Associations between OCS and the two-level categorical variable indexing psychosis liability (sibling versus controls) were investigated, now adjusting for phenotypically expressed subclinical psychotic symptoms, i.e. with SIS-R positive and negative symptoms as covariates in the model. In case of significant associations, the model was adjusted for the a priori determined confounders. These analyses were repeated excluding the siblings of patients with OCD (Y-box score >=16).

\section{Cross-sib within trait and cross-sib cross-trait associations}

Second, it was examined whether familial clustering of the OCD phenotype shown in the general population was also encountered in a sample with psychosis liability, and, additionally, whether clustering of OCD and psychosis phenotypes could be detected. For this purpose, the cross-sibling within-trait associations (association of trait $x$ in sibling $A$ (patient) with trait $x$ in related sibling $B$ (sibling)) and cross-sibling cross-trait associations (the association of trait $x$ in sibling $A$ (patient) with trait $y$ in related sibling $B$ (sibling)) were investigated. (Fig. 1) In the case of families contributing more than 1 patient or more than 1 sibling, all possible patient-unaffected sibling pairs were included in the analyses.

Figure1: Cross-sib cross-trait design.

Trait 1

Patients

Siblings

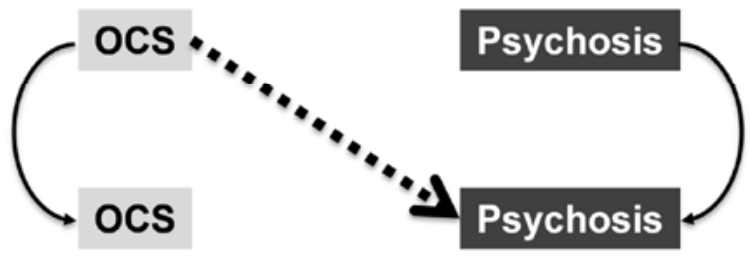

Trait 2

Psychosis 
psychotic symptoms were associated across siblings. Therefore, the SIS-R scores of unaffected relatives were regressed on the dichotomous YBOCS scores in patients using the XTMIXED routine. Multilevel modelling was used as some families contributed more than 1 sibling. Effect sizes were expressed as coefficient $b$ from linear regression analyses. In case of a significant association, the model was adjusted for the a priori determined demographical confounders (sex, age, ethnicity, marital status (single or not), level of education, IQ) and next for use of antidepressant and antipsychotic agents.

\section{Results}

Sample characteristics:

A total of 3,686 persons was included in the GROUP-study. Of these, 1,120 (30.4\%) were patients coming from 1,060 families. A total of 1,976 relatives was included ( $53.6 \%$ of total sample), coming from 919 families. The control group consisted of 590 healthy persons coming from 494 non-affected families. The total number of families included in the study was 1,561, with a maximum of 8 included relatives per family. Patients with missing diagnoses (and their relatives) were excluded from the present study (6 patients, 7 relatives). Of the remaining 3,673 persons, 297 (8.1\%) did not have valid information on the presence or absence of obsessive-compulsive symptoms and were also excluded. All 850 parents were excluded. Overall, 2,526 subjects were included in one or more analyses (987 patients and 973 siblings, coming from 978 families, and 566 controls).

Table 1: Distribution of 2526 subjects in 1458 families Notation: number of subjects in (number of families)

\begin{tabular}{|c|c|c|c|c|}
\hline & (patients + sibs) & Patients & Siblings & Controls \\
\hline \multicolumn{5}{|l|}{2526 (1458) } \\
\hline Fam. with psychosis liability & 1960 (978) & 987 (934) & $973(770)$ & - \\
\hline Gen. Pop. controls & - & - & - & $566(480)$ \\
\hline Fam. with OCD pts. & $169(83)$ & $91(83)$ & $78(65)$ & - \\
\hline Fam. without OCD pts. & $1740(851)$ & $896(851)$ & $844(661)$ & - \\
\hline Fam.without pts.* & $51(44)$ & - & $51(44)$ & - \\
\hline
\end{tabular}

* families without patients with sufficient valid ybocs scores

\section{Demographic and basic clinical characteristics}

Descriptives of the total sample are presented in Table 2. Compared to controls, patients were more often of male sex $\left(\chi^{2}(1)=151, p<0.001\right)$, younger $(t(1)=5.5, p<0.001)$, of lower educational level $\left(\chi^{2}(3)=143, p<0.001\right)$, single $\left(\chi^{2}(2)=209, p<0.001\right)$, and of non-white ethnic group $\left(\chi^{2}(1)=40.4, p<0.001\right)$; patients also had a lower IQ $(t(1)=17.5, p<0.001)$ and more often used cannabis $\left(\chi^{2}(1)=47.7, p<0.001\right)$. Sibs were younger $(t(1)=5.4, p<0.000)$, of lower educational level $\left(\chi^{2}(3)=42, p<0.000\right)$, of non-white ethnic group $\left(\chi^{2}(1)=14.5, p<\right.$ $0.000)$; they also had a lower IQ $(t(1)=9.0, p<0.000)$ and more often used cannabis 
$\left(\chi^{2}(1)=7.3, p<0.007\right)$ than controls, but showed no significant differences in $\operatorname{sex}\left(\chi^{2}(1)=0,04\right.$, $p=0.8)$ and relationship status (single or with partner) $\left(\chi^{2}(2)=0.0, p=1.0\right)$.

Table 2. Descriptives of study population

\begin{tabular}{|c|c|c|c|}
\hline tabel1 & $\begin{array}{l}\text { Patients } \\
(\mathrm{n}=987)\end{array}$ & $\begin{array}{l}\text { Siblings } \\
(\mathrm{n}=973)\end{array}$ & $\begin{array}{l}\text { Controls } \\
(n=566)\end{array}$ \\
\hline Sex (\% male) & 76.3 & 45.9 & 45.4 \\
\hline Age (mean, sd) & $27.8(8.2)$ & $27.8(8.3)$ & $30.4(10.6)$ \\
\hline \multicolumn{4}{|l|}{ Educational level } \\
\hline$\%<=$ primary & 12.7 & 7.8 & 2.8 \\
\hline \% secondary (VMBO/HAVO/MBO) & 59.8 & 51.8 & 43.1 \\
\hline$\%$ higher (VWO/HBO/WO) & 25.2 & 38.4 & 53.4 \\
\hline \multicolumn{4}{|l|}{ Marital status } \\
\hline$\%$ married/living together & 9.1 & 49.9 & 39.8 \\
\hline Ethnicity (\% White) & 77.2 & 83.0 & 90.1 \\
\hline Cannabis in urine (\% positive) & 16.6 & 8.0 & 4.3 \\
\hline IQ (mean, sd) & $95.0(16.0)$ & $\begin{array}{l}102.3 \\
(15.5)\end{array}$ & $109.7(15.2)$ \\
\hline Quality of life (\% bad) & 14.9 & 3.6 & 1.6 \\
\hline \multicolumn{4}{|l|}{ Patient descriptives } \\
\hline GAF(mean, sd) & 56 (15.9) & & \\
\hline \multicolumn{4}{|l|}{ Diagnosis (number, \% of patients) } \\
\hline Schizophrenia & $659(66,8 \%)$ & & \\
\hline Schizophreniform disorder & $51(5,2 \%)$ & & \\
\hline Other psychotic disorder & $156(15,8 \%)$ & & \\
\hline $\begin{array}{l}\text { Mood component (bipolar, } \\
\text { schizoaffective, depressive) }\end{array}$ & $121(15.8 \%)$ & & \\
\hline Duration of illness (median, 95\% range) & $3.6(0.2-15.1)$ & & \\
\hline Age at onset (mean, sd) & $22.3(6.8)$ & & \\
\hline $\begin{array}{l}\text { Number of psychotic episodes (100\% } \\
\text { range) }\end{array}$ & $1-8$ & & \\
\hline \multicolumn{4}{|l|}{$\begin{array}{l}\text { Current use of antipsychotic medication } \\
\text { (\%) }\end{array}$} \\
\hline No or unknown & 29.6 & & \\
\hline Classic antipsychotics & 8.1 & & \\
\hline Risperidon/quetiapine/aripiprazole & 28.6 & & \\
\hline Clozapine & 7.7 & & \\
\hline Olanzapine & 21.4 & & \\
\hline Combinations & 4.5 & & \\
\hline
\end{tabular}

\section{Association between OCS and status}

Broadly defined OCS were significantly more prevalent in patients $(22.7 \%, n=224)$ (OR=6.7, 95\% $\mathrm{Cl}: 4.3-10.6, \mathrm{p}<0.000)$ and siblings $(8.2 \%, \mathrm{n}=80)(\mathrm{OR}=1.8,95 \% \mathrm{Cl}: 1.1-3.0, \mathrm{p}<0.012)$ compared to controls $(4.8 \%, n=27)$. Patients reported significantly more OCS compared to siblings $\left(\chi^{2}(1)=70.4, p<0.000\right)$.

Clinical OCS were significantly more prevalent in patients $(19.0 \%, \mathrm{n}=188)(\mathrm{OR}=18.4,95 \%$ $\mathrm{Cl}: 8.8-38.7, \mathrm{p}<0.000)$ and siblings $(4.3 \%, \mathrm{n}=42)(\mathrm{OR}=2.9,95 \% \mathrm{Cl}: 1.4-6.2, \mathrm{p}<0.006)$ compared to controls $(1.6 \%, n=9)$. Patients reported significantly more clinical OCS compared to 
siblings $\left(\chi^{2}(1)=80.6, p<0.00005\right)$. The associations remained significant after adjusting for confounders. (Fig. 2 )

Figure 2: Prevalence of OCS in function of 3-level psychosis liability (status).

* Differences in prevalence between distinct psychosis liability groups are all significant

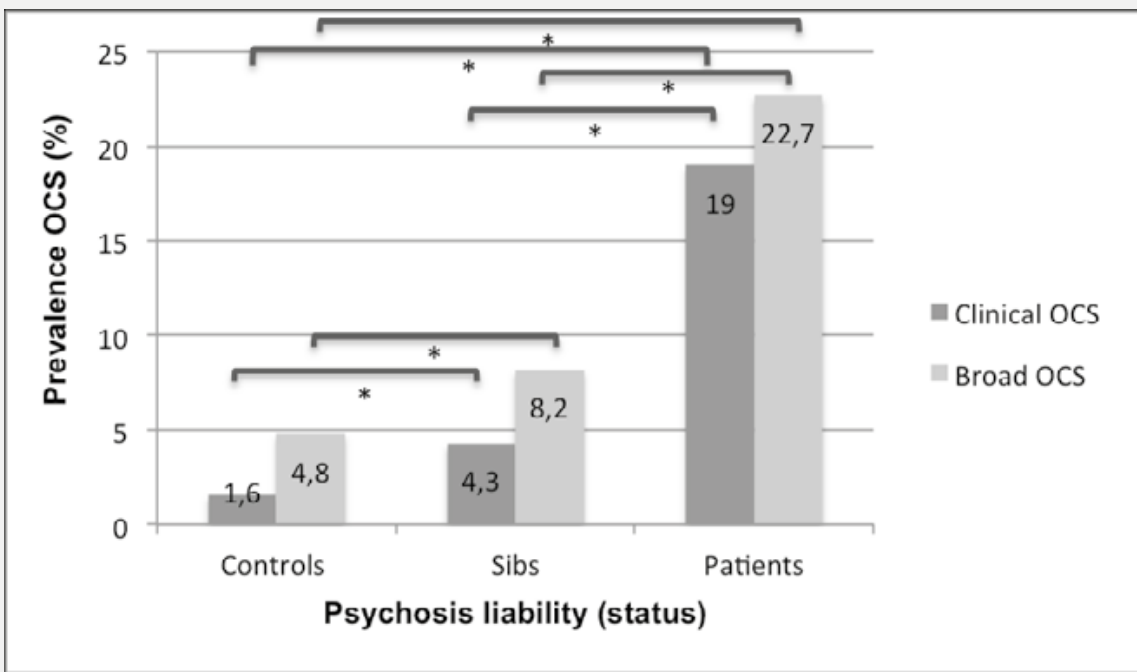

In the next step, analyses were restricted to siblings and controls. It was examined whether the association between OCS and two-level status (sibling versus controls, or sibling status) remained significant when adjusted for positive and negative subclinical psychotic symptoms as assessed with the SIS-R. The association between OCS and two-level status remained significant (broadly defined OCS: $\mathrm{OR}=1.7,95 \% \mathrm{Cl}$ : 1.0-2.6, $\mathrm{p}<0.032$; clinical OCS: $\mathrm{OR}=2.7,95 \%$ $\mathrm{Cl}: 1.3-5.9, \mathrm{p}<0.01)$. Additional adjustment for the confounders did not substantially alter the results.

When adjusted for a diagnosis of depression in the subsample with CASH data, the association with sibling status was just short of conventional alpha $(\mathrm{OR}=1.6,95 \% \mathrm{Cl}: 1.0-2.7$, $\mathrm{p}<0.056)$, similar to additional adjustment for other confounders: $\mathrm{OR}=1.7,95 \% \mathrm{Cl}: 1.0-2.9$, $\mathrm{p}<0.053)$. When conducting the analyses in the subsample of families without patients with OCD (exclusion of 91 patients, i.e. 9.2\% of the patient group), the association between OCS and sibling status remained significant for broadly defined and clinical OCS, even when adjusted for subclinical psychotic symptoms and demographical confounders (Table 3, Fig. 3). 
Table 3: Associations between OCS and sibling status psychosis liability (controls= reference $=0$; sibling of patient=1). Associations are from multilevel logistic regression analysis, expressed in odds ratios;

OR (95\% Cl: ), p

\section{Siblings vs. controls}

\begin{tabular}{lll}
\hline SAMPLE & Level of expression of OC phenotype & OR (95\% Cl: ), p
\end{tabular}

All families in whole sample Broad OCS

Adjusted for SIS-R pos. and neg. symptoms 1.7 (1.0-2.6); $p<0.03$

Additionally adjusted for confounders * 1.8 (1.1-2.9), $\mathrm{p}<0.02$ Clinical OCS

Adjusted for SIS-R pos. and neg. symptoms 2.7 (1.3-5.9), $p<0.01$ Additionally adjusted for confounders * 2.8 (1.3-6.2), $p<0.01$

Within fam. without OCD pts. Broad OCS

\begin{tabular}{rr} 
Unadjusted & $1.8(1.1-2.8), \mathrm{p}<0.01$ \\
Adjusted for SIS-R pos. and neg. symptoms & $1.6(1.0-2.6), \mathrm{p}<0.04$ \\
Additionally adjusted for confounders * & $1.7(1.0-2.8), \mathrm{p}<0.03$ \\
Clinical OCS & \\
Unadjusted & $2.5(1.2-5.5) . \mathrm{p}<0.01$ \\
Adjusted for SIS-R pos. and neg. symptoms & $2.7(1.3-5.9), \mathrm{p}<0.01$ \\
Additionally adjusted for confounders * & $2.4(1.1-5.5), \mathrm{p}<0.03$ \\
\hline
\end{tabular}

*age, sex, level of education, IQ, marital status

Fig 3: Association of OCS with familial psychosis liability, adjusted for expression of subclinical psychotic symptoms (SIS-R) and confounders.

All associations are significant.

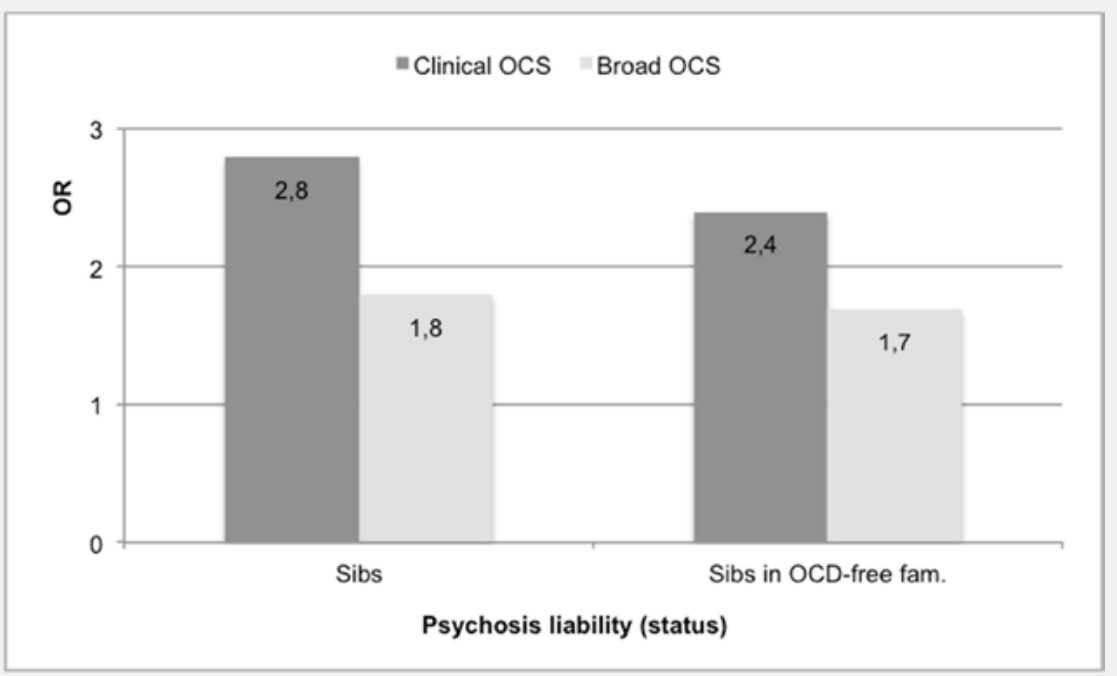




\section{Cross-sib within trait associations}

The cross-sib within-trait analysis revealed that broadly defined OCS in patients were significantly associated with those of their related sibling (OR=1.9; 95\% Cl: $1.1-3.1 ; p<0.014)$. When adjusted for age, sex, $I Q$, level of education, marital status and use of antipsychotics and antidepressants, effect sizes and specificity did not change substantially (OR= 1.9 (1.13.1); $\mathrm{p}<0.017)$. Similarly, clinical OCS in patients were significantly associated with those of their related siblings $(\mathrm{OR}=2.6,95 \% \mathrm{Cl}$ : 1.4-5.0, $\mathrm{p}=0.004$; adjusted $\mathrm{OR}=2.3(1.2-4.7), \mathrm{p}<0.02)$.

\section{Cross-sib cross-trait associations}

In the cross-sibling cross-trait analysis, the broadly defined OCS in the patients were at trend level associated with the subclinical positive psychotic symptoms in their unaffected siblings, assessed with the SIS-R (table 4). When adjusted for sex, IQ, level of education and marital status in sibs and patients, the specificity of the association reached conventional alpha. When additionally adjusted for age, it lost specificity (table 4). Clinical OCS in patients were not significantly associated with the positive subclinical psychotic symptoms in their siblings, although directionally similar to the broadly defined OCS (Table 4).

Neither broadly defined nor clinical OCS in patients showed a significant association with subclinical negative psychotic symptoms in unaffected siblings.

\section{Table 4:}

Multilevel linear regression estimates with sibling SIS-R scores as dependent variable and patient dichotomous YBOCS scores as independent variable. Associations from multilevel linear regression equations, expressed as $\mathrm{B}(95 \% \mathrm{Cl}), \mathrm{p}$

* Adjusted for confounders sex, level of education, $I Q$, marital status,

**Additionally adjusted for age

**Additionally adjusted for use of antidepressants, use of antipsychotics.

\begin{aligned} & \hline Level of expression of OC phenotype $\mathrm{B}(95 \% \mathrm{Cl}), \mathrm{p} \\ &$\hline Broad OCS $0.5(-0.02-0.95), \mathrm{p}<0.06 \\ &$ Adjusted demo (not age)* $0.5(.02-1.0), \mathrm{p}<.04 \\ &$ Adjusted demo (incl. age)*** $0.5(-0.04-0.95), \mathrm{p}<.07 \\ &$ Adjusted demo + pharma*** $0.4(-0.1-0.9), \mathrm{p}<0.2 \\ &$ Clinical OCS $0.4(-0.1-0.9), \mathrm{p}<0.1 \\ &$ Adjusted demo (not age)* $0.4(-0.1-0.9), \mathrm{p}<0.1 \\ &$ Adjusted demo (incl. age)** $0.4(-0.1-0.9), \mathrm{p}<0.1 \\ &$ Adjusted demo + pharma**** $0.3(-0.28-0.8), \mathrm{p}<0.4 \\ &$\hline\end{aligned}




\section{Discussion}

To our knowledge, this study is the first to demonstrate (i) an association between OCS and familial psychosis liability, independent of the phenotypical expression of subclinical psychotic symptoms, (ii) clustering of OCS within families of patients with psychotic disorder, and iii) familial clustering of subclinical positive psychotic symptoms with OCS. Taken together, the findings are suggestive of a shared, possibly genetic, etiological mechanism for psychosis and OCS.

The first main finding in the current study is a significantly higher rate of expression of OCS in patients with non-affective psychotic disorder and their unaffected siblings, compared to controls, as well as a significant association between these OCS and psychosis liability, independent of the expression of (subclinical) psychotic symptoms. These associations were present for broadly defined OCS, and somewhat more pronounced in more narrowly defined "clinical" OCS, showing a dose-response relationship. The clinical OCS prevalence rate of $19 \%$ in the patients diagnosed with non-affective psychotic disorder is in line with previously reported rates (Achim et al., 2011; Fabisch, Fabisch, Langs, Huber, \& Zapotoczky, 2001; Nechmad et al., 2003). Only a few studies have assessed OCS in siblings of patients with psychosis. The clinical OCS rate of $4.3 \%$ we found in the siblings is in line with one earlier family study on OCD in relatives of probands with psychotic disorder, though data cannot be compared exactly. Poyurovsky et al. (2005) found a rate of $6.6 \%$ of clinical OCD in relatives of probands with "OCD schizophrenia", $1.4 \%$ in relatives of probands with "non-OCDschizophrenia", and $0.7 \%$ in relatives of controls (Poyurovsky et al., 2005). The difference between non-OCD-schizophrenia-relatives and controls was not significant. However, with a number of 210 relatives of 60 non-OCD-schizophrenia probands, the analyses may have been underpowered. The current study examined a considerably larger sample and found rates of clinical OCS (YBOCS $>9$ ) of $10.3 \%$ in relatives of patients with "OCD-psychotic disorder", compared to $4.0 \%$ in relatives of "non-OCD-psychotic disorder" patients and $1.6 \%$ in controls. The latter difference was significant, using a t-test $(p<0.01)$. Moreover, clinical OCS in unaffected sibs of patients with non-OCD psychotic disorder were significantly associated with psychosis liability indexed by sibling status. These findings are suggestive of a shared etiological pathway of the psychosis and OCD phenotype, independent of diseaserelated factors.

Essentially, Poyurovsky et al. (2005) showed that the familial clustering of the OCD phenotype that exists in the general population also exists in families with a member with diagnosis of schizophrenia. However, whether the OCD phenotype clusters with the psychosis phenotype, was not investigated in that study. Moreover, though the data may be compatible with an a priori defined "schizo-obsessive" diagnostic category, they do not support the validity of such a new diagnostic category.

It is of note that, although OCS in the present study were associated with (subclinical) negative symptoms in siblings in individual subjects, OCS in patients were not associated 
with subclinical negative symptoms in their unaffected sibling. This differential association of OCS with the positive, not negative symptom factor in psychosis, is in line with earlier findings (de Haan, Hoogenboom, Beuk, van Amelsvoort, \& Linszen, 2005). However, in other work, no difference in positive or negative symptoms was found between a group with psychosis with OCD versus without OCD (Berman et al., 1998; Nechmad et al., 2003; Poyurovsky et al., 2001).

Second, we demonstrated that the OCD extended phenotype clusters within families of patients with psychosis, as it does in the general population. It has been shown earlier that an OCD phenotype, extending beyond the diagnostic threshold, can be measured in the general population, and that this OCD phenotype clusters within families, similar to the psychosis extended phenotype (Grabe et al., 2006; Nestadt et al., 2000; Pauls, 2010; Pauls, Alsobrook, Goodman, Rasmussen, \& Leckman, 1995). The data in the current study show that the distributions of the extended phenotypes are preserved in this sample. This confirms the validity of the definition of the phenotype, even at subtreshold level and in the presence of co-occurring symptoms of other phenotypes. Furthermore, these findings suggest that the co-occurrence encountered is not merely due to treatment bias or invalid diagnostic definitions.

Third, it was shown that OCS in patients were, at trend level, associated with subclinical positive psychotic symptoms in their unaffected siblings. When adjusted for demographical confounders in patients as well as siblings, other than age, the association became significant suggesting familial clustering of subclinical positive psychotic symptoms with broadly defined OCS.

When adjusted for age, the associations lost specificity. However, as the a priori determined demographical confounders were present in the subjects with the dependent as well as in those with the independent variable, a straightforward hypothesis about the expected potential impact of the variables selected as confounders cannot readily be made. In our analysis, there was no significant difference in age between sibs and patients. The role of age is particularly hard to predict, given the fact that OCD had a bimodal distribution of age of onset, and mean age of onset of OCD is expected to be lower than the mean age of onset of psychosis (Faragian et al., 2012). Therefore, the role of age as a confounder in this analysis should be interpreted cautiously (Hernán, Hernández-Díaz, Werler, \& Mitchell, 2002; Janszky, Ahlbom, \& Svensson, 2010). Apart from these included confounders, there may well be environmental confounding factors shared in families, that were not mapped in the current analysis, as demonstrated in a recent large study (Mataix-Cols D \& et al., 2013). Despite a large sample, the cross-sib cross-trait analysis may have been underpowered. Strikingly, the effect size $(~(=0.5)$ of the association between OCS in patients and subclinical positive psychotic symptoms in unaffected relatives showed little variation in the models with broadly or more narrowly defined OCS, with or without confounders. The specificity 
however, was lower in the models with more stringently defined ("clinical") OCS, probably due to lower power consequent to lower numbers.

Theoretically, cross-sib cross-trait analyses within the group of unaffected sibs would provide an elegant way to investigate an etiological association between the (subclinical level of expression of the) two extended phenotypes, ruling out disease-related factors more thoroughly. However, the number of sibs (158 pairs) proved too low to conduct these analyses.

The combination of (i) the association of OCS with familial psychosis liability in the whole sample, (ii) the preservation of familial clustering of the OCD phenotype within families with psychosis liability and (iii) the association, within families, between OCS in patients diagnosed with schizophrenia and subclinical positive psychotic symptoms in their unaffected sibs, may find its origin in a shared etiological, possibly genetic mechanism. The higher than chance cross-sectional and longitudinal co-occurrence of the psychosis and OC extended phenotype extensively described in earlier work (Fontenelle et al., 2011; Van Dael et al., 2011) fits well with this hypothesis. The associations found in the current study should be considered as compatible with, but certainly not a proof of a shared genetic etiology.

\section{Strengths and limitations}

A strength of this study is the design with patients and their siblings in the same family, and an additional control group, in a large sample. The investigation of symptoms, including the lower end of the distribution of expression of the phenotype in unaffected siblings, allows ruling out the role of disease-related confounders. In addition, the hierarchical familial clustering of the data, and particularly the cross-sib cross-trait analyses, also enables to resolve the issue of disease- and treatment-related confounding and within-person confounding.

There are however some limitations. Some other mechanisms than those discussed above may contribute to the associations found.

First, the divergent (construct) validity of the concepts of positive psychotic symptoms and obsessions may be insufficient (Borsboom, Mellenbergh, \& van Heerden, 2004; Cronbach \& Meehl, 1955). Delusions and obsessions share some features in their conceptualisation: both concern persistent thoughts or ideas that become overvalued and go together with elevated preoccupation, distress, anxiety and, frequently, impact on behaviour (Freeman, Garety, Kuipers, Fowler, \& Bebbington, 2002; Jenike, 2004). Although obsessions are typically "egosyntonic" and accompanied with insight, whereas delusions are not, the differences in the population are gradual, as implied in the specifier "with poor insight" in the OCD criteria of the DSM IV(Association, 1994), yielding possible overlap between the concepts. As a consequence, the association between OCS and positive subclinical psychotic symptoms may be spurious to the extent the concepts overlap. On the other hand, in an attempt to overcome the potential overlap between $\mathrm{OC}$ and psychosis symptoms as mentioned above, 
obsessions were defined as distressful thoughts not related to the subject's psychotic symptoms, with full insight, and compulsions were defined as repetitive goal directed rituals clinically distinguishable from schizophrenic mannerisms or posturing. These definitions reduce the probability of misdiagnosing delusions for obsessions, however they may result in an underestimation of OCS (Bland, Newman, \& Orn, 1987; Karno, Golding, Sorenson, \& Burnam, 1988).

Second, use of antidepressants in patients apparently reduced the specificity of the association in the cross-sib cross-trait analyses. Most likely, the use of antidepressants is a proxy for the presence of OCS and affective symptoms in patients. The first-choice treatment of OCD consists of antidepressants. Thus, use of antidepressants most likely is an epiphenomenon.

Third, it was shown in earlier work that antipsychotics are associated with the induction of OCS. In the GROUP sample, (only) clozapine used for a period of over 6 months showed an association with OCS (Scheltema Beduin et al., 2012). As a consequence, the decrease in specificity of the association between OCD in patients and subclinical psychotic symptoms in siblings, may be attributable to confounding.

The possibility of a partially shared etiological mechanism may have consequences for clinical practice, particularly as there is evidence that the course and outcome of cooccurring OCS and psychosis is unfavorable (Niendam, Berzak, Cannon, \& Bearden, 2009). Therefore, co-occurrence of OCS with psychosis, particularly if persisting (Fontenelle et al., 2011), may be reason for intensified monitoring. Further research is needed to further disentangle and understand the possible etiologic association of OCD and psychosis.

\section{Acknowledgements:}

We are grateful for the generosity of time and effort by the families who make the GROUP project possible. M. Drukker and J. Peen are acknowledged for her contribution on methods and statistics. 


\section{References}

Achim, A. M., Maziade, M., Raymond, É., Olivier, D., Mérette, C., \& Roy, M.-A. (2011). How Prevalent Are Anxiety Disorders in Schizophrenia? A Meta-Analysis and Critical Review on a Significant Association. Schizophrenia Bulletin, 37(4), 811-821. doi: 10.1093/schbul/sbp148

Andreasen, N. C., Flaum, M., \& Arndt, S. (1992). The Comprehensive Assessment of Symptoms and History (CASH). An instrument for assessing diagnosis and psychopathology. Archives of General Psychiatry, 49(8), 615-623.

Arrindell, W. A., de Vlaming, I. H., Eisenhardt, B. M., van Berkum, D. E., \& Kwee, M. G. (2002). Crosscultural validity of the Yale-Brown Obsessive Compulsive Scale. J Behav Ther Exp Psychiatry, 33(3-4), 159-176.

Association, A. P. (1994). Diagnostic and statistic manual of mental disorders (4th edn. ed.). Washington,DC: American Psychiatric Press.

Berman, I., Merson, A., Viegner, B., Losonczy, M. F., Pappas, D., \& Green, A. I. (1998). Obsessions and compulsions as a distinct cluster of symptoms in schizophrenia: a neuropsychological study. $J$ Nerv Ment Dis, 186(3), 150-156.

Bijl, R. V., Ravelli, A., \& van Zessen, G. (1998). Prevalence of psychiatric disorder in the general population: results of The Netherlands Mental Health Survey and Incidence Study (NEMESIS). Soc Psychiatry Psychiatr Epidemiol, 33(12), 587-595.

Bland, R. C., Newman, S. C., \& Orn, H. (1987). Schizophrenia: lifetime co-morbidity in a community sample. Acta Psychiatr Scand, 75(4), 383-391.

Borsboom, D., Mellenbergh, G. J., \& van Heerden, J. (2004). The concept of validity. Psychol Rev, 111(4), 1061-1071. doi: 10.1037/0033-295X.111.4.1061

Boyette, L., Swets, M., Meijer, C., Wouters, L., \& Authors, G. R. O. U. P. (2011). Factor structure of the Yale-Brown Obsessive-Compulsive Scale (Y-BOCS) in a large sample of patients with schizophrenia or related disorders and comorbid obsessive-compulsive symptoms. Psychiatry Res, 186(2-3), 409-413. doi: S0165-1781(10)00480-4

Buckley, P. F., Miller, B. J., Lehrer, D. S., \& Castle, D. J. (2009). Psychiatric Comorbidities and Schizophrenia. Schizophrenia Bulletin, 35(2), 383-402. doi: 10.1093/schbul/sbn135

Cronbach, L. J., \& Meehl, P. E. (1955). Construct validity in psychological tests. Psychol Bull, 52(4), 281-302.

de Haan, L., Beuk, N., Hoogenboom, B., Dingemans, P., \& Linszen, D. (2002). Obsessive-compulsive symptoms during treatment with olanzapine and risperidone: a prospective study of 113 patients with recent-onset schizophrenia or related disorders. J Clin Psychiatry, 63(2), 104107.

de Haan, L., Hoogeboom, B., Beuk, N., Wouters, L., Dingemans, P. M., \& Linszen, D. H. (2006). Reliability and validity of the Yale-Brown Obsessive-Compulsive Scale in schizophrenia patients. Psychopharmacol Bull, 39(1), 25-30.

de Haan, L., Hoogenboom, B., Beuk, N., van Amelsvoort, T., \& Linszen, D. (2005). Obsessivecompulsive symptoms and positive, negative, and depressive symptoms in patients with recent-onset schizophrenic disorders. Can J Psychiatry, 50(9), 519-524.

de Haan, L., Linszen, D. H., \& Gorsira, R. (1999). Clozapine and obsessions in patients with recentonset schizophrenia and other psychotic disorders. J Clin Psychiatry, 60(6), 364-365.

Fabisch, K., Fabisch, H., Langs, G., Huber, H. P., \& Zapotoczky, H. G. (2001). Incidence of obsessivecompulsive phenomena in the course of acute schizophrenia and schizoaffective disorder. Eur Psychiatry, 16(6), 336-341.

Fanous, A., Gardner, C., Walsh, D., \& Kendler, K. S. (2001). Relationship between positive and negative symptoms of schizophrenia and schizotypal symptoms in nonpsychotic relatives. Arch Gen Psychiatry, 58(7), 669-673.

Faragian, S., Fuchs, C., Pashinian, A., Weizman, R., Weizman, A., \& Poyurovsky, M. (2012). Age-ofonset of schizophrenic and obsessive-compulsive symptoms in patients with schizo-obsessive disorder. Psychiatry Research, 197(1-2), 19-22. doi: 10.1016/j.psychres.2012.02.024 
Fontenelle, L. F., Lin, A., Pantelis, C., Wood, S. J., Nelson, B., \& Yung, A. R. (2011). A longitudinal study of obsessive-compulsive disorder in individuals at ultra-high risk for psychosis. Journal of Psychiatric Research, 45(9), 1140-1145. doi: 10.1016/j.jpsychires.2011.03.005

Freeman, D., Garety, P. A., Kuipers, E., Fowler, D., \& Bebbington, P. E. (2002). A cognitive model of persecutory delusions. Br J Clin Psychol, 41(Pt 4), 331-347.

Frost, R. O., Steketee, G., Krause, M. S., \& Trepanier, K. L. (1995). The relationship of the Yale-Brown Obsessive Compulsive Scale (YBOCS) to other measures of obsessive compulsive symptoms in a nonclinical population. J Pers Assess, 65(1), 158-168.

G.R.O.U.P. (2011). Evidence that familial liability for psychosis is expressed as differential sensitivity to cannabis: an analysis of patient-sibling and sibling-control pairs. Arch Gen Psychiatry, 68(2), 138-147. doi: archgenpsychiatry.2010.132 [pii]10.1001/archgenpsychiatry.2010.132

Goodman, W. K., Price, L. H., Rasmussen, S. A., Mazure, C., Delgado, P., Heninger, G. R., \& Charney, D. S. (1989). The Yale-Brown Obsessive Compulsive Scale. II. Validity. Archives of General Psychiatry, 46(11), 1012-1016.

Goodman, W. K., Price, L. H., Rasmussen, S. A., Mazure, C., Fleischmann, R. L., Hill, C. L., . . Charney, D. S. (1989). The Yale-Brown Obsessive Compulsive Scale. I. Development, use, and reliability. Archives of General Psychiatry, 46(11), 1006-1011.

Grabe, H. J., Ruhrmann, S., Ettelt, S., Buhtz, F., Hochrein, A., Schulze-Rauschenbach, S., . . W Wagner, M. (2006). Familiality of obsessive-compulsive disorder in nonclinical and clinical subjects. Am J Psychiatry, 163(11), 1986-1992.

Hernán, M. A., Hernández-Díaz, S., Werler, M. M., \& Mitchell, A. A. (2002). Causal Knowledge as a Prerequisite for Confounding Evaluation: An Application to Birth Defects Epidemiology. American Journal of Epidemiology, 155(2), 176-184. doi: 10.1093/aje/155.2.176

Janszky, I., Ahlbom, A., \& Svensson, A. C. (2010). The Janus face of statistical adjustment: confounders versus colliders. European Journal of Epidemiology, 25(6), 361-363. doi: $10.2307 / 40793039$

Jenike, M. A. (2004). Clinical practice. Obsessive-compulsive disorder. N Engl J Med, 350(3), 259-265.

Jonkers, F., \& De Haan, L. (2002). Olanzapine-induced obsessive-compulsive symptoms in a patient with bipolar II disorder. Psychopharmacology (Berl), 162(1), 87-88.

Karno, M., Golding, J. M., Sorenson, S. B., \& Burnam, M. A. (1988). The epidemiology of obsessivecompulsive disorder in five US communities. Arch Gen Psychiatry, 45(12), 1094-1099.

Kendler, K. S., Lieberman, J. A., \& Walsh, D. (1989). The Structured Interview for Schizotypy (SIS): a preliminary report. Schizophrenia Bulletin, 15(4), 559-571.

Kessler, R. C., Berglund, P., Demler, O., Jin, R., Merikangas, K. R., \& Walters, E. E. (2005). Lifetime prevalence and age-of-onset distributions of DSM-IV disorders in the National Comorbidity Survey Replication. Arch Gen Psychiatry, 62(6), 593-602. doi: 62/6/593 [pii]

10.1001/archpsyc.62.6.593

Kessler, R. C., Chiu, W. T., Demler, O., Merikangas, K. R., \& Walters, E. E. (2005). Prevalence, severity, and comorbidity of 12 -month DSM-IV disorders in the National Comorbidity Survey Replication. Arch Gen Psychiatry, 62(6), 617-627. doi: 62/6/617 [pii]

10.1001/archpsyc.62.6.617

Lysaker, P. H., \& Whitney, K. A. (2009). Obsessive-compulsive symptoms in schizophrenia: prevalence, correlates and treatment. Expert review of neurotherapeutics, 9(1), 99-107. doi: 10.1586/14737175.9.1.99

Lysaker, P. H., Whitney, K. A., \& Davis, L. W. (2009). Associations of executive function with concurrent and prospective reports of obsessive-compulsive symptoms in schizophrenia. $J$ Neuropsychiatry Clin Neurosci, 21(1), 38-42. doi: 21/1/38 [pii]

10.1176/appi.neuropsych.21.1.38

Mataix-Cols D, B. M. M. B., \& et al. (2013). Population-based, multigenerational family clustering study of obsessive-compulsive disorder. JAMA Psychiatry, 1-9. doi: 10.1001/jamapsychiatry.2013.3 
Maxwell, E. (1992). The Family Interview for Genetic Studies Manual. Washington, DC: National Institute of Mental Health, Intramural Research Program, Clinical Neurogenetics Branch.

Mukhopadhaya, K., Krishnaiah, R., Taye, T., Nigam, A., Bailey, A. J., Sivakumaran, T., \& Fineberg, N. A. (2009). Obsessive-compulsive disorder in UK clozapine-treated schizophrenia and schizoaffective disorder: a cause for clinical concern. J Psychopharmacol, 23(1), 6-13. doi: 0269881108089582 [pii]

$10.1177 / 0269881108089582$

Nechmad, A., Ratzoni, G., Poyurovsky, M., Meged, S., Avidan, G., Fuchs, C., . . Weizman, R. (2003). Obsessive-compulsive disorder in adolescent schizophrenia patients. Am J Psychiatry, 160(5), $1002-1004$.

Nestadt, G., Samuels, J., Riddle, M., Bienvenu, O. J., 3rd, Liang, K. Y., LaBuda, M., . . . Hoehn-Saric, R. (2000). A family study of obsessive-compulsive disorder. Arch Gen Psychiatry, 57(4), 358-363.

Niendam, T. A., Berzak, J., Cannon, T. D., \& Bearden, C. E. (2009). Obsessive compulsive symptoms in the psychosis prodrome: Correlates of clinical and functional outcome. Schizophr Res, 108(13), $170-175$

Pauls, D. L. (2010). The genetics of obsessive-compulsive disorder: a review. Dialogues in Clinical Neuroscience, 12(2), 149-163.

Pauls, D. L., Alsobrook, J. P., 2nd, Goodman, W., Rasmussen, S., \& Leckman, J. F. (1995). A family study of obsessive-compulsive disorder. Am J Psychiatry, 152(1), 76-84.

Polanczyk, G., Moffitt, T. E., Arseneault, L., Cannon, M., Ambler, A., Keefe, R. S., . . Caspi, A. (2010). Etiological and clinical features of childhood psychotic symptoms: results from a birth cohort. Archives of General Psychiatry, 67(4), 328-338. doi: 10.1001/archgenpsychiatry.2010.14

Poyurovsky, M., Hramenkov, S., Isakov, V., Rauchverger, B., Modai, I., Schneidman, M., . . W Weizman, A. (2001). Obsessive-compulsive disorder in hospitalized patients with chronic schizophrenia. Psychiatry Res, 102(1), 49-57.

Poyurovsky, M., Kriss, V., Weisman, G., Faragian, S., Schneidman, M., Fuchs, C., . . Weizman, R. (2005). Familial aggregation of schizophrenia-spectrum disorders and obsessive-compulsive associated disorders in schizophrenia probands with and without OCD. Am J Med Genet B Neuropsychiatr Genet, 133(1), 31-36.

Reznik, I., \& Sirota, P. (2000). Obsessive and compulsive symptoms in schizophrenia: a randomized controlled trial with fluvoxamine and neuroleptics. J Clin Psychopharmacol, 20(4), 410-416.

Scheltema Beduin, A., Swets, M., Machielsen, M., Korver, N., the Genetic, R., \& Outcome of Psychosis, I. (2012). Obsessive-compulsive symptoms in patients with schizophrenia: a naturalistic cross-sectional study comparing treatment with clozapine, olanzapine, risperidone, and no antipsychotics in 543 patients. The Journal of clinical psychiatry, 73(11), 1395-1402. doi: 10.4088/JCP.11m07164

StataCorporation. (1985-2011). STATA Statistical Software: Release 12.0. Texas: College Station.

Sullivan, P. F., Kendler, K. S., \& Neale, M. C. (2003). Schizophrenia as a complex trait: evidence from a meta-analysis of twin studies. Arch Gen Psychiatry, 60(12), 1187-1192.

Swets, M., Dekker, J., van Emmerik-van Oortmerssen, K., Smid, G. E., Smit, F., de Haan, L., \& Schoevers, R. A. (2013). The obsessive compulsive spectrum in schizophrenia, a meta-analysis and meta-regression exploring prevalence rates. Schizophr Res. doi: 10.1016/j.schres.2013.10.033

Van Dael, F., van Os, J., de Graaf, R., ten Have, M., Krabbendam, L., \& Myin-Germeys, I. (2011). Can obsessions drive you mad? Longitudinal evidence that obsessive-compulsive symptoms worsen the outcome of early psychotic experiences. Acta Psychiatr Scand, 123(2), 136-146. doi: 10.1111/j.1600-0447.2010.01609.x

Vollema, M. G., \& Ormel, J. (2000). The Reliability of the Structured Interview for Schizotypy-Revised. Schizophrenia Bulletin, 26(3), 619-629.

Vollema, M. G., Sitskoorn, M. M., Appels, M. C. M., \& Kahn, R. S. (2002). Does the Schizotypal Personality Questionnaire reflect the biological-genetic vulnerability to schizophrenia? Schizophrenia Research, 54(1-2), 39-45. 
Wing, J. K., Babor, T., Brugha, T., Burke, J., Cooper, J. E., Giel, R., . . Sartorius, N. (1990). SCAN. Schedules for Clinical Assessment in Neuropsychiatry. Archives of General Psychiatry, 47(6), 589-593. 


\title{
Chapter
}

\section{4}

\section{Evidence that hallucinations as well as obsessions originate from intrusive thoughts and that transition to psychosis is mediated by delusional appraisal}

\author{
Frank Van Dael ${ }^{(1)}$, Inez Myin-Germeys ${ }^{(1)}$, Roselind Lieb ${ }^{(2,3)}$, \\ Hans-Ulrich Wittchen ${ }^{(2,4)}$, Jim van Os ${ }^{(1,5)}$
}

(1) Department of Psychiatry and Neuropsychology, South Limburg Mental Health Research and Teaching Network, EURON, Maastricht University Medical Centre, PO BOX 616 (DRT 10), 6200 MD Maastricht, The Netherlands

(2) Clinical Psychology and Epidemiology Unit, Max Planck Institute of Psychiatry, Kraepelinstrasse 2, Munich, Germany

(3) Epidemiology and Health Psychology, Institute of Psychology, University of Basel, Missionsstrasse 60-62, Basel, Switzerland

(4) Institute of Clinical Psychology and Psychotherapy, Technical University Dresden, Chemnitzerstr 46, Dresden, Germany

(5) King's College London, King's HealthPartners, Department of Psychosis Studies, Institute of Psychiatry, Denmark Hill, London, UK 



\section{Abstract}

\section{Objective}

Although substantial comorbidity exists between psychotic disorder and obsessivecompulsive disorder (OCD), little is known about how the two phenotypes, at clinical and subclinical level, covary and impact on each other over time. The hypothesis was tested that co-occurrence of obsessive and psychotic symptoms originates from a partially shared pathway leading from intrusive thoughts to obsessions or hallucinatory experiences respectively, with delusional appraisals facilitating the pathway to clinically relevant expression of psychosis.

\section{Method}

A prospective cohort study was conducted in a general population sample of 3021 adolescents, aged 14-17 years, in Munich, Germany (Early Developmental Stages of Psychopathology Study). Expression of psychiatric symptoms was assessed 4 times (T0-T3) over a period of 8.4 years.

\section{Results}

Obsessive-compulsive (OC) and psychotic symptoms co-occurred more often than predicted by chance cross-sectionally. T0 intrusive thoughts predicted T2 obsessions as well as T2 hallucinatory experiences, and also predicted T3 clinical psychosis characterized by impairment and help-seeking. Given the presence of intrusive thoughts at T0, the cooccurrence of $\mathrm{T} 2$ incident delusional symptoms with $\mathrm{T} 2 \mathrm{OC}$ symptoms significantly increased the risk of T3 clinical psychosis. Similarly, the co-occurrence of T2 incident delusion with hallucinatory experiences significantly increased the risk for T3 clinical psychosis, contingent on presence of TO intrusive thoughts.

\section{Conclusion}

Intrusive thoughts may reflect the earliest stage of obsessions as well as of hallucinatory experiences. Superimposed incident delusional ideation may represent a deepening of the early psychotic state resulting in impairment and help-seeking. These findings are in line with contemporary cognitive models of psychosis and OCD and recent neurobiological findings, and may help to understand the mechanism underlying the observed comorbidity between OCD and psychosis, and its poor prognosis. 


\section{Introduction}

The presence of obsessive-compulsive $(\mathrm{OC})$ symptoms in psychosis has been extensively documented for more than a century (Bleuler, 1911; Westphal, 1878). Most studies investigating the association between $\mathrm{OC}$ and psychotic symptoms have defined their cooccurrence in terms of comorbidity, and, although varying in focus and methodology, generally concur in showing that the presence of OC symptoms in schizophrenia is impacting negatively on clinical and functional outcomes and duration of illness (Van Dael et al., 2011). However, little is known about the mechanisms underlying the co-occurrence of $\mathrm{OC}$ and psychotic symptoms.

Cognitive psychological models on the origin and maintenance of OC symptoms and positive psychotic symptoms show similarity and overlap to some extent. Obsessions may develop from intrusive thoughts (IT) that are perceived as unwanted or unacceptable (Rachman, 1997). Individuals prone to OC disorder typically tend to make unsuccessful attempts to suppress IT, paradoxically making them reoccur more repetitively and vividly (Tolin, Abramowitz, Przeworski, \& Foa, 2002). A particular metacognitive style, characterized by (over)responsibility for the possible consequences of someone's own thoughts and actions, and the belief that anticipated harm has to be neutralized, may increase distress, consequently reinforcing this process and resulting in symptoms (Barrera \& Norton, 2011; Rachman \& Hodgson, 1980; Salkovskis \& Harrison, 1984). Similarly, hallucinatory experiences may result from unwanted or unacceptable IT that are misattributed to an external source (A. P. Morrison \& Haddock, 1997). This process too may be influenced by metacognitive beliefs. Such beliefs may contribute to a bias against labeling such thoughts as internally generated (Bentall, Kinderman, \& Kaney, 1994; Freeman, Garety, \& Kuipers, 2001), possibly in combination with deficits in self-monitoring (Johns et al., 2001) or other informationprocessing deficits. Hallucinations are frequently observed in combination with delusions, possibly because hallucinatory experiences may give rise to secondary delusional interpretation (Brendan A. Maher, 1988) or aberrant attribution of salience (Kapur, 2003). This implies that delusions superimposed on hallucinatory experiences may represent a crucial deepening of the early psychotic state, increasing the risk for need for care and patient status (Krabbendam et al., 2004; Smeets et al., 2010).

Individuals prone to develop OC disorder as well as those prone to develop hallucinatory experiences seem to share some features in their cognitive style, for example a high subjective need to control thoughts together with negative beliefs about the uncontrollability of IT, low cognitive confidence, a high self-consciousness and a tendency to make negative interpretations that involve the idea that the person's choice can result in harm (Moritz, Peters, Larøi, \& Lincoln, 2010; Varese \& Bentall, 2011). When an OC symptom or hallucinatory symptom is appraised as personally significant and threatening, and attempts to control fail, a delusional appraisal may arise, facilitated by pre-existing cognitive biases such as deficits in source- and self-monitoring, a tendency to jump to conclusions, and an external attribution bias. 
In the present study, it is hypothesized that the co-occurrence of obsessive and psychotic symptoms may originate from a partially shared pathway from IT to obsessions or hallucinatory experiences respectively, with delusional appraisals facilitating the pathway to clinically relevant psychotic outcomes. The aim of the present study therefore is to investigate in a large general population longitudinal study whether

1) IT precede the development of hallucinatory experiences as well as OC symptoms,

2) OC symptoms and hallucinatory experiences increase the risk for development of clinical psychosis

3) Delusional appraisals "toxically" interact with OC symptoms, as they do with hallucinatory experiences, increasing the risk for clinical psychosis, characterized by impairment and helpseeking,

4) Combining hypotheses 1-3 above (Fig. 1) predicts that the baseline IT increases the risk for clinical psychosis, and that this risk is mediated by incident hallucinatory experiences c.q. OC symptoms, and moderated by co-occuring delusional symptoms.

Fig 1. Hypothesized mechanism: from IT to obsessive symptoms to clinical psychosis, mediated by delusions.

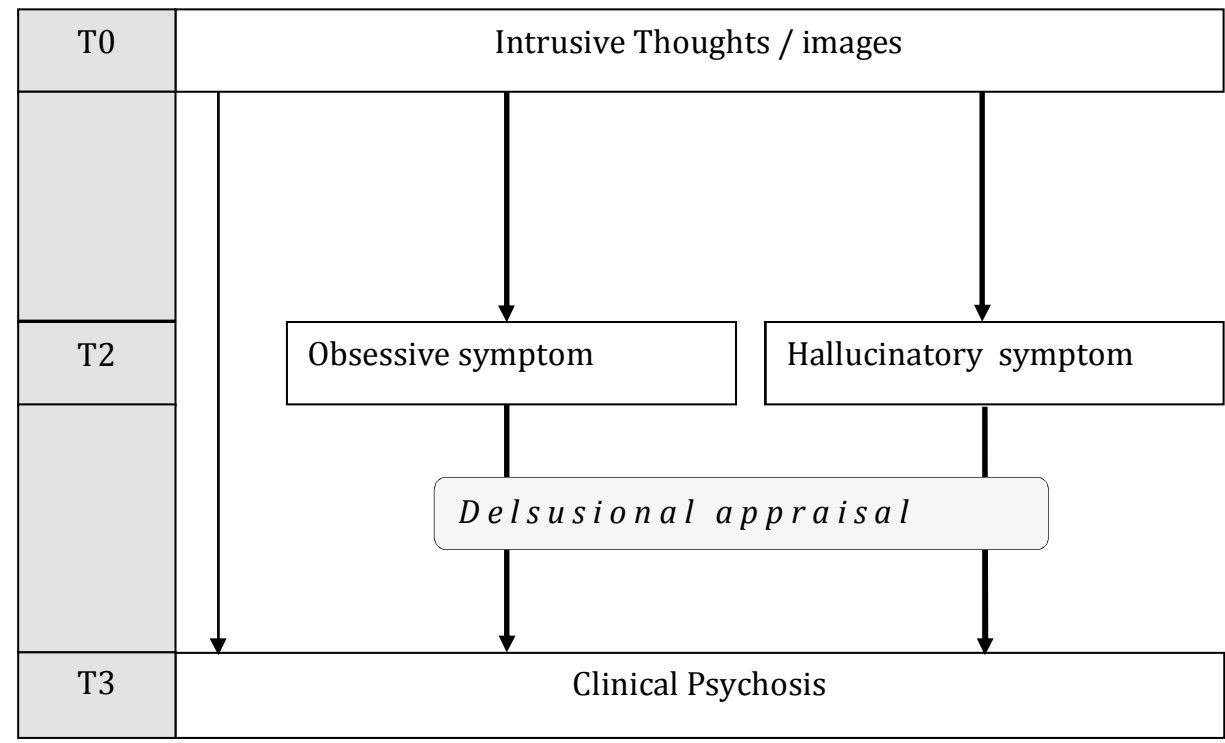

\section{Method}

\section{Sample}

Data came from the Early Developmental Stages of Psychopathology (EDSP) Study, which collected data on the prevalence, incidence, risk factors, comorbidity, and course of mental disorders in a random, representative population sample of adolescents and young adults in the general population. The baseline sample, following ethics committee approval, was 
randomly drawn, in 1994, from the respective population registry offices of Munich and its 29 counties, to mirror the distribution of individuals expected to be 14-24 years of age at the time of the baseline (T0) interview in 1995. The base population were all those born between June 1, 1970, and May 31, 1981, registered as residents in these localities and having German citizenship. These registers can be regarded as highly accurate because (1) each German is registered by his town, (2) they are regularly updated, (3) in the interest of scientific studies, any number of randomly drawn addresses with a given sex and age-group can be obtained, and (4) strict enforcement of registration by law and the police applies. More details on the sampling, representativeness, instruments, procedures, and statistical methods of the EDSP Study sample have previously been presented (Lieb, Isensee, von Sydow, \& Wittchen, 2000; H. U. Wittchen, Perkonigg, Lachner, \& Nelson, 1998).

\section{Study Design}

The overall design of this cohort study is longitudinal and prospective, consisting of a baseline (TO) and 3 follow-up surveys, covering a time period of on average 1.6 years (TO-T1, $\mathrm{SD}=0.2)$, 3.5 years $(\mathrm{TO}-\mathrm{T} 2, \mathrm{SD}=0.3)$, and 8.4 years $(\mathrm{TO}-\mathrm{T} 3$, range $=7.3-10.5 \mathrm{y}, \mathrm{SD}=0.7)$. Response rates were $83.5 \%$ at T2 $(n=2524)$ and $73.2 \%$ at T3 $(n=2210)$. After description of the study to the subjects, written informed consent was obtained. As only a subset of the sample was examined at $\mathrm{T} 1$, this survey was not considered in this study.

\section{Instruments}

The Self-report Symptom Checklist-90-R.

At all time points, participants completed the self-report symptom checklist-90-R (SCL-90-R), a comprehensive self-report symptom inventory, multidimensional in nature, and oriented to screen for a broad range of psychological problems and psychopathology in community respondents and respondents with somatic and psychiatric disorders. Reliability and validity of the SCL-90-R were established previously (Derogatis \& Cleary, 1977). The time frame is the past 2 weeks.

The Munich-Composite International Diagnostic Interview.

Participants were also assessed using the computerized version of the Munich-Composite International Diagnostic Interview (DIA-X/M-CIDI) (H.U. Wittchen \& Pfister, 1997), an updated version of the World Health Organization's CIDI version 1.2 (Organization, 1990). The DIA-X/M-CIDI is a comprehensive, fully standardized diagnostic interview and assesses symptoms, syndromes, and diagnoses of various mental disorders in accordance with the definitions and criteria of the International Classification of Diseases, Tenth Revision, and Diagnostic and Statistical Manual of Mental Disorders (Fourth Edition), along with information about onset, duration, severity of symptoms, and psychosocial impairment. The CIDI has been primarily designed for use in epidemiological studies of mental disorders and can also be used for clinical purposes. IT is divided into 16 sections: 1 sociodemographic section, 12 sections assessing 288 symptoms of groups of mental disorders (including 
"schizophrenia and other psychotic", and "OC disorders), and 3 final sections containing concluding questions, interviewer observations, and interviewer ratings.

The instrument, designed for use by trained interviewers who are not clinicians, has shown high interrater ( $\mathrm{c}>0.70$ ) (Cottler, Helzer, Mager, Spitznagel, \& Compton, 1991; H. U. Wittchen et al., 1991) and test-retest reliability (Reed et al., 1998; H.-U. Wittchen, 1994). However, the assessment of psychosis with CIDI by lay interviewers is not considered reliable (Anthony et al., 1985; H.-U. Wittchen, 1994). Therefore, in the EDSP Study, trained and experienced clinical interviewers at the level of psychologist, who were allowed to probe with follow-up clinical questions, conducted the interviews in the respondents' homes.

At baseline, the DIA-X/M-CIDI lifetime version was used. At each of the follow-up assessments, participants applied the interval version, which covers the period of assessment from the last interview until the next. However, data on the $\mathrm{G}$ section concerning psychosis and its clinical relevance were only collected at time point 2 (lifetime version) and time point 3 (interval version).

\section{Variables}

IT at TO

The definition, nature and assessment of IT has been subject to varying accents and changes over time (Parkinson \& Rachman, 1981). Different aspects were emphasized depending on the model or the disorders investigated (Clark \& Purdon, 1995). In this study, the early, broad definition by Rachman was adopted: "repetitive thoughts that are unacceptable or unwanted, usually accompanied by discomfort and interrupting ongoing activity (Rachman \& de Silva, 1978; Rachman \& Hodgson, 1980) . The items "unwanted persistent thoughts" (item 3) and "worrying about sloppiness or carelessness" (item 10) from the SCL-90-R were used. Both items showed a skewed continuous distribution, corresponding to the psychological model of Rachman and Salkovskis.

The mean score was dichotomized: any mean rating higher than 2/5 ("moderately") was defined as $I T$ being present, 2 and lower was defined as absent. This cut-off defines $18.6 \%$ of the sample at baseline.

\section{OC symptoms at TO/T2}

The 9-item OC symptom dimension of the SCL-90-R checks persistent, unpleasant thoughts, loss of control, uncertainty, checking and repetition (items 3, 9, 10, 28, 38, 45, 46, 51, 65). The severity scale of each symptom was scored from "not at all" (1) to "extremely" (5). The SCL-90 OC symptom dimension has good correlation with the Maudsley ObsessiveCompulsive Inventory ( $\mathrm{MOCl}$ ) and Yale-Brown Obsessive Compulsive Scale (Ybocs) symptoms (r 0.41 - 0.76) (Hunter et al., 2005; Kim, Dysken, \& Kuskowski, 1992), but poorer divergent validity (Woody, Steketee, \& Chambless, 1995). The scale yielded continuous scores displaying a skewed continuous distribution at all time points (TO-T3), in line with previous research making dimensional assessments of OC features with other instruments (de Bruijn, 
Beun, de Graaf, Ten Have, \& Denys, 2010; Ruscio, Stein, Chiu, \& Kessler, 2010; Van Dael et al., 2011). Scores were dichotomized: any mean rating of $2 / 5$ ("moderately") or higher was defined as indicating the $\mathrm{OC}$ feature was present, whereas scores lower than the cut-off indicated the feature was absent. This cut-off coincided with the highest $10 \%$ of the distribution and was the closest approximation to the definition of "subtreshold OC symptoms" that was recently developed systematically in an earlier study (de Bruijn et al., 2010).

\section{Psychotic symptoms at TO}

The 6-item paranoid ideation dimension of the SCL-90-R was used to assess paranoid delusional symptoms at T0, and the 10-item psychoticism dimension of the SCL-90-R was used to index psychotic experiences, including items first-rank symptoms of schizophrenia such as hallucinations. Conform previous research in this sample, the SCL-90-R psychoticism and paranoid ideation dimensions were combined into one psychosis scale by summing their scores (Henquet et al., 2005). A binary psychotic symptoms score was defined by dichotomizing the psychosis scale around the $90 \%$ percentile in the sample, conform previous work in this sample (Dominguez, Saka, Lieb, Wittchen, \& van Os, 2010).

\section{Psychotic symptoms at T2 and T3}

Participants were first invited by the psychologist to read a list of all the psychotic experiences and then asked whether they ever experienced such symptoms (list and phrasing available upon request). Presence of positive psychotic experiences was broadly defined as any rating of "present" on any of the $20 \mathrm{DIA}-\mathrm{X} / \mathrm{M}-\mathrm{CIDI}$ core psychosis, including 14 delusion items (G1, G2a, G3, G5, G4, G7, G8, G9, G10, G11, G12, G13, G13b, G14) items, 5 hallucination items (G17, G18, G20, G20C and $G 21)$, and 1 item on passivity phenomena.

\section{Clinically relevant psychotic symptoms at T3}

Clinical relevance related to psychotic experiences at T3 was assessed by interview ratings from the DIA-X/M-CIDI in terms of psychotic impairment, representing the first step that needs explaining and predicting in tracking the ontogenesis of psychotic disorder in the general population. In order to define psychotic impairment, secondary dysfunction and help-seeking behavior were examined in individuals with evidence of DIA-X/M-CIDI-positive psychotic symptoms at T2 (lifetime) and T3 (interval version).

\section{T3 Clinical psychosis outcome}

T3 clinical psychosis outcome was defined using the X16 DIA-X/M-CIDI item. This item, rating the interviewer's opinion regarding clinical evidence of psychological ill health, consists of 4 levels: essentially not noticeable (0), not very noticeable (1), clearly ill (2), and very ill (3). The dichotomous variable "T3 clinical psychosis outcome" was defined as any score above 1 , thus indicating individuals with a clinical case of psychosis. 


\section{Statistical Analyses}

All analyses were conducted using the software package STATA, version 11 (StataCorporation, 1984-2009).

\section{Risk Set}

The longitudinal analyses were conducted in the subjects who (1) had been examined at T0 (baseline), T2 and T3 of the study, (2) had completed the SCL-90-R at T0 and (3) had completed the DIA-X/M-CIDI psychosis G section at T2 and T3. Of the 3021 subjects in the whole sample at baseline, 2024 (67.0\%) fulfilled these criteria.

1. Does $T O I T$ increase the risk for $T 2 O C /$ hallucinatory experiences and $T 3$ clinical psychosis outcome?

First, the difference in risk for incident T2 OC symptoms, excluding 265 participants (12.9\%) with OC symptoms at TO (Angst, 2004; Eisen et al., 2010; Nelson \& Rice, 1997), was calculated as a function of TO IT. Similar analyses were conducted for incident T2 hallucinatory experiences, excluding participants with T0 hallucinatory experiences ( $n=61$, i.e. 3.0\% of the whole sample) (Hanssen, Bak, Bijl, Vollebergh, \& van Os, 2005). In order to account for the mutual impact of $O C$ and psychotic symptoms over time reported in earlier work (Van Dael et al., 2011), both analyses were repeated after exclusion of TO OC and TO hallucinatory and delusional symptoms ( $n=414$, i.e. $20.5 \%$ ).

Similarly, risk for incident T3 clinical psychosis outcome was estimated as a function of TO IT. For this analysis, we aimed to exclude all T0 clinical cases of psychosis.

Since the CIDI psychosis section was not available at T0, all subjects with $\mathrm{T} 2$ clinical psychosis outcome $(n=51)$ and subjects without data on clinical assessment $(n=4)$ were excluded (together $n=55$, i.e. $2.7 \%$ of the whole sample). Furthermore, analysis were repeated after additional exclusion of the subjects with the highest $10 \%$ scores $(n=184)$ on the combined paranoia/psychoticism scale of the SCL-90-R at T0.

\section{Do T2 OC/hallucinatory experiences increase the risk for later development of T3 clinical} psychosis outcome?

First, the difference in risk for developing T3 clinical psychosis outcome was estimated as a function of T2 OC symptoms. The 55 (2.7\%) participants with T2 clinical psychosis outcome or lacking clinical assessment were additionally excluded, leaving 1969 participants in this analysis. Second, analyses were repeated with $\mathrm{T} 2$ hallucinatory experiences as the exposure variables.

\section{Do T2 delusional symptoms in combination with $T 2 \mathrm{OC} /$ hallucinatory experiences increase} the risk forT3 clinical psychosis outcome more than either in isolation A variable (hereafter: "obs-del") denoting the different combinations of the presence of OC symptoms and delusional symptoms at T2 was defined as follows: "no symptoms" (value "0"), "isolated OC symptoms" (value " 1 "; all delusional symptoms $=0$ and any OC 
symptoms= 1), "isolated delusional symptoms" (value " 2 "; any delusion = 1 and all OC symptoms $=0$ ), OC-delusional symptoms (value " 3 "; any delusional symptoms $=1$ and any OC symptom $=1$ ).

Similarly, a variable "hal-del" with the 4 possible combinations of presence/absence of hallucinatory and delusional symptoms at $\mathrm{T} 2$ was defined.

Risks were estimated as the proportion of subjects with T3 clinical psychosis outcome. Differences in risk for T3 clinical psychosis outcome were calculated by Wald test as a function of the presence of $\mathrm{T} 2$ delusional symptoms/T2 OC symptoms in combination versus in isolation (and similarly for the T2 delusional/T2 hallucinatory experiences).

4. Is the association between TO IT and T3 clinical case of psychosis mediated by T2 OC symptoms/hallucinatory experiences combined with $T 2$ delusional symptoms?

To test the hypothesis that the association between TO IT and T3 clinical psychosis is mediated by $\mathrm{T} 2 \mathrm{OC}$ symptoms/hallucinatory experiences and delusional symptoms in isolation or in combination, a mediation analysis was conducted.

Mediation analysis

Associations were expressed as relative risks and their $95 \%$ confidence intervals (Cls). An interaction was fitted between TO IT and the T2 obs-del variable as independent variables, and T3 clinical case of psychosis as dependent variable.

A similar interaction model was fitted with TO IT and the T2 hal-del variable as independent variables. In line with recent advances in the conceptualization of interaction, we calculated the statistical additive interaction rather than the multiplicative interaction, as the former is more likely to yield Information on the degree of synergism between causes, that is the extent to which both causes depend on each other or co-participate in disease causation (Darroch, 1997). In order to calculate the statistical interaction in an additive model, the BINREG procedure in the STATA statistical program (StataCorporation, 1984-2009), which fits generalized linear models for the binomial family estimating risk differences, was used. Interactions were assessed by Wald test.

\section{Results}

\section{Descriptives}

The distribution of demographic data and $\mathrm{OC}$ and psychosis variables in the whole sample and risk set are shown in table 1 . The distribution of demographic variables in the risk set and in the whole sample was comparable. Comorbidity of $\mathrm{OC}$ and psychotic symptoms as well as clinical case of psychosis at T2 was found. Prevalence of T2 OC symptoms was $12.8 \%$ in subjects with versus $5.8 \%$ without $\mathrm{T} 2$ hallucinatory and/or delusional symptoms. Prevalence of T2 OC symptoms was $27.5 \%$ in subjects with versus $6.8 \%$ without $\mathrm{T} 2$ clinical case of psychosis. 
Table 1: Demographic characteristics, OCD and psychosis variables of the whole sample and the risk set.

\begin{tabular}{|c|c|c|}
\hline & Whole sample & Risk set \\
\hline $\mathbf{n}$ & 3021 & 2024 \\
\hline Mean age (SD) & $18,3(3,3)$ & $18,3(3,3)$ \\
\hline Gender $\mathbf{n}$ (\% male) & $1533(50,7 \%)$ & $1047(51,7 \%)$ \\
\hline \multicolumn{3}{|l|}{ Level of education $\mathbf{n}(\%)$} \\
\hline low & $1631(54 \%)$ & $1215(60,0 \%)$ \\
\hline medium & $915(30,3 \%)$ & $588(29,0 \%)$ \\
\hline high & $475(15,7 \%)$ & $221(10,9 \%)$ \\
\hline \multicolumn{3}{|l|}{ Residence } \\
\hline Rural & $859(28,4 \%)$ & $603(29,8 \%)$ \\
\hline Urban (Munchen) & $2162(71,6 \%)$ & $1421(70,2 \%)$ \\
\hline TO IT & $547(18.1 \%)$ & $377(18.6 \%)$ \\
\hline TO OC symptoms & $383(12.7 \%)$ & $260(12.8 \%)$ \\
\hline T2 OC symptoms & - & $145(7.2 \%)$ \\
\hline T2 hallucinatory experiences & - & $91(4.5 \%)$ \\
\hline T2 delusional symptoms & - & $430(21.3 \%)$ \\
\hline T2 clinical case of psychosis & - & $51(2.5 \%)$ \\
\hline T3 clinical case of psychosis & - & $40(2.0 \%)$ \\
\hline
\end{tabular}

1. Do TO IT increase the risk for T2 OC/ hallucinatory experiences and an outcome of clinical case of psychosis at T3?

The risk for incident T2 OC symptoms was $4.3 \%$ higher in subjects with TO IT than in those without (Table 2). TO IT showed significant association with incident T2 OC symptoms, i.e. after exclusion of TO OC symptoms. When adjusted for T2 paranoid delusional symptoms and for the confounders age, sex, level of education, marital status, the associations remained significant ( $\mathrm{OR}=2.1,95 \% \mathrm{Cl}: 1.2-3.7, \mathrm{p}<0.01)$. After exclusion of TO OC, hallucinatory and paranoid delusional symptoms, the association between TO IT and T2 OC symptoms remained significant (Table 2).

The risk for incident $\mathrm{T} 2$ hallucinatory experiences was 3.7\% higher in subjects with compared to subjects without TO IT, after exclusion of TO hallucinatory experiences (table 2). IT at TO were significantly associated with incident T2 hallucinatory experiences (Table 2). When adjusted for $\mathrm{T} 2$ paranoid delusional symptoms and for the confounders age, sex, level of education, marital status, the associations remained significant $(\mathrm{OR}=2.2,95 \% \mathrm{Cl}$ : 1.4-3.7, $p<0.001$ ).

After exclusion of TO OC, hallucinatory and paranoid delusional symptoms, the association between TO IT and T2 OC symptoms remained significant. (Table 2)

The risk for incident T3 clinical cases of psychosis was $2.9 \%$ higher in subject with compared to subjects without TO IT. IT at TO were significantly associated with T3 clinical cases of psychosis after exclusion of $\mathrm{T} 2$ clinical cases of psychosis and adjustment for any scores higher than 12 out of 30 on the psychosis items of the SCL-90-R at T0 (Table 3). When additionally adjusted for the confounders age, sex, level of education, marital status, the associations remained significant. 


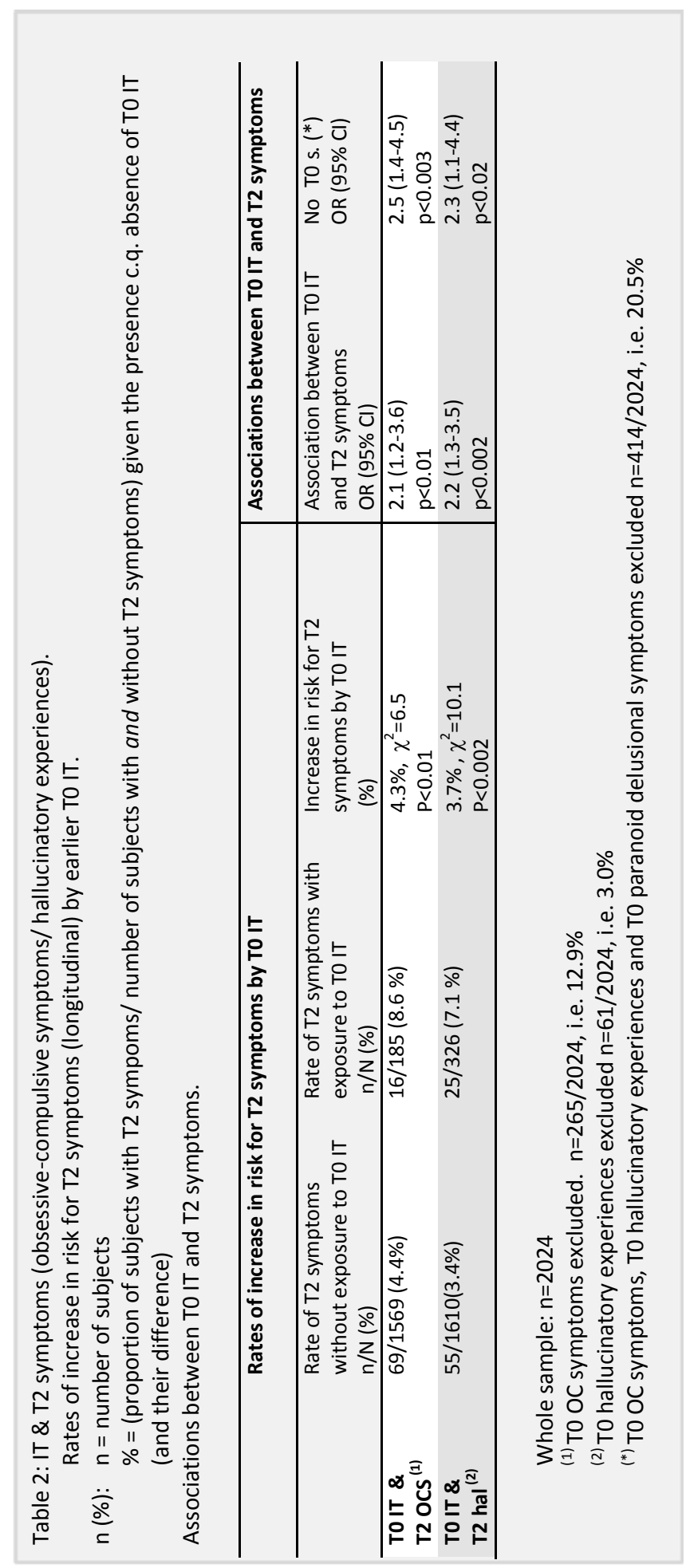




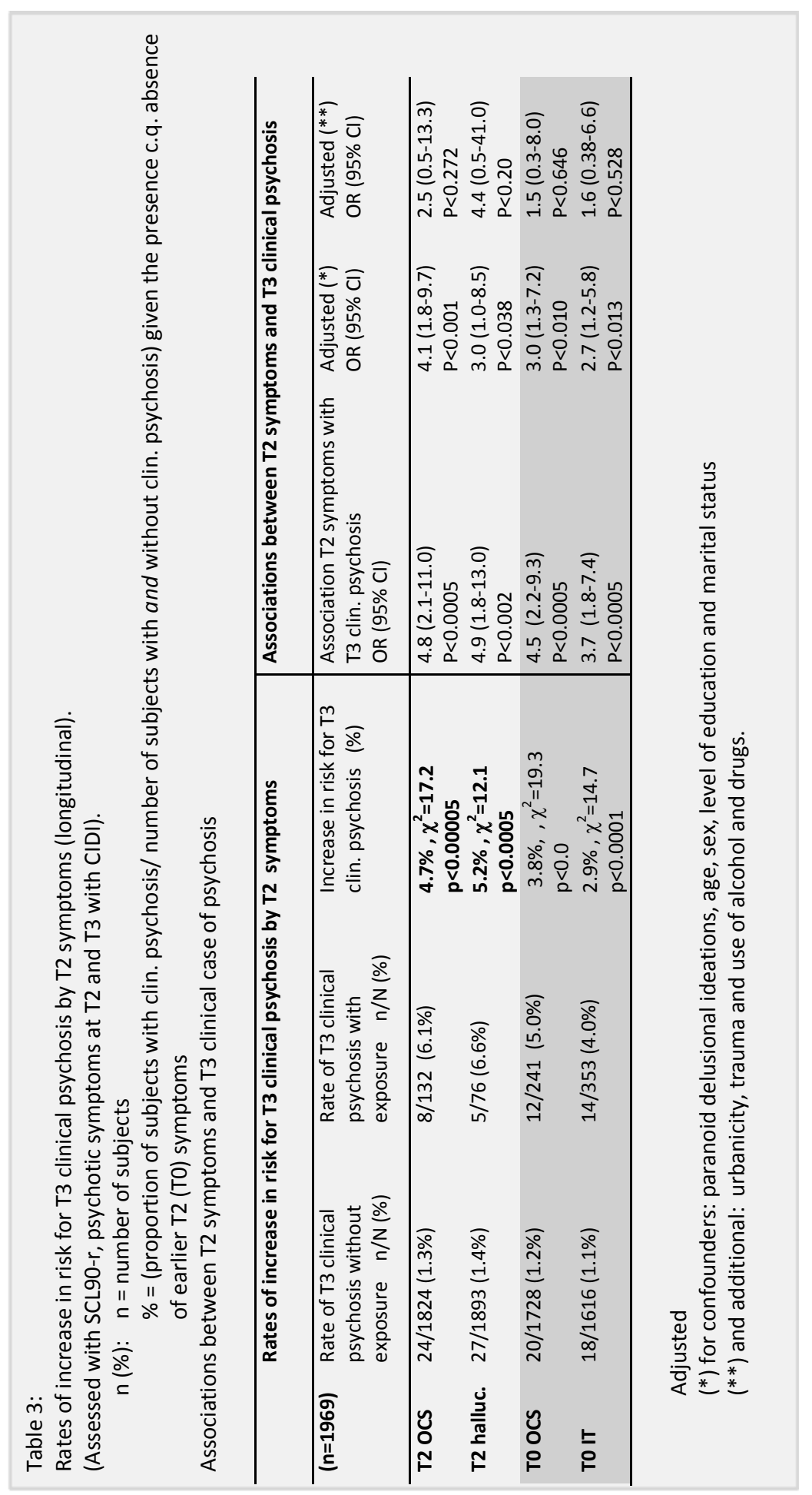


2. Do T2 OC/hallucinatory experiences increase the risk for development of clinical case of psychosis at T3?

The risk for clinical case of psychosis at T3 was $4.7 \%$ higher in subjects with T2 OC symptoms compared to those without. In the logistic regression model, OC symptoms at $\mathrm{T} 2$ showed significant association with T3 clinical case of psychosis (table 3). When adjusted for T2 paranoid delusional symptoms and for the confounders age, sex, level of education, marital status, the associations remained significant. Hallucinatory experiences at T2 similarly increased the risk for T3 clinical psychosis with 5.2\%. Hallucinatory experiences were significantly associated with T3 clinical psychosis (table 3). When adjusted for T2 paranoid delusional symptoms and for the confounders age, sex, level of education, marital status, the associations remained significant.

\section{Do $T 2$ delusional symptoms in combination with $T 2 O C /$ hallucinatory experiences} increase the risk for an outcome of T3 clinical psychosis more than either one of them in isolation.

The co-occurrence of $\mathrm{T} 2 \mathrm{OC}$ and delusional symptoms increased the risk for an outcome of T3 clinical case of psychosis significantly, with greater effect size and specificity than either one of them in isolation (table 4).

Similarly, the co-occurrence of $\mathrm{T} 2$ hallucinatory and delusional symptoms increased the risk for an outcome of T3 clinical case of psychosis significantly, with greater effect size and specificity than either one of them in isolation (table 4)

\section{Do TO IT interact with T2 OC/hallucinatory experiences combined with T2 delusional} symptoms on the path to T3 clinical case of psychosis?

The risk-increasing effect of TO IT for an outcome of T3 clinical case of psychosis was significantly higher for the subjects with combined T2 delusional and OC symptoms compared to those without, and compared to subjects with only T2 OC c.q. T2 delusional symptoms in isolation.

Similarly, the risk-increasing effect of TO IT for an outcome of T3 clinical case of psychosis was significantly higher in the presence of combined occurrence $\mathrm{T} 2$ hallucinatory and delusional symptoms then in presence of $\mathrm{T} 2$ hallucinatory experiences in isolation, but not significantly different from the effect of delusional symptoms in isolation, assessed with Wald test. (Table 4)

\section{Discussion}

The results of this prospective study in the general population showed that baseline IT increased the risk for the development of hallucinatory experiences as well as OC symptoms. $\mathrm{T} 2 \mathrm{OC}$ symptoms as well as T2 hallucinations in turn increased the risk for an incident T3 clinical case of psychosis, specifically in combination with $\mathrm{T} 2$ delusional symptoms. These findings support the hypothesis that IT predispose to hallucinations as well as to obsessions, and that further delusional appraisal leads to a deepening of the psychotic state, 
Table 4: Risk difference for T3 clinical psychosis by $\mathrm{T} 2 \mathrm{OC} /$ delusional symptoms in isolation or in combination.

(Sample with inclusion of T2 clinical psychosis).

\begin{tabular}{|c|c|c|c|c|c|c|c|c|}
\hline \multirow{2}{*}{$\begin{array}{c}(n=2024) \\
\begin{array}{c}\text { Isolated } \\
\text { Obs }\end{array}\end{array}$} & \multicolumn{2}{|c|}{$\begin{array}{l}\text { Risk for T3 psychosis } \\
\%(95 \% \mathrm{Cl})\end{array}$} & \multicolumn{2}{|c|}{$\begin{array}{l}\text { Wald test obs+del } \\
\text { vs. dummy }\end{array}$} & \multicolumn{2}{|c|}{ Interaction with T0 IT } & \multicolumn{2}{|c|}{$\begin{array}{l}\text { Wald test interaction } \\
\text { obs+del vs. dummy }\end{array}$} \\
\hline & $\begin{array}{c}3.2 \% \\
(-0.9-7.4)\end{array}$ & $p<0.1$ & $\chi^{2}=3.0$ & $\begin{array}{c}\mathrm{P}<0.0 \\
8\end{array}$ & $\begin{array}{c}-8.3 \% \\
(-15.2-1.4)\end{array}$ & $p<0.019$ & $\chi^{2}=13.1$ & $p<0.0003$ \\
\hline Isolated Del & $\begin{array}{c}2.1 \% \\
(0.2-3.9)\end{array}$ & $p<0.03$ & $\chi^{2}=4.5$ & $\begin{array}{c}\mathrm{p}<0.0 \\
3\end{array}$ & $\begin{array}{c}1.9 \% \\
(-3.6-7.4)\end{array}$ & $\mathrm{p}<0.5$ & $\chi^{2}=6.7$ & $P<0.01$ \\
\hline \multirow[t]{2}{*}{$\begin{array}{l}\text { Combined } \\
\text { Obs-del }\end{array}$} & $\begin{array}{c}12.0 \% \\
(2.9-21.1)\end{array}$ & $p<0.01$ & $\chi 2=1.7(*)$ & $\mathrm{p}<0.2$ & $\begin{array}{c}24.6 \% \\
(7.9-41.2)\end{array}$ & $P<0.004$ & $\chi^{2}=10.7(*)$ & $p<0.001$ \\
\hline & \multicolumn{4}{|c|}{$\begin{array}{l}\text { Wald test hal+del } \\
\text { vs. dummy }\end{array}$} & & & \multicolumn{2}{|c|}{$\begin{array}{c}\text { Wald test hal+del vs } \\
\text { dummy }\end{array}$} \\
\hline Isolated Hal & $\begin{array}{c}5.4 \% \\
(-3.4-14.4)\end{array}$ & $p<0.2$ & $\chi^{2}=0.3$ & $P<0.6$ & $\begin{array}{c}-11.5 \% \\
(-25.4-2.5)\end{array}$ & $p<0.1$ & $\chi^{2}=6.5$ & $p<0.01$ \\
\hline Isolated Del & $\begin{array}{c}2.3 \% \\
(-0.4-4.3)\end{array}$ & $p<0.02$ & $\chi^{2}=2.6$ & $P<0.1$ & $\begin{array}{c}4.4 \% \\
(-1.5-10.3)\end{array}$ & $\mathrm{p}<0.1$ & $\chi^{2}=1.94$ & $\mathrm{p}<0.2$ \\
\hline $\begin{array}{l}\text { Combined } \\
\text { hal-del }\end{array}$ & $\begin{array}{c}8.6 \% \\
(1.1-16.1)\end{array}$ & $p<0.02$ & $\chi^{2}=0.02$ & $P<0.9$ & $\begin{array}{c}17.1 \% \\
(0.0-34.4)\end{array}$ & $P<0.0005$ & $\begin{array}{c}\chi^{2}=4.37 \\
(* *)\end{array}$ & $p<0.04$ \\
\hline \multicolumn{9}{|c|}{ After exclusion T2 clinical case of psychosis } \\
\hline$(n=1969)$ & & & & & & & \multicolumn{2}{|c|}{$\begin{array}{c}\text { Wald test interaction } \\
\text { obs+del vs. dummy }\end{array}$} \\
\hline $\begin{array}{l}\text { Isolated } \\
\text { Obs }\end{array}$ & $\begin{array}{c}2.5 \% \\
(-1.4-6.5)\end{array}$ & $p<0.2$ & & & $\begin{array}{c}-7.2 \% \\
(-13.7-0.6)\end{array}$ & $p<0.032$ & $\chi^{2}=8.9$ & $p<0.003$ \\
\hline Isolated Del & $\begin{array}{c}1.6 \% \\
(-0.2-3.3)\end{array}$ & $p<0.08$ & & & $\begin{array}{c}1.7 \% \\
(-3.7-7.3)\end{array}$ & $p<0.5$ & $\chi^{2}=4.07$ & $p<0.04$ \\
\hline $\begin{array}{l}\text { Combined } \\
\text { Obs-del }\end{array}$ & $\begin{array}{c}9.6 \% \\
(7.9-18.5)\end{array}$ & $p<0.033$ & & & $\begin{array}{c}19.3 \% \\
(2.9-35.7)\end{array}$ & $p<0.021$ & $\chi^{2}=7.05$ & $p<0.008$ \\
\hline
\end{tabular}

$\left({ }^{*}\right)$ Cpmbined obs-del vs. dummy sum of obs + del.

$(* *)$ Cpmbined hal-del vs. dummy sum of hal + del.

with higher probability of impairment and help-seeking. These findings suggest that the welldocumented high comorbidity between psychosis and OCD may originate from a partially shared pathway from IT to OC or hallucinatory experiences respectively, with delusional appraisals facilitating the pathway to further psychosis.

\section{The path from IT to OC symptoms c.q. hallucinatory experiences}

IT are reported to be very common in the general population, with a content that is often very similar to that of clinical obsessions (Clark \& Rhyno, 2005; Freeston, Ladouceur, Thibodeau, \& Gagnon, 1991; Purdon \& Clark, 1993). The findings in this study are in line with the notion of psychological models of OCD, that common IT can develop to obsessions in 
presence of particular metacognitive style characterized by inflated responsibility in combination with high self-focused attention but low cognitive confidence, and cognitive biases like impaired monitoring of thoughts and action (Kathleen Marie Corcoran \& B., 2007; García-Soriano, Belloch, Morillo, \& Clark, 2011; D. Julien, O'Connor K, \& Aardema, 2007; Moritz et al., 2010). Working together, these factors may facilitate the experience of threat and personal significance. Subsequent vain attempts to neutralize the IT can increase distress, and facilitate further overestimation of the importance of the thought, its threat, and the need to control it, giving way to clinical OCD. While the mechanisms in operation on the path from of IT to OC symptoms have been described in largely convergent models and is well documented, the role of IT in the development of hallucinations is less unequivocal. Hallucinations in clinical and non-clinical populations have been proposed to originate from rumination or inner dialogue, via the mediation of IT, i.e. when experienced as alien (Fowler et al., 2006; Jones \& Fernyhough, 2009; Moritz \& Larøi, 2008; Anthony P. Morrison, Haddock, \& Tarrier, 1995). Cognitive biases and metacognitive mechanisms comparable to those in the development of OC symptoms may play a facilitating role here: IT that are regarded as unacceptable, particularly in presence of a high self-focused attention, may be paradoxically reinforced after attempts to suppress them, and therefore can be experienced as uncontrollable. When subsequently attributed externally, IT may be perceived as hallucinations (Anthony P. Morrison, 2001).

\section{The path from hallucinatory c.q. OC symptoms with co-occurent delusions to clinical case of psychosis}

As expected, hallucinatory experiences, usually considered a core symptom of psychosis, predicted later clinical case of psychosis. OC symptoms showed an association with later clinical cases of psychosis with even higher specificity. Delusional symptoms superimposed on hallucinatory experiences significantly increased the risk for later clinical outcome of psychosis, more so than either one of them in isolation. These findings are in line with earlier models stating that psychosis may arise from a delusional appraisal of disturbing puzzling experiences, with aberrant salience attribution maintaining and reinforcing the symptoms (Kapur, 2003; B. A. Maher, 1974; Brendan A. Maher, 1988; B. A. Maher, 2006). Very interestingly, delusional symptoms co-occurring with OC symptoms showed a very similar association with a later clinical outcome of psychosis, also stronger than either one of them as uncontrollable. When subsequently attributed externally, IT may be perceived as hallucinations (Anthony P. Morrison, 2001).

\section{The path from hallucinatory c.q. OC symptoms with co-occurent delusions to clinical case of psychosis}

As expected, hallucinatory experiences, usually considered a core symptom of psychosis, predicted later clinical case of psychosis. OC symptoms showed an association with later clinical cases of psychosis with even higher specificity. Delusional symptoms superimposed on hallucinatory experiences significantly increased the risk for later clinical outcome of 
psychosis, more so than either one of them in isolation. These findings are in line with earlier models stating that psychosis may arise from a delusional appraisal of disturbing puzzling experiences, with aberrant salience attribution maintaining and reinforcing the symptoms (Kapur, 2003; B. A. Maher, 1974; Brendan A. Maher, 1988; B. A. Maher, 2006). Very interestingly, delusional symptoms co-occurring with $\mathrm{OC}$ symptoms showed a very similar association with a later clinical outcome of psychosis, also stronger than either one of them in isolation. This finding is compatible with the concept of a similar mechanism operating, with an analogy in the role of hallucinatory and OC symptoms.

\section{Interaction of IT with combined delusional-hallucinatory c.q. delusional-obsessive symptoms.}

The apparent similarity in the role of $\mathrm{OC}$ and hallucinatory experiences in the development to clinical case of psychosis may need some further explication. Hallucinations and obsessions are conceptually distinct phenomena: obsessions are defined as thoughts, impulses or images, while hallucinations are defined as distortions in perception (Association, 1994). However, in epidemiologic and phenomenological studies, a continuum between both symptoms and their typical features is reported. For example, voice-hearers reported that the perceptual qualities of their hallucinations differed from other ("real") perceptions: $52 \%$ reported them to be less loud, and $37 \%$ admitted that the voices did not appear very real, independent of their diagnosis (Moritz \& Larøi, 2008). Moreover, voicehearers reported a greater vividness of mental events, even for common "normal" thoughts. Obsessions on the other hand, are often experienced as triggered by a perception (Dominic Julien, O'Connor, \& Aardema, 2009; Lee, Lee, Kim, Kwon, \& Telch, 2005). Models on the origin and persistence of hallucinations as well as obsessions are growing more complex over time but keep showing overlap. Bottom-up processes (anomalies of input, as mentioned earlier) seem to interplay with top-down processes (anomalies of interpretation, such as metacognitive beliefs and cognitive biases)(Moritz \& Larøi, 2008). For example, meta-cognitive beliefs about the uncontrollability of thoughts in combination with the need to control them, and beliefs about their (cultural) unacceptability or threat play a role in the development of obsessions and hallucinations (García-Montes, Pérez-Álvarez, Soto Balbuena, Perona Garcelán, \& Cangas, 2006; Moritz et al., 2010; Varese \& Bentall, 2011). Cognitive biases contributing to the development of obsessions and hallucinations are interrelated, for instance deficits in self-monitoring (Johns et al., 2001; Maltby, Tolin, Worhunsky, O'Keefe, \& Kiehl, 2005; Ursu, Stenger, Shear, Jones, \& Carter, 2003; F. Waters, Woodward, Allen, Aleman, \& Sommer, 2010), impaired inhibition (Badcock, Waters, \& Maybery, 2007; Enright \& Beech, 1993; F. A. Waters, Badcock, Maybery, \& Michie, 2003), deficits in recognition of facial expression (K. M. Corcoran, Woody, \& Tolin, 2008; Kohler, Walker, Martin, Healey, \& Moberg, 2010) and reasoning biases and alterations in decisionmaking (Cavedini, Gorini, \& Bellodi, 2006; Simpson, Cove, Fineberg, Msetfi, \& Ball, 2007; Veckenstedt et al., 2011). 
These findings may contribute to a better understanding of the well-established high comorbidity of psychosis and OCD. Further investigation on the communalities in the etiologic pathway, and particularly of the neurobiological underpinning of the psychological models is needed, promising but challenging. For clinical practice, our findings may have an implication for cognitive behavioral therapeutic interventions. Particularly in the bottom-up processes, the analytical thinking promoted in cognitive behavioral therapy, and the focus on making (intrusive) thoughts more explicit, may be of limited benefit or even bear the risk of promote a counterproductive reasoning style. It is attractive to speculate that a broader perspective, a more "mindful" approach or attention to metacognitive processes may be more suited.

\section{Limitations and methodological issues}

The rate of hallucinations was much lower than delusions. An unlikely explanation is that most delusions represent false positives and most hallucinations true positives. A more likely (partial) explanation is that the M-CIDI measures for delusions are more sensitive and numerous than those

for hallucinations and, additionally, that a range of more subtle, perceptual anomalies can occur in the early phases of psychosis that are not picked up by the M-CIDI.

It was hypothesized that the risk for a future outcome of clinical case of psychosis was increased by combined incident delusional and hallucinatory (c.q. OC) symptoms, i.e. de novo developed between T0 and T2. However, as data on the psychosis (G) section of the M$\mathrm{CIDI}$ were not collected earlier as at $\mathrm{T} 2$, the lifetime version was used at that point. Although theoretically the interval version would be more suited for these analyses, it can be advocated that the lifetime version will do. First, there is a well-documented recall bias in retrospective lifetime questionnaires, resulting in considerable underrating of lifetime prevalence of (psychiatric) symptoms compared to prospective assessment (Kruijshaar et al., 2005; Patten, 2003). Past-year-to-lifetime ratios were as high as $65 \%$ with retrospective questionnaires across disorders (Moffitt et al., 2010). In the current study, there is reason to assume that the pretended "lifetime assessment" of psychotic experiences probably approximates the interval assessment even closer, as the interval assessed (T0-T2) spanned a substantial 3.5 years $(S D=0.3)$, and the mean age of the sample at T0 was 18.3 years (range 13-25; $S D=3.3$ ), which is younger then the generally reported mean age at onset of psychotic symptoms (Esterberg, Trotman, Holtzman, Compton, \& Walker, 2010; Jablensky, 1997). Second, as mentioned above, the most severe existing psychotic symptoms already present at baseline (TO) as assessed with the psychosis items of the SCL-90, were excluded from these analyses.

IT at TO were assessed with two items from the OC symptom dimension of the SCL-90-R ("unwanted persistent thoughts" (item 3 ) and "worrying about sloppiness or carelessness" (item 10). These were lifetime assessments, which carries the risk of including subjects who 
once had a positive score on these items, but not anymore at the time of assessment. However, as it is plausible that a "remitted" IT is even less likely to be remembered and reported than a remitted real symptom, it is plausible that the proportion of reported lifetime IT that were in remission at TO is low. For comparison, past-year and lifetime prevalences of OC symptoms showed only small differences in earlier studies $(0.4 \%$ vs. $0.5 \%$ for OCD and $2.0 \%$ vs. $1.6 \%$ for subclinical OCD (Grabe et al., 2000), $2.3 \%$ vs. $1.2 \%$ for OCD (Ruscio et al., 2010)). More important, the validity of the assessment of IT with these two items could be questioned. The items were chosen on the basis of correspondence with the original definition by Rachman ("repetitive thoughts that are unacceptable or unwanted, usually accompanied by discomfort and interrupting ongoing activity"), , though not covering all aspects of it (Rachman \& de Silva, 1978). The distribution of these items was continuous, but skewed: a larger proportion showed low intensity scores on these items. This is in line with earlier In line with earlier reports that unwanted IT with a similar content as obsessions is very common (80-90\%) in the general population without OCD, but less distressing and uncontrollable (Clark \& Purdon, 1995; Freeston et al., 1991; Purdon \& Clark, 1993). The cutoff point for dichotomization of the continuous score was chosen at a relatively low intensity level of a mean rating higher than 2/5 ("moderately"), below pathology level, representing the highest $18.6 \%$ in the whole sample at baseline, a considerably larger proportion than the prevalences of diagnoses of OCD or psychosis.

The definition of the concept of an IT is independent of a diagnosis. In this study, IT are defined using items of the OC symptom dimension of the SCL-90-R, theoretically possibly contaminating the definition of IT and the analyses. Therefore, TO OC c.q. hallucinatory and delusional symptoms were excluded in analyses with T2 OC symptoms c.q. T2 hallucinatory and delusional symptoms as variables. Moreover, analyses were repeated with a variant definition of IT, composed of seven items from different symptom dimensions of the SCL-90$\mathrm{R}$ (items added: "worrying too much about things" (item 31, depression dimension), "having thoughts that are not of your own", "having bothering thoughts about sex" and "the idea that something is wrong with your mind" (item 62, 84 and 90 respectively, psychoticism dimension) and "thoughts of death or dying" (item 59, no dimension). Although dichotomization with the same cut-off value (higher than $2 / 5$ ) yielded a smaller proportion with IT ( $7.30 \%$ of the sample compared to $18.6 \%$ with the two-item definition of IT), findings were very similar with this alternative definition of IT (data available on request). 


\section{References}

Angst, J. A. J. R. V. D. s. W. (2004). Obsessive-compulsive severity spectrum in the community: prevalence, comorbidity, and course. European Archives of Psychiatry \& Clinical Neuroscience, 254(3), 156-164.

Anthony, J. C., Folstein, M., Romanoski, A. J., Von Korff, M. R., Nestadt, G. R., Chahal, R., . . Gruenberg, E. M. (1985). Comparison of the Lay Diagnostic Interview Schedule and a Standardized Psychiatric Diagnosis: Experience in Eastern Baltimore. Arch Gen Psychiatry, 42(7), 667-675. doi: 10.1001/archpsyc.1985.01790300029004

Association, A. P. (1994). Diagnostic and statistic manual of mental disorders (4th edn. ed.). Washington,DC: American Psychiatric Press.

Badcock, J. C., Waters, F. A. V., \& Maybery, M. (2007). On keeping (intrusive) thoughts to one's self: Testing a cognitive model of auditory hallucinations. Cognitive Neuropsychiatry, 12(1), 78 89.

Barrera, T. L., \& Norton, P. J. (2011). The Appraisal of Intrusive Thoughts in Relation to ObsessionalCompulsive Symptoms. Cogn Behav Ther, 1.

Bentall, R. P., Kinderman, P., \& Kaney, S. (1994). The self, attributional processes and abnormal beliefs: towards a model of persecutory delusions. Behav Res Ther, 32(3), 331-341.

Bleuler, E. (1911). The Fundamental Symptoms of Dementia Praecox or the Group of Schizophrenias (Translated by Zinkin J., Trans.). New York: International Universties Press.

Cavedini, P., Gorini, A., \& Bellodi, L. (2006). Understanding Obsessive-Compulsive Disorder: Focus on Decision Making. Neuropsychol Rev.

Clark, D. A., \& Purdon, C. L. (1995). The assessment of unwanted intrusive thoughts: A review and critique of the literature. Behaviour Research and Therapy, 33(8), 967-976.

Clark, D. A., \& Rhyno, S. (2005). Unwanted Intrusive Thoughts in Nonclinical Individuals: Implications for Clinical Disorders Intrusive thoughts in clinical disorders: Theory, research, and treatment. (pp. 1-29): New York, NY, US: Guilford Press.

Corcoran, K. M., \& B. (2007). Appraisals of intrusive thoughts: An examination of the cognitive theory of obsessions. (68), ProQuest Information \& Learning, US. Retrieved from http://search.ebscohost.com/login.aspx?direct=true\&db=psyh\&AN=2007-99200$114 \&$ site $=$ ehost-live \&scope $=$ site

Corcoran, K. M., Woody, S. R., \& Tolin, D. F. (2008). Recognition of facial expressions in obsessivecompulsive disorder. J Anxiety Disord, 22(1), 56-66

Cottler, L. B., Helzer, J. E., Mager, D., Spitznagel, E. L., \& Compton, W. M. (1991). Agreement between DSM-III and III-R substance use disorders. Drug Alcohol Depend, 29(1), 17-25.

Darroch, J. (1997). Biologic synergism and parallelism. Am J Epidemiol, 145(7), 661-668.

de Bruijn, C., Beun, S., de Graaf, R., Ten Have, M., \& Denys, D. (2010). Subthreshold symptoms and obsessive-compulsive disorder: evaluating the diagnostic threshold. Psychol Med, 40(6), 989997.

Derogatis, L. R., \& Cleary, P. A. (1977). Confirmation of the dimensional structure of the scl-90: A study in construct validation. Journal of Clinical Psychology, 33(4), 981-989. doi: 10.1002/1097-4679(197710)33:4<981::aid-jclp2270330412>3.0.co;2-0

Dominguez, M. D. G., Saka, M. C., Lieb, R., Wittchen, H. U., \& van Os, J. (2010). Early Expression of Negative/Disorganized Symptoms Predicting Psychotic Experiences and Subsequent Clinical Psychosis: A 10-Year Study. American Journal of Psychiatry, 167(9), 1075-1082. doi: 10.1176/appi.ajp.2010.09060883

Eisen, J. L., Pinto, A., Mancebo, M. C., Dyck, I. R., Orlando, M. E., \& Rasmussen, S. A. (2010). A 2-Year Prospective Follow-Up Study of the Course of Obsessive-Compulsive Disorder. Journal of Clinical Psychiatry, 71(8), 1033-1039. doi: 10.4088/JCP.08m04806blu

Enright, S. J., \& Beech, A. R. (1993). Further evidence of reduced cognitive inhibition in obsessivecompulsive disorder. Personality and Individual Differences, 14(3), 387-395. 
Esterberg, M. L., Trotman, H. D., Holtzman, C., Compton, M. T., \& Walker, E. F. (2010). The impact of a family history of psychosis on age-at-onset and positive and negative symptoms of schizophrenia: a meta-analysis. Schizophr Res, 120(1-3), 121-130.

Fowler, D., Freeman, D., Steel, C., Hardy, A., Smith, B., \& Hackman, C. (2006). The catastrophic interaction hypothesis: how do stress, trauma, emotion and information processing abnormalities lead to psychosis? In W. Larkin \& A. P. Morrison (Eds.), Trauma and psychosis (pp. 101-124): Hove: Routledge.

Freeman, D., Garety, P. A., \& Kuipers, E. (2001). Persecutory delusions: developing the understanding of belief maintenance and emotional distress. Psychol Med, 31(7), 1293-1306.

Freeston, M. H., Ladouceur, R., Thibodeau, N., \& Gagnon, F. (1991). Cognitive intrusions in a nonclinical population. I. Response style, subjective experience, and appraisal. Behaviour Research and Therapy, 29(6), 585-597.

García-Montes, J. M., Pérez-Álvarez, M., Soto Balbuena, C., Perona Garcelán, S., \& Cangas, A. J. (2006). Metacognitions in patients with hallucinations and obsessive-compulsive disorder: The superstition factor. Behaviour Research and Therapy, 44(8), 1091-1104.

García-Soriano, G., Belloch, A., Morillo, C., \& Clark, D. A. (2011). Symptom dimensions in obsessivecompulsive disorder: From normal cognitive intrusions to clinical obsessions. Journal of Anxiety Disorders, 25(4), 474-482.

Grabe, H. J., Meyer, C., Hapke, U., Rumpf, H. J., Freyberger, H. J., Dilling, H., \& John, U. (2000). Prevalence, quality of life and psychosocial function in obsessive-compulsive disorder and subclinical obsessive-compulsive disorder in northern Germany. Eur Arch Psychiatry Clin Neurosci, 250(5), 262-268.

Hanssen, M., Bak, M., Bijl, R., Vollebergh, W., \& van Os, J. (2005). The incidence and outcome of subclinical psychotic experiences in the general population. Br J Clin Psychol, 44(Pt 2), 181191.

Henquet, C., Krabbendam, L., Spauwen, J., Kaplan, C., Lieb, R., Wittchen, H. U., \& van Os, J. (2005). Prospective cohort study of cannabis use, predisposition for psychosis, and psychotic symptoms in young people. Bmj, 330(7481), 11.

Hunter, E. E., Penick, E. C., Powell, B. J., Othmer, E., Nickel, E. J., \& Desouza, C. (2005). Development of scales to screen for eight common psychiatric disorders. J Nerv Ment Dis, 193(2), 131-135. doi: 00005053-200502000-00008 [pii]

Jablensky, A. (1997). The 100-year epidemiology of schizophrenia Schizophr Res, 28(2-3), 111-125.

Johns, L. C., Rossell, S., Frith, C., Ahmad, F., Hemsley, D., Kuipers, E., \& McGuire, P. K. (2001). Verbal self-monitoring and auditory verbal hallucinations in patients with schizophrenia. Psychol Med, 31(4), 705-715.

Jones, S. R., \& Fernyhough, C. (2009). Rumination, reflection, intrusive thoughts, and hallucinationproneness: towards a new model. Behav Res Ther, 47(1), 54-59.

Julien, D., O'Connor K, P., \& Aardema, F. (2007). Intrusive thoughts, obsessions, and appraisals in obsessive-compulsive disorder: A critical review. Clin Psychol Rev.

Julien, D., O'Connor, K. P., \& Aardema, F. (2009). Intrusions related to obsessive-compulsive disorder: a question of content or context? Journal of Clinical Psychology, 65(7), 709-722. doi: $10.1002 /$ jclp. 20578

Kapur, S. (2003). Psychosis as a state of aberrant salience: a framework linking biology, phenomenology, and pharmacology in schizophrenia. Am J Psychiatry, 160(1), 13-23.

Kim, S. W., Dysken, M. W., \& Kuskowski, M. (1992). The Symptom Checklist-90: ObsessiveCompulsive Subscale: A reliability and validity study. Psychiatry Res, 41(1), 37-44. doi: 01651781(92)90016-V [pii]

Kohler, C. G., Walker, J. B., Martin, E. A., Healey, K. M., \& Moberg, P. J. (2010). Facial emotion perception in schizophrenia: a meta-analytic review. Schizophr Bull, 36(5), 1009-1019

Krabbendam, L., Myin-Germeys, I., Hanssen, M., Bijl, R. V., de Graaf, R., Vollebergh, W., ... van Os, J. (2004). Hallucinatory experiences and onset of psychotic disorder: evidence that the risk is mediated by delusion formation. Acta Psychiatr Scand, 110(4), 264-272. 
Kruijshaar, M. E., Barendregt, J., Vos, T., de Graaf, R., Spijker, J., \& Andrews, G. (2005). Lifetime prevalence estimates of major depression: An indirect estimation method and a quantification of recall bias. European Journal of Epidemiology, 20(1), 103-111.

Lee, H. J., Lee, S. H., Kim, H. S., Kwon, S. M., \& Telch, M. J. (2005). A comparison of autogenous/reactive obsessions and worry in a nonclinical population: a test of the continuum hypothesis. Behav Res Ther, 43(8), 999-1010.

Lieb, R., Isensee, B., von Sydow, K., \& Wittchen, H. U. (2000). The Early Developmental Stages of Psychopathology Study (EDSP): A Methodological Update. European Addiction Research, 6(4), 170-182.

Maher, B. A. (1974). Delusional thinking and perceptual disorder. J Individ Psychol, 30(1), 98-113.

Maher, B. A. (1988). Anomalous experience and delusional thinking: The logic of explanations. In B. A. Maher \& T. F. Oltmanns (Eds.), Delusional beliefs. (pp. 15-33). Oxford England: John Wiley \& Sons.

Maher, B. A. (2006). The relationship between delusions and hallucinations. Curr Psychiatry Rep, 8(3), 179-183.

Maltby, N., Tolin, D. F., Worhunsky, P., O'Keefe, T. M., \& Kiehl, K. A. (2005). Dysfunctional action monitoring hyperactivates frontal-striatal circuits in obsessive-compulsive disorder: an eventrelated fMRI study. Neuroimage, 24(2), 495-503.

Moffitt, T. E., Caspi, A., Taylor, A., Kokaua, J., Milne, B. J., Polanczyk, G., \& Poulton, R. (2010). How common are common mental disorders? Evidence that lifetime prevalence rates are doubled by prospective versus retrospective ascertainment. Psychological Medicine, 40(06), 899-909. doi: doi:10.1017/\$0033291709991036

Moritz, S., \& Larøi, F. (2008). Differences and similarities in the sensory and cognitive signatures of voice-hearing, intrusions and thoughts. Schizophrenia Research, 102(1-3), 96-107.

Moritz, S., Peters, M. J. V., Larøi, F., \& Lincoln, T. M. (2010). Metacognitive beliefs in obsessivecompulsive patients: A comparison with healthy and schizophrenia participants. Cognitive Neuropsychiatry, 15(6), 531-548.

Morrison, A. P. (2001). The interpretation of intrusions in psychosis: An integrative cognitive approach to hallucinations and delusions. Behavioural and Cognitive Psychotherapy, 29(3), 257-276.

Morrison, A. P., \& Haddock, G. (1997). Cognitive factors in source monitoring and auditory hallucinations. Psychol Med, 27(3), 669-679.

Morrison, A. P., Haddock, G., \& Tarrier, N. (1995). Intrusive Thoughts and Auditory Hallucinations: A Cognitive Approach. Behavioural and Cognitive Psychotherapy, 23(03), 265-280. doi: doi:10.1017/S1352465800015873

Nelson, E., \& Rice, J. (1997). Stability of diagnosis of obsessive-compulsive disorder in the Epidemiologic Catchment Area study. Am J Psychiatry, 154(6), 826-831.

Organization, W. H. (1990). Composite International Diagnostic Interview (CIDI), Version 1.0. : Geneva, Switzerland: WHO.

Parkinson, L., \& Rachman, S. (1981). Part II. The nature of intrusive thoughts. Advances in Behaviour Research and Therapy, 3(3), 101-110.

Patten, S. B. (2003). Recall bias and major depression lifetime prevalence. Social Psychiatry and Psychiatric Epidemiology, 38(6), 290-296. doi: 10.1007/s00127-003-0649-9

Purdon, C., \& Clark, D. A. (1993). Obsessive intrusive thoughts in nonclinical subjects. Part I. Content and relation with depressive, anxious and obsessional symptoms. Behaviour Research and Therapy, 31(8), 713-720.

Rachman, S. (1997). A cognitive theory of obsessions. Behav Res Ther, 35(9), 793-802.

Rachman, S., \& de Silva, P. (1978). Abnormal and normal obsessions. Behav Res Ther, 16(4), 233-248.

Rachman, S., \& Hodgson, R. (1980). Obsessions and compulsions. New Jersey: Prentice/Hall International: Hemel Hempstead.

Reed, V., Gander, F., Pfister, H., Steiger, A., Sonntag, H., Trenkwalder, C., . . Wittchen, H.-U. (1998). To what degree does the Composite International Diagnostic Interview (CIDI) correctly 
identify DSM-IV disorders? Testing validity issues in a clinical sample. International Journal of Methods in Psychiatric Research, 7(3), 142-155. doi: 10.1002/mpr.44

Ruscio, A. M., Stein, D. J., Chiu, W. T., \& Kessler, R. C. (2010). The epidemiology of obsessivecompulsive disorder in the National Comorbidity Survey Replication. Mol Psychiatry, 15(1), 53-63.

Salkovskis, P. M., \& Harrison, J. (1984). Abnormal and normal obsessions--a replication. Behav Res Ther, 22(5), 549-552.

Simpson, J., Cove, J., Fineberg, N., Msetfi, R. M., \& Ball, L. J. (2007). Reasoning in people with obsessive-compulsive disorder. British Journal of Clinical Psychology, 46(4), 397-411.

Smeets, F., Lataster, T., Dominguez, M.-d.-G., Hommes, J., Lieb, R., Wittchen, H.-U., \& van Os, J. (2010). Evidence That Onset of Psychosis in the Population Reflects Early Hallucinatory Experiences That Through Environmental Risks and Affective Dysregulation Become Complicated by Delusions. Schizophrenia Bulletin. doi: 10.1093/schbul/sbq117

StataCorporation. (1984-2009). STATA Statistical Software: Release 11.0. Texas: College Station.

Tolin, D. F., Abramowitz, J. S., Przeworski, A., \& Foa, E. B. (2002). Thought suppression in obsessivecompulsive disorder. Behaviour Research and Therapy, 40(11), 1255-1274.

Ursu, S., Stenger, V. A., Shear, M. K., Jones, M. R., \& Carter, C. S. (2003). Overactive action monitoring in obsessive-compulsive disorder: evidence from functional magnetic resonance imaging. Psychol Sci, 14(4), 347-353. doi: psci_24411 [pii]

Van Dael, F., van Os, J., de Graaf, R., ten Have, M., Krabbendam, L., \& Myin-Germeys, I. (2011). Can obsessions drive you mad? Longitudinal evidence that obsessive-compulsive symptoms worsen the outcome of early psychotic experiences. Acta Psychiatr Scand, 123(2), 136-146. doi: 10.1111/j.1600-0447.2010.01609.x

Varese, F., \& Bentall, R. P. (2011). The metacognitive beliefs account of hallucinatory experiences: A literature review and meta-analysis. Clinical Psychology Review, 31(5), 850-864.

Veckenstedt, R., Randjbar, S., Vitzthum, F., Hottenrott, B., Woodward, T. S., \& Moritz, S. (2011). Incorrigibility, jumping to conclusions, and decision threshold in schizophrenia. Cognitive Neuropsychiatry, 16(2), 174-192. doi: 10.1080/13546805.2010.536084

Waters, F., Woodward, T., Allen, P., Aleman, A., \& Sommer, I. (2010). Self-recognition Deficits in Schizophrenia Patients With Auditory Hallucinations: A Meta-analysis of the Literature. Schizophrenia Bulletin. doi: 10.1093/schbul/sbq144

Waters, F. A., Badcock, J. C., Maybery, M. T., \& Michie, P. T. (2003). Inhibition in schizophrenia: association with auditory hallucinations. Schizophr Res, 62(3), 275-280.

Westphal, K. (1878). Ueber Zwangvorstellungen. Arch. Psychiatr. Nervenkr., 8, 734-750.

Wittchen, H.-U. (1994). Reliability and validity studies of the WHO-Composite International Diagnostic Interview (CIDI): A critical review. Journal of Psychiatric Research, 28(1), 57-84.

Wittchen, H. U., Perkonigg, A., Lachner, G., \& Nelson, C. N. (1998). Early Developmental Stages of Psychopathology Study (EDSP): Objectives and Design. European Addiction Research, 4(1-2), 18-27.

Wittchen, H. U., \& Pfister, H. (1997). DIS-X-Interviews: Manual für Screening-Verfahren und Interview; Interviewheft Längsschnittuntersuchung (DIA-X-Lifetime); Ergänzungsheft (DIA-X-Lifetime); Interviewheft Querschnittsuntersuchung (DIA-X-12 Monats-Version); Ergänzungsheft (DIA-X12 Monats-Version); PC-Programm zur Durchführung der Interviews (Längsund Querschnittsuntersuchung). Auswertungsprogramm. : Frankfurt, Germany: Swets \& Zeitlinger.

Wittchen, H. U., Robins, L. N., Cottler, L. B., Sartorius, N., Burke, J. D., \& Regier, D. (1991). Crosscultural feasibility, reliability and sources of variance of the Composite International Diagnostic Interview (CIDI). The Multicentre WHO/ADAMHA Field Trials. Br J Psychiatry, 159, 645-653, 658.

Woody, S. R., Steketee, G., \& Chambless, D. L. (1995). The usefulness of the Obsessive Compulsive Scale of the Symptom Checklist-90-Revised. Behav Res Ther, 33(5), 607-611. 
When you develop your opinions on the basis of weak evidence, you will have difficulty interpreting subsequent information that contradicts these opinions, even if this new information is obviously more accurate.

Nassim Nicholas Taleb, The Black Swan: The Impact of the Highly Improbable 


\section{Chapter}

\section{Data gathering: biased in psychosis?}

F. Van Dael ${ }^{a}$, D. Versmissen ${ }^{a, b}$, I. Janssen ${ }^{a, b}$, I. Myin-Germeys ${ }^{a, b}$, J.van Os ${ }^{a, c}$, L. Krabbendam ${ }^{a}$

aDepartment of Psychiatry and Neuropsychology, South Limburg Mental Health Research and Teaching Network, EURON, Maastricht University, PO BOX 616 (DRT 10), 6200 MD Maastricht, The Netherlands.

${ }^{\mathrm{b}}$ Mondriaan Zorggroep, Section Social Cognition, Postbus 4436, 6401 CX Heerlen, the Netherlands. 'Division of Psychological Medicine, Institute of Psychiatry, De Crespigny Park, Denmark Hill, London SE5 8AF, UK. 


\section{Abstract}

\section{Objective}

This study examined whether the probabilistic reasoning bias referred to as a "jumping-toconclusions" (JTC) style of reasoning, which according to previous research is associated with particular psychotic symptoms such as delusions, represents a trait that can also be detected in non-psychotic relatives of patients with schizophrenia and in non-psychotic individuals with a high level of psychotic experiences.

\section{Method}

Participants were, in order of level of psychosis liability, 40 patients with schizophrenia or a schizo-affective disorder, 40 first-degree non-psychotic relatives, 41 participants from the general population with above average expression of psychotic experiences and 53 participants from the general population with an average level of psychotic experiences. A "Jumping-to-conclusions" bias was assessed using the beads task.

\section{Results}

A dose-response relationship was found in the association between level of psychosis liability and JTC (defined as needing only a single bead to complete the beads task) (OR linear trend $=1.59 ; 95 \% \mathrm{Cl}: 1.13-2.24$ ) and, independently, a linear association was apparent between JTC and level of delusional ideation (OR linear trend $=2.59 ; 95 \% \mathrm{Cl}: 1.18$ 5.69). In addition, the association between psychosis liability and JTC was generally much stronger as the level of delusional ideation was higher.

\section{Conclusion}

JTC is associated with liability to psychosis (trait), in particular if the psychosis phenotype is characterised by delusional ideation (state). 


\section{Introduction}

Contemporary models of delusions have shown a role for a specific reasoning bias referred to as a "jumping-to-conclusions" (JTC) style of reasoning in people with active delusions.(Garety \& Freeman, 1999; Garety, Kuipers, Fowler, Freeman, \& Bebbington, 2001). Individuals with delusions may incline to early acceptance, and to a lesser extent, early rejection of hypotheses. More precisely, they show a tendency to seek less information to reach a decision, indicated as a data gathering bias. This may under certain conditions contribute to erroneous inferences, and, as is hypothesised, to the formation and/or maintenance of delusions.

The question whether this reasoning bias has the quality of a state rather than a trait is poorly investigated. In the former case, it concerns a dynamic characteristic that waxes and wanes with the development and remission of a delusional belief. In the latter, it concerns a characteristic that is relatively stable in time independent of the presence or severity of delusional symptoms. It has been postulated that a JTC reasoning bias with the quality of a state might at most be a mediating factor in the maintenance of delusional ideation, while as a trait it could possibly contribute to the formation of delusions and be part of the vulnerability to psychosis (Colbert \& Peters, 2002; Linney, Peters, \& Ayton, 1998).

JTC was found in seven out of eight studies in currently deluded participants, irrespective of a diagnosis of schizophrenia or delusional disorder (Colbert \& Peters, 2002; Conway et al., 2002; R. E. Dudley, John, Young, \& Over, 1997a, 1997b; R. E. J. Dudley \& Over, 2003; Fear \& Healy, 1997; Garety \& Freeman, 1999; Huq, Garety, \& Hemsley, 1988; John \& Dodgson, 1994; Moritz \& Woodward, 2005; Mortimer et al., 1996; E. R. Peters, Day, \& Garety, 1997; Young \& Bentall, 1997). In a longitudinal study, the data-gathering bias was found to persist even when the participants were no longer deluded (E. Peters \& Garety, 2005; E. R. Peters, 2003; E. R. Peters \& Garety, 1999). In another recent study, the JTC reasoning bias was found in subjects with an "at risk mental state" for transition to psychosis (without delusions), as well as in subjects in their first episode of psychosis and experiencing delusions of persecution (Broome et al., 2003). JTC was also found in a sample of patients with schizophrenia, some of them without delusions, and no correlation was found between JTC and the number and severity of delusions on an "index of deludedness" (Mortimer et al., 1996). Taken together, the possibility of a JTC reasoning bias having the qualities of a state remains, but unmistakable evidence for at least partial characteristics of a trait emerges from studies with longitudinal as well as cross-sectional designs. The combination of state and trait within one and the same characteristic is not uncommon. For example, trait low self-esteem is a risk factor for depression, but during episodes of depression, low selfesteem will also co-vary with intensity of the depressed state and contribute to the persistence of depression (Brown, Andrews, Harris, Adler, \& Bridge, 1986; Brown, Bifulco, \& Andrews, 1990; Dent \& Teasdale, 1988). More in general, many risk factors for onset of 
psychiatric disorder are also risk factors for persistence of the same disorder (Van Os, Jones, Sham, Bebbington, \& Murray, 1998).

One way to further investigate the trait and/or state nature of reasoning biases would be to investigate individuals who have no clinical needs, but are at risk for psychosis, for example first-degree relatives of patients with psychosis, and individuals with subclinical psychotic experiences in the general population (Baron et al., 1985; Fanous, Gardner, Walsh, \& Kendler, 2001; Johns \& van Os, 2001; Kendler et al., 1993a; van Os, Hanssen, Bijl, \& Vollebergh, 2001). A number of studies have suggested that the symptoms of psychosis are prevalent in the general population and exist as part of a continuous, albeit skewed, distribution (Tien, 1991; van Os, Hanssen, Bijl, \& Ravelli, 2000). This suggests that the clinical disorder is at the extreme end of a continuum, which ranges from healthy functioning, through eccentricity and subclinical psychotic experiences to florid psychosis with clinical need (van Os et al., 2000; van Os et al., 2001). Not only (sub)clinical symptoms of psychosis, but also particular endophenotypic abnormalities in cognition, features of personality and functional and structural aspects of the brain that have been found in subjects with diagnosis of schizophrenia, are found too, albeit to lesser degree, in relatives and in individuals at higher risk for schizophrenia (G. Claridge, 1994; Faraone et al., 1995; Faraone et al., 2000; Gilvarry et al., 2001; M. F. Green \& Nuechterlein, 1999; Keefe et al., 1994; Krabbendam, Marcelis, Delespaul, Jolles, \& van Os, 2001; Kremen et al., 1994; Schurhoff et al., 2003; Whalley et al., 2004).

These findings possibly differentially reflect the expression of a graded genetic predisposition to the disorder, such that relatives, and to a lesser extent individuals with subclinical psychotic experiences, may be more at risk than the general population for later development of schizophrenia or have an undiagnosed but genetically related schizophrenia spectrum disorder.

Two studies have examined JTC reasoning bias in individuals from the general population with a proneness to delusions, both of which showed evidence of such a bias (Colbert \& Peters, 2002; Linney et al., 1998). To our knowledge, no study on JTC reasoning bias involving relatives of patients with schizophrenia has been carried out. In the present study, we set out to what degree the JTC reasoning bias as a trait reflects the familial vulnerability for psychosis, to what degree the JTC reasoning bias as a state co-varies with delusional states, and whether there is an interaction between psychosis liability and delusions in their effect on JTC. We predicted that the groups with psychosis liability (i.e. unrelated controls with a proneness to delusions and in particular the non-psychotic relatives of patients) would display less JTC reasoning bias than patients with a diagnosis of schizophrenia, but more than members of the general population with an average proneness to delusions (Faraone et al., 2000; Shedlack et al., 1997). 


\section{Materials and Methods}

Procedure and Sample

Four groups differing in the degree of vulnerability to psychosis were included in the "Cognitive functioning in Psychosis" (CoP) study: i) patients with history of non-affective psychosis, ii) first degree relatives of patients with non-affective psychosis, iii) participants scoring high ( $>75^{\text {th }}$ percentile) on the positive dimension of psychosis-proneness measured by the Community Assessment of Psychic Experiences (CAPE; see Instruments section) (M. Hanssen, Krabbendam, Vollema, Delespaul, \& Van Os, 2005; Stefanis et al., 2002) and iv) "healthy controls", i.e. participants scoring in the average range $\left(40^{\text {th }}-60^{\text {th }}\right.$ percentile $)$ on the CAPE.

All participants were between the ages of 18-59 years, sufficiently fluent in Dutch and without a history of neurological disorders such as epilepsy and concussion with loss of consciousness. Written informed consent, in accordance with the local ethical committee guidelines, was obtained from all participants.

Patients were recruited from the catchment area (source population: 350,000 ) Community Mental Health Centre and the catchment area Psychiatric Hospital. Initial inclusion criteria for patients were the lifetime prevalence of a period of psychosis (at least 2 weeks) in clear consciousness, according to the RDC (Research Diagnosis Criteria (Spitzer, Endicott, \& Robins, 1978)).

Relatives (free from a lifetime history of psychosis) were sampled through participating patients or through associations for relatives of patients with psychotic symptoms.

Participants with average and high levels of psychotic experiences were recruited from an earlier longitudinal family study in the general population conducted in the city of Sittard (Continuum of Mental Disorders study, COMED) (M. Hanssen et al., 2003). Participants of the COMED-study were aged 36-65 years and had been randomly selected and sent a letter in which they were asked to participate. Additionally, participants were asked through a snowball-sampling procedure to invite their family members to participate. Overall, 768 participants from a total of 116 families were included. All participants filled in the Community Assessment of Psychic Experiences (CAPE; see Instruments section) (M. Hanssen et al., 2005; Stefanis et al., 2002). The participants with a mean (i.e. between $40^{\text {th }}$ and $60^{\text {th }}$ percentile) and a high (i.e. above $75^{\text {th }}$ percentile) score on the CAPE positive psychosis dimensions were invited to participate in the CoP study.

The present study included 45 patients with psychosis (39.5\% inpatients), 47 non-psychotic first-degree relatives, 41 participants with a high level of subclinical psychotic experiences (psychosis-prone) and 54 healthy controls with an average level of psychotic experiences (controls). Of the 47 healthy relatives, there were 13 mothers, 8 fathers, 15 sisters, 8 brothers, 2 daughters and one son. Twenty-seven families contributed at least one patient and one relative. Four relatives participated without their ill family member. 
All participants were screened for symptoms listed in the Operational Criteria Checklist for Psychotic Disorder (OCCPI) (McGuffin, Farmer, \& Harvey, 1991). Where necessary, additional information was derived from interviews with ward staff or personal case-managers. Using the combined information in the OCCPI, the computerised program OPCRIT (McGuffin et al., 1991) yielded RDC diagnoses (Spitzer et al., 1978).

Current use of illicit drugs and alcohol was assessed using section I of the Composite International Diagnostic Interview (CIDI; version 1.1) (Smeets \& Dingemans, 1993).

\section{Instruments}

\section{CAPE}

The Community Assessment of Psychic Experiences (CAPE) (Stefanis et al., 2002); http://www.cape42.homestead.com/), is a self-report instrument developed to assess dimensions of sub-clinical psychosis phenotype. The CAPE includes dimensions of positive psychotic experiences ( 20 items), negative psychotic experiences (14 items) and depressive experiences ( 8 items). For a detailed description of the development of the CAPE, we refer to (M. Hanssen et al., 2005; M. S. Hanssen, Bijl, Vollebergh, \& van Os, 2003; Stefanis et al., 2002; Verdoux \& van Os, 2002). The CAPE was used to split up the psychosis-prone group from the control group in the general population sample.

\section{SAPS and SANS}

The Scale for the Assessment of Positive Symptoms (SAPS) (N. C. Andreasen, 1984) and the Scale for the Assessment of Negative Symptoms (SANS) (N. Andreasen, 1983; N. C.

Andreasen, 1982) are complementary instruments used to assess the severity of symptoms in patients with schizophrenia or other psychotic disorders. The goal of the SAPS is to assess positive symptoms and disorganization. The SANS is designed to rate the presence and severity of negative symptoms.

The SAPS contains 30 items divided over 4 domains including hallucinations, delusions, disorganisation or bizarre behaviour, and formal thought disorder. The SANS contains 20 items divided over 5 domains including affective flattening and blunting, alogia, avolitionapathy, anhedonia-asociality and attentional impairment. In addition to the individual SAPS and SANS items, a global severity rating is made for each domain. Ratings were made by trained interviewers on the basis of a standard clinical interview, observed behaviour during the interview and review of all available clinical material. A subscale score for each domain was constructed as the sum of the scores for each item in that domain. The time frame covered by the rating was lifetime.

PSE

The purpose of the Present State Examination (PSE) (Wing, Cooper, \& Sartorius, 1974) is to assess the presence and severity of symptoms associated with a broad range of major psychiatric disorders over a designated period, i.c. last week, by means of a structured clinical interview with the patient. In this study, only the sections that cover items signs and 
symptoms of delusions were used (29 items: PSE55-PSE59 and PSE71-PSE92, in addition to their subscale scores).

\section{CDSS}

The Calgary Depression Scale for Schizophrenia (CDSS) was developed to assess symptoms of major depressive disorder in patients with schizophrenia. The CDSS consists of nine items, all of them typical depressive symptoms that do not appear to overlap with the negative symptoms of schizophrenia. The CDSS is a reliable and valid measure of the severity of depressive symptoms in patients with schizophrenia (Addington, Addington, \& MatickaTyndale, 1993a, 1993b, 1994).

The SAPS, SANS and CDSS are developed for use in patients with psychotic disorders. The PSE was designed to provide dimensional ratings of symptoms and syndromes that are not wedded to any single classification or diagnostic system.

In the SAPS as well as in the PSE, more than ten different types of delusions, corresponding to their content, can be rated in severity on a 6-point c.q. 4-point Likert scale. The rationale for using these scales not only in patients, but also in relatives and psychosis-prone participants in the general population is that at the lower end of the spectrum, ratings like "supposed "and "mild" are used. This makes sensitivity sufficient to assess subclinical experiences.

\section{General intelligence}

General intelligence was measured by a combined score on one performance subtest and one verbal subtest from the Groningen Intelligence Test (GIT), a widely used Dutch intelligence test, (Luteijn \& van der Ploeg, 1983). This test yields results that are comparable to those of the Wechsler Adult Intelligence Scale-Revised (Wechsler, 1981).

General intelligence is lower in people with schizophrenia. Hence, an association between JTC and general intelligence could indicate that general intelligence has the role of a confounder or mediator between JTC and psychosis liability.

\section{Beads task}

A computerised version of the beads task outlined by Phillips \& Edwards was used (Phillips \& Edwards, 1966). In this experiment, participants are shown a pair of jars on a screen. One jar contains 85 green and 15 red beads, and the other jar the opposite ratio. Participants are informed of the proportions, and the jars are removed from view. One of the jars then is chosen, still hidden from view, and a bead is drawn from it and shown on the screen to the participant. Beads are sequentially being drawn and always replaced. Although the participants are told that beads are being selected randomly, the sequence of colours is predetermined according to the ratio of the two colours. The participant's task is to work out whether the experimenter is drawing from the mainly green or the mainly red jar. In this study, the condition is chosen in which participants are free to determine how many beads 
are drawn and the trial is only terminated once they affirm that they are certain about their choice.

\section{Analyses}

Statistical analyses were carried out with STATA version 8 (StataCorporation, 1984-2009). A four-level group variable was constructed reflecting the hypothesised order in liability for psychosis, with controls (coded 0), psychosis-prone participants (coded 1), relatives (coded 2 ), and patients (coded 3 ) in the highest category. The number of beads requested by a subject yielded a continuous outcome variable within a range from 0 to 20 . This variable was found to be non-normally distributed because the majority of participants requested less than 5 beads. In order to examine the JTC outcome, a variable was constructed indicating whether or not a subject showed a JTC reasoning bias, defined as requesting only one bead before deciding (hereafter: JTC\#1). This cut-off was chosen a priori as it reflects the most definite expression of the reasoning bias under investigation and should therefore be most discriminating between groups. In order to test this assumption, associations were also tested using less stringent cut-off values (i.e. using 2, 3 or more beads before deciding).

\section{JTC\#1 and psychosis liability}

The association between JTC\#1 and psychosis liability (i.e., the four-level group variable reflecting liability for schizophrenia), was examined using logistic regression analysis, and progressively less stringent selections of JTC cut-offs were also considered. Effect sizes were expressed as odds ratios with their $95 \%$ confidence intervals. The following a priori selected confounders of the association between JTC and psychosis liability were included in the logistic regression model: age, sex, general intelligence, level of education (8 point-scale, for the analysis summarized into three levels: low, medium, high), and use of psychotropic medication on a regular basis (self-reported as daily to weekly use versus less than daily to weekly use) and illicit drugs (self-reported as "present use" versus no use) or alcohol (selfreported as more than 20 units/week versus less than 20 units/week).

\section{JTC\#1 and symptoms of psychosis}

The distribution of the subscale scores on the SAPS, SANS and PSE was highly skewed, because most participants were in partial or full remission or simply did not reach a level of psychotic symptoms that could be detected by these measures. Therefore, the subscale scores were dichotomised (score 0 or 1 ), a score of 0 indicating that the subject did not have any symptom on that domain, a score of 1 indicating that the subject had at least one of the symptoms in that domain. For those having any delusional symptoms, the sum of the (nondichotomised) subscale score of the delusions domains of the PSE was taken as a measure for the severity of the delusions. The distribution of these non-zero scores was normal, allowing the distribution to be divided by its tertiles creating three tertile groups. The distribution of the sum scores on the Calgary Depression Scale for Schizophrenia (CDSS) was moderately skewed, also allowing it to be divided by its tertiles creating three tertile groups. 
Associations between JTC\#1 on the beads task and presence of delusions as measured with the PSE were examined using logistic regression analysis. For each significant association between JTC\#1 and the presence of delusions, the association with severity was also assessed.

In order to assess whether any association with delusions was independent from other positive and negative or depressive symptoms, subsequent analyses were performed in which all symptom domains, assessed with the SAPS, the SANS, and the CDSS, were entered simultaneously in the model.

In order to control for any effect of patient status, the association between JTC\#1 and delusions was additionally adjusted for psychosis liability.

Any association between JTC\#1 on the one hand and both the presence of psychotic symptoms as well as psychosis liability on the other, was further examined by comparing the associations between JTC\#1 and psychosis liability in a selection of participants with delusions to that in participants without delusions within each of the three groups. In order to control for any bias induced by clinical severity, we examined the association between JTC and psychosis liability as well as the association between JTC and delusions when inpatients were excluded from the sample.

Furthermore, we examined whether any JTC reasoning bias was particularly associated with schizophrenia liability by excluding all patients with RDC diagnoses other than narrow schizophrenia and schizo-affective disorder.

Power analysis

Assuming a proportion of $20 \%$ of JTC in the whole study sample and a relative risk of 3.5 in the patient group the power to detect differences between the patient group and the control group at a conventional alpha-level of 0.05 (two-sided) is 0.8 .

\section{Results}

\section{Sample characteristics}

Two patients were excluded because data on diagnosis and symptoms were missing. Data on performance on the beads task were missing for 3 patients (all 3 with diagnosis of narrow schizophrenia), 7 relatives and one subject from the control group, leaving 40 patients, 40 relatives, 41 psychosis-prone participants and 53 controls. There were 28 patients $(70.0 \%)$ with a diagnosis of schizophrenia, 5 patients (12.5\%) with a diagnosis of schizoaffective disorder, 5 patients (12.5\%) with a diagnosis of unspecified functional psychosis. For 2 patients (5.0\%) OCCPI data were missing, but lifetime presence of positive psychotic symptoms was confirmed with the SAPS. The mean age of the whole sample was 41.6 years $(S D=11.2)$. The mean age of the patients was lower than that of the other groups (see Table 1). The patient group had a significantly lower general intelligence and level of education compared to the control group. 


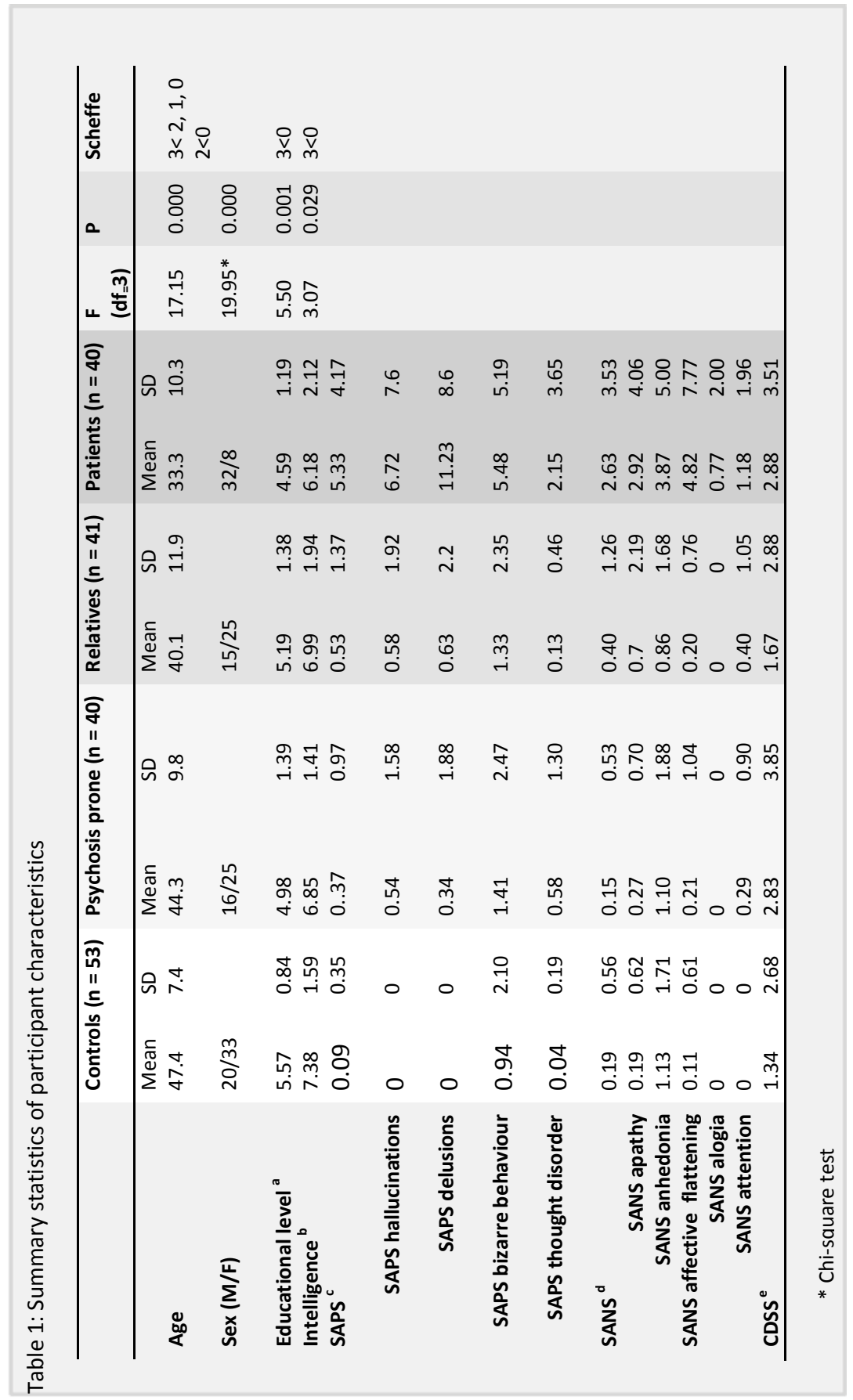


Antipsychotic agents were used in the past week by 28 participants, all of whom were in the patient group (28 of 40 patients, i.e. $70 \%$ ). Eight out of forty patients (i.e. $20 \%$ ) reported current use of illicit drugs, which in all cases but two was restricted to cannabis. Two out of 53 controls (i.e. 3.7\%), 3 out of 41 delusion-prone participants (i.e. $7.3 \%$ ) and 5 out of 40 relatives (i.e. $12.5 \%$ ) reported use of illicit drugs, which in all cases but one (relative) was restricted to cannabis.

There was no significant difference in alcohol use between groups. There were 7 out of 53 controls (i.e. 13.2\%), 7 out of 41 delusion-prone participants (i.e. 17.1\%) and 2 out of 40 relatives (i.e. $5 \%$ ) and 5 out of 40 patients (i.e. $12.5 \%$ ) who reported the use of more than 20 units alcohol/week?

\section{Association between JTC and psychosis liability}

In the whole sample, 35 (20.1\%) of the participants showed a JTC\#1 reasoning bias, of whom 6 from 53 participants in the control group (11.3\%), 6 from 41 in the psychosis-prone group (14.6\%), 10 from 40 in the relatives (25\%) and 13 from 40 in the patients (32.5\%). A linear trend was apparent in the association between JTC\#1 and psychosis liability, the association being stronger as the psychosis liability increased (OR linear trend:1.59; $95 \% \mathrm{Cl}: 1.13-2.24)$. When entered as three dummy variables comparing associations with the reference control group, it reached significance for the patient group (OR=3.77; $95 \% \mathrm{Cl}$ : $1.28-11.07$, see Table 2), indicating that the patient group was more likely to jump to conclusions than the controls. When the inpatients were excluded, the association between JTC and psychosis liability in the patient group reduced but did not nullify (OR $=3.23 ; 95 \% \mathrm{Cl}$ : 0.94 - 10.96). When only the patients with RDC diagnoses of narrow schizophrenia and schizo-affective disorder were included, the association between JTC and psychosis liability grew stronger and more specific (OR $=5.09 ; 95 \% \mathrm{Cl}: 1.70-15.29)$. The strength and statistical precision of the association between JTC\#1 and the psychosisliability variable was reduced when adjusted for the confounders age, gender, level of education, general intelligence and use of cannabis or other illicit drugs (see Table 2). This reduction was largely attributable to the effect of "general intelligence". As the cut-off criterion of number of beads used to define JTC became progressively less stringent, the association between this selection and the schizophrenia-liability variable was also progressively weaker, as expected (for JTC $\leq 2$, in the patient group, $\mathrm{OR}=2.23 ; 95 \% \mathrm{Cl}$ : $0.97-5.15$, in the relatives $\mathrm{OR}=1.49 ; 95 \% \mathrm{Cl}: 0.65-3.43$ and in the psychosis-prone group $\mathrm{OR}=0.95 ; 95 \% \mathrm{Cl}: 0.41-2.21$ ).

\section{Association between JTC and delusions}

There was a significant association between JTC\#1 and the dichotomised score on the delusions subscales from the PSE (OR $=2.59 ; 95 \% \mathrm{Cl}: 1.18-5.69)$. The association became less specific after adjustment for age, gender and level of education, general intelligence and use of cannabis and other illicit drugs ( $O R=6.72 ; 95 \% \mathrm{Cl}: 0.45-100.41)$. Again, the reduction in specificity was largely attributable to the effect of general intelligence. 
Table 2. Associations between number of beads requested = 1 (JTC\#1) and the group variable reflecting psychosis liability (linear trend and each value compared to control group).

\begin{tabular}{|c|c|c|c|}
\hline JTC\#1 & OR & $\mathbf{P}$ & $95 \% \mathrm{Cl}$ \\
\hline $\begin{array}{l}\text { PL (linear trend) } \\
\text { (unadjusted) }\end{array}$ & 1.59 & 0.008 & $1.13-2.24$ \\
\hline PL (linear trend) * & 1.57 & 0.034 & $1.04-2.39$ \\
\hline PL (linear trend) ** & 1.37 & 0.10 & $0.94-1.99$ \\
\hline PL (linear trend) $* * *$ & 1.34 & 0.20 & $0.86-2.09$ \\
\hline Group = 1 & 1.34 & 0.63 & $0.40-4.52$ \\
\hline Group $=2$ & 2.61 & 0.09 & $0.86-7.93$ \\
\hline Group $=3$ & 3.77 & 0.016 & $1.28-11.07$ \\
\hline PL; Group = $1 *$ & 1.21 & 0.76 & $0.35-4.23$ \\
\hline PL; Group $=2 *$ & 2.30 & 0.16 & $0.72-7.35$ \\
\hline PL; Group = 3 * & 3.60 & 0.06 & $0.96-13.44$ \\
\hline PL ; Group = $1 * *$ & 1.24 & 0.73 & $0.36-4.23$ \\
\hline PL ; Group = $2 * *$ & 2.08 & 0.21 & $0.66-6.55$ \\
\hline PL ; Group $=3 * *$ & 2.40 & 0.15 & $0.73-7.92$ \\
\hline $\mathrm{PL} ;$ Group $=1 * * *$ & 1.19 & 0.78 & $0.34-4.14$ \\
\hline $\mathrm{PL} ; \mathrm{Group}=2 * * *$ & 1.78 & 0.35 & $0.53-5.94$ \\
\hline $\mathrm{PL} ;$ Group $=3 * * *$ & 2.30 & 0.25 & $0.56-9.50$ \\
\hline
\end{tabular}

$\mathrm{PL}=$ psychosis liability (group $=0$ : controls; group $=1$ : psychosis prone; group = 2: relatives; group $=3$ : patients)

* adjusted for age, gender and level of education, use of cannabis and other illicit drugs

** adjusted for general intelligence

***adjusted for age, gender, level of education, use of cannabis and other illicit drugs and general intelligence

When the inpatients were excluded from the sample, the association between JTC and delusions hardly changed ( $\mathrm{OR}=2.07 ; 95 \% \mathrm{Cl}: 0.80-5.29)$.

When the patients with RDC diagnoses other than narrow schizophrenia and schizo-affective disorder were excluded, the association between JTC and delusions grew stronger and more specific (OR = 3.13; 95\% Cl:\%: $1.40-7.00)$.

As the cut-off criterion of number of beads used to define JTC became progressively less stringent, the association between this selection and the dichotomized score on the delusions subscales from the PSE was also progressively weaker.

In order to examine any dose-response relationship between JTC\#1 and severity of delusions, the distribution of the non-zero scores on the delusions domain of the PSE was divided by its tertiles. Compared to those without delusions, the strength of the association increased with increasing levels of delusions, yielding a dose-response relationship (OR linear trend: $1.69 ; 95 \% \mathrm{Cl}: 1.18-2.43$; Table 3). When entered as three dummy variables for 
comparison with the reference category of no delusions, it reached significance for the delusions score in the highest tertile, even when adjusted for age, gender, level of education and use of cannabis and other illicit drugs (OR=4.95; 95\%Cl: $1.20-20.33)$. The association reduced but not nullified when general intelligence was added to the equation $(O R=3.49$; $95 \% \mathrm{Cl}: 0.74-16.42)$.

Table 3: Logistic regression with number of beads requested and level of delusions measured with the PSE (each of the tertiles of the scores $>0$ compared with no delusions). (Unadjusted odds ratios.)

\begin{tabular}{llll}
\hline JTC \& & \multicolumn{3}{c}{ JTC=1 } \\
PSE Delusions (tertiles) & $\mathrm{OR}$ & $\mathrm{p}$ & $95 \% \mathrm{Cl}$ \\
\cline { 2 - 4 } Linear trend & 1.69 & 0.004 & $1.18-2.43$ \\
$\mathbf{1}^{\text {st }}$ tertile & 1.43 & 0.560 & $0.43-4.73$ \\
$\mathbf{2}^{\text {nd }}$ tertile & 2.86 & 0.116 & $0.77-10.56$ \\
$\mathbf{3}^{\text {rd }}$ tertile & 5.00 & 0.010 & $1.48-16.88$ \\
\hline
\end{tabular}

Examining the association of each of the symptom domains of the SAPS and SANS and the scores on the CDSS with JTC\#1, only the association with the dichotomized score on the delusions subscale proved significant (see Table 4). After including all the subscale scores from the SAPS and SANS en CDSS in one multiple logistic regression model, the association with this delusion subscale score was the strongest by far, although not significant anymore (OR $=3.07 ; 95 \% \mathrm{Cl}: 0.88-10.75)$.

Table 4: Associations between JTC=1 and dichotomized scores on all symptom domains of the SAPS and SANS and depression on the CDSS (tertiles) (logistic regression).

\begin{tabular}{l|lll|lll}
\hline JTC $=1$ \& subscales SAPS/ SANS & $\mathbf{O R}^{*}$ & $\mathbf{p}^{*}$ & $\mathbf{9 5 \%} \mathbf{C I}$ & $\mathbf{O R}^{* *}$ & $\mathbf{p}^{* *}$ & $\mathbf{9 5 \%} \mathbf{C I} *$ \\
\hline Hallucinations & 2.04 & 0.092 & $0.89-4.68$ & 0.84 & 0.772 & $0.26-2.71$ \\
Delusions & 2.81 & 0.011 & $1.27-6.23$ & 3.07 & 0.079 & $0.88-10.75$ \\
Disorganisation & 1.31 & 0.469 & $0.63-2.73$ & 0.81 & 0.633 & $0.33-1.95$ \\
Formal thought disorder & 2.33 & 0.057 & $0.98-5.55$ & 1.65 & 0.329 & $0.60-4.52$ \\
& & & & & & \\
Apathy & 1.50 & 0.328 & $0.67-3.37$ & 0.90 & 0.848 & $0.31-2.62$ \\
$\begin{array}{l}\text { Anhedonia } \\
\text { Affective }\end{array}$ & 1.42 & 0.345 & $0.68-2.97$ & 1.14 & 0.759 & $0.50-2.56$ \\
Alogia & 0.97 & 0.964 & $0.34-2.81$ & 0.54 & 0.390 & $0.13-2.19$ \\
Attention & 1.12 & 0.886 & $0.22-5.67$ & 0.59 & 0.612 & $0.08-4.50$ \\
& 2.14 & 0.096 & $0.87-5.24$ & 2.03 & 0.209 & $0.67-6.11$ \\
Depression (tertiles) & & & & & & \\
\hline & 1.26 & 0.318 & $0.80-1.98$ & 1.09 & 0.724 & $0.65-1.85$ \\
\hline
\end{tabular}

*calculated in different models with JTC and one symptom domain at a time

** calculated in one equation with JTC and all symptom domains 


\section{Association between JTC and delusions and psychosis liability}

The association between JTC\#1 and the presence of delusions diminished when psychosis liability was brought into the equation (JTC\#1 and presence of delusions, OR: $1.64 ; 95 \% \mathrm{Cl}$ : 0.59 - 4.54; JTC\#1 and psychosis liability: OR: $1.4 ; 95 \% \mathrm{Cl}: 0.91-2.15)$.

Within each of the 3 groups, the association with JTC\#1 in participants without delusions was compared with the association with JTC\#1 in participants with delusions. In the patient group (coded 3 ) the association with JTC\#1 was stronger in the participants with delusions $(\mathrm{OR}=4.95,95 \% \mathrm{Cl}: 1.62-15.09)$ than in those without $(\mathrm{OR}=0.98,95 \% \mathrm{Cl}: 0.10-9.25)$. In both at risk groups, the associations with JTC\#1 were not significant.

\section{Association between JTC and general intelligence}

There was a significant association between JTC\#1 and general intelligence $(O R=0.79$; $95 \% \mathrm{Cl}: 0.64-0.98)$.

\section{Discussion}

The results show that there is a dose-response relationship in the association between JTC and psychosis liability. Controlling for age, gender, educational level and drugs only reduced the association by small amounts. Adjusting for general intelligence generally reduced the association and made it no longer statistically significant. There was also a significant association between JTC reasoning bias and having delusions, and a dose-response relationship between JTC\#1 -i.e. showing the highest possible and a priori hypothesised JTC reasoning bias- and severity of delusions, even when adjusted for age, gender and level of education. The association with delusions overlapped with the effect of psychosis liability. However, there was an interaction between psychosis liability and having delusions in their effect on JTC: no association with JTC\#1 was found for the patients without delusions, whereas the association was strong and significant in those with delusions, indicating that the association with delusions cannot be attributed fully to the effect of having a diagnosis of psychosis.

\section{Dimensions in schizophrenia and JTC.}

When the associations between JTC\#1 and each of the symptom domains of the SAPS/SANS and CDSS were considered independently, the association with delusions was the strongest, followed in order by the association with positive formal thought disorder, hallucinations, attention and depression. When controlled for each other in one equation, this ranking did not change much, except for the association between JTC\#1 and hallucinations, which became much weaker, suggesting that the association with hallucinations was indirectly occasioned by the strong association between hallucinations and delusions (Krabbendam et al., 2004). The association with the typical negative symptom domains (alogia, anhedonia, apathy, affective flattening) and behavioural disorganisation remained the weakest. 
The heterogeneous phenotype of schizophrenia has proven to be composed of separable, though correlated symptom factors that can also be observed in their relatives and participants with schizotypy, according to most factor analytic studies. Typically, a positive and a negative symptom factor is found, in addition to a disorganisation or a depressive factor (Lenzenweger \& Dworkin, 1996; Stefanis et al., 2002; Stuart, Pantelis, Klimidis, \& Minas, 1999) (G. Claridge, 1994; Gordon Claridge \& Beech, 1995; G. Claridge et al., 1996; Fanous et al., 2001; Faraone et al., 2000; M. Hanssen et al., 2003; Johns \& van Os, 2001; van Os et al., 2000; van Os et al., 2001). The findings in our study indicate that JTC is associated with the positive symptoms of delusions specifically, and to a much lesser extent and statistically imprecise with other positive symptoms (such as hallucinations) and with components of the disorganisational symptom factor (attention, formal thought disorder). The role of general intelligence and cognitive capacities in reasoning bias in delusions is poorly investigated. In other studies, no evidence was found for a role of memory impairment (Garety \& Freeman, 1999) and mixed evidence for the ability to process sequential information (Colbert \& Peters, 2002; Linney et al., 1998; Young \& Bentall, 1995). In our study, we found a significant association between JTC\#1 and general intelligence. General intelligence impacted on the association between JTC and schizophrenia by reducing its effect size and the statistical precision. However, this does not mean that JTC cannot be causally implicated in the cognitive liability to psychosis. Rather, the current findings may indicate that JTC and general intelligence are both independently associated with schizophrenia, or alternatively that JTC is a mediator in the association between general intelligence and schizophrenia. For example, a lower level of intelligence may lead to a jumping-to-conclusions cognitive style, which in turn may make someone vulnerable to develop delusional ideation.

\section{Trait or state}

The dose-response association between JTC and psychosis liability is in favour of the hypothesis that JTC has -at least in part- features of a trait reflecting liability for schizophrenia. The dose-response association between JTC and delusions indicates that JTC also has characteristics of a state, as it covaries with the level of delusions. The JTC reasoning bias could therefore be involved in the formation as well as in the maintenance of delusions.

It is a well-established finding that relatives of patients with schizophrenia are at higher risk for developing schizophrenia spectrum disorders and show more schizotypal signs and symptoms, which may be an attenuated expression of the trait (Kendler et al., 1993b). The present findings as well as previous studies suggest that psychological mechanisms associated with psychotic symptoms also seem to operate at lower levels of the continuum in these individuals (M. J. Green \& Phillips, 2004; Melissa J. Green, Williams, \& Davidson, 2003; Melissa J. Green, Williams, \& Davidson, 2001; Janssen, Krabbendam, Jolles, \& van Os, 2003; Krabbendam et al., 2001; Van Os et al., 1999). In previous studies, some of the proposed mechanisms in delusion formation and/ or maintenance were also found in 
relatives and delusion-prone individuals of the general population, notably the JTC reasoning bias (Colbert \& Peters, 2002; Linney et al., 1998) and the attentional bias related to social threatening social stimuli (Melissa J. Green et al., 2003; Melissa J. Green et al., 2001). Other mechanisms contributing to delusion formation and maintenance have features of a trait as well as a state, for example in alterations in theory of mind (Corcoran, Mercer, \& Frith, 1995; Frith \& Corcoran, 1996; Janssen et al., 2003; Wykes, Hamid, \& Wagstaff, 2001), or only features of a state, as is the case with attributional bias (Bentall, Corcoran, Howard, Blackwood, \& Kinderman, 2001; Bentall, Kinderman, \& Kaney, 1994). Apparently, psychological mechanisms associated with psychotic symptoms can have both state and trait-like features. However, the state-trait dichotomy in itself is somewhat problematic, and so is the inference that the difference between a trait or state determines whether a certain mechanism is involved in the formation or in the maintenance of delusions. Firstly, a factor with a trait quality can be a necessary but not yet sufficient condition to develop a symptom, and a covarying state quality does not add much information with regard to etiological mechanisms. So there may be other factors in operation that make the trait come to expression, just like a (genetic) predisposition can come to expression under certain conditions (!!! INVALID CITATION !!!; I. Myin-Germeys, L. Krabbendam, P. Delespaul, \& J. van Os, 2003; I. Myin-Germeys, L. Krabbendam, P. A. Delespaul, \& J. Van Os, 2003; Van Os \& Marcelis, 1998). Secondly, as Bentall stated, the assumption behind the dichotomous traitstate distinction is that abnormalities are either present prior to the emergence of symptoms (in which case they may play a causal role) or covary with symptoms (in which case they may be either part of the symptom-picture or epiphenomena) (Bentall, 1999). In fact, there is a larger range of possibilities in changes and interactions of qualities over time than just being stable or covarying together. It may be possible that one quality (for example JTC), increases over time, and at a certain point elicits the expression of another (for example delusions). In order to clarify this relationship, a longitudinal design with more measurements in time would be more suitable. The dichotomy between state and trait therefore seems to be artificial as it does not correspond to the way qualities are present in nature, and provides little information on causal or even temporal relationships. Taking these remarks into account, it seems unlikely that a single factor such as a JTC reasoning bias can be linked with either the formation or the maintenance of delusional beliefs. More likely, a dynamic interplay exists between delusional symptoms and cognitive processes. For example, it is possible that the cognitive processes of deluded patients are not dysfunctional under optimum environmental conditions but, because of their reciprocal influences on each other, are more easily "disturbed" by adverse events than those of individuals who never have delusional experiences (Bentall, 1999) (Van Os et al., 1998).

\section{Processes involved in JTC}

In recent paradigms of delusions, multifactorial models are proposed, in which changes in perceptual and cognitive processes, prior cultural conditioned beliefs, motivation and affect 
may play a part (Bentall et al., 2001; Freeman, Garety, Kuipers, Fowler, \& Bebbington, 2002; Garety \& Freeman, 1999; Garety et al., 2001).

The "jumping to conclusions" is in itself a complex phenomenon in which different underlying cognitive processes may be involved. Both our and previous studies have suggested that people with delusions who jump to conclusions show a data gathering bias, a tendency to seek less information to reach a decision (R. E. Dudley et al., 1997a; Garety \& Freeman, 1999; Linney et al., 1998). They also show a "disconfirmation bias": just as individuals are willing to accept a hypothesis on the basis of little evidence, they are also more ready to reject it on the basis of little potentially contradictory evidence (Garety \& Freeman, 1999; Garety, Hemsley, \& Wessely, 1991; Young \& Bentall, 1997). Furthermore, people with paranoid delusions also show a tendency to discard disconfirmatory evidence (Freeman et al., 2002). People with delusions and a JTC reasoning bias apparently do not show a probabilistic reasoning bias: their estimation of probabilities does not differ from other groups (R. E. Dudley et al., 1997a; Garety \& Freeman, 1999; Garety et al., 1991; Linney et al., 1998). Deluded patients also seemed to take random variation into account, in a variant of the beads task with base rate change (60:40 vs. $85: 15$ ). When emotionally salient material was used, the JTC reasoning bias increased (R. E. Dudley et al., 1997b; McGuire, Junginger, Adams, Burright, \& Donovick, 2001; Young \& Bentall, 1997). Furthermore, people with delusions show a high need for closure: they prefer a definite answer compared to indecisiveness and ambiguity(Bentall \& Swarbrick, 2003; Kruglanski, 1989; Kruglanski \& Webster, 1996). Evidence is mixed, however, as to whether this need for closure is associated with JTC (Bentall \& Swarbrick, 2003; Colbert \& Peters, 2002; R. E. J. Dudley \& Over, 2003).

Finally, it could be possible that in addition to a cognitive reasoning bias other factors such as impulse control, have an impact on the JTC bias. However, to our knowledge, no associations between impulse control and delusions or between impulse control and JTC have been reported. A previous study examining this issue concluded that the early responses do seem to reflect a reasoning bias, rather than impulsiveness (R. E. Dudley et al., 1997b).

\section{Limitations}

Statistical power was restricted due to small numbers in some cases, especially when examining dose-response relationships. For example, only 14 individuals of those jumping to conclusions after one bead had delusions, and in the relatives and high schizotypy group there were only 3 such individuals in each group.

Although subclinical phenotypes were investigated, we used psychometric instruments developed for clinical use in order to assess the presence and severity of delusions and other psychotic symptoms (SAPS/SANS/PSE). However, it has been shown in earlier work that clinical instruments such as the BPRS can be suited for the assessment of subclinical 
phenomena in the general population(M. Hanssen et al., 2005; Krabbendam, Myin-Germeys, Hanssen, \& van Os, 2005).

JTC was associated with general intelligence. Controlling for general intelligence reduced the critical associations below level of statistical significance. In order to determine the character of the relationship between general intelligence, JTC and delusions, and in order to examine whether more specific cognitive domains, such as general reasoning, are responsible for the association with general intelligence, future studies using a broader range of cognitive tests should be carried out.

The data in this study come from a snapshot comparison between groups, lacking the variable "time", which is useful in discriminating between a trait and state quality. For example, our study does not supply information on how changes in JTC and changes in delusions are related over time. Furthermore, although a measurement of psychotic symptoms during last week as well as lifetime was available, only four participants reported having had delusions lifetime, but not in the past week, which may suggest that participants were prone to report recent experience when asked for lifetime experiences.

In conclusion, we showed that there is a dose-response relationship between JTC and psychosis liability and between JTC and the severity of delusions, partly overlapping with the association between JTC and general intelligence. We argued that the manifestation of delusions is the result of a dynamic interplay between JTC and other factors. JTC seems correlated with the presence of delusions, and to a lesser extent with other positive symptoms and with the disorganisational symptom factor of schizophrenia.

Further research with a similar but longitudinal design in which more realistic situations, disconfirmation bias, need for closure, emotional salience and meta-cognition is brought into the model, is needed for a better understanding of the formation and maintenance of delusions, which may eventually lead to targeted cognitive-behavioural interventions. 


\section{References}

Addington, D., Addington, J., \& Maticka-Tyndale, E. (1993a). Assessing depression in schizophrenia: the Calgary Depression Scale. Br J Psychiatry Suppl(22), 39-44.

Addington, D., Addington, J., \& Maticka-Tyndale, E. (1993b). Rating depression in schizophrenia. A comparison of a self-report and an observer report scale. J Nerv Ment Dis, 181(9), 561-565.

Addington, D., Addington, J., \& Maticka-Tyndale, E. (1994). Specificity of the Calgary Depression Scale for schizophrenics. Schizophr Res, 11(3), 239-244.

Andreasen, N. (1983). Scale for assessment of negative symptoms (SANS). Iowa City, IA: University of lowa.

Andreasen, N. C. (1982). Negative symptoms in schizophrenia. Definition and reliability. Arch Gen Psychiatry, 39(7), 784-788.

Andreasen, N. C. (1984). Scale for the assessment of positive symptoms (SAPS). lowa City, IA: University of lowa.

Baron, M., Gruen, R., Rainer, J. D., Kane, J., Asnis, L., \& Lord, S. (1985). A family study of schizophrenic and normal control probands: implications for the spectrum concept of schizophrenia. Am J Psychiatry, 142(4), 447-455.

Bentall, R. P. (1999). Commentary on Garety \& Freeman. III: Three psychological investigators and an elephant. Br J Clin Psychol, 38 ( Pt 3), 323-327.

Bentall, R. P., Corcoran, R., Howard, R., Blackwood, N., \& Kinderman, P. (2001). Persecutory delusions: a review and theoretical integration. Clin Psychol Rev, 21(8), 1143-1192.

Bentall, R. P., Kinderman, P., \& Kaney, S. (1994). The self, attributional processes and abnormal beliefs: towards a model of persecutory delusions. Behav Res Ther, 32(3), 331-341.

Bentall, R. P., \& Swarbrick, R. (2003). The best laid schemas of paranoid patients: autonomy, sociotropy and need for closure. Psychol Psychother, 76(Pt 2), 163-171.

Broome, M., Brett, C., Johns, L. C., Woolley, J., Peters, E., Garety, P., \& McGuire, P. K. (2003). Reasoning styles and delusions in early psychosis. Schizophrenia Research, 60(1, Supplement 1), 12-13.

Brown, G. W., Andrews, B., Harris, T., Adler, Z., \& Bridge, L. (1986). Social support, self-esteem and depression. Psychol Med, 16(4), 813-831.

Brown, G. W., Bifulco, A., \& Andrews, B. (1990). Self-esteem and depression. IV. Effect on course and recovery. Soc Psychiatry Psychiatr Epidemiol, 25(5), 244-249.

Claridge, G. (1994). Single indicator of risk for schizophrenia: probable fact or likely myth? Schizophr Bull, 20(1), 151-168.

Claridge, G., \& Beech, T. (1995). Fully and quasi-dimensional constructions of schizotypy. In T. E. Lencz, et al. \& A. E. Raine (Eds.), Schizotypal personality (Vol. xv, 510 pp., pp. pp.192 216). New York, NY, US:: Cambridge University Press.

Claridge, G., McCreery, C., Mason, O., Bentall, R., Boyle, G., Slade, P., \& Popplewell, D. (1996). The factor structure of "schizotypal" traits: A large replication study. British Journal of Clinical Psychology, 35(1), 103-115.

Colbert, S. M., \& Peters, E. R. (2002). Need for closure and jumping-to-conclusions in delusion-prone individuals. J Nerv Ment Dis, 190(1), 27-31.

Conway, C. R., Bollini, A. M., Graham, B. G., Keefe, R. S., Schiffman, S. S., \& McEvoy, J. P. (2002). Sensory acuity and reasoning in delusional disorder. Compr Psychiatry, 43(3), 175-178.

Corcoran, R., Mercer, G., \& Frith, C. D. (1995). Schizophrenia, symptomatology and social inference: investigating "theory of mind" in people with schizophrenia. Schizophr Res, 17(1), 5-13.

De Bie, S. E. (1987). Standaardvragen 1987: Voorstellen voor uniformering van vraagstellingen naar achtergrondkenmerken en interviews. [Standard questions 1987: proposal for uniformization of questions regarding background variables and interviews] (2nd ed. ed.). Leiden.

Dent, J., \& Teasdale, J. D. (1988). Negative cognition and the persistence of depression. J Abnorm Psychol, 97(1), 29-34. 
Dudley, R. E., John, C. H., Young, A. W., \& Over, D. E. (1997a). The effect of self-referent material on the reasoning of people with delusions. Br J Clin Psychol, 36 ( Pt 4), 575-584.

Dudley, R. E., John, C. H., Young, A. W., \& Over, D. E. (1997b). Normal and abnormal reasoning in people with delusions. Br J Clin Psychol, 36 ( Pt 2), 243-258.

Dudley, R. E. J., \& Over, D. E. (2003). People with Delusions Jump to Conclusions: A Theoretical Account of Research Findings on the Reasoning of People with Delusions. Clinical Psychology and Psychotherapy, 10(5), 263-274.

Fanous, A., Gardner, C., Walsh, D., \& Kendler, K. S. (2001). Relationship between positive and negative symptoms of schizophrenia and schizotypal symptoms in nonpsychotic relatives. Arch Gen Psychiatry, 58(7), 669-673.

Faraone, S. V., Kremen, W. S., Lyons, M. J., Pepple, J. R., Seidman, L. J., \& Tsuang, M. T. (1995). Diagnostic accuracy and linkage analysis: how useful are schizophrenia spectrum phenotypes? Am J Psychiatry, 152(9), 1286-1290.

Faraone, S. V., Seidman, L. J., Kremen, W. S., Toomey, R., Pepple, J. R., \& Tsuang, M. T. (2000). Neuropsychologic functioning among the nonpsychotic relatives of schizophrenic patients: the effect of genetic loading. Biol Psychiatry, 48(2), 120-126.

Fear, C. F., \& Healy, D. (1997). Probabilistic reasoning in obsessive-compulsive and delusional disorders. Psychol Med, 27(1), 199-208.

Freeman, D., Garety, P. A., Kuipers, E., Fowler, D., \& Bebbington, P. E. (2002). A cognitive model of persecutory delusions. Br J Clin Psychol, 41(Pt 4), 331-347.

Frith, C. D., \& Corcoran, R. (1996). Exploring 'theory of mind' in people with schizophrenia. Psychol Med, 26(3), 521-530.

Garety, P. A., \& Freeman, D. (1999). Cognitive approaches to delusions: a critical review of theories and evidence. Br J Clin Psychol, 38 ( Pt 2), 113-154.

Garety, P. A., Hemsley, D. R., \& Wessely, S. (1991). Reasoning in deluded schizophrenic and paranoid patients. Biases in performance on a probabilistic inference task. J Nerv Ment Dis, 179(4), 194-201.

Garety, P. A., Kuipers, E., Fowler, D., Freeman, D., \& Bebbington, P. E. (2001). A cognitive model of the positive symptoms of psychosis. Psychol Med, 31(2), 189-195.

Gilvarry, C. M., Russell, A., Jones, P., Sham, P., Hemsley, D., \& Murray, R. M. (2001). Verbal fluency in patients with schizophrenia and affective psychoses and their first-degree relatives. Psychol Med, 31(4), 695-704.

Green, M. F., \& Nuechterlein, K. H. (1999). Backward masking performance as an indicator of vulnerability to schizophrenia. Acta Psychiatr Scand Suppl, 395, 34-40.

Green, M. J., \& Phillips, M. L. (2004). Social threat perception and the evolution of paranoia. Neurosci Biobehav Rev, 28(3), 333-342.

Green, M. J., Williams, L. M., \& Davidson, D. (2003). Visual scanpaths and facial affect recognition in delusion-prone individuals: Increased sensitivity to threat? Cognitive Neuropsychiatry, 8(1), 19-41.

Green, M. J., Williams, L. M., \& Davidson, D. J. (2001). Processing of threat-related affect is delayed in delusion-prone individuals. British Journal of Clinical Psychology, 4O(2), 157-165.

Hanssen, M., Krabbendam, L., Vollema, M., Delespaul, P., \& Van Os, J. (2005). Evidence for Instrument and Family-Specific Variation of Subclinical Psychosis Dimensions in the General Population. Journal of Abnormal Psychology, in press.

Hanssen, M., Peeters, F., Krabbendam, L., Radstake, S., Verdoux, H., \& van Os, J. (2003). How psychotic are individuals with non-psychotic disorders? Soc Psychiatry Psychiatr Epidemiol, 38(3), 149-154.

Hanssen, M. S., Bijl, R. V., Vollebergh, W., \& van Os, J. (2003). Self-reported psychotic experiences in the general population: a valid screening tool for DSM-III-R psychotic disorders? Acta Psychiatr Scand, 107(5), 369-377.

Huq, S. F., Garety, P. A., \& Hemsley, D. R. (1988). Probabilistic judgements in deluded and nondeluded subjects. Q J Exp Psychol A, 40(4), 801-812. 
Janssen, I., Krabbendam, L., Jolles, J., \& van Os, J. (2003). Alterations in theory of mind in patients with schizophrenia and non-psychotic relatives. Acta Psychiatr Scand, 108(2), 110-117.

John, C. H., \& Dodgson, C. (1994). Inductive reasoning in delusional thought. Journal of mental health $U K, 3,31-49$.

Johns, L. C., \& van Os, J. (2001). The continuity of psychotic experiences in the general population. Clin Psychol Rev, 21(8), 1125-1141.

Keefe, R. S., Silverman, J. M., Roitman, S. E., Harvey, P. D., Duncan, M. A., Alroy, D., . . Mohs, R. C. (1994). Performance of nonpsychotic relatives of schizophrenic patients on cognitive tests. Psychiatry Res, 53(1), 1-12.

Kendler, K. S., McGuire, M., Gruenberg, A. M., O'Hare, A., Spellman, M., \& Walsh, D. (1993a). The Roscommon Family Study. I. Methods, diagnosis of probands, and risk of schizophrenia in relatives. Arch Gen Psychiatry, 50(7), 527-540.

Kendler, K. S., McGuire, M., Gruenberg, A. M., O'Hare, A., Spellman, M., \& Walsh, D. (1993b). The Roscommon Family Study. III. Schizophrenia-related personality disorders in relatives. Arch Gen Psychiatry, 50(10), 781-788.

Krabbendam, L., Marcelis, M., Delespaul, P., Jolles, J., \& van Os, J. (2001). Single or multiple familial cognitive risk factors in schizophrenia? Am J Med Genet, 105(2), 183-188.

Krabbendam, L., Myin-Germeys, I., Hanssen, M., Bijl, R. V., de Graaf, R., Vollebergh, W., . . van Os, J. (2004). Hallucinatory experiences and onset of psychotic disorder: evidence that the risk is mediated by delusion formation. Acta Psychiatr Scand, 110(4), 264-272.

Krabbendam, L., Myin-Germeys, I., Hanssen, M., \& van Os, J. (2005). Familial covariation of the subclinical psychosis phenotype and verbal fluency in the general population. Schizophr Res, 74(1), 37-41.

Kremen, W. S., Seidman, L. J., Pepple, J. R., Lyons, M. J., Tsuang, M. T., \& Faraone, S. V. (1994). Neuropsychological risk indicators for schizophrenia: a review of family studies. Schizophr Bull, 20(1), 103-119.

Kruglanski, A. W. (1989). Lay epistemics and human knowledge: Cognitive and motivational bases. New York: Plenum.

Kruglanski, A. W., \& Webster, D. M. (1996). Motivated closing of the mind: "seizing" and "freezing". Psychol Rev, 103(2), 263-283.

Lenzenweger, M. F., \& Dworkin, R. H. (1996). The dimensions of schizophrenia phenomenology. Not one or two, at least three, perhaps four. Br J Psychiatry, 168(4), 432-440.

Linney, Y. M., Peters, E. R., \& Ayton, P. (1998). Reasoning biases in delusion-prone individuals. Br J Clin Psychol, 37 ( Pt 3), 285-302.

Luteijn, F., \& van der Ploeg, F. (1983). Handleiding Groninger Intelligentietest (GIT) [Manual Groningen Intelligence Test]. Lisse, The Netherlands: Swets \& Zeitlinger.

McGuffin, P., Farmer, A., \& Harvey, I. (1991). A polydiagnostic application of operational criteria in studies of psychotic illness. Development and reliability of the OPCRIT system. Arch Gen Psychiatry, 48(8), 764-770.

McGuire, L., Junginger, J., Adams, S. G., Jr., Burright, R., \& Donovick, P. (2001). Delusions and delusional reasoning. J Abnorm Psychol, 110(2), 259-266.

Moritz, S., \& Woodward, T. S. (2005). Jumping to conclusions in delusional and non-delusional schizophrenic patients. Br J Clin Psychol, 44(Pt 2), 193-207.

Mortimer, A. M., Bentham, P., McKay, A. P., Quemada, I., Clare, L., Eastwood, N., \& McKenna, P. J. (1996). Delusions in schizophrenia: A phenomenological and psychological exploration. Cognitive Neuropsychiatry, 1(4), 289-303.

Myin-Germeys, I., Krabbendam, L., Delespaul, P., \& van Os, J. (2003). Can cognitive deficits explain differential sensitivity to life events in psychosis? Soc Psychiatry Psychiatr Epidemiol, 38(5), 262-268.

Myin-Germeys, I., Krabbendam, L., Delespaul, P. A., \& Van Os, J. (2003). Do life events have their effect on psychosis by influencing the emotional reactivity to daily life stress? Psychol Med, 33(2), 327-333. 
Peters, E., \& Garety, P. (2005). Cognitive functioning in delusions: A longitudinal analysis. Behav Res Ther.

Peters, E. R. (2003). Cognitive biases involved in the formation of delusional beliefs. Schizophrenia Research, 60(1 (Supplement 1)), 178.

Peters, E. R., Day, S., \& Garety, P. (1997). From preconscious to conscious processing--where does the abnormality lie in delusions? Schizophrenia Research, 24(1-2), 120.

Peters, E. R., \& Garety, P. A. (1999). A longitudinal study of cognitive abnormalities in delusions at different levels of information processing. Schizophrenia Research, 36, 180.

Phillips, L. D., \& Edwards, W. (1966). Conservatism in a simple probabilistic inference task. Journal of Experimental Psychology, 72, 346-354.

Schurhoff, F., Szoke, A., Meary, A., Bellivier, F., Rouillon, F., Pauls, D., \& Leboyer, M. (2003). Familial aggregation of delusional proneness in schizophrenia and bipolar pedigrees. Am J Psychiatry, 160(7), 1313-1319.

Shedlack, K., Lee, G., Sakuma, M., Xie, S. H., Kushner, M., Pepple, J., . . DeLisi, L. E. (1997). Language processing and memory in ill and well siblings from multiplex families affected with schizophrenia. Schizophr Res, 25(1), 43-52.

Smeets, R., \& Dingemans, P. M. A. J. (1993). Composite International Diagnostic Interview (CIDI) Versie 1.1. Amsterdam/Geneva: World Health Organisation.

Spitzer, R. L., Endicott, J., \& Robins, E. (1978). Research diagnostic criteria: rationale and reliability. Arch Gen Psychiatry, 35(6), 773-782.

StataCorporation. (1984-2009). STATA Statistical Software: Release 11.0. Texas: College Station.

Stefanis, N. C., Hanssen, M., Smirnis, N. K., Avramopoulos, D. A., Evdokimidis, I. K., Stefanis, C. N., . . Van Os, J. (2002). Evidence that three dimensions of psychosis have a distribution in the general population. Psychol Med, 32(2), 347-358.

Stuart, G. W., Pantelis, C., Klimidis, S., \& Minas, I. H. (1999). The three-syndrome model of schizophrenia: meta-analysis of an artefact. Schizophr Res, 39(3), 233-242.

Tien, A. Y. (1991). Distributions of hallucinations in the population. Social Psychiatry and Psychiatric Epidemiology, 26(6), 287-292.

van Os, J., Hanssen, M., Bijl, R. V., \& Ravelli, A. (2000). Strauss (1969) revisited: a psychosis continuum in the general population? Schizophr Res, 45(1-2), 11-20.

van Os, J., Hanssen, M., Bijl, R. V., \& Vollebergh, W. (2001). Prevalence of psychotic disorder and community level of psychotic symptoms: an urban-rural comparison. Arch Gen Psychiatry, 58(7), 663-668.

Van Os, J., Jones, P., Sham, P., Bebbington, P., \& Murray, R. M. (1998). Risk factors for onset and persistence of psychosis. Soc Psychiatry Psychiatr Epidemiol, 33(12), 596-605.

Van Os, J., \& Marcelis, M. (1998). The ecogenetics of schizophrenia: a review. Schizophr Res, 32(2), 127-135.

Van Os, J., Verdoux, H., Maurice-Tison, S., Gay, B., Liraud, F., Salamon, R., \& Bourgeois, M. (1999). Self-reported psychosis-like symptoms and the continuum of psychosis. Soc Psychiatry Psychiatr Epidemiol, 34(9), 459-463.

Verdoux, H., \& van Os, J. (2002). Psychotic symptoms in non-clinical populations and the continuum of psychosis. Schizophr Res, 54(1-2), 59-65.

Wechsler, D. (1981). Wechsler Adult Intelligence Scale-Revised. New York: Psychological Corporation.

Whalley, H. C., Simonotto, E., Flett, S., Marshall, I., Ebmeier, K. P., Owens, D. G., . . Lawrie, S. M. (2004). fMRI correlates of state and trait effects in subjects at genetically enhanced risk of schizophrenia. Brain, 127(Pt 3), 478-490.

Wing, J. K., Cooper, J. E., \& Sartorius, N. (1974). Measurement and classification of psychiatric symptoms; An instruction manual for the PSE and Catego program. Oxford, England: Cambridge U Press.

Wykes, T., Hamid, S., \& Wagstaff, K. (2001). Theory of mind and executive functions in the nonpsychotic siblings of patients with schizophrenia. Schizophrenia Research, 49(Suppl.), 148149. 
Young, H. F., \& Bentall, R. P. (1995). Hypothesis testing in patients with persecutory delusions: comparison with depressed and normal subjects. Br J Clin Psychol, 34 ( Pt 3), 353-369.

Young, H. F., \& Bentall, R. P. (1997). Probabilistic reasoning in deluded, depressed and normal subjects: effects of task difficulty and meaningful versus non-meaningful material. Psychol Med, 27(2), 455-465. 
Chapter 5

A common plague of humanity is the fallacy of attributing to one cause what is due to many causes.

Alfred Korzybski 


\section{Chapter}

General Discussion 

The aim of this thesis was to investigate the relation between psychosis and obsessivecompulsive disorder. Though the notion of comorbidity by definition implies the existence of nosological entities, it was argued in the introduction that an appropriate design for the research on the co-occurrence, overlap and mutual impact of the psychosis and OCD phenotype should account for (1) symptom dimensions, (2) a continuous distribution of the extended phenotype, including subclinical phenomena in the general population and (3) longitudinal follow-up over time (Klein \& Riso, 1993; Leckman, Bloch, \& King, 2009; MataixCols, Rosario-Campos, \& Leckman, 2005; McGorry, Bell, Dudgeon, \& Jackson, 1998; van Os \& Kapur, 2009).

\section{Quantitative variation of expression of psychosis and OCD}

In this thesis, it was shown that both phenotypes can be found below the diagnostic threshold in the general population. The prevalence of subclinical expressions of OCD as well as psychosis in the general population is more common than that of clinical symptoms in clinical samples (chapter 1, chapter 2). These findings are in line with population-based cross-sectional studies convincingly demonstrating that the OCD and psychosis phenotypes show a continuous distribution well beyond the diagnostic threshold (Angst et al., 2004; Bijl, Ravelli, \& van Zessen, 1998; Blom, Hagestein-de Bruijn, de Graaf, ten Have, \& Denys, 2011; de Bruijn, Beun, de Graaf, Ten Have, \& Denys, 2010; Fullana, Mataix-Cols, et al., 2009; Kendler, Gallagher, Abelson, \& Kessler, 1996; Valleni-Basile et al., 1994; van Os, 2003). Attenuated expressions of experiences qualitatively resembling the symptom dimensions of psychosis (positive, negative and affective symptom dimension) and OCD

(sexual/aggressive/blasphemous, contamination and washing, symmetry and order and hoarding) are observed in otherwise "healthy" subjects of the general population (GarcíaSoriano, Belloch, Morillo, \& Clark, 2011; Hanssen, Krabbendam, Vollema, Delespaul, \& Van Os, 2006; Krabbendam, Myin-Germeys, De Graaf, et al., 2004).

In addition and more importantly, in chapter 2, 3 and 4 of this thesis, it was univocally shown that the psychosis and OCD phenotype co-occur at a higher than chance rate in the lower grade expressions of the phenotype. The psychosis as well as the OCD phenotype clusters in families. As expected, when both phenotypes co-occur, familial clustering is still found for the OCD as well as for the psychosis phenotype. In addition, the expression of both phenotypes appeared to impact on each other. The association of the cross-sectional cooccurrence of the OCD and psychosis phenotype at subclinical level in the general population grows stronger as their expression is more pronounced, showing a doseresponse relationship. The cross-sectional association was symmetrical: psychotic symptoms were associated with OCS and vice versa.

Previous research on the comorbidity of OCD and psychosis has been inconsistent, in part because it was hampered by the fuzziness and poor validity of the concepts, and by methodological problems consequent to patient status and treatment. An obstacle specific for the research of OCS in psychosis is that most subjects with psychotic disorder are exposed to antipsychotic agents that have been shown to elicit or aggravate obsessivecompulsive symptoms, though findings are still divergent (Sareen et al., 2004; Scheltema Beduin et al., 2012; Schirmbeck et al., 2013; Ulhaq \& Abba-Aji, 2012). In this thesis, these methodological shortcomings have been largely overcome by including subjects with expression of the phenotype below the diagnostic threshold and relatives of patients, who have an enhanced genetic liability, without having a patient status themselves, not receiving treatment. 


\section{Quantitative variation of the expression of psychosis and OCD over time}

Longitudinal studies are necessary to unravel the relevance of sub-clinical experiences for the later development of clinical disorder. For psychosis, it has been shown that subclinical psychotic experiences, often emerging in adolescence, increase the likelihood of developing a psychotic disorder in later life. Though the majority of the subthreshold psychotic symptoms are transitory (Chapman, Chapman, Kwapil, Eckblad, \& Zinser, 1994; Hanssen, Bak, Bijl, Vollebergh, \& van Os, 2005; Poulton et al., 2000), in case of exposure to additional risk factors, such as cannabis use, childhood trauma and urban environment, the usually transient phenomena become more persistent (Cougnard et al., 2007). Persistence of subclinical symptoms increases the risk of transition to psychotic disorder, with distress and disability and need for care. The sequence as a whole has been descriptively referred to as the proneness-persistence-impairment model (Dominguez, Wichers, Lieb, Wittchen, \& van Os, 2011). Similar trajectories are seen in longitudinal cohort studies of the extended OCD phenotype, some of which cover periods of up to 4 decades. Mild subclinical symptoms are common in the general population, tend to emerge in childhood and often are transient (Evans et al., 1997; Fullana, Vilagut, et al., 2009; Valleni-Basile et al., 1994; Valleni-Basile et al., 1996). Longer duration of symptoms is a significant predictor of a longer and less favorable course (Dell'osso et al., 2013; Eisen et al., 2013; Stewart et al., 2004). Among the clinical relevant symptoms that recover, a substantial proportion does so in the first year(s) after onset (Michael H. Bloch et al., 2013; Marcks, Weisberg, Dyck, \& Keller, 2011; Skoog \& Skoog, 1999). Comorbid anxiety and affective disorders, particularly bipolar disorder, are associated with worse outcome (Anholt et al., 2011; M. H. Bloch et al., 2009; Eisen et al., 2010; Fineberg, Hengartner, et al., 2013b; Fineberg, Hengartner, Bergbaum, Gale, Gamma, et al., 2013; Fullana, Mataix-Cols, et al., 2009; Klein Hofmeijer-Sevink et al., 2013; Skoog \& Skoog, 1999; Thomsen \& Mikkelsen, 1995; Timpano, Rubenstein, \& Murphy, 2012). In this thesis, we examined whether the co-occurrence of both psychotic and OC subclinical symptoms would increase the risk for development of either psychotic or OC disorder. In chapter 2, it was shown that the risk for persistence of psychotic symptoms and the risk for transition of psychotic symptoms to psychotic disorder were considerably increased by the co-occurrence of (subclinical) OCS. Existing psychotic symptoms were much more likely to persist over a period of 2 years in the presence of OCS then without OCS (risk difference: $47 \%$ ). The risk for transition of psychotic symptoms to a clinical psychotic disorder in the next two years likewise was much higher in the presence of OCS (risk difference: 40\%). This association appeared to be directional: OCS predicted later psychotic symptoms and psychotic disorder, again with a dose response relationship, but not the other way around: psychotic symptoms did not predict later OCD. Given the similar prevalence of both disorders, these findings seem to be in line with the consistent reports of higher rates of cooccurrence of OCD in psychosis than of psychosis in OCD phenotype, at level of the disorder (Bottas, Cooke, \& Richter, 2005; L. de Haan, Dudek-Hodge, Verhoeven, \& Denys, 2009), as well as at subthreshold level (Bland, Newman, \& Orn, 1987; Karno, Golding, Sorenson, \& Burnam, 1988; Kolada, Bland, \& Newman, 1994). Yet, this apparent direction of the longitudinal association in the NEMESIS study may in part be explained by relative underreporting of OCD outcome and by the limited sample size. 
These findings allow two conclusions. First, OCS as well as positive psychotic experiences can be seen as the behavioral expression of vulnerability with a similar broad distribution in the general population. The vulnerabilities for both disorders apparently show overlap, particularly for obsessions and positive psychotic symptoms. Second, (subclinical) OC symptoms may act as a risk factor for persistence of psychotic symptoms and impairment to a clinical psychotic state.

\section{Comorbidity between OCD and psychosis: overlapping symptom dimensions?}

We have shown that the psychosis and OCD phenotype co-occur at a higher than chance rate in the lower grade expressions of the phenotype. The question then arises whether this may be due to overlap in symptom dimensions or in specific associations between separate symptom dimensions related to the two phenotypes.

Both the psychosis and OCD phenotype are heterogeneous and consisting of separable symptom dimensions. In the psychosis phenotype, 3 to 5 factors provide the best fit (van der Gaag et al., 2006). Typically, a positive, negative and depressive symptom factor can be distinguished, each with a distribution in the general population (Fanous, Gardner, Walsh, \& Kendler, 2001; Stefanis et al., 2002; Vollema \& Hoijtink, 2000). For OCD, 4 factors provide the best fit: (i) forbidden thoughts (sexual/aggressive/blasphemous), (ii) contamination and cleaning, (iii) symmetry and order and (iv) hoarding (García-Soriano et al., 2011; Leckman et al., 2009).

A specific association between OCS and positive symptoms of psychosis is quite consistently found (Cunill, Castells, \& Simeon, 2009; Kayahan, Ozturk, Veznedaroglu, \& Eraslan, 2005; Lysaker et al., 2000), as is an association between OCS and affective symptoms (Lieuwe de Haan, Sterk, Wouters, \& Linszen, 2011; Nestadt et al., 2001). Reports on the association of OCS with the negative symptom dimension are mixed (Lysaker, Whitney, \& Davis, 2006; Nechmad et al., 2003; Owashi, Ota, Otsubo, Susa, \& Kamijima, 2010; Poyurovsky et al., 2008; Sevincok, Akoglu, \& Arslantas, 2006; Tibbo, Kroetsch, Chue, \& Warneke, 2000). Most of the data to date on the association of expression of specific symptom dimensions of both disorders are based on clinical samples, thus involving potential biases. Similar to the findings in clinical samples, we found OCS to be associated with the positive but not negative symptom dimensions of psychosis at subclinical as well as clinical level of expression, even when adjusted for the expression of affective symptoms (chapter 2, 3 and 4). The affective symptom dimension also has a special role in the co-occurrence of both phenotypes. Affective symptoms are highly prevalent in OCD (Denys, Tenney, van Megen, de Geus, \& Westenberg, 2004; LaSalle et al., 2004; Mancebo et al., 2008; Nestadt et al., 2001; Quarantini et al., 2011; Spinella, 2005) as well as in psychosis (Bora, Yucel, Fornito, Berk, \& Pantelis, 2008; Brockington, Kendell, \& Wainwright, 1980; Brockington, Kendell, Wainwright, Hillier, \& Walker, 1979; Peralta \& Cuesta, 2009; Taylor, 1992), at clinical as well as subclinical level of expression of each of both phenotypes (Fineberg, Hengartner, et al., 2013a; Klaassen, Heins, Luteijn, van der Gaag, \& van Beveren, 2013; Krabbendam, Myin-Germeys, De Graaf, et al., 2004; Ruscio, Stein, Chiu, \& Kessler, 2010; van Rossum, Dominguez, Lieb, Wittchen, \& van Os, 2011). In OCD, depressive symptoms showed an association with obsessions rather than compulsions in some studies (Ricciardi \& McNally, 1995; Timpano et al., 2012), whereas in psychosis, they show an association with positive symptoms (Cuesta, Peralta, Gil, \& Artamendi, 2003; Krabbendam, Myin-Germeys, De Graaf, et al., 2004; Rössler 
et al., 2011; van Rossum et al., 2011) as well as negative symptoms (Klaassen et al., 2013; Peralta \& Cuesta, 2009; Toomey, Faraone, Simpson, \& Tsuang, 1998).

These findings may reflect phenomenological overlap between specific symptom dimensions. For example the conceptualization of delusions and obsessions may be overlapping. A belief or a thought held with strong conviction with the properties of an obsession is distinguished from a delusion mainly by degree of resistance and level of insight, i.e. the notion that the thought is the product from one's own mind and is not experienced as external reality. As the notion of insight seems to have a pivotal role in the transition of OCS to psychosis, it is further discussed later in this chapter.

On the other hand, the data also suggest that specific associations exist between separate symptom dimensions of both phenotypes, possibly fueling the co-occurrence. More specifically, co-occurring symptom dimensions may impact on each other over time, even below the threshold for clinical disorder. Obviously, if the expression of one symptom dimension interferes with mentation and behavior, the expression of more symptom dimensions will likely cause more such interference, not necessarily implicating an impact on each other. However, the dose-response relationship of the association between OCS severity and positive psychotic symptom severity as well as the big risk differences in longitudinal associations are indicative for a true impact on each other. Such a mutual impact is particularly relevant if the co-occurrence of the symptom dimensions in question is high, as is the case with OCS and positive psychotic symptoms. Given the indications for a shared etiological, possibly genetic liability, the association of $\mathrm{OC}$ and positive psychotic symptoms dimensions may reflect the clustering of behavioral expression of vulnerabilities with partial overlap in distribution.

Thus, the data may represent different longitudinal individual trajectories of course of symptoms and symptom dimensions. While it may be possible that for some subjects an obsessive-compulsive symptom transforms into a psychotic symptom as proposed as long as a century ago by Bleuler and later by Gordon, the data described in this thesis show that obsessive-compulsive symptoms impact on the course of co-existing psychotic symptoms over time.

\section{Insight and cognitive functioning}

As mentioned earlier, insight seems to have a pivotal role in the "transit zone" from obsession to delusion. Level of insight in OCD has been shown to be broadly distributed along a continuum, ranging from cases in which subjects clearly recognize the excessiveness and/or senselessness of their concerns, to others in which subjects consider their obsessions as realistic and reasonable(Eisen \& Rasmussen, 1993; Insel \& Akiskal, 1986; Ito, de Araujo, Hemsley, \& Marks, 1995; Rachman \& Hodgson, 1980; R. Stern \& Cobb, 1978). Level of insight has been shown highly correlated with degree of resistance (Catapano, Sperandeo, Perris, Lanzaro, \& Maj, 2001), giving support to the idea that when resistance becomes zero in a subject with poor insight, the content of the thought is accepted and the obsession can turn into a delusion (Solyom, DiNicola, Phil, Sookman, \& Luchins, 1985). Further support for the role of poor insight in $O C D$ as a vulnerability factor for developing psychotic symptoms comes from a study by Catapano et al., showing an association between poor insight in subjects with $O C D$ and a higher rate of psychotic disorders in their first-degree relatives (Catapano et al., 2001). The manifest role of insight has yielded regained research interest in 
the topic, more particular in identifying neurocognitive correlates and neurobiological basis of insight.

Despite inconsistent findings on insight in psychosis in earlier research, a meta-analysis of 35 studies found a significant mean correlation between insight ratings and executive functioning, more specific, impairment in set-shifting and error monitoring (Aleman, Agrawal, Morgan, \& David, 2006). In OCD, it was similarly shown that poor insight was associated with executive functions, particularly conflict resolution/response inhibition, verbal fluency and verbal recall (Catapano et al., 2001; Fontenelle, 2012; Kashyap, Kumar, Kandavel, \& Reddy, 2012). Thus, the neuropsychological deficits correlating with poor insight in $O C D$ are similar to those in psychosis.

Numerous studies comparing the neurocognitive functions in patients with comorbid psychosis and OCS versus patients with psychosis without OCS, have yielded mixed findings, with some suggesting no difference (Hwang, Morgan, \& Losconzcy, 2000; Lysaker, Bryson, Marks, Greig, \& Bell, 2002; Lysaker et al., 2000; Tiryaki \& Özkorumak, 2010), and others showing worse performance on memory and executive functioning tasks in patients with comorbid psychosis and OCS (Bottas et al., 2005; Ongur \& Goff, 2005; Whitney, Fastenau, Evans, \& Lysaker, 2004). Two studies comparing subjects with schizophrenia, OCD with good and OCD with poor insight, found that executive functions of subjects with OCD with poor insight were significantly worse than in subjects with OCD with good insight, and closely resembled executive functions of subjects with schizophrenia (Kitis et al., 2007; Tumkaya et al., 2009).

Taken together, these findings suggest that neurocognitive deficits involving executive functions contribute to poor insight, which in the context of OCS "drives" transition to psychotic symptoms and poor clinical outcome.

\section{Cognitive models and single symptoms}

Co-occurrence of psychotic symptoms and OCS may also be understood from a neurocognitive perspective. Cognitive models for the formation (onset) and maintenance (persistence) of psychotic symptoms such as delusions and hallucinations on the one hand and obsessions on the other hand are concurrent to a large extent.

A predominant model originally developed by Rachman and Salkovskis, proposed that obsessions may develop from intrusive thoughts that are perceived as unwanted or unacceptable (Rachman, 1997).

Proneness to OCD may involve a tendency to make unsuccessful attempts to suppress intrusive thoughts, paradoxically making them reoccur more repetitively and vividly (Tolin, Abramowitz, Przeworski, \& Foa, 2002). A metacognitive style, characterized by (over)responsibility for the possible consequences of one's own thoughts and actions, and the belief that anticipated harm has to be neutralized, may increase distress, consequently reinforcing this process and resulting in symptoms (Barrera \& Norton, 2011; Rachman \& Hodgson, 1980; Salkovskis \& Harrison, 1984).

In the ongoing debate on the genesis of hallucinatory experiences, a consensus has emerged that hallucinatory experiences are the consequence of the misattribution of internally generated cognitive events to external sources (Bentall, 1990; Hoffman, 1986; Laroi \& Woodward, 2007). The "metacognitive beliefs" model, proposed by Morrison, assumes that hallucinatory experiences may result from unexpected or unwanted intrusive thoughts that generate a negative arousal. Incompatible metacognitive beliefs further lead to cognitive dissonance, a state of distress that subjects are motivated to escape (Leon, 1957). Hence, 
metacognitive beliefs may contribute to a bias against labeling such thoughts as internally generated (Bentall, Kinderman, \& Kaney, 1994; Freeman, Garety, \& Kuipers, 2001), possibly in combination with deficits in self-monitoring (Johns et al., 2001) or other informationprocessing deficits, resulting in intrusive thoughts being misattributed to an external source (A. P. Morrison \& Haddock, 1997). Next, in a context of increased arousal and distress hallucinatory experiences may give rise to secondary delusional interpretation (Maher, 1988) or aberrant attribution of salience (Kapur, 2003), giving way to a deepening of the early psychotic state, increasing the risk for need for care and patient status (Krabbendam, Myin-Germeys, Hanssen, et al., 2004; Smeets et al., 2010).

In a recent literature review and meta-analysis on the metacognitive model of hallucinations, the association between intrusive thoughts and hallucinatory experiences was found to be robust in subclinical samples, and somewhat smaller in clinical samples after adjustment for anxiety and depression(Filippo Varese \& Bentall, 2011). Furthermore, intrusive thoughts have been shown to be associated with paranoid delusions as well ( $F$. Varese, Barkus, \& Bentall, 2012). Some researchers have suggested that metacognitive beliefs may as well be implicated in the etiology of first-rank Schneiderian symptoms like thought insertion and delusions of control (Linney \& Peters, 2007; Anthony P. Morrison, 2001).

Thus, intrusive thoughts which are highly prevalent in the general population, may function as a "seed" for OCS as well as hallucinatory experiences, and some common features in cognitive style are involved in the further development to OCS or hallucinatory experiences respectively - basically a high need to control combined with uncertainty, a low cognitive confidence, and a tendency to make negative interpretations that involve the idea that the person's choice can result in harm (Steffen Moritz, Peters, LarÃ,i, \& Lincoln, 2010; Filippo Varese \& Bentall, 2011). Next, an appraisal of the experience as personally significant and threatening may arise, facilitated by pre-existing cognitive biases such as deficits in sourceand self-monitoring, and the amount of data gathered for decision-making.

In the EDSP study in chapter 4, it was indeed confirmed for the first time in an epidemiological study in a large sample that intrusive thoughts increased the risk for the development of hallucinatory experiences as well as OC symptoms. OC symptoms as well as hallucinations in turn increased the risk for an incident clinical case of psychosis, and more so if combined with delusional symptoms. These findings suggest that the well-documented high comorbidity between psychosis and OCD may originate from a partially shared pathway from intrusive thoughts to $\mathrm{OC}$ or hallucinatory experiences respectively, with delusional appraisals facilitating the pathway to further psychosis. Though typically the degree of insight and quality of content is different in positive psychotic symptoms and OCS, they apparently can vary over a spectrum and in time.

These findings fit very well with the proneness-persistence-impairment hypothesis. Intrusive thoughts, though even more prevalent in the general population than subthreshold psychotic or obsessive-compulsive symptoms, do increase the risk for later psychotic symptoms and even clinical psychotic disorder. Environmental risk factors, though not investigated in this study, are likely to contribute to the persistence and eventually transition of intrusion thoughts into subclinical symptoms.

Cognitive biases have been demonstrated in the psychosis and OCD extended phenotype. 
Some of these cognitive biases show overlap, for instance deficits in eye tracking dysfunctions (Docherty et al., 2012; Kloft, Reuter, Riesel, \& Kathmann, 2012; Lennertz et al., 2012; Radant et al., 2010), sensorimotor gating (Ahmari, Risbrough, Geyer, \& Simpson, 2012; Braff, Swerdlow, \& Geyer, 1999; Decoster et al., 2012; Foxe et al., 2011; Olincy et al., 2010; Turetsky et al., 2007) and cognitive inhibitory control (Chamberlain \& Menzies, 2009; Chambers, Garavan, \& Bellgrove, 2009; Daskalakis, Fitzgerald, \& Christensen, 2007; Enright \& Beech, 1993; Hasan et al., 2012; He, Cassaday, Park, \& Bonardi, 2012; Krikorian, Zimmerman, \& Fleck, 2004; Menzies et al., 2007; Waters, Badcock, Maybery, \& Michie, 2003; Wobrock et al., 2008), error monitoring (Alain, McNeely, He, Christensen, \& West, 2002; Mathalon, Jorgensen, Roach, \& Ford, 2009; Perez et al., 2012; Rajender et al., 2011; Riesel, Endrass, Kaufmann, \& Kathmann, 2011; Silver et al., 2006; E. R. Stern et al., 2011) and action monitoring (Franck et al., 2001; Hermans et al., 2008; Maltby, Tolin, Worhunsky, O'Keefe, \& Kiehl, 2005; O'Toole, Weinborn, \& Fox, 2012; Ursu, Stenger, Shear, Jones, \& Carter, 2003; Versmissen et al., 2007), emotion recognition (Aigner et al., 2007; Bersani et al., 2012; Bozikas et al., 2009; Montagne et al., 2008) and decision-making under uncertainty (Cavedini, Zorzi, Piccinni, Cavallini, \& Bellodi, 2010; Lincoln, Ziegler, Mehl, \& Rief, 2010; S. Moritz, Van Quaquebeke, \& Lincoln, 2012; Paulus, Frank, Brown, \& Braff, 2003; Rubio et al., 2011; Viswanath, Janardhan Reddy, Kumar, Kandavel, \& Chandrashekar, 2009). In chapter 4 of this thesis, a data gathering bias in decision making under uncertainty was investigated in subjects with a diagnosis of psychosis, their unaffected first-degree relatives, subjects with a high psychometric risk for psychosis compared to healthy controls. The jumping to conclusions reasoning bias was associated with familial psychosis liability as well as with the expression of the positive symptom dimension, more specific with delusions. The propensity to jump to conclusions was mainly attributable to a tendency to gather less information before making a decision, rather than an inadequate estimation of probability. In other work, it was shown that subjects with delusions that jumped to conclusions, when confronted with potentially disconfirmatory evidence after their first decision, easily changed their decision. However, they kept endorsing a high degree of confidence about their decision (Balzan, Delfabbro, Galletly, \& Woodward, 2012; S. Moritz \& Woodward, 2005; Speechley, Whitman, \& Woodward, 2010), although their decisions were less accurate then in controls(Warman, Lysaker, Martin, Davis, \& Haudenschield, 2007). Indeed, a liberal acceptance bias was found to associated with delusional proneness, and with impaired cognitive insight. The association between level of delusion-proneness and the bias to jump to conclusions increases when the stimuli used were emotionally salient stimuli with negative valence (Warman \& Martin, 2006).

In subjects with a diagnosis of $O C D$, in contrast, no evidence for a jumping to conclusions bias is found. On the contrary, a tendency to defer the decision in probabilistic reasoning tasks was found (Fear \& Healy, 1997; Volans, 1976). Degree of conviction about the obsessions did not affect the associations (Jacobsen, Freeman, \& Salkovskis, 2012). In the light of disconfirmatory evidence, subjects with OCD exhibited more doubt about their conclusion than controls (Fear \& Healy, 1997; Pélissier, O'Connor, \& Dupuis, 2009; Pelissier \& O'Connor, 2002).

\section{Clinical implications}

The presented data have raised questions about the conceptualization and nosological classification of "comorbid" psychotic disorder and OCD. Such concepts may have consequences for the diagnostic process and clinical management in clinical practice. The 
high comorbidity between (symptom dimensions) of the OCD and psychosis phenotype and the indication for a distinctive, unfavorable course has inspired some authors to propose new diagnostic categories or subtypes such as obsessive psychosis or "schizo-obsessive disorder" as a distinct nosological entity (Bottas et al., 2005; Gross-Isseroff, Hermesh, Zohar, \& Weizman, 2003; Patel et al., 2010; Reznik, Mester, Kotler, \& Weizman, 2001; Sevincok et al., 2006). Given the quantitative variation in symptoms dimensions across the current diagnostic categories of psychotic disorders and $O C D$, it is unlikely that the overlap of both heterogeneous diagnostic categories will show homogeneity or higher validity. Rather, an alternative model accounting for quantitative variation of different symptom dimensions and their course over time in individual trajectories, will give a better hold to go for clinical management as well as research purposes. We will elaborate on this topic in the section "directions for future research" below.

Finally, can the studies in this thesis contribute to a progression in detection of management in clinical practice? For years, a considerable effort is made to ameliorate the identification of subjects at (ultra) (high) risk of developing psychosis in order to prevent a transition to disorder (McGorry et al., 2013; A. P. Morrison et al., 2011). However, as discussed earlier, most of the subclinical psychotic symptoms are transient, i.e. "false-positive". The diagnostic value of psychotic experiences and subclinical OC features in the general population is low in relation to the rare disorder of schizophrenia c.q. OCD. For example, the probability of developing a psychotic disorder over a 2-year follow-up period given the presence of psychotic experiences is only $8 \%$ (Hanssen et al., 2005). Even if the follow-up period is extended to 15 years, the risk of developing a psychotic disorder does not exceed $25 \%$ (Poulton et al., 2000). Intervening in the lives of the "false positive" subjects holds the risk of unintended side-effects like unnecessary stress or stigma, or inevitably, financial cost. Thus, the prediction of need for care, given the presence of subclinical positive psychotic experiences with variable frequency, distress, preoccupation and influence of behavior is crucial. It has been shown in this thesis that the co-occurrence of obsessive-compulsive symptoms, particularly when persistent, increases the risk for need for care with $40 \%$. Admitted, the total proportion of the general population having subclinical $O C$ and psychotic feature will be low. However, the co-occurrence of (other) anxiety and affective symptoms apparently is a predictor of the likelihood of developing need for care (Fusar-Poli, Nelson, Valmaggia, Yung, \& McGuire, 2012; Kelleher et al., 2012; Rietdijk et al., 2013; Wigman et al., 2012). Thus, screening a help-seeking population with affective, obsessive-compulsive or (other) anxiety symptoms, particularly when persistent, may be useful in more effectively detecting the subjects that will develop need for care.

The necessity of early detection and intervention is high because treatment, particularly pharmacological treatment, in a later clinical stage holds a conundrum. Most atypical antipsychotic agents have been reported to induce OCS, most of all clozapine, probably due to an antiserotonergic effect on the $5 \mathrm{HT} 2 \mathrm{a}$ receptors. However, they can also have a beneficiary effect on the OCS (Sareen et al., 2004; Schirmbeck et al., 2013; Schirmbeck \& Zink, 2013). Positive as well as negative psychotic symptoms often diminish along with the OCS. SSRI's are often indicated, but response is limited, and increase of psychotic symptoms has been reported. Electroconvulsion therapy (ECT) is reserved for severe cases, and a fortiori is deep brain stimulation (DBS). Nonpharmacological treatment, particularly cognitive behavioral therapy, may yield the best results and certainly the fewest side-effects (Ekers, Carman, \& Schlich, 2004; Tundo et al., 2012). 


\section{Directions for Future Research: A network perspective on comorbidity}

Though a dimensional model as used here already allows a more fine-grained description and understanding of the co-occurrence of symptoms than a model of comorbidity of categorical diagnoses, the question remains: what exactly is observed when (symptom dimensions of) two disorders covary. For instance, if stated earlier that a mutual impact of symptom dimensions is relevant because of their high co-occurrence and mutual influence on each others course over time, a question that remains unanswered is whether this cooccurrence is a genuine phenomenon that is independent of diagnostic criteria and measurement scales, or (in part) an artifact of the structure of these criteria (Borsboom, 2002; Neale \& Kendler, 1995). The former possibility implies that a genuine source of comorbidity exists. More precisely, that the symptom-producing disorders themselves are comorbid, which causes the symptoms of such comorbid disorders (c.q. dimensions) to correlate. The latter possibility (of an artifact) holds that comorbidity is a product of the way we empirically identify these disorders, for instance because disorders actually merely are defined as a collection of symptoms that often are shared with other disorders, which leads to an artificially increased comorbidity rate (Cramer, Waldorp, van der Maas, \& Borsboom, 2010). Neither of both possibilities seems to provide a satisfactory account for the processes in operation.

Network models, on the other hand, do provide possibilities for a better fitting integrative model to describe and understand the trajectories of symptoms over time. In the "traditional" diagnostic perspective, symptoms are supposed to arise from a disorder, and consequently comorbidity is supposed to arise from a root cause that is shared by two or more latent disorders. However, observations increasingly suggest that symptoms are unlikely to be merely passive indicators of latent conditions. They rather have active properties: they interact with other symptoms and themselves with an autonomous causal relevance. That is, when symptoms arise, they can actively cause other symptoms on their own (Borsboom, Cramer, Schmittmann, Epskamp, \& Waldorp, 2011). For instance, as shown in the NEMESIS study in chapter 2, incident OCS may cause psychotic symptoms to arise, increase and persist, and together, the co-occurring symptoms clearly increase the risk for impairment and help-seeking.

In this network approach, alternative to a diagnostic or dimensional approach, disorders are considered as networks that consist of symptoms and causal relations between them. This approach does not exclude the possibility that these relations between symptoms are mediated or moderated by processes that are not directly observable. Rather, network models exceed diagnostic and dimensional models, in that they can separately account for the co-occurrence of symptoms, the strength of the connection between two symptoms, frequency of symptoms and the weighted sum of the number of connections a symptom has.

Though models with latent variables (disorders) certainly have had their merits in explaining and conceptualizing pathology, they have poor explanatory virtues as it comes to comorbidity of heterogeneous disorders with fuzzy boundaries and overlapping symptoms (Kendell, 1975). When mental disorders are conceptualized as networks of symptoms, and comorbidity as a combination of the networks of the symptoms of two disorders, then boundaries are fuzzy merely because they do not exist: the networks are connected with 
each other. Overlapping ("bridge") symptoms are central connecting nodes between the symptoms of both networks. Whereas overlapping symptoms in diagnostic models often are considered as problematic in the sense of hampering discrimination and demarcation between disorders, in a network model, comorbidity may be more real than the mental disorders on which it is defined. In an application of network models on the comorbidity of anxiety and depression, it was shown that overlapping symptoms played a crucial role in explaining comorbidity: subjects who displayed at least one pair of overlapping symptoms showed much stronger connection between anxiety and depression symptoms (Cramer et al., 2010). It is likely that symptoms, among which there is a strong connection, will preferentially influence each other, probably reflecting the sequence of the development of symptoms over time. Also, recursive positive or negative feedback may occur, contributing to transition or increase/persistence of symptoms respectively.

Though network models were not used in the research in this thesis, they are likely to provide useful possibilities for future research and clinical practice that other models do not. For instance, the sequence described above may be illustrative for the symptom connectivity. Unsuccessful attempts to suppress an intrusive thought may bring along insomnia, which can increase the need to suppress the unwanted thought, paradoxically reinforcing them. As the situation persists, distress increases and loss of control is perceived, increasing the risk that an intrusive thought is misattributed to an external source, giving rise to the formation of an occasional hallucination. The experience of loss of control may lead to increased arousal and distress, fueling anxiety as well as secondary delusional interpretation. Anxiety may further increase the alertness for potentially threat, thus strengthening the delusional ideation. In sum, as positive feedback and feed forward mechanisms continue over time, impairment and need for help will arise.

The visualization of the position of and connections between symptoms such as intrusions, obsessions, delusions, hallucinations, but also negative symptoms, affective symptoms and anxiety would learn more about the mutual impact of symptoms over time, i.e. which are bridging or pivotal symptoms, particularly when followed over time with higher frequency monitoring. [figure] In this thesis, longitudinal data sets consisted of 2 to 5 waves of measurement, in large cohorts. When the variation in symptoms and other factors would be monitored in a higher frequency, for instance with the experience sampling method (ESM) (refs), network patterns of individual trajectories could be revealed. In the past, quite a lot of different sequences and their corresponding possible underpinning mechanisms have been proposed. As for the co-occurrence of OCD and psychosis, many authors could not resist to propose subtypes based on different temporal order or amount of particular symptoms, or based on a supposed hierarchy of disorders causing symptoms, most often still lacking satisfactory homogeneity and validity. Indeed, from a network perspective, it is unlikely that a adding a new diagnostic category, i.e. e new latent variable, for instance "schizo-obsessive disorder", will adequately model the co-occurring symptoms.

Longitudinal data have shown that many different individual trajectories exist, with different temporal order of symptoms and other factors, yet with shared vulnerabilities and risk factors. Until now, it has been problematic that findings on course and outcome of cooccurring OCS and psychotic symptoms in groups often are divergent. When enough data on enough items and their connections are available over time in an individual subject, network 
models may be capable to predict the course on short or longer term in individual subjects. Such models would also account for mitigating influences of negative feedback/-forward. When the network that is investigated is extended with external variables reflecting social functioning and well-being, or (environmental) risk factors, more accurate and differentiated information may be obtained. Possibly shared etiologic agents may impact directly on the symptoms as well as on the relations between symptoms. As such, a network perspective may not only be consistent with the fact that the phenotypes are heterogeneous and polygenic, but the relation between symptoms may be a better focus than the symptoms themselves for genetic research.

Subsequently, network models can contribute to better tune clinical care. The clinical staging model embodies the major efforts that have been made in trying to identify the subjects at risk and quantifying their risk for an unfavorable course (McGorry et al., 2013). Even when symptoms and need for care are expressed, it often remains hard to provide adequate and timely interventions for the first episode or the critical period. One of the hardships is that not every individual trajectory fits well in the clinical staging model. The combination of monitoring with an apt frequency and analyzing with network models may help to visualize individual trajectories and add a powerful tool for secondary prevention, enhanced selfmanagement and empowerment of individuals experiencing (subclinical) symptoms. 


\section{References}

Ahmari, S. E., Risbrough, V. B., Geyer, M. A., \& Simpson, H. B. (2012). Impaired Sensorimotor Gating in Unmedicated Adults with Obsessive-Compulsive Disorder. Neuropsychopharmacology, 37(5), 1216-1223.

Aigner, M., Sachs, G., Bruckmüller, E., Winklbaur, B., Zitterl, W., Kryspin-Exner, I., . . Katschnig, H. (2007). Cognitive and emotion recognition deficits in obsessive-compulsive disorder. Psychiatry Research, 149(1-3), 121-128. doi: http://dx.doi.org/10.1016/j.psychres.2005.12.006

Alain, C., McNeely, H. E., He, Y., Christensen, B. K., \& West, R. (2002). Neurophysiological evidence of error-monitoring deficits in patients with schizophrenia. Cereb Cortex, 12(8), 840-846.

Aleman, A., Agrawal, N., Morgan, K. D., \& David, A. S. (2006). Insight in psychosis and neuropsychological function: meta-analysis. Br J Psychiatry, 189, 204-212. doi: 10.1192/bjp.189.3.204

Angst, J., Gamma, A., Endrass, J., Goodwin, R., Ajdacic, V., Eich, D., \& Rössler, W. (2004). Obsessivecompulsive severity spectrum in the community: prevalence, comorbidity, and course. European Archives of Psychiatry \& Clinical Neuroscience, 254(3), 156-164. doi: 10.1007/s00406-004-0459-4

Anholt, G. E., Aderka, I. M., van Balkom, A. J., Smit, J. H., Hermesh, H., de Haan, E., \& van Oppen, P. (2011). The impact of depression on the treatment of obsessive-compulsive disorder: results from a 5-year follow-up. J Affect Disord, 135(1-3), 201-207. doi: 10.1016/j.jad.2011.07.018

Balzan, R. P., Delfabbro, P. H., Galletly, C. A., \& Woodward, T. S. (2012). Over-adjustment or miscomprehension? A re-examination of the jumping to conclusions bias. Australian and New Zealand Journal of Psychiatry, 46(6), 532-540. doi: 10.1177/0004867411435291

Barrera, T. L., \& Norton, P. J. (2011). The Appraisal of Intrusive Thoughts in Relation to ObsessionalCompulsive Symptoms. Cogn Behav Ther, 1.

Bentall, R. P. (1990). The illusion of reality: a review and integration of psychological research on hallucinations. Psychol Bull, 107(1), 82-95.

Bentall, R. P., Kinderman, P., \& Kaney, S. (1994). The self, attributional processes and abnormal beliefs: towards a model of persecutory delusions. Behav Res Ther, 32(3), 331-341.

Bersani, G., Bersani, F. S., Valeriani, G., Robiony, M., Anastasia, A., Colletti, C., . . Polli, E. (2012). Comparison of facial expression in patients with obsessive-compulsive disorder and schizophrenia using the Facial Action Coding System: a preliminary study. Neuropsychiatr Dis Treat, 8, 537-547. doi: 10.2147/ndt.s37174

Bijl, R. V., Ravelli, A., \& van Zessen, G. (1998). Prevalence of psychiatric disorder in the general population: results of The Netherlands Mental Health Survey and Incidence Study (NEMESIS). Soc Psychiatry Psychiatr Epidemiol, 33(12), 587-595.

Bland, R. C., Newman, S. C., \& Orn, H. (1987). Schizophrenia: lifetime co-morbidity in a community sample. Acta Psychiatr Scand, 75(4), 383-391.

Bloch, M. H., Craiglow, B. G., Landeros-Weisenberger, A., Dombrowski, P. A., Panza, K. E., Peterson, B. S., \& Leckman, J. F. (2009). Predictors of early adult outcomes in pediatric-onset obsessivecompulsive disorder. Pediatrics, 124(4), 1085-1093. doi: 10.1542/peds.2009-0015

Bloch, M. H., Green, C., Kichuk, S. A., Dombrowski, P. A., Wasylink, S., Billingslea, E., . . Pittenger, C. (2013). Long-Term Outcome In Adults With Obsessive-Compulsive Disorder. Depression and Anxiety, 30(8), 716-722. doi: 10.1002/da.22103

Blom, R. M., Hagestein-de Bruijn, C., de Graaf, R., ten Have, M., \& Denys, D. A. (2011). Obsessions in normality and psychopathology. Depression and Anxiety, 28(10), 870-875. doi: 10.1002/da.20853

Bora, E., Yucel, M., Fornito, A., Berk, M., \& Pantelis, C. (2008). Major psychoses with mixed psychotic and mood symptoms: are mixed psychoses associated with different neurobiological markers? Acta Psychiatr Scand, 118(3), 172-187. 
Borsboom, D. (2002). THe structure of the dsm. Archives of General Psychiatry, 59(6), 569-570.

Borsboom, D., Cramer, A. O., Schmittmann, V. D., Epskamp, S., \& Waldorp, L. J. (2011). The small world of psychopathology. PLOS ONE, 6(11), e27407. doi: 10.1371/journal.pone.0027407

Bottas, A., Cooke, R. G., \& Richter, M. A. (2005). Comorbidity and pathophysiology of obsessivecompulsive disorder in schizophrenia: is there evidence for a schizo-obsessive subtype of schizophrenia? J Psychiatry Neurosci, 30(3), 187-193.

Bozikas, V. P., Kosmidis, M. H., Giannakou, M., Saitis, M., Fokas, K., \& Garyfallos, G. (2009). Emotion perception in obsessive-compulsive disorder. J Int Neuropsychol Soc, 15(1), 148-153. doi: $10.1017 / \mathrm{s} 1355617708090097$

Braff, D. L., Swerdlow, N. R., \& Geyer, M. A. (1999). Symptom correlates of prepulse inhibition deficits in male schizophrenic patients. Am J Psychiatry, 156(4), 596-602.

Brockington, I., Kendell, R., \& Wainwright, S. (1980). Depressed patients with schizophrenic or paranoid symptoms. Psychol Med, 10(4), 665-675.

Brockington, I., Kendell, R., Wainwright, S., Hillier, V., \& Walker, J. (1979). The distinction between the affective psychoses and schizophrenia. The British Journal of Psychiatry, 135(3), 243-248.

Catapano, F., Sperandeo, R., Perris, F., Lanzaro, M., \& Maj, M. (2001). Insight and resistance in patients with obsessive-compulsive disorder. Psychopathology, 34(2), 62-68.

Cavedini, P., Zorzi, C., Piccinni, M., Cavallini, M. C., \& Bellodi, L. (2010). Executive Dysfunctions in Obsessive-Compulsive Patients and Unaffected Relatives: Searching for a New Intermediate Phenotype. Biological Psychiatry, 67(12), 1178-1184. doi: 10.1016/j.biopsych.2010.02.012

Chamberlain, S. R., \& Menzies, L. (2009). Endophenotypes of obsessive-compulsive disorder: rationale, evidence and future potential. Expert Review of Neurotherapeutics, 9(8), 11331146. doi: 10.1586/ern.09.36

Chambers, C. D., Garavan, H., \& Bellgrove, M. A. (2009). Insights into the neural basis of response inhibition from cognitive and clinical neuroscience. Neuroscience \& Biobehavioral Reviews, 33(5), 631-646. doi: http://dx.doi.org/10.1016/j.neubiorev.2008.08.016

Chapman, L. J., Chapman, J. P., Kwapil, T. R., Eckblad, M., \& Zinser, M. C. (1994). Putatively psychosisprone subjects 10 years later. J Abnorm Psychol, 103(2), 171-183.

Cougnard, A., Marcelis, M., Myin-Germeys, I., De Graaf, R., Vollebergh, W., Krabbendam, L., . . Van Os, J. (2007). Does normal developmental expression of psychosis combine with environmental risk to cause persistence of psychosis? A psychosis proneness-persistence model. Psychol Med, 37(4), 513-527. doi: 10.1017/S0033291706009731

Cramer, A. O., Waldorp, L. J., van der Maas, H. L., \& Borsboom, D. (2010). Comorbidity: a network perspective. Behav Brain Sci, 33(2-3), 137-150; discussion 150-193. doi: 10.1017/S0140525X09991567

Cuesta, M. J., Peralta, V., Gil, P., \& Artamendi, M. (2003). Psychopathological dimensions in firstepisode psychoses. From the trunk to the branches and leaves. Eur Arch Psychiatry Clin Neurosci, 253(2), 73-79. doi: 10.1007/s00406-003-0410-0

Cunill, R., Castells, X., \& Simeon, D. (2009). Relationships between obsessive-compulsive symptomatology and severity of psychosis in schizophrenia: a systematic review and metaanalysis. J Clin Psychiatry, 70(1), 70-82.

Daskalakis, Z. J., Fitzgerald, P. B., \& Christensen, B. K. (2007). The role of cortical inhibition in the pathophysiology and treatment of schizophrenia. Brain Research Reviews, 56(2), 427-442. doi: http://dx.doi.org/10.1016/j.brainresrev.2007.09.006

de Bruijn, C., Beun, S., de Graaf, R., Ten Have, M., \& Denys, D. (2010). Subthreshold symptoms and obsessive-compulsive disorder: evaluating the diagnostic threshold. Psychol Med, 40(6), 989997. doi: S0033291709991012 [pii]10.1017/S0033291709991012

de Haan, L., Dudek-Hodge, C., Verhoeven, Y., \& Denys, D. (2009). Prevalence of psychotic disorders in patients with obsessive-compulsive disorder. CNS Spectrums, 14(8), 415-417. 
de Haan, L., Sterk, B., Wouters, L., \& Linszen, D. H. (2011). The 5-Year Course of ObsessiveCompulsive Symptoms and Obsessive-Compulsive Disorder in First-Episode Schizophrenia and Related Disorders. Schizophrenia Bulletin. doi: 10.1093/schbul/sbr077

Decoster, J., De Hert, M., Viechtbauer, W., Nagels, G., Myin-Germeys, I., Peuskens, J., . . van Winkel, R. (2012). Genetic association study of the P300 endophenotype in schizophrenia. Schizophrenia Research, 141(1), 54-59. doi: 10.1016/j.schres.2012.07.018

Dell'osso, B., Benatti, B., Buoli, M., Altamura, A. C., Marazziti, D., Hollander, E., . . group, I. (2013). The influence of age at onset and duration of illness on long-term outcome in patients with obsessive-compulsive disorder: A report from the International College of Obsessive Compulsive Spectrum Disorders (ICOCS). Eur Neuropsychopharmacol, 23(8), 865-871. doi: 10.1016/j.euroneuro.2013.05.004

Denys, D., Tenney, N., van Megen, H. J., de Geus, F., \& Westenberg, H. G. (2004). Axis I and II comorbidity in a large sample of patients with obsessive-compulsive disorder. J Affect Disord, 80(2-3), 155-162.

Docherty, A. R., Coleman, M. J., Tu, X., Deutsch, C. K., Mendell, N. R., \& Levy, D. L. (2012). Comparison of putative intermediate phenotypes in schizophrenia patients with and without obsessivecompulsive disorder: Examining evidence for the schizo-obsessive subtype. Schizophrenia Research, 140(1-3), 83-86. doi: 10.1016/j.schres.2012.06.033

Dominguez, M. D., Wichers, M., Lieb, R., Wittchen, H. U., \& van Os, J. (2011). Evidence that onset of clinical psychosis is an outcome of progressively more persistent subclinical psychotic experiences: an 8-year cohort study. Schizophr Bull, 37(1), 84-93.

Eisen, J. L., Pinto, A., Mancebo, M. C., Dyck, I. R., Orlando, M. E., \& Rasmussen, S. A. (2010). A 2-year prospective follow-up study of the course of obsessive-compulsive disorder. J Clin Psychiatry, 71(8), 1033-1039. doi: 10.4088/JCP.08m04806blu

Eisen, J. L., \& Rasmussen, S. A. (1993). Obsessive compulsive disorder with psychotic features. J Clin Psychiatry, 54(10), 373-379.

Eisen, J. L., Sibrava, N. J., Boisseau, C. L., Mancebo, M. C., Stout, R. L., Pinto, A., \& Rasmussen, S. A. (2013). Five-year course of obsessive-compulsive disorder: predictors of remission and relapse. J Clin Psychiatry, 74(3), 233-239. doi: 10.4088/JCP.12m07657

Ekers, D., Carman, S., \& Schlich, T. (2004). Successful Outcome Of Exposure And Response Prevention In The Treatment Of Obsessive Compulsive Disorder In A Patient With Schizophrenia. Behavioural and Cognitive Psychotherapy, 32(03), 375-378. doi: doi:10.1017/S135246580400147X

Enright, S. J., \& Beech, A. R. (1993). Reduced cognitive inhibition in obsessive-compulsive disorder. British Journal of Clinical Psychology, 32(1), 67-74. doi: 10.1111/j.2044-8260.1993.tb01028.x

Evans, D. W., Leckman, J. F., Carter, A., Reznick, J. S., Henshaw, D., King, R. A., \& Pauls, D. (1997). Ritual, habit, and perfectionism: the prevalence and development of compulsive-like behavior in normal young children. Child development, 68(1), 58-68.

Fanous, A., Gardner, C., Walsh, D., \& Kendler, K. S. (2001). Relationship between positive and negative symptoms of schizophrenia and schizotypal symptoms in nonpsychotic relatives. Arch Gen Psychiatry, 58(7), 669-673.

Fear, C. F., \& Healy, D. (1997). Probabilistic reasoning in obsessive-compulsive and delusional disorders. Psychol Med, 27(1), 199-208.

Fineberg, N. A., Hengartner, M. P., Bergbaum, C., Gale, T., Rossler, W., \& Angst, J. (2013a). Lifetime comorbidity of obsessive-compulsive disorder and sub-threshold obsessive-compulsive symptomatology in the community: impact, prevalence, socio-demographic and clinical characteristics. Int J Psychiatry Clin Pract, 17(3), 188-196. doi: 10.3109/13651501.2013.777745

Fineberg, N. A., Hengartner, M. P., Bergbaum, C., Gale, T., Rossler, W., \& Angst, J. (2013b). Remission of obsessive-compulsive disorders and syndromes; evidence from a prospective community cohort study over 30 years. Int J Psychiatry Clin Pract. doi: 10.3109/13651501.2013.777744 
Fineberg, N. A., Hengartner, M. P., Bergbaum, C. E., Gale, T. M., Gamma, A., Ajdacic-Gross, V., . . . Angst, J. (2013). A prospective population-based cohort study of the prevalence, incidence and impact of obsessive-compulsive symptomatology. Int J Psychiatry Clin Pract. doi: 10.3109/13651501.2012.755206

Fontenelle, L. F. (2012). New neuropsychological data might help build a model of poor insight in obsessive-compulsive disorder: an editorial comment to Kashyap H, Kumar K, Kandavel T, Janardhan Reddy Yc. 'neuropsychological correlates of insight in obsessive-compulsive disorder' (1). Acta Psychiatr Scand, 126(2), 83-84. doi: 10.1111/j.1600-0447.2012.01836.x

Foxe, J. J., Yeap, S., Snyder, A. C., Kelly, S. P., Thakore, J. H., \& Molholm, S. (2011). The N1 auditory evoked potential component as an endophenotype for schizophrenia: high-density electrical mapping in clinically unaffected first-degree relatives, first-episode, and chronic schizophrenia patients. European archives of psychiatry and clinical neuroscience, 261(5), 331-339. doi: 10.1007/s00406-010-0176-0

Franck, N., Farrer, C., Georgieff, N., Marie-Cardine, M., Dalery, J., d'Amato, T., \& Jeannerod, M. (2001). Defective recognition of one's own actions in patients with schizophrenia. Am J Psychiatry, 158(3), 454-459.

Freeman, D., Garety, P. A., \& Kuipers, E. (2001). Persecutory delusions: developing the understanding of belief maintenance and emotional distress. Psychol Med, 31(7), 1293-1306.

Fullana, M. A., Mataix-Cols, D., Caspi, A., Harrington, H., Grisham, J. R., Moffitt, T. E., \& Poulton, R. (2009). Obsessions and compulsions in the community: prevalence, interference, helpseeking, developmental stability, and co-occurring psychiatric conditions. Am J Psychiatry, 166(3), 329-336.

Fullana, M. A., Vilagut, G., Rojas-Farreras, S., Mataix-Cols, D., de Graaf, R., Demyttenaere, K., . . . Alonso, J. (2009). Obsessive-compulsive symptom dimensions in the general population: Results from an epidemiological study in six European countries. J Affect Disord.

Fusar-Poli, P., Nelson, B., Valmaggia, L., Yung, A. R., \& McGuire, P. K. (2012). Comorbid Depressive and Anxiety Disorders in 509 Individuals With an At-Risk Mental State: Impact on Psychopathology and Transition to Psychosis. Schizophr Bull. doi: 10.1093/schbul/sbs136

García-Soriano, G., Belloch, A., Morillo, C., \& Clark, D. A. (2011). Symptom dimensions in obsessivecompulsive disorder: From normal cognitive intrusions to clinical obsessions. J Anxiety Disord, 25(4), 474-482. doi: http://dx.doi.org/10.1016/j.janxdis.2010.11.012

Gross-Isseroff, R., Hermesh, H., Zohar, J., \& Weizman, A. (2003). Neuroimaging communality between schizophrenia and obsessive compulsive disorder: a putative basis for schizo-obsessive disorder? World J Biol Psychiatry, 4(3), 129-134.

Hanssen, M., Bak, M., Bijl, R., Vollebergh, W., \& van Os, J. (2005). The incidence and outcome of subclinical psychotic experiences in the general population. Br J Clin Psychol, 44(Pt 2), 181191.

Hanssen, M., Krabbendam, L., Vollema, M., Delespaul, P., \& Van Os, J. (2006). Evidence for Instrument and Family-Specific Variation of Subclinical Psychosis Dimensions in the General Population. Journal of Abnormal Psychology, 115(1), 5-14. doi: 10.1037/0021-843X.115.1.5

Hasan, A., Wobrock, T., Grefkes, C., Labusga, M., Levold, K., Schneider-Axmann, T., .. . Bechdolf, A. (2012). Deficient inhibitory cortical networks in antipsychotic-naive subjects at risk of developing first-episode psychosis and first-episode schizophrenia patients: a cross-sectional study. Biological Psychiatry, 72(9), 744-751. doi: 10.1016/j.biopsych.2012.03.005

He, Z., Cassaday, H. J., Park, S. B. G., \& Bonardi, C. (2012). When to Hold That Thought: An Experimental Study Showing Reduced Inhibition of Pre-trained Associations in Schizophrenia. PLOS ONE, 7(7), e42175. doi: 10.1371/journal.pone.0042175

Hermans, D., Engelen, U., Grouwels, L., Joos, E., Lemmens, J., \& Pieters, G. (2008). Cognitive confidence in obsessive-compulsive disorder: Distrusting perception, attention and memory. Behaviour Research and Therapy, 46(1), 98-113.

Hoffman, R. E. (1986). Verbal hallucinations and language production processes in schizophrenia. Behavioral and Brain Sciences, 9(03), 503-517. doi: doi:10.1017/S0140525X00046781 
Hwang, M. Y., Morgan, J. E., \& Losconzcy, M. F. (2000). Clinical and neuropsychological profiles of obsessive-compulsive schizophrenia: a pilot study. J Neuropsychiatry Clin Neurosci, 12(1), 91 94.

Insel, T. R., \& Akiskal, H. S. (1986). Obsessive-compulsive disorder with psychotic features: a phenomenologic analysis. Am J Psychiatry, 143(12), 1527-1533.

Ito, L. M., de Araujo, L. A., Hemsley, D. R., \& Marks, I. M. (1995). Beliefs and resistance in obsessivecomplulsive disorder: Observations from a controlled study. Journal of Anxiety Disorders, 9(4), 269-281. doi: http://dx.doi.org/10.1016/0887-6185(95)00008-C

Jacobsen, P., Freeman, D., \& Salkovskis, P. (2012). Reasoning bias and belief conviction in obsessivecompulsive disorder and delusions: Jumping to conclusions across disorders? British Journal of Clinical Psychology, 51(1), 84-99. doi: 10.1111/j.2044-8260.2011.02014.x

Johns, L. C., Rossell, S., Frith, C., Ahmad, F., Hemsley, D., Kuipers, E., \& McGuire, P. K. (2001). Verbal self-monitoring and auditory verbal hallucinations in patients with schizophrenia. Psychol Med, 31(4), 705-715.

Kapur, S. (2003). Psychosis as a state of aberrant salience: a framework linking biology, phenomenology, and pharmacology in schizophrenia. Am J Psychiatry, 160(1), 13-23.

Karno, M., Golding, J. M., Sorenson, S. B., \& Burnam, M. A. (1988). The epidemiology of obsessivecompulsive disorder in five US communities. Arch Gen Psychiatry, 45(12), 1094-1099.

Kashyap, H., Kumar, J. K., Kandavel, T., \& Reddy, Y. C. (2012). Neuropsychological correlates of insight in obsessive-compulsive disorder. Acta Psychiatr Scand, 126(2), 106-114. doi: 10.1111/j.1600-0447.2012.01845.x

Kayahan, B., Ozturk, O., Veznedaroglu, B., \& Eraslan, D. (2005). Obsessive-compulsive symptoms in schizophrenia: prevalance and clinical correlates. Psychiatry Clin Neurosci, 59(3), 291-295.

Kelleher, I., Keeley, H., Corcoran, P., Lynch, F., Fitzpatrick, C., Devlin, N., . . Cannon, M. (2012). Clinicopathological significance of psychotic experiences in non-psychotic young people: evidence from four population-based studies. Br J Psychiatry, 201(1), 26-32. doi: 10.1192/bjp.bp.111.101543

Kendell, R. E. (1975). The concept of disease and its implications for psychiatry. The British journal of psychiatry : the journal of mental science, 127, 305-315.

Kendler, K. S., Gallagher, T. J., Abelson, J. M., \& Kessler, R. C. (1996). Lifetime prevalence, demographic risk factors, and diagnostic validity of nonaffective psychosis as assessed in a US community sample. The National Comorbidity Survey. Arch Gen Psychiatry, 53(11), 10221031.

Kitis, A., Akdede, B. B. K., Alptekin, K., Akvardar, Y., Arkar, H., Erol, A., \& Kaya, N. (2007). Cognitive dysfunctions in patients with obsessive-compulsive disorder compared to the patients with schizophrenia patients: Relation to overvalued ideas. Progress in Neuro-Psychopharmacology and Biological Psychiatry, 31(1), 254-261. doi: http://dx.doi.org/10.1016/i.pnpbp.2006.06.022

Klaassen, R. M., Heins, M., Luteijn, L. B., van der Gaag, M., \& van Beveren, N. J. (2013). Depressive symptoms are associated with (sub)clinical psychotic symptoms in patients with nonaffective psychotic disorder, siblings and healthy controls. Psychol Med, 43(4), 747-756. doi: 10.1017/s0033291712001572

Klein, D. N., \& Riso, L. P. (1993). Psychiatric disorders: problems of boundaries and comorbidity. In C. G. Costello (Ed.), Basic Issues in Psychopathology (pp. 19-66). New York: Guilford Press.

Klein Hofmeijer-Sevink, M., van Oppen, P., van Megen, H. J., Batelaan, N. M., Cath, D. C., van der Wee, N. J., . . van Balkom, A. J. (2013). Clinical relevance of comorbidity in obsessive compulsive disorder: The Netherlands OCD Association study. J Affect Disord. doi: 10.1016/j.jad.2013.03.014

Kloft, L., Reuter, B., Riesel, A., \& Kathmann, N. (2012). Impaired volitional saccade control: first evidence for a new candidate endophenotype in obsessive-compulsive disorder. European archives of psychiatry and clinical neuroscience. doi: 10.1007/s00406-012-0331-x 
Kolada, J. L., Bland, R. C., \& Newman, S. C. (1994). Epidemiology of psychiatric disorders in Edmonton. Obsessive-compulsive disorder. Acta Psychiatr Scand Suppl, 376, 24-35.

Krabbendam, L., Myin-Germeys, I., De Graaf, R., Vollebergh, W., Nolen, W. A., ledema, J., \& Van Os, J. (2004). Dimensions of depression, mania and psychosis in the general population. Psychol Med, 34(7), 1177-1186.

Krabbendam, L., Myin-Germeys, I., Hanssen, M., Bijl, R. V., de Graaf, R., Vollebergh, W., . . van Os, J. (2004). Hallucinatory experiences and onset of psychotic disorder: evidence that the risk is mediated by delusion formation. Acta Psychiatr Scand, 110(4), 264-272.

Krikorian, R., Zimmerman, M. E., \& Fleck, D. E. (2004). Inhibitory control in Obsessive-Compulsive Disorder. Brain and Cognition, 54(3), 257-259. doi: http://dx.doi.org/10.1016/j.bandc.2004.02.038

Laroi, F., \& Woodward, T. S. (2007). Hallucinations from a cognitive perspective. Harv Rev Psychiatry, 15(3), 109-117. doi: 10.1080/10673220701401993

LaSalle, V. H., Cromer, K. R., Nelson, K. N., Kazuba, D., Justement, L., \& Murphy, D. L. (2004). Diagnostic interview assessed neuropsychiatric disorder comorbidity in 334 individuals with obsessive-compulsive disorder. Depress Anxiety, 19(3), 163-173. doi: 10.1002/da.20009

Leckman, J. F., Bloch, M. H., \& King, R. A. (2009). Symptom dimensions and subtypes of obsessivecompulsive disorder: a developmental perspective. Dialogues in Clinical Neuroscience, 11(1), 21-33. doi: D - NLM: PMC3181902 EDAT- 2009/05/13 09:00 MHDA- 2009/07/08 09:00 CRDT2009/05/13 09:00 PST - ppublish

Lennertz, L., Rampacher, F., Vogeley, A., Schulze-Rauschenbach, S., Pukrop, R., Ruhrmann, S., . . Wagner, M. (2012). Antisaccade performance in patients with obsessive-compulsive disorder and unaffected relatives: further evidence for impaired response inhibition as a candidate endophenotype. European archives of psychiatry and clinical neuroscience. doi: 10.1007/s00406-012-0311-1

Leon, F. (1957). A theory of cognitive dissonance. Stanford: SUP.

Lincoln, T. M., Ziegler, M., Mehl, S., \& Rief, W. (2010). The jumping to conclusions bias in delusions: Specificity and changeability. Journal of Abnormal Psychology, 119(1), 40-49.

Linney, Y. M., \& Peters, E. R. (2007). The psychological processes underlying symptoms of thought interference in psychosis. Behav Res Ther, 45(11), 2726-2741. doi: S0005-7967(07)00159-3 [pii]10.1016/j.brat.2007.07.011

Lysaker, P. H., Bryson, G. J., Marks, K. A., Greig, T. C., \& Bell, M. D. (2002). Association of obsessions and compulsions in schizophrenia with neurocognition and negative symptoms. $J$ Neuropsychiatry Clin Neurosci, 14(4), 449-453.

Lysaker, P. H., Marks, K. A., Picone, J. B., Rollins, A. L., Fastenau, P. S., \& Bond, G. R. (2000). Obsessive and compulsive symptoms in schizophrenia: clinical and neurocognitive correlates. J Nerv Ment Dis, 188(2), 78-83.

Lysaker, P. H., Whitney, K. A., \& Davis, L. W. (2006). Obsessive-compulsive and negative symptoms in schizophrenia: associations with coping preference and hope. Psychiatry Res, 141(3), 253259. doi: S0165-1781(05)00307-0 [pii]10.1016/j.psychres.2005.09.016

Maher, B. A. (1988). Anomalous experience and delusional thinking: The logic of explanations. In B. A. Maher \& T. F. Oltmanns (Eds.), Delusional beliefs. (pp. 15-33). Oxford England: John Wiley \& Sons.

Maltby, N., Tolin, D. F., Worhunsky, P., O'Keefe, T. M., \& Kiehl, K. A. (2005). Dysfunctional action monitoring hyperactivates frontal-striatal circuits in obsessive-compulsive disorder: an eventrelated fMRI study. Neuroimage, 24(2), 495-503.

Mancebo, M. C., Garcia, A. M., Pinto, A., Freeman, J. B., Przeworski, A., Stout, R., . . Rasmussen, S. A. (2008). Juvenile-onset OCD: clinical features in children, adolescents and adults. Acta Psychiatr Scand, 118(2), 149-159. doi: ACP1224 [pii]10.1111/j.1600-0447.2008.01224.x

Marcks, B. A., Weisberg, R. B., Dyck, I., \& Keller, M. B. (2011). Longitudinal course of obsessivecompulsive disorder in patients with anxiety disorders: a 15-year prospective follow-up study. Comprehensive Psychiatry, 52(6), 670-677. 
Mataix-Cols, D., Rosario-Campos, M. C., \& Leckman, J. F. (2005). A multidimensional model of obsessive-compulsive disorder. Am J Psychiatry, 162(2), 228-238. doi: 162/2/228 [pii] 10.1176/appi.ajp.162.2.228

Mathalon, D. H., Jorgensen, K. W., Roach, B. J., \& Ford, J. M. (2009). Error detection failures in schizophrenia: ERPs and FMRI. Int J Psychophysiol, 73(2), 109-117. doi: 10.1016/j.ijpsycho.2009.02.005

McGorry, P. D., Bell, R. C., Dudgeon, P. L., \& Jackson, H. J. (1998). The dimensional structure of first episode psychosis: an exploratory factor analysis. Psychological Medicine, 28(4), 935-947.

McGorry, P. D., Nelson, B., Phillips, L. J., Yuen, H. P., Francey, S. M., Thampi, A., . . Yung, A. R. (2013). Randomized controlled trial of interventions for young people at ultra-high risk of psychosis: twelve-month outcome. J Clin Psychiatry, 74(4), 349-356. doi: 10.4088/JCP.12m07785

Menzies, L., Achard, S., Chamberlain, S. R., Fineberg, N., Chen, C. H., del Campo, N., . . Bullmore, E. (2007). Neurocognitive endophenotypes of obsessive-compulsive disorder. Brain, 130(Pt 12), 3223-3236. doi: 10.1093/brain/awm205

Montagne, B., de Geus, F., Kessels, R., Denys, D., de Haan, E., \& Westenberg, H. (2008). Perception of facial expressions in obsessive-compulsive disorder: a dimensional approach. European psychiatry : the journal of the Association of European Psychiatrists, 23(1), 26-28. doi: 10.1016/j.eurpsy.2007.07.007

Moritz, S., Peters, M. J. V., LarÃ ,i, F., \& Lincoln, T. M. (2010). Metacognitive beliefs in obsessivecompulsive patients: A comparison with healthy and schizophrenia participants. Cognitive Neuropsychiatry, 15(6), 531-548.

Moritz, S., Van Quaquebeke, N., \& Lincoln, T. M. (2012). Jumping to conclusions is associated with paranoia but not general suspiciousness: a comparison of two versions of the probabilistic reasoning paradigm. Schizophr Res Treatment, 2012, 384039. doi: 10.1155/2012/384039

Moritz, S., \& Woodward, T. S. (2005). Jumping to conclusions in delusional and non-delusional schizophrenic patients. Br J Clin Psychol, 44(Pt 2), 193-207.

Morrison, A. P. (2001). The interpretation of intrusions in psychosis: An integrative cognitive approach to hallucinations and delusions. Behavioural and Cognitive Psychotherapy, 29(3), 257-276.

Morrison, A. P., \& Haddock, G. (1997). Cognitive factors in source monitoring and auditory hallucinations. Psychol Med, 27(3), 669-679.

Morrison, A. P., Stewart, S. L., French, P., Bentall, R. P., Birchwood, M., Byrne, R., . . Dunn, G. (2011). Early detection and intervention evaluation for people at high-risk of psychosis-2 (EDIE-2): trial rationale, design and baseline characteristics. Early Interv Psychiatry, 5(1), 24-32. doi: 10.1111/j.1751-7893.2010.00254.x

Neale, M. C., \& Kendler, K. S. (1995). Models of comorbidity for multifactorial disorders. Am J Hum Genet, 57(4), 935-953.

Nechmad, A., Ratzoni, G., Poyurovsky, M., Meged, S., Avidan, G., Fuchs, C., . . Weizman, R. (2003). Obsessive-compulsive disorder in adolescent schizophrenia patients. Am J Psychiatry, 160(5), 1002-1004.

Nestadt, G., Samuels, J., Riddle, M. A., Liang, K. Y., Bienvenu, O. J., Hoehn-Saric, R., . . Cullen, B. (2001). The relationship between obsessive-compulsive disorder and anxiety and affective disorders: results from the Johns Hopkins OCD Family Study. Psychol Med, 31(3), 481-487.

O'Toole, S. A., Weinborn, M., \& Fox, A. M. (2012). Performance monitoring among non-patients with obsessive-compulsive symptoms: ERP evidence of aberrant feedback monitoring. Biological psychology, 91(2), 221-228. doi: 10.1016/j.biopsycho.2012.06.005

Olincy, A., Braff, D. L., Adler, L. E., Cadenhead, K. S., Calkins, M. E., Dobie, D. J., . . Freedman, R. (2010). Inhibition of the P50 cerebral evoked response to repeated auditory stimuli: results from the Consortium on Genetics of Schizophrenia. Schizophrenia Research, 119(1-3), 175182. doi: 10.1016/j.schres.2010.03.004

Ongur, D., \& Goff, D. C. (2005). Obsessive-compulsive symptoms in schizophrenia: associated clinical features, cognitive function and medication status. Schizophr Res, 75(2-3), 349-362. 
Owashi, T., Ota, A., Otsubo, T., Susa, Y., \& Kamijima, K. (2010). Obsessive-compulsive disorder and obsessive-compulsive symptoms in Japanese inpatients with chronic schizophrenia - A possible schizophrenic subtype. Psychiatry Research, 179(3), 241-246. doi: 10.1016/j.psychres.2009.08.003

Patel, D. D., Laws, K. R., Padhi, A., Farrow, J. M., Mukhopadhaya, K., Krishnaiah, R., \& Fineberg, N. A. (2010). The neuropsychology of the schizo-obsessive subtype of schizophrenia: a new analysis. Psychological Medicine, 40(06), 921-933. doi: doi:10.1017/\$0033291709991255

Paulus, M. P., Frank, L., Brown, G. G., \& Braff, D. L. (2003). Schizophrenia subjects show intact success-related neural activation but impaired uncertainty processing during decisionmaking. Neuropsychopharmacology, 28(4), 795-806.

Pélissier, M.-C., O'Connor, K. P., \& Dupuis, G. (2009). When doubting begins: Exploring inductive reasoning in obsessive-compulsive disorder. Journal of Behavior Therapy and Experimental Psychiatry, 40(1), 39-49. doi: 10.1016/j.jbtep.2008.03.003

Pelissier, M. C., \& O'Connor, K. P. (2002). Deductive and inductive reasoning in obsessive-compulsive disorder. Br J Clin Psychol, 41(Pt 1), 15-27.

Peralta, V., \& Cuesta, M. J. (2009). Characterization of affective domains within the nonaffective psychotic disorders. Schizophr Res, 111(1-3), 61-69. doi: 10.1016/j.schres.2009.03.008

Perez, V. B., Ford, J. M., Roach, B. J., Woods, S. W., McGlashan, T. H., Srihari, V. H., . . Mathalon, D. H. (2012). Error monitoring dysfunction across the illness course of schizophrenia. J Abnorm Psychol, 121(2), 372-387. doi: 10.1037/a0025487

Poulton, R., Caspi, A., Moffitt, T. E., Cannon, M., Murray, R., \& Harrington, H. (2000). Children's selfreported psychotic symptoms and adult schizophreniform disorder: a 15-year longitudinal study. Arch Gen Psychiatry, 57(11), 1053-1058.

Poyurovsky, M., Faragian, S., Pashinian, A., Heidrach, L., Fuchs, C., Weizman, R., \& Koran, L. (2008). Clinical characteristics of schizotypal-related obsessive-compulsive disorder. Psychiatry Research, 159(1-2), 254-258. doi: http://dx.doi.org/10.1016/j.psychres.2007.02.019

Quarantini, L. C., Torres, A. R., Sampaio, A. S., Fossaluza, V., Mathis, M. A., do Rosario, M. C., . . . Koenen, K. C. (2011). Comorbid major depression in obsessive-compulsive disorder patients. Compr Psychiatry, 52(4), 386-393. doi: 10.1016/j.comppsych.2010.09.006

Rachman, S. (1997). A cognitive theory of obsessions. Behav Res Ther, 35(9), 793-802.

Rachman, S., \& Hodgson, R. (1980). Obsessions and compulsions. New Jersey: Prentice/Hall International: Hemel Hempstead.

Radant, A. D., Dobie, D. J., Calkins, M. E., Olincy, A., Braff, D. L., Cadenhead, K. S., ... Tsuang, D. W. (2010). Antisaccade performance in schizophrenia patients, their first-degree biological relatives, and community comparison subjects: data from the COGS study. Psychophysiology, 47(5), 846-856. doi: 10.1111/j.1469-8986.2010.01004.x

Rajender, G., Bhatia, M. S., Kanwal, K., Malhotra, S., Singh, T. B., \& Chaudhary, D. (2011). Study of neurocognitive endophenotypes in drug-naïve obsessive-compulsive disorder patients, their first-degree relatives and healthy controls. Acta Psychiatrica Scandinavica, 124(2), 152-161. doi: 10.1111/j.1600-0447.2011.01733.x

Reznik, I., Mester, R., Kotler, M., \& Weizman, A. (2001). Obsessive-compulsive schizophrenia: a new diagnostic entity? J Neuropsychiatry Clin Neurosci, 13(1), 115-116.

Ricciardi, J. N., \& McNally, R. J. (1995). Depressed mood is related to obsessions, but not to compulsions, in obsessive-compulsive disorder. J Anxiety Disord, 9(3), 249-256.

Riesel, A., Endrass, T., Kaufmann, C., \& Kathmann, N. (2011). Overactive error-related brain activity as a candidate endophenotype for obsessive-compulsive disorder: evidence from unaffected first-degree relatives. The American journal of psychiatry, 168(3), 317-324. doi: 10.1176/appi.ajp.2010.10030416

Rietdijk, J., Ising, H. K., Dragt, S., Klaassen, R., Nieman, D., Wunderink, L., . . van der Gaag, M. (2013). Depression and social anxiety in help-seeking patients with an ultra-high risk for developing psychosis. Psychiatry Res. doi: 10.1016/j.psychres.2013.01.012 
Rössler, W., Angst, J., Gamma, A., Haker, H., Stulz, N., Merikangas, K., \& Ajdacic-Gross, V. (2011). Reappraisal of the interplay between psychosis and depression symptoms in the pathogenesis of psychotic syndromes: results from a twenty-year prospective community study. European Archives of Psychiatry and Clinical Neuroscience, 261(1), 11-19. doi: 10.1007/s00406-010-0123-0

Rubio, J. L., Ruiz-Veguilla, M., Hernandez, L., Barrigon, M. L., Salcedo, M. D., Moreno, J. M., . . Ferrin, M. (2011). Jumping to conclusions in psychosis: a faulty appraisal. Schizophr Res, 133(1-3), 199-204. doi: 10.1016/j.schres.2011.08.008

Ruscio, A. M., Stein, D. J., Chiu, W. T., \& Kessler, R. C. (2010). The epidemiology of obsessivecompulsive disorder in the National Comorbidity Survey Replication. Mol Psychiatry, 15(1), 53-63.

Salkovskis, P. M., \& Harrison, J. (1984). Abnormal and normal obsessions--a replication. Behav Res Ther, 22(5), 549-552.

Sareen, J., Kirshner, A., Lander, M., Kjernisted, K. D., Eleff, M. K., \& Reiss, J. P. (2004). Do antipsychotics ameliorate or exacerbate Obsessive Compulsive Disorder symptoms?: A systematic review. Journal of Affective Disorders, 82(2), 167-174. doi: http://dx.doi.org/10.1016/i.jad.2004.03.011

Scheltema Beduin, A. A., Swets, M., Machielsen, M., Korver, N., Genetic, R., \& Outcome of Psychosis, I. (2012). Obsessive-compulsive symptoms in patients with schizophrenia: a naturalistic cross-sectional study comparing treatment with clozapine, olanzapine, risperidone, and no antipsychotics in 543 patients. J Clin Psychiatry, 73(11), 1395-1402. doi: 10.4088/JCP.11m07164

Schirmbeck, F., Rausch, F., Englisch, S., Eifler, S., Esslinger, C., Meyer-Lindenberg, A., \& Zink, M. (2013). Differential effects of antipsychotic agents on obsessive-compulsive symptoms in schizophrenia: a longitudinal study. J Psychopharmacol, 27(4), 349-357. doi: 10.1177/0269881112463470

Schirmbeck, F., \& Zink, M. (2013). Comorbid obsessive-compulsive symptoms in schizophrenia: contributions of pharmacological and genetic factors. Front Pharmacol, 4, 99. doi: 10.3389/fphar.2013.00099

Sevincok, L., Akoglu, A., \& Arslantas, H. (2006). Schizo-obsessive and obsessive-compulsive disorder: comparison of clinical characteristics and neurological soft signs. Psychiatry Res, 145(2-3), 241-248. doi: 10.1016/j.psychres.2005.11.010

Silver, H., Goodman, C., Bilker, W., Gur, R. C., Isakov, V., Knoll, G., \& Feldman, P. (2006). Impaired error monitoring contributes to face recognition deficit in schizophrenia patients. Schizophr Res, 85(1-3), 151-161. doi: 10.1016/j.schres.2006.02.027

Skoog, G., \& Skoog, I. (1999). A 40-year follow-up of patients with obsessive-compulsive disorder [see commetns]. Arch Gen Psychiatry, 56(2), 121-127.

Smeets, F., Lataster, T., Dominguez, M.-d.-G., Hommes, J., Lieb, R., Wittchen, H.-U., \& van Os, J. (2010). Evidence That Onset of Psychosis in the Population Reflects Early Hallucinatory Experiences That Through Environmental Risks and Affective Dysregulation Become Complicated by Delusions. Schizophrenia Bulletin. doi: 10.1093/schbul/sbq117

Solyom, L., DiNicola, V. F., Phil, M., Sookman, D., \& Luchins, D. (1985). Is there an obsessive psychosis? Aetiological and prognostic factors of an atypical form of obsessive-compulsive neurosis. Can J Psychiatry, 30(5), 372-380.

Speechley, W. J., Whitman, J. C., \& Woodward, T. S. (2010). The contribution of hypersalience to the "jumping to conclusions" bias associated with delusions in schizophrenia. $J$ Psychiatry Neurosci, 35(1), 7-17.

Spinella, M. (2005). Mood in relation to subclinical obsessive-compulsive symptoms. Int J Neurosci, 115(4), 433-443.

Stefanis, N. C., Hanssen, M., Smirnis, N. K., Avramopoulos, D. A., Evdokimidis, I. K., Stefanis, C. N., ... Van Os, J. (2002). Evidence that three dimensions of psychosis have a distribution in the general population. Psychol Med, 32(2), 347-358. 
Stern, E. R., Welsh, R. C., Fitzgerald, K. D., Gehring, W. J., Lister, J. J., Himle, J. A., . . Taylor, S. F. (2011). Hyperactive error responses and altered connectivity in ventromedial and frontoinsular cortices in obsessive-compulsive disorder. Biol Psychiatry, 69(6), 583-591. doi: S0006-3223(10)01017-6 [pii]10.1016/j.biopsych.2010.09.048

Stern, R., \& Cobb, J. (1978). Phenomenology of obsessive-compulsive neurosis. British Journal of Psychiatry.

Stewart, S. E., Geller, D. A., Jenike, M., Pauls, D., Shaw, D., Mullin, B., \& Faraone, S. V. (2004). Longterm outcome of pediatric obsessive-compulsive disorder: a meta-analysis and qualitative review of the literature. Acta Psychiatrica Scandinavica, 110(1), 4-13. doi: 10.1111/j.16000447.2004.00302.x

Taylor, M. A. (1992). Are schizophrenia and affective disorder related? A selective literature review. The American journal of psychiatry.

Thomsen, P. H., \& Mikkelsen, H. U. (1995). Course of obsessive-compulsive disorder in children and adolescents: a prospective follow-up study of 23 Danish cases. J Am Acad Child Adolesc Psychiatry, 34(11), 1432-1440.

Tibbo, P., Kroetsch, M., Chue, P., \& Warneke, L. (2000). Obsessive-compulsive disorder in schizophrenia. J Psychiatr Res, 34(2), 139-146.

Timpano, K. R., Rubenstein, L. M., \& Murphy, D. L. (2012). Phenomenological features and clinical impact of affective disorders in OCD: a focus on the bipolar disorder and OCD connection. Depress Anxiety, 29(3), 226-233. doi: 10.1002/da.20908

Tiryaki, A., \& Özkorumak, E. (2010). Do the obsessive-compulsive symptoms have an effect in schizophrenia? Comprehensive Psychiatry, 51(4), 357-362. doi: 10.1016/j.comppsych.2009.10.007

Tolin, D. F., Abramowitz, J. S., Przeworski, A., \& Foa, E. B. (2002). Thought suppression in obsessivecompulsive disorder. Behaviour Research and Therapy, 4O(11), 1255-1274.

Toomey, R., Faraone, S. V., Simpson, J. C., \& Tsuang, M. T. (1998). Negative, positive, and disorganized symptom dimensions in schizophrenia, major depression, and bipolar disorder. $J$ Nerv Ment Dis, 186(8), 470-476.

Tumkaya, S., Karadag, F., Oguzhanoglu, N. K., Tekkanat, C., Varma, G., Ozdel, O., \& Ateşçi, F. (2009). Schizophrenia with obsessive-compulsive disorder and obsessive-compulsive disorder with poor insight: A neuropsychological comparison. Psychiatry Research, 165(1-2), 38-46. doi: http://dx.doi.org/10.1016/i.psychres.2007.07.031

Tundo, A., Salvati, L., Di Spigno, D., Cieri, L., Parena, A., Necci, R., \& Sciortino, S. (2012). CognitiveBehavioral Therapy for Obsessive-Compulsive Disorder as a Comorbidity with Schizophrenia or Schizoaffective Disorder. Psychotherapy and Psychosomatics, 81(1), 58-60.

Turetsky, B. I., Calkins, M. E., Light, G. A., Olincy, A., Radant, A. D., \& Swerdlow, N. R. (2007). Neurophysiological endophenotypes of schizophrenia: the viability of selected candidate measures. Schizophrenia Bulletin, 33(1), 69-94. doi: 10.1093/schbul/sbl060

Ulhaq, I., \& Abba-Aji, A. (2012). Haloperidol induced obsessive compulsive symptom (OCS) in a patient with learning disability and bipolar affective disorder. BMJ Case Rep, 2012. doi: 10.1136/bcr.11.2011.5161

Ursu, S., Stenger, V. A., Shear, M. K., Jones, M. R., \& Carter, C. S. (2003). Overactive action monitoring in obsessive-compulsive disorder: evidence from functional magnetic resonance imaging. Psychol Sci, 14(4), 347-353. doi: psci_24411 [pii]

Valleni-Basile, L. A., Garrison, C. Z., Jackson, K. L., Waller, J. L., McKeown, R. E., Addy, C. L., \& Cuffe, S. P. (1994). Frequency of obsessive-compulsive disorder in a community sample of young adolescents. J Am Acad Child Adolesc Psychiatry, 33(6), 782-791.

Valleni-Basile, L. A., Garrison, C. Z., Waller, J. L., Addy, C. L., McKeown, R. E., Jackson, K. L., \& Cuffe, S. P. (1996). Incidence of obsessive-compulsive disorder in a community sample of young adolescents. J Am Acad Child Adolesc Psychiatry, 35(7), 898-906.

van der Gaag, M., Cuijpers, A., Hoffman, T., Remijsen, M., Hijman, R., de Haan, L., . . Wiersma, D. (2006). The five-factor model of the Positive and Negative Syndrome Scale I: confirmatory 
factor analysis fails to confirm 25 published five-factor solutions. Schizophr Res, 85(1-3), 273279. doi: S0920-9964(06)00170-8 [pii]10.1016/j.schres.2006.04.001

van Os, J. (2003). Is there a continuum of psychotic experiences in the general population? Epidemiologia e psichiatria sociale, 12(4), 242-252.

van Os, J., \& Kapur, S. (2009). Schizophrenia. Lancet, 374(9690), 635-645. doi: 10.1016/S01406736(09)60995-8

van Rossum, I., Dominguez, M. D., Lieb, R., Wittchen, H. U., \& van Os, J. (2011). Affective dysregulation and reality distortion: a 10 -year prospective study of their association and clinical relevance. Schizophr Bull, 37(3), 561-571. doi: sbp101 [pii]10.1093/schbul/sbp101

Varese, F., Barkus, E., \& Bentall, R. P. (2012). Dissociation mediates the relationship between childhood trauma and hallucination-proneness. Psychol Med, 42(5), 1025-1036. doi: S0033291711001826 [pii]10.1017/S0033291711001826

Varese, F., \& Bentall, R. P. (2011). The metacognitive beliefs account of hallucinatory experiences: A literature review and meta-analysis. Clinical Psychology Review, 31(5), 850-864.

Versmissen, D., Myin-Germeys, I., Janssen, I., Franck, N., Georgieff, N., a Campo, J., . . . Krabbendam, L. (2007). Impairment of self-monitoring: part of the endophenotypic risk for psychosis. $\mathrm{Br} \mathrm{J}$ Psychiatry Suppl, 51, s58-62. doi: 191/51/s58 [pii]10.1192/bjp.191.51.s58

Viswanath, B., Janardhan Reddy, Y. C., Kumar, K. J., Kandavel, T., \& Chandrashekar, C. R. (2009). Cognitive endophenotypes in OCD: A study of unaffected siblings of probands with familial OCD. Progress in Neuro-Psychopharmacology and Biological Psychiatry, 33(4), 610-615. doi: 10.1016/j.pnpbp.2009.02.018

Volans, P. J. (1976). Styles of decision-making and probability appraisal in selected obsessional and phobic patients. Br J Soc Clin Psychol, 15(3), 305-317.

Vollema, M. G., \& Hoijtink, H. (2000). The Multidimensionality of Self-Report Schizotypy in a Psychiatric Population: An Analysis Using Multidimensional Rasch Models. Schizophrenia Bulletin, 26(3), 565-575.

Warman, D. M., Lysaker, P. H., Martin, J. M., Davis, L., \& Haudenschield, S. L. (2007). Jumping to conclusions and the continuum of delusional beliefs. Behav Res Ther, 45(6), 1255-1269.

Warman, D. M., \& Martin, J. M. (2006). Jumping to conclusions and delusion proneness: the impact of emotionally salient stimuli. J Nerv Ment Dis, 194(10), 760-765.

Waters, F. A., Badcock, J. C., Maybery, M. T., \& Michie, P. T. (2003). Inhibition in schizophrenia: association with auditory hallucinations. Schizophr Res, 62(3), 275-280.

Whitney, K. A., Fastenau, P. S., Evans, J. D., \& Lysaker, P. H. (2004). Comparative neuropsychological function in obsessive-compulsive disorder and schizophrenia with and without obsessivecompulsive symptoms. Schizophr Res, 69(1), 75-83.

Wigman, J. T. W., van Nierop, M., Vollebergh, W. A. M., Lieb, R., Beesdo-Baum, K., Wittchen, H.-U., \& van Os, J. (2012). Evidence That Psychotic Symptoms Are Prevalent in Disorders of Anxiety and Depression, Impacting on IIIness Onset, Risk, and Severity-Implications for Diagnosis and Ultra-High Risk Research. Schizophrenia Bulletin, 38(2), 247-257. doi: $10.1093 / \mathrm{schbul} / \mathrm{sbr} 196$

Wobrock, T., Schneider, M., Kadovic, D., Schneider-Axmann, T., Ecker, U. K. H., Retz, W., .. Falkai, P. (2008). Reduced cortical inhibition in first-episode schizophrenia. Schizophrenia Research, 105(1-3), 252-261. doi: http://dx.doi.org/10.1016/i.schres.2008.06.001

OCD: obsessive-compulsive disorder

OCD: obsessive-compulsive symptoms 


\section{Chapter 7}

\section{Valorization}

Isaac Newton zag een appel en dacht: zie ik dat goed? Het is niet wat het is, ' $t$ is wat je ermee doet. 


\section{Unmet needs}

Mental health problems lay a heavy burden on every person affected, his or her family and friends and for society. The burden on the affected persons, apart from the unpleasant experience of symptoms, often includes much other kinds of interference in someone's life. For developmental disorders such as psychosis and also for obsessive-compulsive disorder $(O C D)$, the confrontation with symptoms often happens in a crucial stage in life, and therefore can have a considerable impact on educational and vocational achievements, social functioning, intimate relationships and self-fulfillment. Need for care often arises, but alas, the provided care cannot always meet the needs. Quality of life is often diminished, and sometimes the ability to live (autonomously) is compromised. Indeed, rates of suicide are enhanced for people with schizophrenia.

Fortunately, not every individual experiencing symptoms at a certain moment in time develops a disorder, and complete recovery also often occurs. But then again, the uncertainty about which trajectory one will follow is distressing. When professional care (which implies: a categorical diagnosis) is given, the prognosis remains uncertain, and the risk for stigma and iatrogenic harm increases. For caring friends and family, and professional caregivers, it is a big challenge to provide adequate support, to facilitate self-management and to tune optimal care. For society, the direct and indirect socio-economic costs of mental health are considerable. In Europe, in 2010 alone, these costs have been estimated at 29 billion euros for psychotic disorders, 65,9 billion euros for anxiety disorders and 113.4 billion euros for mood disorders, corresponding with a cost per subject of 5805 euros for psychotic disorders, 1076 euros for anxiety disorders and 3406 euros for mood disorders (Gustavsson et al., 2011).

As shown in chapter 2, the co-occurrence of OCD and schizophrenia has been associated with poor prognosis, and consequently most probably higher socio-economic costs (Poyurovsky et al., 2003; Poyurovsky, Weizman, \& Weizman, 2004; Van Dael et al., 2011). Pharmacological treatment for psychotic disorders as well as OCD has its merits but also important limitations, i.e. insufficient effect and appreciable side effects, particularly in the long term. For co-occurring psychosis and $O C D$, the limitations are even stronger, as secondgeneration antipsychotics, can induce or aggravate obsessive-compulsive symptoms, although in other cases they clearly have a beneficial effect on these symptoms (Schirmbeck et al., 2013). To date, the response still is highly unpredictable, causing a challenge for clinical management.

Thus, alternative treatment options are urgently needed. Several options are conceivable.

(i) Pharmacological agents with higher response rates and less side effects, i.e. with other working mechanisms.

(ii) Further development of non-pharmacological treatment, such as cognitive behavioral therapy, acceptance and commitment therapy, or meta-cognitive therapy. 
(iii) A more accurate prediction of the risk for an evolution to more and more severe symptoms, resulting in need for care for an individual subject.

(iv) Options that do not focus on reducing symptoms, but increasing resilience and adaptation.

Each of these options holds promises and face obstacles.

Ad (i). All antipsychotic agents, now used for over half a century, share (mesolimbic) dopamine D2 receptor antagonism as the main mechanism of action. Dopamine is supposed to have role in the formation and maintenance of $O C D$, and there are scarce reports of beneficial effects of antipsychotic agents on obsessive-compulsive symptoms. However success is limited. The second generation antipsychotics show a $5 \mathrm{HT} 2 \mathrm{C}$ antagonism, which is supposed to have a role in the suppression of OCD in some cases, and in the provocation of OCD in other cases.

The classic option of an SSRI or another antidepressant has a limited response rate. Hence, other options are necessary, but not yet available nor in the pipeline. Glutamatergic agents probably are most promising, given growing evidence for the role of glutamate in the pathogenesis of psychosis as well as OCD. However, taken together, at present, the response to psychopharmacological treatment is limited and insufficiently predictable, while side effects often occur.

Ad (ii). Non-pharmacological treatments, particularly different kinds of psychotherapy, have deservedly gained more interest in recent years. Their added value, compared to pharmacotherapy, lies in higher acceptability, substantially lower side effects, and the possibility to provide them tailor-made, rather than in higher response rates. For example, in metacognitive therapy, metacognitions and cognitive biases can be individually traced, and skills to recognize and counter them can be trained. As shown in chapter 5 of this thesis, a jumping to conclusions (JTC) cognitive bias is present in subjects with a liability to psychosis and seems to play a role in the formation and maintenance of delusions. Addressing the JTC and particular other metacognitions and cognitive biases has proven successful in psychosis and OCD (Briki et al., 2014; Moritz, Jelinek, Hauschildt, \& Naber, 2010; Solem, Myers, Fisher, Vogel, \& Wells, 2010), and therefore are likely to be successful in co-occuring psychosis and OCD. Indeed, up to date, the parallel psychological models of psychosis and OCD offer the possibility for an integrated yet tailor-made treatment plan for metacognitive therapy.

Ad (iii). Substantial efforts are made to reduce the duration of untreated psychosis (DUP), mainly by improving early detections of the subjects with an at-risk mental state (ARMS) or a at ultra-high risk (UHR) (Cechnicki et al., 2014). Without any doubt, progression has been made: early intervention services succeeded in shortening the DUP. However, the sensitivity and specificity with which we can predict the course and tune care is not satisfying. The clinical staging model accounts for the aspecific presentation of psychopathology in the early stages, and assumes that along the way it becomes crystallized, showing more disorderspecific symptoms: the so-called transition. Hopefully, better knowledge and monitoring of 
biomarkers and risk factors would enhance sensitivity and specificity (McGorry, Nelson, Goldstone, \& Yung, 2010), and account for the numerous cases without "transition". In this thesis, particularly in chapter 2 and 4 , it was shown that the co-occurrence of obsessivecompulsive and psychotic features, below diagnostic threshold, implies a substantial increase in risk for higher symptom severity with need for care. Other mood and anxiety probably have a similar, though distinct effect (Fusar-Poli, Nelson, Valmaggia, Yung, \& McGuire, 2012; van Os \& Murray, 2013). Thus, it may make sense to focus on treating psychosis in non-psychotic disorders. This has consequences for the diagnose-specific organization of mental health care.

As discussed in chapter 6 , network models can account for the symptom connectivity and its dynamic changes over time. Connections between symptoms can be weak or stronger, and function as positive or negative feedforward or feedback loops. With the knowledge gained from large-scale networks such as the internet and well-established methods such as the experience sampling method, a new possibility to analyse and monitor these network interactions emerges. Moreover, thanks to fast evolving ICT, small but powerful devices, such as smartphones and wearables containing sensors, processors and connectivity, provide new possibilities for monitoring and analyzing parameters, providing feedback on the spot and almost real time.

Ad (iv). These network models shed new light on prediction and prevention. In the past, therapy often was focused on symptom reduction, because of lack of causal remedies, and on pooled individual risk factors, with disappointing predictive value. In the near future, focus probably will shift to resilience, in terms of stability of a network of symptoms. Strength of connections and dynamic mutual influences in someone's individual network probably enable to predict a "tipping point".

Taken together, these options can contribute to get to personalized medicine in psychiatry, which would be a major innovation. Today, mental health care is entrapped in the Procrustean bed of stringent financing categories, based on the categorical diagnoses of the Diagnostic and Statistical Manual, neglecting the heterogeneity of phenotypes and the diversity of trajectories. Clearly, this approach has not proved very helpful to increase the performance of mental health care. Luckily, in other contexts, efforts are made to implement personalized medicine in psychiatry, based on successful examples in pharmacology, oncology and other disciplines (Jain, 2002; Ozomaro, Wahlestedt, \& Nemeroff, 2013). This encompasses assessing genetic and epigenetic factors associated with a given mental disorder, guiding pharmacologic therapies (i.e. estimating the choice and dosage of medication based on genetic profiles). Adding knowledge of network models, more precisely

information on individual networks of connected symptoms, probably can give a boost to the development of personalized medicine in psychiatry. 
In addition to new ways to process a new kind of information, implementation of these methods will contribute to self-management and empowerment of persons with symptoms and need for care. Consequently, economic and societal costs may be reduced.

\section{Dissemination}

The work in this thesis is published in scientific journals and presented at scientific and professional conferences. As mentioned above, the relevance is not only scientific, but has consequences for clinical practice.

Projects with large-scale longitudinal datasets containing data of patients, relatives and healthy controls, have yielded valuable results and new insights. The value is not only in each of the published results or in a rich store of data, but in the fact that large-scale research collaborations, such as GROUP, leave a network of researchers and clinicians and an infrastructure. As described with symptom networks above, research networks too offer possibilities that the pooled individuals don't. The infrastructure provides possibilities for implanting research-driven improvements in clinical practice.

Epidemiologic and health data are not only collected and used for scientific purposes, but also for clinical and economic use. Nowadays, it is technically easier then ever before to collect, save and analyze data, which indeed happens on large scale. Recently, parallel with the growing recognition of value of data and the power of analyses, the extreme importance of safety, ownership, control and purpose of data has become clear. In mental health care in the Netherlands, health providers are forced to collect large sets of personal data of patients that are stored by third parties for use by government and insurance companies for political and ecomomic use. One problematic consequence of this practice is that the management and use of these patient data de facto are withdrawn from patients, clinicians and scientific researchers. This brings along a latent risk, but also a loss of involvement of important stakeholders in mental health care: every citizen facing the possibility of a future mental health problem, every patient and every provider of care. The work presented in this thesis hopefully convincingly demonstrates that collaboration with researchers and clinicians can produce valuable results and actually is too indispensable to disregard.

\section{Uncertainty}

Although we showed the added value and potential applications resulting from the findings presented in this thesis, we realize that the valorization of research is hard to predict and highly subjective. After all, some of the most used applications today, were not forseen at the time of their discovery, and were by no means a motivation for the original research. For example, data encryption as used massively by anyone of us, is based on number theory, which had almost no practical application for more then a century. Moreover, it is claimed that future progression in number theory, may imply a threat for the safety of data encryption. Would that imply "devalorisation"? 


\section{References}

Briki, M., Monnin, J., Haffen, E., Sechter, D., Favrod, J., Netillard, C., . . . Vandel, P. (2014). Metacognitive training for schizophrenia: a multicentre randomised controlled trial. Schizophr Res, 157(1-3), 99-106. doi: 10.1016/j.schres.2014.06.005

Cechnicki, A., Cichocki, L., Kalisz, A., Bladzinski, P., Adamczyk, P., \& Franczyk-Glita, J. (2014). Duration of untreated psychosis (DUP) and the course of schizophrenia in a 20-year follow-up study. Psychiatry Res, 219(3), 420-425. doi: 10.1016/j.psychres.2014.05.046

Fusar-Poli, P., Nelson, B., Valmaggia, L., Yung, A. R., \& McGuire, P. K. (2012). Comorbid Depressive and Anxiety Disorders in 509 Individuals With an At-Risk Mental State: Impact on Psychopathology and Transition to Psychosis. Schizophr Bull. doi: 10.1093/schbul/sbs136

Gustavsson, A., Svensson, M., Jacobi, F., Allgulander, C., Alonso, J., Beghi, E., . . Olesen, J. (2011). Cost of disorders of the brain in Europe 2010. European Neuropsychopharmacology, 21(10), 718-779. doi: http://dx.doi.org/10.1016/j.euroneuro.2011.08.008

Jain, K. K. (2002). Personalized medicine. Curr Opin Mol Ther, 4(6), 548-558.

McGorry, P. D., Nelson, B., Goldstone, S., \& Yung, A. R. (2010). Clinical staging: a heuristic and practical strategy for new research and better health and social outcomes for psychotic and related mood disorders. Can J Psychiatry, 55(8), 486-497.

Moritz, S., Jelinek, L., Hauschildt, M., \& Naber, D. (2010). How to treat the untreated: effectiveness of a selfhelp metacognitive training program (myMCT) for obsessive-compulsive disorder. Dialogues Clin Neurosci, 12(2), 209-220.

Ozomaro, U., Wahlestedt, C., \& Nemeroff, C. B. (2013). Personalized medicine in psychiatry: problems and promises. BMC Med, 11, 132. doi: 10.1186/1741-7015-11-132

Poyurovsky, M., Kriss, V., Weisman, G., Faragian, S., Kurs, R., Schneidman, M., . . W Weizman, R. (2003). Comparison of clinical characteristics and comorbidity in schizophrenia patients with and without obsessive-compulsive disorder: schizophrenic and OC symptoms in schizophrenia. J Clin Psychiatry, 64(11), 1300-1307.

Poyurovsky, M., Weizman, A., \& Weizman, R. (2004). Obsessive-compulsive disorder in schizophrenia: clinical characteristics and treatment. CNS Drugs, 18(14), 989-1010.

Schirmbeck, F., Rausch, F., Englisch, S., Eifler, S., Esslinger, C., Meyer-Lindenberg, A., \& Zink, M. (2013). Differential effects of antipsychotic agents on obsessive-compulsive symptoms in schizophrenia: a longitudinal study. J Psychopharmacol, 27(4), 349-357. doi: 10.1177/0269881112463470

Solem, S., Myers, S. G., Fisher, P. L., Vogel, P. A., \& Wells, A. (2010). An empirical test of the metacognitive model of obsessive-compulsive symptoms: replication and extension. J Anxiety Disord, 24(1), 79-86. doi: 10.1016/j.janxdis.2009.08.009

Van Dael, F., van Os, J., de Graaf, R., ten Have, M., Krabbendam, L., \& Myin-Germeys, I. (2011). Can obsessions drive you mad? Longitudinal evidence that obsessive-compulsive symptoms worsen the outcome of early psychotic experiences. Acta Psychiatr Scand, 123(2), 136-146. doi: 10.1111/j.16000447.2010.01609.x

van Os, J., \& Murray, R. M. (2013). Can we identify and treat "schizophrenia light" to prevent true psychotic illness? Bmj, 346, f304. doi: 10.1136/bmj.f304 


\title{
Chapter
}

\section{Epilogue}

\author{
Summary \\ Samenvatting \\ Dankwoord \\ Curriculum Vitae \\ Publications
}




\section{Summary}

OCD and schizophrenia co-occur far more often than expected by chance. The mechanism underpinning this high co-occurrence is not very well understood. If OCD and psychosis cooccur, symptom severity tends to be higher and the impact on social functioning and need for care seems to be stronger.

Symptom dimensions of both disorders show overlap. Psychological and neurobiological models of both disorders show analogies, but how the disorders and their symptoms dimensions co-vary and impact on each other remains insufficiently explained.

The objective of this thesis was to help provide a better understanding of the development and course of the co-occurrence of obsessive-compulsive and psychosis symptoms. Previous research often was hampered by lack of validity of categorical diagnoses and treatment and selection bias. In order to overcome these limitations, the research reported in this thesis accounts for (i) symptom dimensions, (ii) a continuous distribution of the extended phenotype below the diagnostic threshold and (iii) changes over time. Therefore, several large samples were used. An introduction to the methods and psychological models is provided in chapter 1.

Chapter 2 examines how the extended phenotypes of OCD and psychosis co-occur and impact on each other over time. It was examined (i) whether obsessions and psychotic symptoms co-occur more often than would be expected by chance, at clinical and subclinical level, and whether this combination increases the risk for higher impairment and helpseeking, i.e. poor prognosis. These questions were examined in a large sample of more than 7000 subjects the Dutch general population, cross-sectionally and longitudinally over a period of 3 years. Results showed that at baseline, cross-sectionally, a lifetime diagnosis of psychotic disorder was present in 1,5\% of the entire sample, in $11,5 \%$ of the people with any obsessive-compulsive symptom and in $23 \%$ of individuals diagnosed with OCD. Also, associations between baseline obsessive-compulsive symptoms and the psychosis phenotype became progressively stronger when increasingly more stringent definitions were used along the psychosis and OCD extended phenotypes respectively.

When followed over time, OC symptoms at baseline predicted incident psychotic symptoms three years later and likewise, psychotic symptoms at baseline predicted the emergence of obsessive-compulsive symptoms 3 years later. The likelihood of persistence of psychotic symptoms and the transition from symptoms to psychotic disorder was higher if the early psychosis was accompanied by OC symptoms. In contrast, no association was found for the reverse association: psychotic symptoms at baseline did not influence persistence of $O C$ symptoms, nor transition tot disorder. These findings show that the tendency of OCD and psychosis to cluster together found in earlier studies, can also be found at subclinical level. The combination of obsessive-compulsive with psychotic symptoms, even at subclinical level, increases the risk for transition to psychotic disorder with need for care. 
Given (i) the evidence for familial and etiological continuity between transitory subclinical phenomena and clinically relevant symptom dimensions in OCD as well as in schizophrenia, (ii) the high rates of co-occurrence of both phenotypes at clinical and subclinical level, shown in chapter 2, and (iii) evidence for shared neuropsychological and neurobiological correlates and parallels in psychological models explaining $O C$ and psychotic symptoms, the question rises whether the $\mathrm{OC}$ and psychosis phenotype share etiological mechanisms. In chapter $\mathbf{3}$, in a large sample with patients, their unaffected relatives and healthy controls in the general population, two approaches are used to test the hypothesis that familial psychosis liability (indexed by patient-unaffected sibling-control) predisposes for OC symptoms. First, the association between OCS and psychosis liability is examined. It was predicted that in case OCS and psychotic symptoms share a familial or genetic etiology, unaffected siblings of patients with psychosis would have an elevated risk for the development of OCS compared to controls.

Second, cross-sib cross-trait analyses were conducted to investigate whether psychosis levels in one sibling are associated with OC symptoms levels in the other sibling. Analogous, in case of a shared genetic or familial etiology, it is expected that OCS in a patient would show an association with psychosis dimensions in the unaffected sibling and vice versa. Findings of the former analyses showed that indeed the expression of OCS was significantly associated with the familial psychosis liability (which is enhanced in the unaffected firstdegree relatives of patients with psychosis), even when adjusted for the actual expression of psychotic symptoms. The second analyses showed that OCS in patients with psychosis were associated with subclinical positive symptoms in their unaffected siblings. It is discussed to what extent the findings are compatible with the existence of a partially shared etiological pathway.

The possibility of a partially shared etiological or pathogenetic pathway is reflected in parallelism of psychological models of OCD and psychosis. In chapter 4, it was examined whether the co-occurrence of obsessive and psychotic symptoms may originate from a partial common pathway from intrusive thoughts to obsessions or hallucinatory symptoms respectively, with delusional appraisals facilitating the pathway to further psychosis. An important paradigm in psychological models of OCD states that intrusive thoughts can lead to later OCS, given the presence of a number of predisposing factors. In chapter 4 , this paradigm was tested and confirmed in a large general population sample, followed over a period of 8,4 years. Similarly, intrusive thoughts predicted later hallucinatory experiences. Next, it was shown that, given the presence of intrusive thoughts at baseline, the cooccurrence of incident delusional symptoms with OC symptoms 3,5 years later, significantly increased the risk of an outcome of clinical psychosis after 8,4 years. Similarly, the cooccurrence of an incident delusion with hallucinatory experiences significantly increased the risk for later clinical psychosis (i.e. with need for care), contingent on presence of initial intrusive thoughts at baseline. 
It was concluded that intrusive thoughts may reflect the earliest stage of obsessions as well as of hallucinatory experiences. Superimposed incident delusional ideation may represent a deepening of the early psychotic state, resulting in impairment and help-seeking. These findings are in line with contemporary cognitive models of psychosis and OCD and recent neurobiological findings, and may help to understand the mechanism underlying the observed comorbidity between OCD and psychosis, and its poor prognosis.

In the aforementioned psychological models describing the development of OCD c.q. psychosis, particular cognitive biases are proposed to facilitate the development of symptoms and eventually clinical disorder. Decision making under uncertainty is at issue for both phenotypes. In chapter $\mathbf{5}$, the role of a particular reasoning bias, referred to as a "jumping to conclusions", or more precisely, a "data gathering bias" in the formation and maintenance of delusions was investigated. In an earlier study, it was shown that a data gathering bias was negatively correlated with obsessive-compulsive disorder. In the present study, involving several measurements in 3 groups (patients, first degree relatives and controls) it was investigated whether this reasoning bias was associated with particular symptoms dimensions of psychosis, and whether the JTC was associated with psychosis liability, defined as genetic (first degree relatives of patients with psychosis) or psychometric risk (group with above average vs. under average delusional experiences). Results showed that the JTC was associated with familial and psychometric psychosis liability (stable trait, possibly qualifying for a candidate endophenotype), and also with level of delusional ideation (temporal state). In addition, the association between psychosis liability and JTC was generally much stronger as the level of delusional ideation was higher. It is concluded that a JTC reasoning bias may have a role in the formation and maintenance of delusions, and contributes to the vulnerability to psychosis.

Chapter 6 provides an integrative summary and discussion of the main findings in the previous chapters. Network models look promising in providing a framework to describe, integrate, explain and possibly predict a lot of the dynamic interactions between symptom dimensions and probably also other phenomena (for instance cognitive biases) over time, where previous frames of reference fell short.

Clinical implications are discussed and directions for future research are proposed. 


\section{Samenvatting}

Obsessief-compulsieve stoornis en schizofrenie komen veel vaker samen voor dan verwacht zou worden op basis van een toevallige verdeling. Hoe dat komt is nog onvoldoende duidelijk. Wel is duidelijk dat het samen voorkomen van obsessief-compulsieve stoornis en psychose leidt tot ernstigere symptomen, grotere impact op sociaal functioneren en grotere zorgbehoefte.

De symptoomdimensies van beide stoornissen overlappen. Psychologische en neurobiologische modellen voor beide stoornissen vertonen ook gelijkenissen. Hoe de stoornissen en bijhorende symptomen samenhangen en elkaar beïnvloeden wordt echter nog onvoldoende begrepen.

Dit proefschrift heeft tot doel bij te dragen aan een beter begrip van het ontstaan en beloop van gecombineerd voorkomende obsessief-compulsieve en psychotische symptomen. De validiteit van bestaand onderzoek op dit gebied wordt vaak beperkt door het gebrek aan validiteit van categorale diagnoses, behandelingsbias en selectiebias. Om niet onderhevig te zijn aan deze beperkingen, is bij het onderzoek beschreven in dit proefschrift uitgegaan van (i) symptoom dimensies, (ii) een continue verdeling van het 'uitgebreide fenotype' (extended phenotype) tot onder de diagnostische drempel en (iii) veranderingen in de tijd. Er werd gebruik gemaakt van grote samples. In hoofdstuk 1 worden de gebruikte methoden en psychologische modellen voor obsessief-compulsieve stoornis en psychose beschreven. Hoofdstuk 2 onderzoekt op welke manier die uitgebreide fenotypes van obsessiefcompulsieve stoornis en psychose samen voorkomen en elkaar beïnvloeden over verloop van tijd. Onderzocht werd (i) of obsessief-compulsieve en psychotische symptomen (en hun subklinische equivalenten) vaker samen voorkomen dan op basis van toeval te verwachten is en (ii) of dit samen-voorkomen de kans op verergering en hulpbehoefte doet toenemen, met andere woorden: de prognose slechter maakt. Deze onderzoeksvragen werden onderzocht in een grote groep van meer dan 7000 personen van de algemene bevolking in Nederland, zowel cross-sectioneel als longitudinaal over een periode van 3 jaar. Een diagnose "psychotische stoornis"

Bij de beginmeting bleek 1,5\% van de hele groep ooit in het leven een diagnose "psychotische stoornis" te hebben gehad. Bij de groep met minstens 1 obsessiefcompulsieve symptoom voldeed $11,5 \%$ ooit aan die diagnose, en bij de groep met obsessiefcompulsieve stoornis was dat $23 \%$. Bovendien bleken de associaties tussen obsessiefcompulsieve symptomen en het fenotype psychose sterker naarmate elk van beide fenotypes strikter afgebakend werd door hogere scores in aantal en ernst van de symptomen te selecteren.

Obsessief-compulsieve symptomen bij de beginmeting bleken het ontstaan van psychotische symptomen drie jaar later te voorspellen. Omgekeerd bleken psychotische symptomen bij de beginmeting ook het ontstaan van obsessief-compulsieve symptomen drie jaar later te voorspellen. Naarmate de vroege psychotische symptomen bij de beginmeting meer gepaard gingen met obsessief-compulsieve symptomen, werd het waarschijnlijker dat de 
psychotische symptomen over een periode van drie jaar bleven bestaan of zelfs evolueerden tot een psychotische stoornis. Het omgekeerde verband werd niet gevonden: psychotische symptomen bij de beginmeting bleken geen invloed te hebben op de persistentie van obsessief-compulsieve symptomen of hun transitie naar een obsessief-compulsieve stoornis. De in eerdere studies aangetoonde neiging tot clusteren van obsessief-compulsieve stoornis en psychotische stoornissen, werd in dit onderzoek ook gevonden op subklinisch niveau. De combinatie van OC en psychotische symptomen, ook op subklinisch niveau, vergroot het risico op transitie naar een psychotische stoornis met zorgbehoefte.

Gegeven (i) de aanwijzingen voor familiale en etiologische continuïteit tussen voorbijgaande subklinische fenomenen en klinisch relevante symptoomdimensies in zowel obsessiefcompulsieve stoornis als schizofrenie, (ii) het vaak gecombineerd voorkomen van beide fenotypes op subklinisch en klinische niveau (aangetoond in hoofdstuk 2), en (iii) de aanwijzingen voor gedeelde psychologische en neurobiologische correlaten, en de gelijkenissen in de psychologische modellen voor OC en psychotische symptomen, stelt zich de vraag of obsessief-compulsieve stoornis en psychose etiologische mechanismen delen. In hoofdstuk 3 werd in een grote groep met patiënten, hun niet-zieke familieleden en gezonde controlepersonen in de algemene bevolking, nagegaan hoe het verband tussen het optreden van obsessief-compulsieve symptomen en familiale kwetsbaarheid voor psychose aanwijzingen kan geven voor een gedeelde etiologie voor beide fenotypes. (Familiale kwetsbaarheid voor psychose werd gemeten als variabele met drie waarden: hoogst voor patiënten, minder hoog voor broers of zussen van patiënten zonder diagnose, en referentiewaarde voor gezonde controlepersonen. ) Twee methodes werden gebruikt. Ten eerste werd directe associatie tussen obsessief-compulsieve symptomen en kwetsbaarheid voor psychotische symptomen nagegaan. Voorspeld werd dat in geval van een gedeeld etiologisch mechanisme, de niet-ziek broers en zussen van patiënten met psychose, een verhoogd risico op het ontwikkelen van obsessief-compulsieve symptomen zouden hebben. Ten tweede werden cross-sib cross-trait analyses uitgevoerd om te onderzoeken of de mate van psychotische symptomen in de ene sibling geassocieerd was met de mate van obsessiefcompulsieve symptomen in de andere. Ook hier werd voorspeld dat, in geval van een gemeenschappelijk etiologisch mechanisme, er een associatie zou zijn tussen obsessiefcompulsieve symptomen bij een patiënt en psychotische symptomen bij een niet-zieke sibling en vice versa. De eerste analyses lieten zien dat het optreden van obsessiefcompulsieve symptomen significant geassocieerd was met familiale kwetsbaarheid voor psychose (die verhoogd is bij eerstegraadsfamilieleden van patiënten met psychose), ook wanneer statistisch gecontroleerd werd voor het werkelijk tot uitdrukking komen van psychotische symptomen. De tweede reeks analyses lieten een associatie zien tussen obsessief-compulsieve symptomen bij patiënten met psychose ene subklinische positief psychotische symptomen bij hun niet-zieke broers en zussen. In hoeverre deze bevindingen een aanwijzing vormen voor een gedeeld etiologisch mechanisme, wordt besproken. De mogelijkheid van gedeeltelijk gemeenschappelijk etiologisch pad naar obsessiefcompulsieve stoornis en psychose wordt weerspiegeld in gedeeltelijk gelijklopende 
psychologische modellen voor obsessief-compulsieve stoornis en psychose. In hoofdstuk 4 werd onderzocht of het samen voorkomen van OC en psychotische symptomen voortkomt uit een gemeenschappelijk pad van intrusieve gedachten naar obsessies c.q. hallucinaties, waarbij vervolgens waanachtige interpretaties leiden tot de verdere weg naar psychose. Een heersend paradigma in de psychologische modellen voor obsessief-compulsieve stoornis stelt dat intrusieve gedachten kunnen leiden tot latere obsessief-compulsieve symptomen, gegeven de aanwezigheid van een aantal voorbeschikkende factoren. In hoofdstuk 4 werd dit paradigma getoetst in een grote groep binnen de algemene bevolking die gedurende 8,4 jaar gevolg werd. Daarnaast bleken IT ook latere hallucinaties te voorspellen. In een volgende stap werd aangetoond dat, gegeven de aanwezigheid van IT bij de beginmeting, het 3,5 jaar later samen-voorkomen van nieuw ontstane waanachtige ervaring gecombineerd met obsessief-compulsieve symptomen, een significant hoger risico inhoudt op het hebben van een klinische diagnose van een psychotische stoornis na 8,4 jaar. Op gelijkaardige manier bleek dat indien IT voorkomen bij de beginmeting, het samenvoorkomen van een nieuw ontstane waanachtige ervaring in combinatie met een hallucinatie eveneens een significant hoger risico inhoudt op het ontstaan van een diagnose van een psychotische stoornis met zorgbehoefte.

De conclusie werd getrokken dat IT het eerste stadium vormen van een proces dat kan leiden tot obsessies of hallucinaties. Als daarbovenop waanachtige interpretaties ontstaan, kan de toestand van vroege psychose ernstiger worden, en uiteindelijk resulteren in een toestand met disfunctioneren en hulpbehoefte. Deze bevindingen liggen in het verlengde van recente cognitieve modellen van psychose en obsessief-compulsieve stoornis, en recente neurobiologische bevindingen. Ze dragen bij tot een beter begrip van de mechanismen die ten grondslag liggen aan de al lang vastgestelde comorbiditeit van obsessief-compulsieve stoornis en psychose, met bijhorende slechte prognose.

In de hogervermelde cognitief psychologische modellen voor obsessief-compulsieve stoornis c.q. psychose, werd de rol van bepaalde cognitieve biases in het ontwikkelen van symptomen en stoornis belicht. Besluitvorming bij onzekerheid is aan de orde bij beide fenotypes. In hoofdstuk $\mathbf{5}$ wordt de rol van een bijzondere redeneerstijl, namelijk "voorbarige conclusies trekken", onderzocht. Preciezer gesteld: er werd onderzocht in welke mate de hoeveelheid gegevens die verzameld wordt om tot een besluit te komen een rol speelt in het ontstaan en aanhouden van psychotische symptomen. In eerdere studies werd al aangetoond dat "voorbarig conclusies trekken" negatief geassocieerd was met obsessief-compulsieve stoornis.

In de studie beschreven in hoofdstuk 5 werd onderzocht of deze redeneerstijl geassocieerd was met bepaalde symptoomdimensies van psychose, en of "voorbarig conclusies trekken" geassocieerd is met kwetsbaarheid voor psychose. Twee verschillende vormen van kwetsbaarheid voor psychose werden onderzocht: (i) kwetsbaarheid op basis van genetisch risico (eerstegraads familieleden van patiënten met psychose) en (ii) kwetsbaarheid op basis van psychometrisch risico (met bovengemiddelde waanachtige ervaringen).

De resultaten lieten zien dat "voorbarig conclusies trekken" geassocieerd is met zowel familiale als psychometrisch bepaalde kwetsbaarheid voor psychose. De familiale kwetsbaarheid is een stabiele eigenschap, een "trek", die mogelijk in aanmerking komt als kandidaat endofenotype. Daarnaast is 
"voorbarig conclusies trekken" geassocieerd met de mate van op een bepaald ogenblik aanwezige waanachtige ideeën, een tijdelijke toestand, een "status". Bovendien was de associatie tussen "voorbarig conclusies trekken" en de kwetsbaarheid voor psychose sterker naarmate er meer waanachtige interpretaties aanwezig waren. We concluderen dat dat een redeneerstijl met "voorbarig conclusies trekken" een rol speelt in het ontstaan en aanhouden van wanen, en op die manier bijdraagt tot vatbaarheid voor psychose.

Hoofdstuk 6 biedt een algemeen overzicht van en discussie over de belangrijkste bevindingen uit eerdere hoofdstukken.

Er wordt aandacht besteed aan netwerkmodellen omdat die een veelbelovend raamwerk om heel wat van de dynamische interacties tussen symptoomdimensies en wellicht ook andere fenomenen zoals cognitieve biases en omgevingsfactoren in de loop van de tijd te beschrijven, integreren en mogelijk ook voorspellingen te maken, waar andere modellen vaak ontoereikend bleken.

De klinische implicaties van het onderzoek in dit proefschrift worden toegelicht en ideeën voor toekomstig onderzoek worden voorgesteld. 


\section{Dankwoord}

Het is niet af. Ik laat het los.

Omdat een dankwoord een aanzienlijke kans om wél gelezen te worden, een disclaimer: het is op geen enkele wijze te verwarren met een testament. Heel wat mensen speelden geen rol bij het tot stand komen van het proefschrift, maar zijn van grote waarde voor mij. Ik hoop mijn dank aan hen elders te kunnen laten blijken.

Dan dit proefschrift. Er zijn vele medeplichtigen bij betrokken, en een paar slachtoffers. Sommigen in een dubbelrol, vrijwillig of minder vrijwillig. Het is me een waar genoegen om ze hier aan te geven.

In de eerste plaats wil ik alle proefpersonen, met of zonder diagnose, danken. Ze hebben zich vaak uit hun (soms zoekgeraakte) comfort zone begeven voor een altruïstisch doel. Ik hoop dat ik dat voorbeeld een beetje heb kunnen volgen. Bij uitbreiding wil ik álle patiënten danken voor wat ze me hebben bijgebracht bij de wisselwerking die er elke keer ontstaat als onze paden kruisen. Dat gebeurt meestal in onvoorziene omstandigheden, die nopen tot verandering terwijl de uitkomst onvoorspelbaar is. Dat kan het beste in een mens naar boven halen.

Mijn top-promotoren, Jim van Os en Inez Myin-Germeys, wil ik hartelijk danken. Inez, vrouw van 6 miljoen, met het hart op de juiste plaats. Het is fantastisch hoe je tegelijk de grote lijn en het detail in de gaten houdt, en ambitieuze obstinaatheid aan inspiratie aan gewone pragmatiek weet te koppelen. Van die geniale combinatie heb ik veel geleerd. Dat je daarbij ook nog schijnbaar moeiteloos het geduld kon opbrengen om het grillige tempo van deze clinicus-dilettant-onderzoeker te volgen, waardeer ik ten zeerste.

Jim, je vroeg me zoveel jaar geleden: “Waarom kom je niet in Maastricht werken?”. Je trefzekere communicatie en nooit dovend vuur bij een grote missie werk enthousiasmerend. De combinatie van scherp inzicht en originele ideeën heeft ook mij geïnspireerd. Dank voor alle mogelijkheden.

Lydia, hoewel één paper met mij volstond om je naar de andere kant van het land te laten vluchten, blijf ik je dankbaar voor de heel fijne samenwerking en voor de interesse die je bij me hebt aangewakkerd voor de capriolen van cognitive biases en sociale interacties.

Philippe, wat ben ik blij dat ik je nog steeds als teamgenoot kan zien, al is dat al sinds jaren niet meer in de kliniek. Het maakt dat ik kan binnenlopen bij een homo universalis, die moeiteloos surft van de abstracte theorie naar het concrete commando, en het allemaal ook nog kan integreren. Je helpt me om zicht te krijgen op de complexe organisatie van zorg. Die zorg moet niet op een eiland, dat onthoud ik tot ik dement ben. Of juist dan. 
Ik wil alle medewerkers van de vakgroep psychiatrie en psychologie bedanken met wie ik in de loop van de voorbije jaren heb samengewerkt. Het zijn er inmiddels te veel om op te noemen.

Toch nog een paar: Marjan, je toonde altijd mededogen voor mijn verworven gebrek bij het begrijpen van statistiek -namelijk dat ik psychiater ben. Meedogenloos was je echter wat betreft de spelling van je naam. Om het goed te maken: Marjan, Marjan.

Ron, hyperthreaded multi-core processor van big en little bits en Kevin, wizard van de command line, dank voor samenwerking en het mogen leren van jullie magic tricks. Trees, Ine en Jolanda, secretaresses, dank voor jullie hulp om een scattered on track te houden.

Ik dank ook alle co-auteurs. Ilse Janssen en Dagmar Versmissen, die betrokken waren bij de CoP-studie. Ron de Graaf en Margreet ten Have dank ik voor de mogelijkheid om met de NEMESIS-data te kunnen werken, en voor de inhoudelijke inbreng. I thank Roselind Lieb and Hans-Ullrich Wittchen for the opportunity to work with the EDSP-data. Ook alle mensen betrokken bij het GROUP-onderzoek wil ik danken, in het bijzonder Lieuwe de Haan, Marije Swets en Robert Schoevers voor alle ideeën en de tenaciteit bij een lang traject. Alle leden van de corona en de beoordelingscommissie wil ik danken.

Een aantal vak- en spitsbroeders beoefenen ook de evenwichtsoefening zorg-onderwijsonderzoek, in de overtuiging dat die kruisbestuiving betere vruchten afwerpt.

Maarten, sparring partner, en zoals je zelf al snel stelde: lotgenoot in het prettig gestoord zijn. Je moet zowat de enige geweest zijn die gezegd heeft op dit boekje te zitten wachten. Als een grote broer wees je me soms op de steen waaraan ik me ging stoten, waarna dat inderdaad gebeurde. Knap! Thanks anyway.

Patrick, de helft van de tandem die we samen vormen. Doorgaans hoeven we er niet al te veel hoogdravende woorden aan te spenderen, maar voor één keer dan: samenwerking waarbij je blind vertrouwen kan hebben dat de ander het roer overneemt als je er niet bent en vice versa, is goud waard. Je popkennis natuurlijk ook.

Companen, we moeten nog iets moois maken.

Koen Schruers laat zijn licht ook schijnen over kwesties die niet over angst en dwang gaan. Dat apprecieer ik. Ritsaert Lieverse, jammer dat je vertrekt. Carla Vermeulen, je hart klopt onverminderd voor De Goede Zaak. Chapeau. Peter Vervoort, Christine van der Leeuw, Irene Weltens, Machteld Marcelis, Jeroen van Dijk, Joost à Campo, Marcel Hilwig, René de Bruijn, Chris Vleugels en alle andere collega's, het is (doorgaans) fijn om met jullie samen te werken. Dan is er natuurlijk het onvolprezen team, dat het ook niet kan helpen dat ze het beste FACT-team zijn. Monique, dank voor je onvoorwaardelijke bereidheid om ergens over van mening te verschillen. Dat we het uiteindelijk vaak eens raken, doet niets af aan die verdienste. Carin, Aafje, Huib, Harrie, Iris, Stephanie, Ingrid, Ruud, Bea, Mariska en Sietske het is een voorrecht geweest om met jullie samen te werken. Hoe ambulant we inmiddels ook geworden zijn, de samenwerking met de afdelingen stellen we onverminderd op prijs. 
De secretaresses vormen een onmisbare schakel om continuïteit te bieden in een organisatie waarin zoveel mensen zoveel verschillende dingen bezig zijn. Daarom: hulde aan Evelien, Jenny, Karin, Marie-Louise, Ans, Esther, Dominique, Monique, Anita en Marlou. Op de spoedeisende psychiatrie verdienen Lenie, Emmy, Annemie en last but not least Ineke, een pluim voor het steeds weer aan elkaar breien van waarnemingsroosters met doeltreffend strategisch gebruik van charme-offensieven. Freddy, Joke, Min: het deeltijd samenwerken is fulltime fijn. We blijven geloven dat er managers zijn die bereid en in staat zijn tot synergie met het belang van de patiënten voor ogen. Ze zijn onmisbaar.

Onderwijs geven dwingt je om expliciet te maken wat anders impliciet blijft. Dank daarom aan nieuwsgierige en kritische studenten en AIOS. Rob van Diest en Inge Crolla: petje af voor jullie inzet voor het onderwijs, en daarmee voor de dokters van de volgende generatie. Het is een plezier om daar met jullie aan mee te doen.

Hans de Veen, voorzitter van de raad van bestuur van Mondriaan en directeuren John Molema en René de Bruijn wil ik feliciteren met de hernieuwde aspiratie tot academisering, ondanks financieel roerige tijden. Het getuigt van visie, ambitie en moed.

Behalve de professionele contacten zijn natuurlijk alle familie en vrienden belangrijk geweest bij de tot stand komen van dit proefschrift. Ik wil alleen de formidabele Greggorius noemen, al lang vertrouwd als vriend, nu voor het eerst paranimf.

Uiteindelijk kom ik toch altijd weer thuis. Mijn ouders dank ik voor alle kansen die ze me hebben gegeven; andere familieleden Ellen, Kaat, Wim en Liesbeth om te zijn wie ze zijn; oma Lieve en opa Peter omdat ze onze kinderen zoveel hebben geboden en ze hebben omringd als wij weer wat anders dachten te moeten doen. Lies, Nele en Kobe, dat uitgerekend jullie onze kinderen zijn geworden, is het beste wat ons is overkomen. Mijn lieve Helke, jij hebt altijd geholpen het belang van al dat wetenschappelijk geschrijf te relativeren, en uiteindelijk toch maar te blijven verdragen, al was het niet omdat ik je had overtuigd. Er zijn vast duurdere, gevaarlijkere en tijdrovendere bezigheden dan het bedrijven van wetenschappelijk onderzoek. Zullen we daar eens aan beginnen, samen? Boswandelingen zijn ook goed. 
Life is what happens to us while we are making other plans.

(Anonymous, 1957) 


\section{Curriculum Vitae}

Frank Van Dael werd geboren op 07-03-1969 in Leuven. In 1987 behaalde hij het diploma Latijn-Wiskunde aan het Sint-Albertuscollege te Haasrode. In 1994 voltooide hij de studie geneeskunde en in 1999 de opleiding tot psychiater, beide aan de KULeuven. Hij volgde een opleiding systeemtherapie aan het Korzybski-instituut in Brugge. Vanaf najaar1999 werkte hij als psychiater in GGZ Meerkanten te Ermelo. Sinds medio 2004 werkt hij in Mondriaan, in een FACT-team. Hij is gedetacheerd naar de Universiteit Maastricht. Daar startte hij met promotie-onderzoek. Hij verzorgt onderwijs in het curriculum geneeskunde en in de Aopleiding tot psychiater.

Hij is gehuwd met Helke Van Dessel en vader van Lies, Nele en Kobe. 



\section{Publications}

\section{Journals}

Van Dael, F., Versmissen, D., Janssen, I., Myin-Germeys, I., van Os, J., \& Krabbendam, L. (2006). Data gathering: biased in psychosis? Schizophr Bull, 32(2), 341-351.

Van Dael F, van Os J, de Graaf R, ten Have M, Krabbendam L, Myin-Germeys I. Can obsessions drive you mad? Longitudinal evidence that obsessive-compulsive symptoms worsen the outcome of early psychotic experiences. Acta Psychiatr Scand Feb 2011;123(2):136-146.

Van Dael F, Myin-Germeys I, Lieb R, H. W, Van Os J. Evidence that hallucinations as well as obsessions originate from intrusive thoughts and that transition to psychosis is mediated by delusional appraisal. Submitted.

Van Dael F., Swets M., Roza S., Schoevers R., de Haan L., Myin-Germeys I, Genetic Risk and Outcome in Psychosis (GROUP) investigators. Evidence for a shared etiological mechanism of psychotic symptoms and obsessive-compulsive symptoms in patients with psychotic disorders and their siblings. Submitted.

van der Zwaard, R., de Leeuw, A. S., Van Dael, F., \& Knook, L. M. (2006). [...with psychotic features? An investigation into the delusional nature of convictions in patients with nonpsychotic disorders]. Tijdschr Psychiatr, 48(6), 461-466.

\section{Conference Presentations}

Van Dael, F., Krabbendam, L., \& van Os, J. (2005). Jumping to conclusions: State or trait? Schizophrenia Bulletin, 31(2), 380-380.

Van Dael, F., Krabbendam, L., \& Van Os, J. (2006a). Obsessive-compulsive disorder predicts psychotic symptoms in the general population. Schizophrenia Research, 81, 188-188.

Van Dael, F., Krabbendam, L., \& Van Os, J. (2006b). Obsessive-compulsive symptoms are associated with but do not predict psychotic symptoms in patients with psychosis.

Schizophrenia Research, 81, 187-188.

Van Dael, F., Van Os, J., de Graaf, R., ten Have, M., \& Myin-Germeys, I. (2011).

Can obsessions drive you mad? Longitudinal evidence that obsessive-compulsive symptoms worsen the outcome of early psychotic experiences. Schizophrenia Bulletin, 37, 22-22. 
